\title{
Measuring the Banking Performance Based on Corporate Social Responsibility Achievement: Decision Support System Adoption
}

\author{
O Okfalisa ${ }^{1, a)}$, R Habib $^{1, b)}$, R Hidayati ${ }^{1, \mathrm{c})}, \mathrm{M} \mathrm{Mahyarni}^{2, \mathrm{~d})}, \mathrm{W}$ Alex $^{3, \mathrm{e})}$, N \\ Gusman $^{4, f)}$, and S Saktioto ${ }^{5, \mathrm{~g})}$ \\ ${ }^{1}$ Department of Informatics, Universitas Islam Negeri Sultan Syarif Kasim Riau, Indonesia. \\ ${ }^{2}$ Department of Management, Universitas Islam Negeri Sultan Syarif Kasim Riau, Indonesia. \\ ${ }^{3}$ Department of Electrical, Universitas Islam Negeri Sultan Syarif Kasim Riau, Indonesia. \\ ${ }^{4}$ Faculty of Industrial Management, Universiti Malaysia Pahang, 26300 Kuantan, Pahang, Malaysia. \\ ${ }^{5}$ Department of Physic, Universitas Riau, Indonesia. \\ a)Corresponding author: okfalisa@gmail.com \\ b) habibramadhan15@gmail.com \\ c)hidayatirusnedy87@gmail.com \\ d) mahyarni@uin-suska.ac.id \\ e)alexwenda@uin-suska.ac.id \\ f)gusman@ump.edu.my \\ ${ }^{\mathrm{g})}$ saktioto@yahoo.com
}

\begin{abstract}
Corporate Social Responsibility (CSR) discloses the social responsibility of a company in contributing to the quality improvement of the community and society. Currently, the banking industries put into concern on this social responsibility as well as CSR report as environmental issues that leveraging the economic business performance through the application of the Global Reporting Initiatives (GRI) framework. The number of the organization using this framework has increased. Unfortunately, several weaknesses have been reviewed on the adoption of this framework as a sustainability report. Therefore, this study tried to strengthening the GRI model by elaborating on the indicators and sub-indicators of GRI-4 to measure the priority weighted-based indicators thus it is utilized to rank the banking performance. Herein, the decision support system-based analytical network process (ANP) is applied to assess standard criteria of the GRI sustainability report as a side of economic, social, and environmental aspects. Three banking companies in Indonesia have been selected as alternatives and then analyzed based on its sustainability report as well as performance measurement. Twenty-four experts from academicians and practices have been asked their quantitative perspectives and weighting score of the criteria through the dissemination of the questionnaire. This study reveals the performance of banking companies following the realization of the CSR position. Thus, the financial services authority of Indonesia (OJK) as an Indonesian government agency is advised on the decision-making on the potential banking performance that more pay attention to environmental sustainability. Besides, the employment of the ANP method in this study can strengthen and accomplish the shortcoming of the GRI model in determining the sustainability report.
\end{abstract}

\section{INTRODUCTION}

Corporate Social Responsibility (CSR) of companies have been a hot topic in the last three decades in modern societies, and a subject of numerous studies by academia [1]. CSR refers to the enterprise to create profits and to bear the legal responsibility of shareholders, at the same time, to pay attention to the production process of human value, 
and the contribution to the environment, consumers, and society [2]. Bowen defines CSR as the obligations of businessmen to pursue the policies, to make decisions, or to follow the lines of action which are desirable in terms of the objectives and values of society[3]. Subsequent studies of CSR were presented by Davis (1960), McGuire (1963), and Network (1975), where they specified the concept and content of social responsibility [4][3]. The evolution of CSR in Indonesia has increased significantly and in line with the global trend in CSR practices. It has been practically adopted mostly in mining and manufacturing companies instead of other industrial businesses. Nevertheless, the banking industry currently has been an account of its social responsibility aspects in its sustainability reports periodically. Moreover, Indonesian Financial Services Authority (OJK) equips the unification of regulation and supervision of the financial services sector at the ministry of finance, Bank Indonesia (BI), capital market supervisory agency, and financial institution including the assessment of CSR practices as well as the sustainability disclosed by the company [5].

Since 2012, many banks company are following the guideline of the Global Reporting Initiative (GRI) standards for their sustainability document. GRI was established place on the concept of the triple bottom line of Green Banking as a key driver for sustainability management strategy [6]. The financial sector divulges the green information to be legitimate in society and improves their value, reputation, sustainability, and the competitiveness of their company thus the banks are engaged with financing manufacturing and non-manufacturing organizations and are directly and indirectly involved in environmental issues as their responsibility for green and sustainable strategy [7]. GRI guidelines develop into the most common and widely used sustainable reporting framework for analyzing, presenting, and reporting sustainability performances in developed and developing countries [8][9]. The GRI framework provides the company standard information on economic indicators, environmental compliance, labor practices, human rights, society, and product responsibility thus each company is facilitated by the flexible reported document on issues of sustainability assurance as to the most prestige for the company and its stakeholders [10]. GRI guidelines have been used extensively due to their wide range of visibility, acceptance, and sustainable policy formulation that associated to several international reporting standards, such as ten principles of UNGC and multinational enterprise guideless of OECD [11], International Integrated Reporting Council (IR) framework, the Sustainability Accounting Standards Board (SASB) guidelines [12]. Thus, GRI guidelines have been adopted by more than 500 companies due to its diversity of stakeholders and accountability of the corporate leaders. The advancement of GRI is continually explored from GRI-3 up to GRI-4.

Despite the spacious admittance of GRI, several weaknesses emerge as encumbrances towards the success of sustainability practice viz. the absence of trust and transparency in GRI reporting, the lack of using GRI reporting as a marketing tool to communicate with stakeholders and society, the unreported negative events in GRI [13][14], the lack of understanding on the stakeholders' engagement processes in decision making which is disclosed to data and verified of reporting, and inadequate analysis and weighting of interdependence among framework elements [15].

Analytical Network Process (ANP) as one method of multi-attribute decision making (MADM) introduced by Saaty (1996) that furnishes a new mechanism of performance analytical as the preference of Analytical Hierarchy Process (AHP) [16][17]. Many decision problems omitted the structured hierarchically and the interaction embarrassment and addiction amongst elements [18]. Meanwhile, ANP works out the problem of dependence among alternatives and criteria and allows the multiple indexes that hard to be quantified by considering the association between variables and sub-variables within a set of variables thus it reflects and describe the decision problem more realistically [19]. The previous researches have been successfully implementing ANP in various fields of study, including Lin et al (2020) who analyzed the factors influencing adoption intention of internet banking by integrating DEMATEL and ANP [20], Gyusun et al (2020) integrated ANP and AHP for measuring the performance of manufacturing operation management [21], Eko et al (2019) develop a sustainable supply chain performance measurement model by combining a balanced scorecard (BSC) with decision making trial and evaluation laboratory (DEMTEL) and ANP [22]. The above studies complied that ANP has been flourishingly in investigating the business excellence models for extracting analysis of related indicators thus it revealed the capability of ANP in structuring and evaluating their performance measurement. Considering the decision-making process by ANP furnished the effective utilization of this approach as decision support tools as well as a decision support system (DSS).

DSS is an application that aids managers in making a reasonable decision through the understanding of knowledgebased components in performance, attitude, and behavior. DSS enhances the effective role of stakeholders and key actors in making decisions [23]. One DSS application development is model-driven DSS that uses algebraic decision analytic, financial, optimization, and simulation models for decision support, including the multi-criteria decision analysis using the ANP method [24].

In a nutshell, this study tried to overcome the inappropriate of the GRI in understanding the stakeholder's involvement that concern on the weighting analysis of the framework's indicators measured. As stated by Alberto 
(2010) the GRI framework required mechanism in mediating the stakeholder's engagements as qualified external sustainability assurance as well as the embracing of new methods to integrate sustainability performance [15]. Herein, DSS based on ANP analytical assesses and weights the standard criteria of the GRI sustainability document from the perspectives of economic, social, and environment. The involvement of external and internal stakeholders is covered by the disseminating of ANP questionnaires as the expert's judgments in verifying the sustainability assurance. Thus, the embracing of DSS-ANP in the GRI framework significantly advance the utilization of this framework in deceiving the sustainability picture and directly engaging the stakeholder's responsibility. To scope this study three Indonesia banking GRI reports are resolved and highlighted as alternatives banking performance measurement.

\section{RESPONSE SURFACE METHODOLOGY}

\section{The Formation of Criteria and Sub-Criteria Data}

The evolution of the GRI report was initiated by the launching of GRI-1 guidelines that informed economic, environmental, and social performance at the side of financial accounting tradition [25]. The G1 guidelines were revised by including transparency, inclusiveness, auditability, relevance, clarity, and timelines to ensure a balanced economic, environmental, and social performance towards sustainability development [26]. Next, the introduction of the GRI G3 generation brought the adoption of three standard disclosures to be more pay attention to the strategy and profile, management approach, and performance indicators at the organization [27]. The upgrading of G3 into the G3.1 guideline provided the revised guideline on local community impacts, human rights, gender, and sustainability report clarification [28]. The GRI G4 guidelines were established to offer a user-friendly guideline, eliminate the ambiguities perceptions, and identifying material issues [38] that describing the sustainability maturity level of the organization report. The GRI-4 has developed 149 disclosure requirements for sustainable purposes with 58 general standards and 91 specific standards [29]. Considering the three significant aspects of GRI-4 standards viz economic, environment, and social, the formation of criteria and sub-criteria defines based on the disclosure requirements of the GRI report 2017 in Indonesia banking (Bank X, Y, and Z). Economic aspects consist of criteria Economic Performance (A) with sub-criteria A1-A4, criteria Market Presence (B) with sub-criteria B1-B2, criteria Indirect Economic Impact (C) with sub-criteria C1 and C2, criteria Procurement Practices (D) with sub-criteria D1. Detail formation of criteria and sub-criteria can be depicted in Fig. 1.

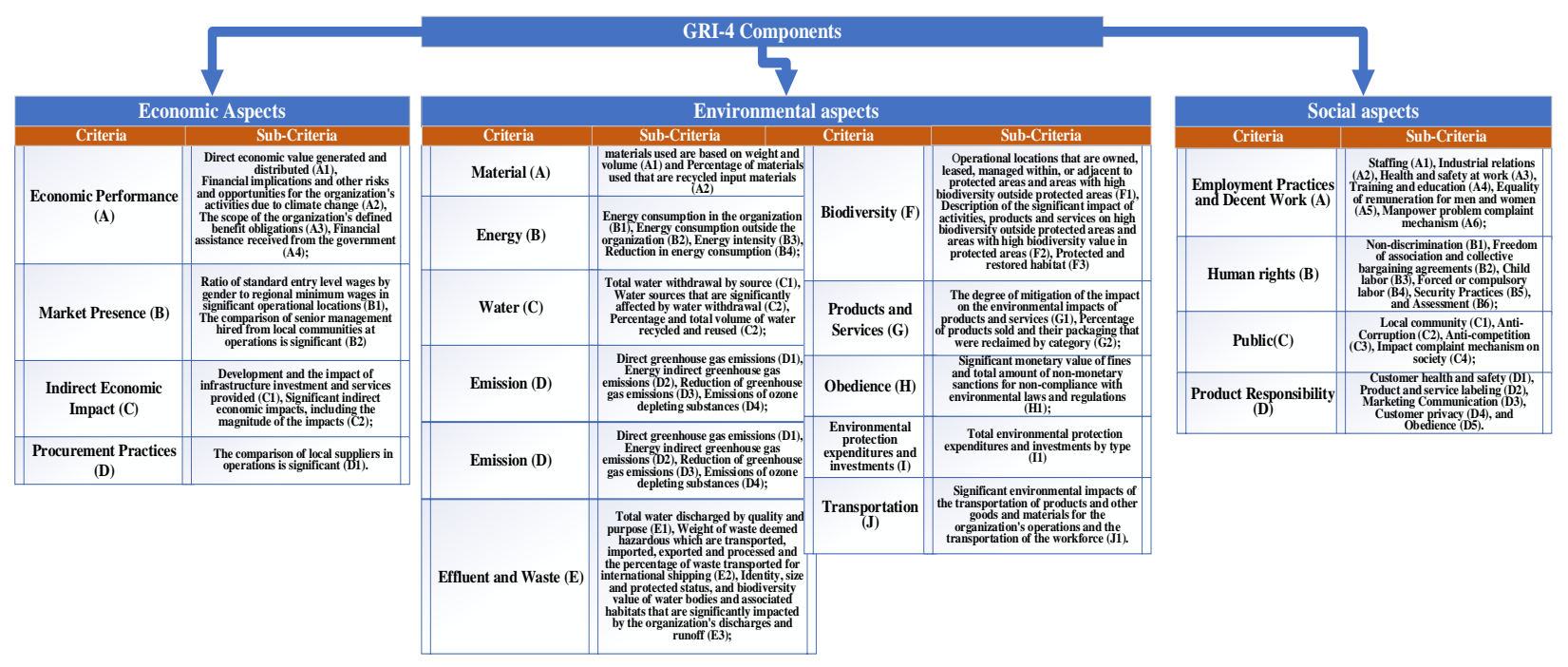

FIGURE 1. Formation of Criteria and Sub-Criteria based on GRI-4

\section{Design of Experiment Setup}

The research is carried out with a series of activities, starting with the problem identification, formulation of criteria and sub-criteria, DSS-ANP analysis, and design. Problem identification was conducted through a thorough literature 
review related to CSR, GRI guidelines, the theory of performance measurement, ANP methods, and the DSS approach. Then, the formulation of criteria and sub-criteria are defined place on the GRI-4 standards disclosures that are adapted as Indonesia banking sustainability report for 2017. Three conventional banking are selected as alternatives for further sustainability performance measurement. In order to preserve the credibility and confidentiality of the companies, Bank X, Y, and Z are designated as a case study. Twenty-four respondents are asked for their perspectives and appraisement on the significant values of indicators proposed by GRI-4 standards through the dissemination of questionnaires. The respondents are derived from five academicians background in economic, social politics, and environment; five expertise from OJK; and fourteen top-level management from bank X, Y, and Z. The questionnaire is designed by following the Saaty (2008) [30] formatted for ANP. Following this, the analysis of DSS-ANP is operated by pursuing the practice below [31].

1. Identifying criteria, sub-criteria by referring GRI-4 disclosure, and alternatives from Bank $\mathrm{X}, \mathrm{Y}$, and $\mathrm{Z}$ then creating a network structure.

2. Make pairwise comparisons of the ANP criteria and sub-criteria using a verbal scale expressed on a numerical scale of 1-9 by following the questionnaire designed.

3. Perform calculations to find the eigenvector value.

Where:

$$
\text { A. } w=\lambda \max . \mathrm{w}
$$

A : Pairwise comparison matrix

$\lambda \max :$ The largest eigenvalue of A.

$\mathrm{W}$ : Eigenvector

4. Checking the inconsistency ratio (CR) and the consistency index (CI) of a comparison matrix by the formula:

Where:

$\mathrm{N} \quad$ : number of elements/criteria

$$
C I=\left(\frac{\lambda m a k s-n}{n-1}\right)
$$

$\lambda \max \quad$ : the sum of the results of multiplying the number of columns with eigenvector

If $\mathrm{CI}=0$, it indicates that the matrix is consistent

$$
C R=\frac{\mathrm{CI}}{R I}
$$

5. Performing pairwise comparison to determine criteria priorities.

6. Performing pairwise comparison to determine alternatives priorities concerning each criterion.

7. Determining overall priority for each alternative.

8. Select the Banking alternative with the highest priority.

The final stage of the proposed methodology is determining the rankings of Banking alternatives as to the highest sustainability performance.

\section{RESULTS AND DISCUSSIONS}

\section{Results}

The DSS-ANP model analysis was scrutinized from the views of main CSR components as well as economic, environmental, and social thus one of the network structures was exemplified in Fig. 2.

Following the ANP stages and the algebraic of Equation (1) to (3), the recapitulation of weighted values of each criterion and sub-criteria are elucidated in Table 1. Table 1 indicated that from an economic perspective the most significant indicators concerned by the stakeholders are component (A) Economic Performance: with the value 0.49 following by components (B): Market Presence, component (D): Procurement Practices, and criteria (C): Indirect Economic Impact with weighting values are $0.23,0.16$, and 0.11 respectively. For environment aspects, the stakeholders paying more attention to the considered criteria of sustainability disclosures performance at criteria $(\mathrm{F})$ : Biodiversity ensuing by criteria (C), (H), (E), (D), (A), (I), (B), (G), and finally is criteria (J): Transportation with the 
weighting values are $0.17,0.15,0.13,0.11,0.10,0.08,0.07,0.05$ and 0.03 respectively. Meanwhile, for social aspects, the entire criteria hand over a similar interest by the stakeholders towards successful sustainability.

Simultaneously, the recapitulation of the limit matrix for economic aspects is explained in Table 2 . Table 2 points out that Bank $\mathrm{Z}$ as the highest priority banking that contributes to the most significant assessment of the sustainability report at scoring 0.009. It is then followed by Bank X and Bank Y at scoring 0.006 and 0.005 respectively. For environment aspects, the calculation of the limit matrix reveals that Bank $\mathrm{Z}$ provides the highest priority banking at scoring 0.009 and it is followed by Bank $\mathrm{Y}$ and Bank X at scoring 0.007 and 0.006 respectively. Meanwhile, for social aspects furnishes that Bank $\mathrm{Z}$ numbering the most priority banking at scoring 0.050 and it is followed by Bank $\mathrm{Y}$ and Bank X at scoring 0.019 and 0.0015 respectively. Graphically the performance of each bank for GRI-4 standards is depicted in Figures 3a, 3b, and 3c.

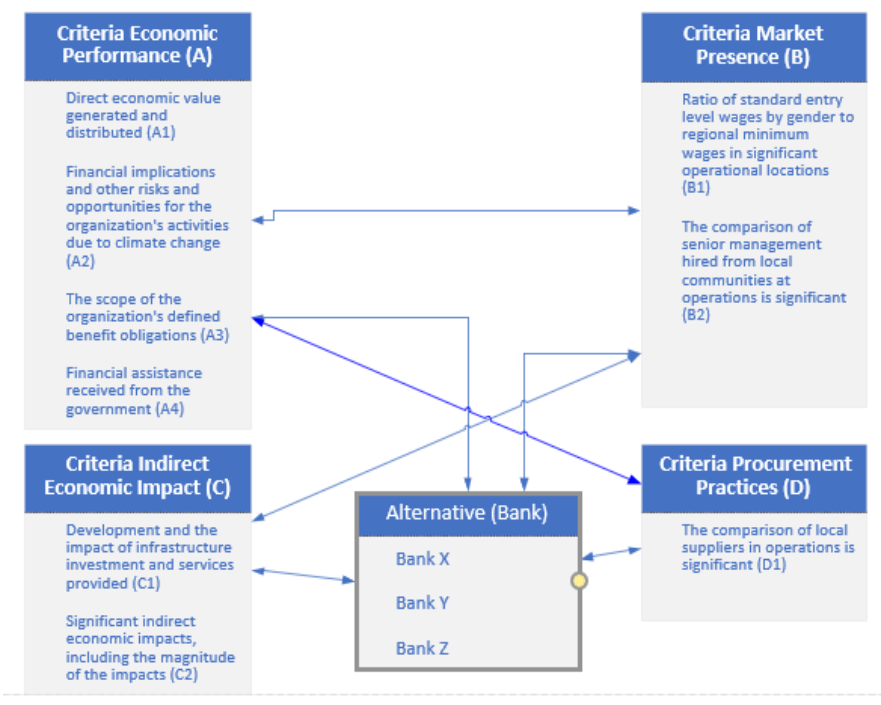

FIGURE 2. Network Structures of DSS-ANP for Economic Aspects

TABLE 1. The recapitulation of weighted values for three aspects GRI-4.

\begin{tabular}{|c|c|c|c|c|c|}
\hline \multicolumn{2}{|c|}{ Economic Aspects } & \multicolumn{2}{|c|}{$\begin{array}{c}\text { Environment } \\
\text { Aspects }\end{array}$} & \multicolumn{2}{|c|}{ Social Aspects } \\
\hline Criteria & $\begin{array}{l}\text { Eigen } \\
\text { Vector }\end{array}$ & Criteria & $\begin{array}{l}\text { Eigen } \\
\text { Vector }\end{array}$ & Criteria & $\begin{array}{l}\text { Eigen } \\
\text { Vector }\end{array}$ \\
\hline A & 0.49 & A & 0,08 & A & 0,25 \\
\hline B & 0.23 & B & 0,07 & B & 0,25 \\
\hline $\mathrm{C}$ & 0.11 & $\mathrm{C}$ & 0,15 & $\mathrm{C}$ & 0,25 \\
\hline \multirow[t]{7}{*}{$\mathrm{D}$} & 0.16 & $\mathrm{D}$ & 0,10 & $\mathrm{D}$ & 0,25 \\
\hline & & $\mathrm{E}$ & 0,11 & & \\
\hline & & $\mathrm{F}$ & 0,17 & & \\
\hline & & G & 0,05 & & \\
\hline & & $\mathrm{H}$ & 0,13 & & \\
\hline & & I & 0,07 & & \\
\hline & & $\mathrm{J}$ & 0,03 & & \\
\hline
\end{tabular}

Investigating the performance of Bank $\mathrm{Z}$ for economic aspects at Fig. 3a, Bank $\mathrm{Z}$ is required to enhance the recognition of sustainability activities on criteria for component A: Economic Performance, such as Direct economic value generated and distributed (A1), Financial implications, and other risks and opportunities for the organization's activities due to climate change (A2), The scope of the organization's defined benefit obligations (A3), and Financial assistance received from the government (A4). This is due to this component (A) provides as the weightiest disclosures from economic previews. Accumulating the sub-criteria of this component will be linearly rising the general performance of these aspects. Meanwhile, Bank Z has reached the achievement of the standards of components B: Market Presence, D: Procurement Practices, and C: Indirect Economic Impact. 
Considering the Bank $Z$ performance on environment aspects at Fig. 3b, it is advised to contribute more awareness and understanding on the significance of sub-criteria in component F: Biodiversity including the operational locations that are owned, leased, managed within, or adjacent to protected areas and areas with high biodiversity outside protected areas (F1), Description of the significant impact of activities, products and services on high biodiversity outside protected areas and areas with high biodiversity value in protected areas (F2), Protected and restored habitat (F3). Moreover, the concern of Bank Z on the achievement of component C: Water, especially for C2: Water sources that are significantly affected by water withdrawal will automatically increase the overall achievement of environmental aspects. For social aspects (See Fig. 3c), the recommendation given for Bank Z is to preserve the sustainability condition for the entire sub-criteria to perform in this concern.

TABLE 2. The limit matrix calculation for economic aspects.

\begin{tabular}{|c|c|c|c|c|c|c|c|c|c|c|c|c|c|}
\hline & & \multicolumn{4}{|c|}{ A } & \multicolumn{2}{|c|}{ B } & \multicolumn{2}{|c|}{$\mathrm{C}$} & \multirow{2}{*}{$\frac{\mathrm{D}}{\mathrm{DI}}$} & \multicolumn{3}{|c|}{ Bank } \\
\hline & & $\mathrm{Al}$ & A2 & A3 & A4 & BI & B2 & $\mathrm{Cl}$ & $\mathrm{C} 2$ & & Bank X & Bank Y & Bank Z \\
\hline \multirow[t]{4}{*}{ A } & $\mathrm{Al}$ & 0.010 & 0.010 & 0.010 & 0.010 & 0.010 & 0.010 & 0.010 & 0.010 & 0.010 & 0.010 & 0.010 & 0.010 \\
\hline & $\mathrm{A} 2$ & 0.007 & 0.007 & 0.007 & 0.007 & 0.007 & 0.007 & 0.007 & 0.007 & 0.007 & 0.007 & 0.007 & 0.007 \\
\hline & A3 & 0.005 & 0.005 & 0.005 & 0.005 & 0.005 & 0.005 & 0.005 & 0.005 & 0.005 & 0.005 & 0.005 & 0.005 \\
\hline & A4 & 0.006 & 0.006 & 0.006 & 0.006 & 0.006 & 0.006 & 0.006 & 0.006 & 0.006 & 0.006 & 0.006 & 0.006 \\
\hline \multirow[t]{2}{*}{ B } & BI & 0.012 & 0.012 & 0.012 & 0.012 & 0.012 & 0.012 & 0.012 & 0.012 & 0.012 & 0.012 & 0.012 & 0.012 \\
\hline & B2 & 0.008 & 0.008 & 0.008 & 0.008 & 0.008 & 0.008 & 0.008 & 0.008 & 0.008 & 0.008 & 0.008 & 0.008 \\
\hline \multirow[t]{2}{*}{$\mathrm{C}$} & $\mathrm{Cl}$ & 0.006 & 0.006 & 0.006 & 0.006 & 0.006 & 0.006 & 0.006 & 0.006 & 0.006 & 0.006 & 0.006 & 0.006 \\
\hline & $\mathrm{C} 2$ & 0.006 & 0.006 & 0.006 & 0.006 & 0.006 & 0.006 & 0.006 & 0.006 & 0.006 & 0.006 & 0.006 & 0.006 \\
\hline $\mathrm{D}$ & DI & 0.000 & 0.000 & 0.000 & 0.000 & 0.000 & 0.000 & 0.000 & 0.000 & 0.000 & 0.000 & 0.000 & 0.000 \\
\hline \multirow[t]{3}{*}{ Bank } & Bank X & 0.006 & 0.006 & 0.006 & 0.006 & 0.006 & 0.006 & 0.006 & 0.006 & 0.006 & 0.006 & 0.006 & 0.006 \\
\hline & Bank Y & 0.005 & 0.005 & 0.005 & 0.005 & 0.005 & 0.005 & 0.005 & 0.005 & 0.005 & 0.005 & 0.005 & 0.005 \\
\hline & Bank Z & 0.009 & 0.009 & 0.009 & 0.009 & 0.009 & 0.009 & 0.009 & 0.009 & 0.009 & 0.009 & 0.009 & 0.009 \\
\hline
\end{tabular}

\section{CONCLUSIONS}

This study has prevailed in propounding a new mechanism of sustainability performance measurement by applying the DSS-ANP. The DSS-ANP has reformed the analysis of GRI-4 standards disclosures through the active engagement of stakeholders. The stakeholders together delivered their emphasis on weighting the criteria and sub-criteria as well as grading the banking performance as reported by sustainability documents. Thus, the transparency, inclusiveness, auditability, relevance, clarity, and verification of disclosures is preserved. The weighting values of criteria and subcriteria have been successfully advised the significant standards that stakeholders must be occupied towards sustainability achievement. The study reveals a detailed analysis of bank performance place on the accomplishment of criteria and sub-criteria. Therefore, the external stakeholders including OJK, government, and social environment are recommended to the highest performance of banks that meet the CSR standards. This of course can be used as a guideline in making the decision and conducting the corrective action in approaching the success of CSR. Further research is required in handling the fuzziness of expert judgments on the standards assessment, for example by integrating the fuzzification on the ANP method. Therefore, the calculation of performance develops into more reflected and unambiguous.

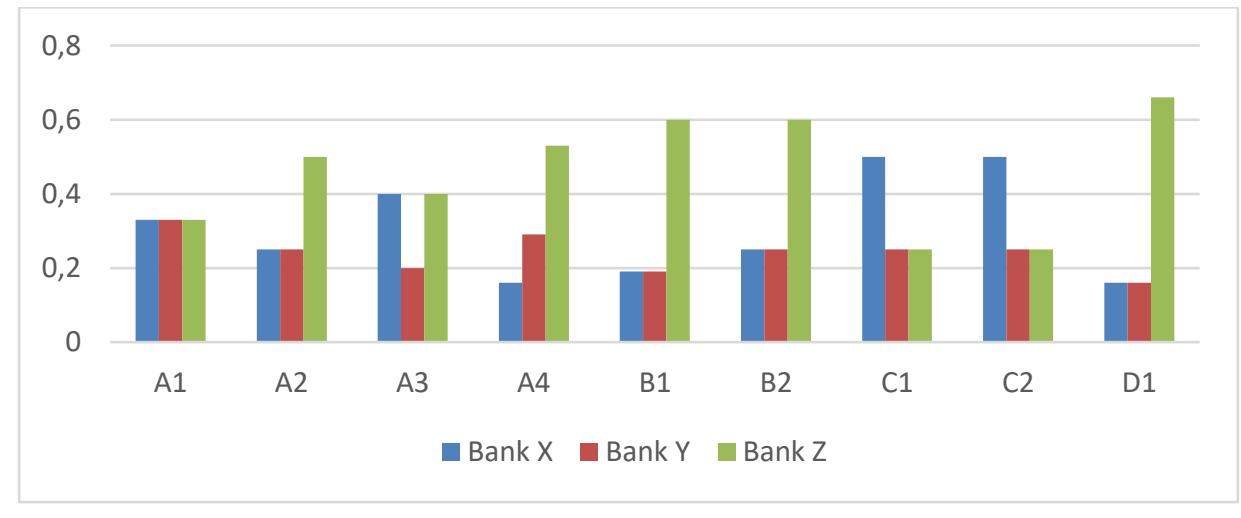

FIGURE 3a. The GRI-4 standards Performance of Banking: Economic Aspects 


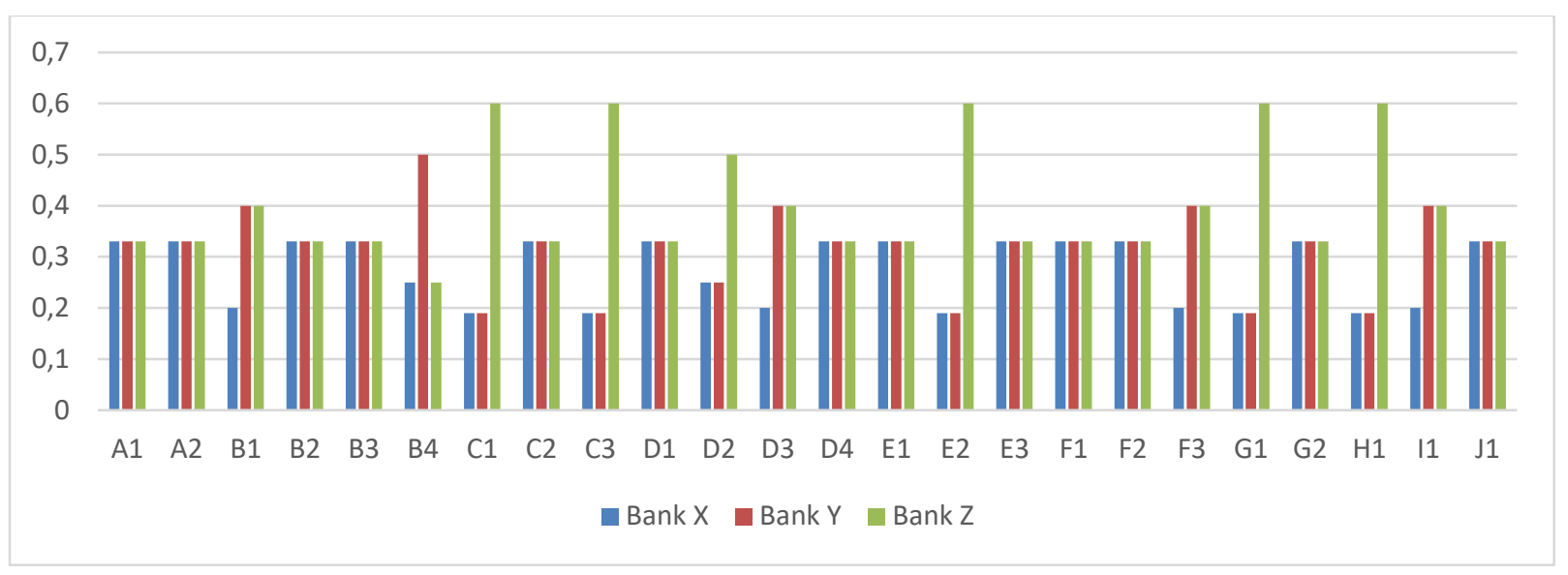

FIGURE 3b. The GRI-4 standards Performance of Banking: Environment Aspects

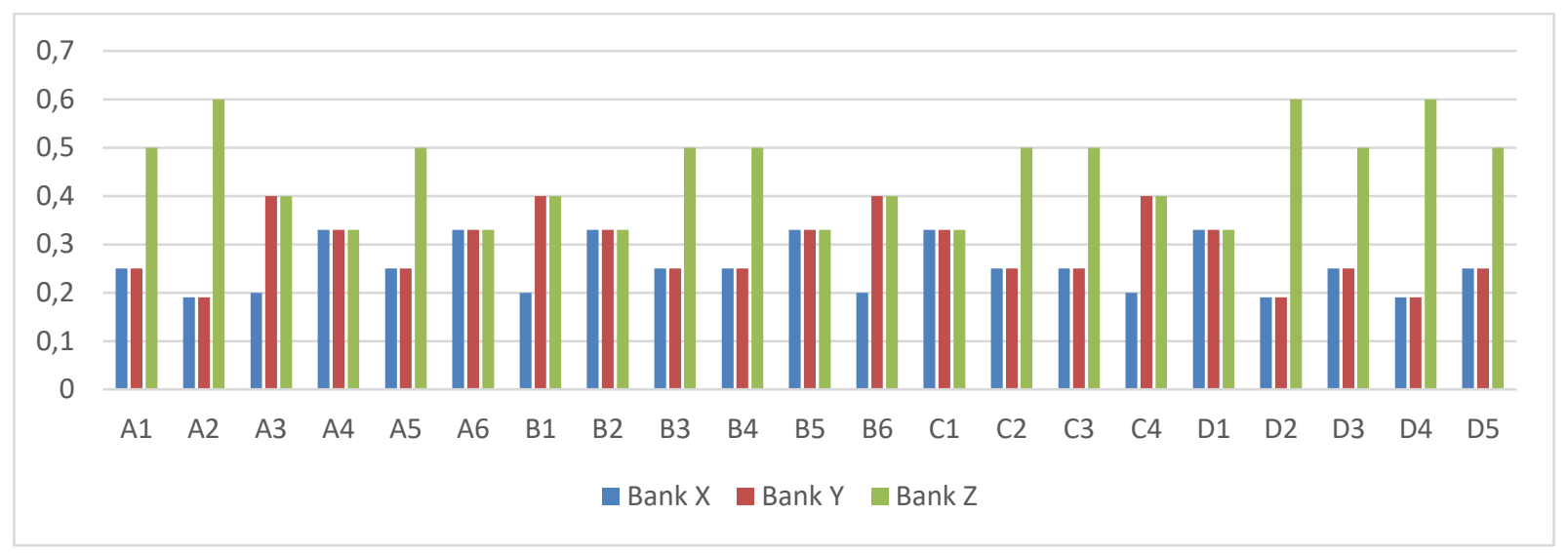

FIGURE 3c. The GRI-4 standards Performance of Banking: Social Aspects

\section{ACKNOWLEDGMENTS}

The authors fully acknowledged Faculty Science and Technology and Faculty Economy and Social Universitas Islam Negeri Sultan Syarif Kasim Riau, Universitas Riau, OJK, and Bank Indonesia for their high contribution to this study. This generates this study to be more viable and effective.

\section{REFERENCES}

1. I. Kostadinova, "Digital models for the transformation of corporate social responsibility education," (29th Annu. Conf. Eur. Assoc. Educ. Electr. Inf. Eng. EAEEIE 2019 - Proc., 2020).

2. Z. Xinhua, "Research on information disclosure of corporate social responsibility based on environmental friendliness," (Proc. 30th Chinese Control Decis. Conf. CCDC 2018), pp. 5558-5563.

3. K. Kampova, K. Makka, Z. Zvakova, and W. Pellowksi, "The eSEC Portal as a Tool for the Concept of Corporate Social Responsibility," (ICETA 2018 - 16th IEEE Int. Conf. Emerg. eLearning Technol. Appl. Proc., no. November, 2018), pp. 261-266.

4. F. Madrakhimova, J. Bus. ans Econ. 4, 6, 509-520 (2013).

5. Mihajat, M. I. S., Journal of Islamic Banking \& Finance Oct-Dec2016 33,4, $72-85$ (2016).

6. A. Hery, S. Yustianti, and D. Susilo, J. Wacana Huk. dan Sains, 20-33 (2015).

7. P. Esteban-Sanchez, M. de la Cuesta-Gonzalez, and J. D. Paredes-Gazquez, J. Clean. Prod. 162, 1102-1110 (2017).

8. M. A. K. Masud, M. S. Hossain, and J. D. Kim, Sustain.10, 4 (2018). 
9. H.-U.-Z. Khan, M. Azizul Islam, and K. Ahmed, "Corporate sustainability reporting of major commercial banks in line with GRI: Bangladesh evidence Corporate sustainability reporting of major banks in line with GRI: Bangladesh evidence" (6th Asia Pacific Interdiscip. Res. Account. Conf., 2011), pp. 347-362.

10. N. E. Landrum and B. Ohsowski, Bus. Strateg. Environ. 27, 1, 128-151 (2018).

11. R. Wagner and P. Seele, J. Bus. Ethics 146, 2, 333-351 (2017).

12. U. N. Galace, Cris. Comment. IV, 11 (2017).

13. O. Boiral, Accounting, Audit. Account. J. 26, 7, 1036-1071 (2013).

14. M. J. Milne, K. Kearins, and S. Walton, Organization 13, 6, 801-839 (2006).

15. A. Fonseca, "Barriers to Strengthening the Global Reporting Initiative Framework : Exploring the perceptions of consultants, practitioners, and researchers" (2nd Can. Sustain. Indic. Netw. Conf. Account. Through Meas. 2010), pp. 1-27.

16. Okfalisa, S. Anugrah, W. Anggraini, M. Absor, S. S. M. Fauzi, and S. Saktioto, Telecommunication Comput. Electron. Control 16, 6, 2703 (2018).

17. L. Nofianti and Okfalisa, Pertanika J. Soc. Sci. Humanit. 27, 2, 1073-1090 (2019).

18. S. Andreasson, Bus. Soc.50, 4, 647-673 (2011).

19. Sun, Hongcai. Tian, Ping. Wang, L. F. "Network analytic hierarchy process, and decision science". (National Defense Industry Press, Beijing, China, 2011).

20. W. R. Lin, Y. H. Wang, and Y. M. Hung, PLoS One 15, 2, 1-25 (2020).

21. G. Hwang, J. H. Han, and T. W. Chang, Sustain.12, 13, 1-15 (2020).

22. E. B. Leksono, S. Suparno, and I. Vanany, Sustain.11, 13 (2019).

23. H. S. Bonjar, S. Salajegheh, M. Pourkiani, and S. Sayadi, Int. J. Supply Chain Manag.8, 2, 735-743 (2019).

24. D. J. Power and R. Sharda, Decis. Support Syst.43, 3, 1044-1061 (2007).

25. Global Reporting Initiative, "Sustainability reporting guidelines, version 2 (G2)," (Boston: Global Reporting Initiative, 2002).

26. P. Jones, D. Comfort, and D. Hillier, J. Public Aff. 16, 3, 222-230 (2015).

27. Global Reporting Initiative, "Global reporting initiative resource library (inside and out)," (2011).

28. Global Reporting Initiative, G. R, “GRI’s History. Global Reporting,” (2015).

29. M. N. Islam and M. A. F. Chowdhury, Int. J. Green Econ. 10, 3/4, 252 (2016).

30. T. L. Saaty, Int. J. Serv. Sci.1, 1, 83-98 (2008).

31. A. Özdemir, A. Özkan, Z. Günkaya, and M. Banar, Environ. Sci. Pollut. Res. 27, 16, 19798-19809 (2020). 

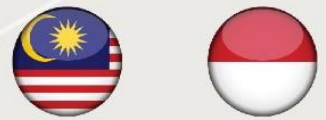

GEGeoGTech QNINNOPA

\section{TH INTERNATIONAL CONFERENCE}

ON ADVANCED MATERIAL ENGINEERING \& TECHNOLOGY (ICAMET2020)

1ST INTERNATIONAL CONFERENCE ON DESIGN INNOVATION, SOCIAL SCIENCE \& TECHNOLOGY (ICDISST2020) 1ST INTERNATIONAL INNOVATION ON SCIENCE, TECHNOLOGY, AND ENGINEERING CONFERENCE (INNOSTEC2020)

\section{MALAYSIAN-INDONESIAN GEOPOLYMER SYMPOSIUM (MIGS2020)}

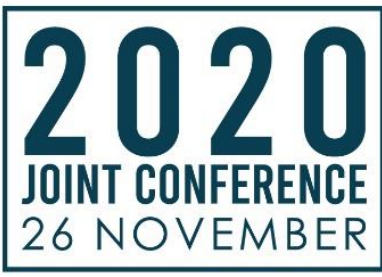




\section{PREFACE}

This joint-conference consists of 4-parallel conferences; 8th International Conference on Advanced Material Engineering \& Technology (ICAMET 2020), 1st International Conference on Design Innovation, Social Science \& Technology (ICDISST 2020), Malaysian-Indonesian Geopolymer Symposium (MIGS 2020) and The FOURTH conference in this event is the 1st International Innovation on Science, Technology, and Engineering Conference (INNOSTEC 2020) that held in this forum.

\section{The 8th International Conference on Advanced Material Engineering \& Technology (ICAMET 2020) \& Malaysian- Indonesian Geopolymer Symposium (MIGS 2020)}

The 8th International Conference on Advanced Material Engineering \& Technology and Malaysian-Indonesian Geopolymer Symposium (MIGS 2020) are the premier forum for the presentation of new advances and research results in the fields of Advanced Material Engineering and Technology which will be held virtually. The conference aims to provide a high-level international forum for researchers, engineers and scientists in the domain of interest from around the world to present their new advances and research results in the field of advanced materials engineering and technology. All papers from ICAMET 2020 and MIGS 2020 will be published in Scopus Indexed Conference Proceeding which covers the entire range of basic and applied aspects of the synthesis and characterization, modelling, processing and application of advanced engineering materials.

The objectives of this conference are:

1. To provide a forum for researchers, educators, students and industries to share and exchange ideas and research findings in new advances and research results in the field of advanced materials engineering and technology. 
2. To provide a broad overview of the latest advances in the field of advanced materials engineering and technology, and that will be as valuable reference source for further research.

3. To create networks and stimulate potential collaborations between researchers in the same field of research. 


\section{1st International Conference on Design Innovation, Social Science \& Technology (ICDISST 2020)}

The conference act as a premier forum accumulating recent research findings and provide opportunities of exchanging ideas related to Design Innovation, Social Sciences and Technology. The conference which is held virtually, brings together researchers, academicians and scientists in the related domain of interests from all around the world. The primary goal of the conference is to provide opportunities to participants in sharing their thoughts and empirical works to those involved in their field or those interested in subjects being researched.

The objectives of ICDISST 2020 conference are:

1. To provide a forum for researchers, educators, practitioners, students and industries to share and exchange ideas and research findings in design, social science and technological fields.

2. To give an opportunity to both academia and industries to communicate on problems faced in current research constraints.

3. To create networks and stimulate potential collaborations between researchers in the same field of research. 


\section{$1^{\text {st }}$ International Innovation on Science, Technology, and Engineering Conference (INNOSTEC) 2020}

With the development of science, the need for more advanced research is needed by Indonesia to sustain the Indonesian nation through research. Based on the 2020 Global Innovation Index, Indonesia ranks 85th for the rank of innovative countries in the world with all of parameters about innovation includes patent, publication, intellectual property, etc.

This deserves special attention for all sections, especially researchers. A global problem requires researchers to be active in finding solutions and publishing them through various kinds of academic conferences. This is the reason for INNOPA to hold the First International Innovation on Science, Technology, and Engineering Conference (INNOSTEC) 2020. The 1st INNOSTEC 2020 facilitates various fields of innovation such as social science, natural science, technology, mathematics, engineering, agriculture, etc. Our main goals are to conduct the potential research to publish their works and provide a platform that academicians, practitioners, individual researchers from private and public company can share their thoughts and experiences about to be a solver at their field or subject.

The objectives of this conference are:

1. To provide quality publications for academics and professionals to disseminate their research.

2. To provide a platform that can be used to discuss ideas and share information to unveil a problem through numerous specific fields.

3. To give opportunities for academicians, professionals, and industries to communicate and collaborate to solve global problems.

4. To build a strong and sustainable network for future collaborations. 


\section{1.

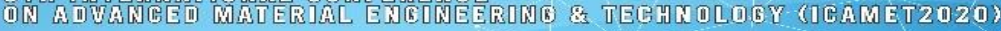

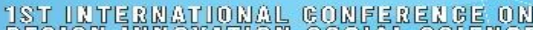

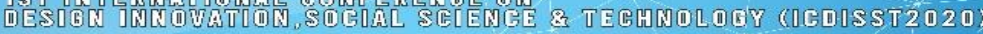

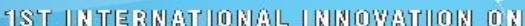

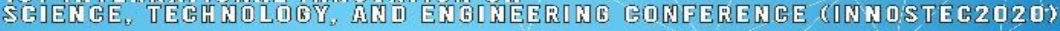

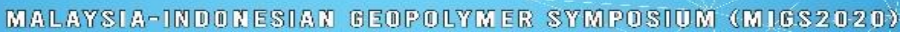 \\ TABLE OF CONTENTS \\ Part I Welcoming Speech by Leader, Center of Excellence Geopolymer and Green Technology (CEGeoGTech) \\ Part II Conference Schedule \\ Part III Keynote Speaker \\ Part IV Invited Speaker \\ Part V Conference Committee \\ Part VI General Information \\ Part VII List of Abstracts}




\section{Part I}

\section{WELCOMING REMARKS}

\section{LEADER OF CEGeoGTech}

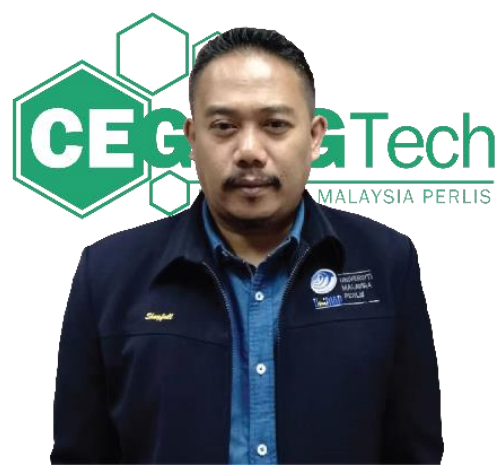

\section{Bismillahirrahmanirrahim}

\section{Assalamualaikum Warahamatullahi Wabarakatuh}

I would like to extend a warm welcome to all guests, speakers and participants to the joint conference that involves; 8th International Conference on Advanced Material Engineering \& Technology (ICAMET 2020), 1st International Conference on Design Innovation, Social Science \& Technology (ICDISST 2020) and Malaysian-Indonesian Geopolymer Symposium (MIGS 2020) organised by Center of Excellence Geopolymer \& Green Technology (CeGeoGTech), Universiti Malaysia Perlis (UniMAP), Perlis.

The FOURTH conference in this event is the 1st International Innovation on Science, Technology, and Engineering Conference (INNOSTEC 2020) organized by Indonesian Invention and Innovation Promotion Association (INNOPA) and co-organized by CeGeoGTech.

This joint conference aims to bring together technologist, researchers and professionals from academics, industries and public sectors in the context 
of multi and inter-disciplinary forum and discussions. This joint conference provides an excellent opportunity of knowledge sharing and exchanging research ideas in the field of engineering, science, and state-of-the-art technology for a better-quality life in facing future challenges.

It is hoped that this conference will be the benchmark to build a strong network between researchers, academic staff and industry.

Finally, congratulations to the working committee and everybody who have supported our efforts in realizing this conference. Stay safe, stay healthy.

Assoc. Professor Ir. Dr. Shayfull Zamree Abd Rahim

Leader,

Center of Excellence Geopolymer and Green Technology

(CEGeoGTech), Universiti Malaysia Perlis (UniMAP) 


\section{Part II}

\section{CONFERENCE SCHEDULE}

November $\mathbf{2 6}^{\text {th }}, \mathbf{2 0 2 0}$

\begin{tabular}{|c|c|c|}
\hline Time & Activity & Link \\
\hline \multicolumn{3}{|c|}{ Opening Ceremony } \\
\hline $\begin{array}{c}0930- \\
0945\end{array}$ & $\begin{array}{l}\text { - Recitation of Do'a } \\
\text { - Welcoming Speech by Prof. Ir. Ts. Dr. R Badlishah } \\
\text { Ahmad (Vice Chancellor of UniMAP) }\end{array}$ & \multirow{6}{*}{$\begin{array}{l}\text { https://meet. } \\
\text { google.com/ } \\
\text { ftt-rknx-mko }\end{array}$} \\
\hline $\begin{array}{c}0945- \\
1005\end{array}$ & $\begin{array}{l}\text { Keynote } 1 \text { by Prof. Dr. Zuruzi Abu Samah, Department } \\
\text { of Mechanical Engineering at Alfaisal University, } \\
\text { Kingdom of Saudi Arabia. }\end{array}$ & \\
\hline $\begin{array}{c}1005- \\
1025\end{array}$ & $\begin{array}{l}\text { Keynote } 2 \text { by Professor Dr Md. Aminul Islam, } \\
\text { Faculty of Applied Sciences and Humanities, Universiti } \\
\text { Malaysia Perlis (UniMAP), Malaysia. }\end{array}$ & \\
\hline $\begin{array}{c}1025- \\
1045\end{array}$ & $\begin{array}{l}\text { Keynote } 3 \text { by Assoc. Prof. Dr Adriano Fagali de Souza, } \\
\text { Federal University of Santa Catarina, Brazil. }\end{array}$ & \\
\hline $\begin{array}{c}1045- \\
1105\end{array}$ & $\begin{array}{l}\text { Keynote } 4 \text { by Assoc. Prof. Ir Dr. Julie Juliewatty } \\
\text { Mohamed, Director of the Intellectual Property and } \\
\text { Commercialisation Division, Centre of Research and } \\
\text { Innovation, Universiti Malaysia Kelantan, Malaysia. }\end{array}$ & \\
\hline $\begin{array}{c}1105- \\
1125\end{array}$ & $\begin{array}{l}\text { Keynote } 5 \text { by Prof. Hamzah Fansuri, Department of } \\
\text { Chemistry, Institut Teknologi Sepuluh Nopember (ITS) in } \\
\text { Surabaya, Indonesia. }\end{array}$ & \\
\hline \multicolumn{3}{|c|}{ Parallel Session } \\
\hline \multirow{2}{*}{$\begin{array}{c}1130- \\
1330\end{array}$} & $\begin{array}{l}\text { PARALLEL SESSION } 1 \\
\text { Keynote } 6 \text { by Prof. Dr Nasir Shafiq, Department of } \\
\text { Management \& Humanities, Universiti Teknologi } \\
\text { PETRONAS, Malaysia. } \\
\text { Presenters from ICAMET } 2020 \text { \& MIGS } 2020\end{array}$ & $\begin{array}{l}\text { https://meet. } \\
\text { google.com/ } \\
\text { yeg-xdyj- } \\
\text { sxm }\end{array}$ \\
\hline & $\begin{array}{l}\text { PARALLEL SESSION } 2 \\
\text { Invited Speaker } 1 \text { by Associate Professor Ts. Dr. Azhari } \\
\text { Md Hashim, Faculty of Art and Design, Universiti } \\
\text { Teknologi MARA, UiTM Kedah, Malaysia. } \\
\text { Presenters from ICDISST } 2020\end{array}$ & $\begin{array}{l}\text { https://meet. } \\
\text { google.com/ } \\
\text { fbw-vdku- } \\
\text { oqg }\end{array}$ \\
\hline
\end{tabular}




\begin{tabular}{|c|c|c|}
\hline Time & Activity & Link \\
\hline \multirow{6}{*}{$\begin{array}{c}1130- \\
1330\end{array}$} & $\begin{array}{l}\text { PARALLEL SESSION } 3 \\
\text { Keynote } 7 \text { by Prof. Dr Abdellah El-Hadj, Faculty of } \\
\text { Technology, University of Medea, Algeria. } \\
\text { Keynote } 8 \text { by Assoc. Prof. Shayfull Zamree Abd Rahim, } \\
\text { Associate Professor Faculty of Mechanical Engineering } \\
\text { Technology, Universiti Malaysia Perlis, Malaysia. } \\
\text { Presenters from INNOSTEC } 2020 \text { \& ICDISST } 2020\end{array}$ & $\begin{array}{l}\text { https://zoom } \\
\text {.us/j/938105 } \\
\text { 68517?pwd } \\
\text { =bFgzRDYz } \\
\text { UzlPNk1Tb } \\
\text { mRER3A4O } \\
\text { Uk3dz09 }\end{array}$ \\
\hline & $\begin{array}{l}\text { PARALLEL SESSION } 4 \\
\text { Keynote } 9 \text { by Dr Idawati Ismail, Faculty of Engineering, } \\
\text { Universiti Malaysia Sarawak, Malaysia. } \\
\text { Presenters from ICAMET } 2020 \text { \& MIGS } 2020\end{array}$ & $\begin{array}{l}\text { https://meet. } \\
\text { google.com/ } \\
\text { fyq-jmaa- } \\
\text { yxh }\end{array}$ \\
\hline & $\begin{array}{l}\text { PARALLEL SESSION } 5 \\
\text { Invited Speaker } 2 \text { by Dr. Abdul Rahman Hemdi, } \\
\text { Faculty of Mechanical Engineering, Universiti Teknologi } \\
\text { Mara, UiTM Penang, Malaysia. } \\
\text { Presenters from ICDISST } 2020\end{array}$ & $\begin{array}{l}\text { https://meet. } \\
\text { google.com/ } \\
\text { rns-zesh-hxf }\end{array}$ \\
\hline & $\begin{array}{l}\text { PARALLEL SESSION } 6 \\
\text { Invited Speaker } 3 \text { by Dr. Zul Ariff Abdul Latiff, } \\
\text { Faculty of Agro Based Industry, Universiti Malaysia } \\
\text { Kelantan, Malaysia. } \\
\text { Presenters from ICDISST } 2020\end{array}$ & $\begin{array}{l}\text { https://meet. } \\
\text { google.com/ } \\
\text { eou-stuv-fzv }\end{array}$ \\
\hline & $\begin{array}{l}\text { PARALLEL SESSION } 7 \\
\text { Presenters from ICDISST } 2020\end{array}$ & $\begin{array}{l}\text { https://meet. } \\
\text { google.com/ } \\
\text { qtc-zkco-tob }\end{array}$ \\
\hline & $\begin{array}{l}\text { PARALLEL SESSION } 8 \\
\text { Presenters from ICDISST } 2020\end{array}$ & $\begin{array}{l}\text { https://meet. } \\
\text { google.com/ } \\
\text { ewd-nqip- } \\
\text { vin }\end{array}$ \\
\hline
\end{tabular}




\begin{tabular}{|l|l|c|}
\hline Time & \multicolumn{1}{|c|}{ Activity } & Link \\
\hline & PARALLEL SESSION 9 & $\begin{array}{c}\text { https://meet. } \\
\text { google.com/ } \\
\text { uut-zyrk-adn }\end{array}$ \\
\cline { 2 - 3 } & PARALLEL SESSION 10 & $\begin{array}{c}\text { https://meet. } \\
\text { google.com/ } \\
\text { ggu-yooy- } \\
\text { ewz }\end{array}$ \\
\hline
\end{tabular}




\section{Part III}

\section{KEYNOTE SPEAKER 1}

\section{Prof. Dr. Zuruzi Abu Samah}

Department of Mechanical Engineering at Alfaisal University, Kingdom of Saudi Arabia.

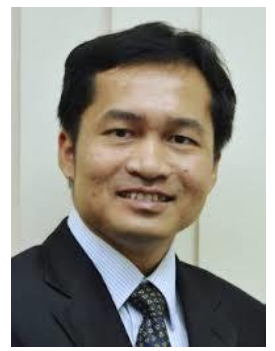

Zuruzi Abu Samah received his academic education in materials. His current research interests are metal oxides, nanomaterials, porous materials and sustainable materials, and their applications for energy, healthcare, and sensing. He is also committed to improve engineering education through research. He received the bachelor and Honours degrees in materials engineering from the Nanyang Technological University, Singapore in 1996 and 1997, respectively. He earned his $\mathrm{PhD}$ at the Materials Department of the University of California, Santa Barbara (UCSB) in 2005. From 1997-2000 he was a junior research staff at the Institute of Materials Research and Engineering (IMRE); an institute of the Agency for Science, Technology and Research (A*STAR), Singapore. In addition to responsibilities for setting up the laboratory infrastructure for the new institute, he also worked in teams that developed nickel silicide contact materials and solder-based joining technologies such as flip-chip and ball grid arrays. His doctoral research is on development of a technology to integrate thin-film nanostructured titania into microsystems which was granted a US patent. Together with collaborators in the chemistry and physics departments, Zuruzi demonstrated applications of the technology in gas sensing and in-silico cell culture applications. He completed a postdoctoral fellowship at Agilent Labs, California where he worked in a team 
developing liquid metal switches. He then joined Intel US as a senior engineer where he contributed efforts to develop Intel's next generation product lines. Since August 2019, Dr Zuruzi has been a full professor at the Department of Mechanical Engineering at Alfaisal University, Kingdom of Saudi Arabia and from September 2019 serves as its chair. Dr Zuruzi gained academic experience as a senior lecturer at Nanyang and Temasek polytechnics in Singapore. His achievement include setting up the diploma in nanotechnology and materials science including its laboratories, curriculum and staffing. He was a founding faculty at the Singapore University of Technology and Design. In early 2015, he joined Universiti Teknologi Brunei (UTB) as a professor in the Mechanical Engineering Programme Area. He served as UTB's Deputy Dean of Graduate Studies and Research Office (GSRO) from July 2015 until June 2017 at which time he was appointed UTB's Assistant Vice-Chancellor (Research). At UTB, he worked with and led teams to roll out masters by coursework programmes and grew graduate student numbers. He also assisted the Vice-Chancellor to develop UTB's five year plan for research. He left UTB in August 2019. His honours include the Regents scholarship of the University of California, the International Fellowship from Agency for Science, Technology and Research and the Graduate Student Silver Award of the Materials Research Society (MRS) during his graduate studies. He received the Outstanding Volunteer Award from IES in 2014 and honoured with a place in the 2016 Emerging Leaders Alliance Program by The Minerals, Metals and Materials Society (TMS). His research has been funded by National Research Foundation, Ministry of Education and Ministry of Defense, TOTE in Singapore, Universiti Teknologi Brunei and Ministry of Defence, Brunei and the Alfaisal University, Kingdom of Saudi Arabia.

\section{Title: Sensing pressure using carbon filled-polydimethylsiloxane foams: From carbon nanotubes to rice-husk biochar}

Abstract. Pressure sensors convert mechanical stimulus into an output signal the magnitude of which depends on pressure applied. Pressure sensors are essential to our modern lifestyle with applications ranging from healthcare to automotive industries. In 2017, the pressure sensors market was estimated to be USD $\$ 10$ billion and is expected to grow by $5 \%$ at compounded annual growth rate until 2025. Sensors using piezoresistive sensing technology is a 
leading market segment. A major advantage of piezoelectric pressure sensors is they do not require additional conditioning such as sensor bridges and temperature compensation. Recently, advancements in contact pressure sensing technology have been made in dense elastomeric materials. Various types of elastomers have been used in sensors applications and with polydimethylsiloxane (PDMS) being widely investigated. Introducing electrical-conducting carbon fillers into PDMS to form stretchable strain sensors provides pressure sensors with improved sensitivity and stretchability. Composites of elastomeric foams have not attracted as much attention as a material for pressure sensing. Here, we present results of our work on carbon-filled PDMS foams for pressure sensing application. In contrast to its dense counterpart, MWCNT/PDMS composite foams exhibit negative pressure coefficient of resistance. A mechanism to explain this observation will be provided. In our effort to explore sustainable sources of carbon, we will also present results of pressure sensing using biochar/PDMS composite foams where biochar are residues from thermochemical conversion of rice husk for bio-fuel extraction. 


\section{KEYNOTE SPEAKER 2}

\section{Professor Dr Md. Aminul Islam}

Faculty of Applied Sciences and Humanities, Universiti Malaysia Perlis (UniMAP), Malaysia.

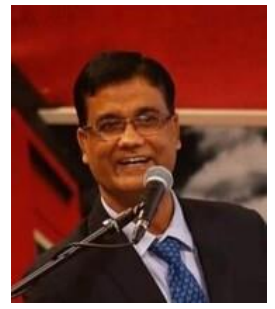

Md. Aminul Islam is currently working as a Professor in the School of Business Innovation and Technopreneurship at Universiti Malaysia Perlis. He received his bachelor's degree from the International Islamic University Malaysia, MBA and Doctor of Philosophy from Universiti Sains Malaysia. He also completed an advanced diploma in teaching in higher education from the Nottingham Trent University. An award-winning Academic and Researcher, Professor Islam received the Raffles Education Founder's Award for being the most deserving academic staff of Olympia College Malaysia 2006, Excellent Academic Support Award 2009, The Best Lecturer Award in 2010 and The Best Supervisor Award in 2018 at Universiti Malaysia Perlis. He also won 'The Best PhD Thesis Award 2011' for the outstanding PhD dissertation at Universiti Sains Malaysia. He is an Advisory Board Member of the Australian Academy of Business Leadership (AABL) Sydney, Australia, a member of Asian Academy of Management and an associate member of Malaysian Finance Association. $\mathrm{He}$ is a visiting Professor of Daffodil International University, East Delta University and Northern University Bangladesh. He has been also serving as an External Academic Advisor of Sentral College Penang, Malaysia. He is the Chief Editor of the Australasian Journal of Islamic finance and Business (AJIFB). He is an editorial board member of number of journals i.e. Business Review, International Journal of Ethics in Social Science, and the founder Chief editor of International Journal of Business and Technopreneurship. He has authored and co-authored three books and about 170 research papers, which include 123 papers published in 
international peer reviewed Journals and 47 papers published in international conference proceedings. His writings have so far attracted about 270,000 READs in the Researchgate and about 2500 citations in Google Scholar. His recent research has spanned issues related to Entrepreneurship, IPO underpricing, Earning Management, Block chain, Islamic banking and Sukuk.

\section{Title: Revisiting Research and Innovation in The Era of Fourth Industrial Revolution}

Abstract. The Fourth Industrial Revolution (4IR) is characterized by the fusion of the digital and physical worlds with the growing utilization of new technologies such as artificial intelligence, cloud computing, robotics, 3D printing, the Internet of Things, and advanced wireless technologies. These developments have ushered in a new era of economic disruption with uncertain socio-economic consequences. The spread of digital technologies have actually empowered researchers with access to information and other necessary services that improve the quality of research and innovation initiatives. The Artificial Intelligence, Internet of Things, and Blockchain have enhanced opportunities for data gathering and analysis for more targeted and effective manners. We do often hear about fresh university graduates who are unable to get jobs due to a misalignment of qualifications with current market demands. Skills and acumen that they acquired are often obsolete even before they enter in the job market. It is predicted that a bulk of present jobs will disappear in the near future. The situation is set to worsen in the post-COVID scenario. Researchers need to engage with the working world to better understand the direction of employment opportunities and strategize their future researches in line with these changing scenarios. Many of the fastest growing jobs and predicted future ones are driven by technology development, increased Internet connectivity, rapid globalization and new business demands. Innovation and Technological skills are required in jobs across industries in different roles and functions and this is expected to create demand for tech-based or tech-related jobs. Are we aligning our research and innovation activities gearing towards these changing scenarios? Are we revisiting and revamping our syllabi and curricula to meet the needs of this new era? 


\title{
KEYNOTE SPEAKER 3
}

\author{
Assoc. Prof. Dr Adriano Fagali de Souza, \\ Federal University of Santa Catarina, Brazil.
}

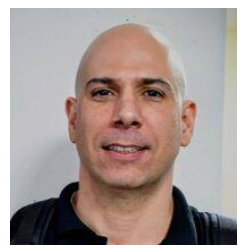

Adriano Fagali de Souza is an associate professor at the Federal University of Santa Catarina - UFSC / Joinville-BRAZIL. He obtained his Dr in Mechanical Engineering from the University of São Paulo -USP in 2004. $\mathrm{He}$ acts and coordinates several research projects, in topics related to the manufacture of products with complex shapes, employing a chain CAD / CAM / CNC - CAx. He is the leader of the Computer Aided Manufacturing Research Group - GPCAM. Takes part on the committee of the Brazilian Association of Technical Standards (ABNT) CEE-261 - for elaboration / revision of the Brazilian Standards on Additive Manufacture. Associate Editor of the Journal of the Brazilian Society of Mechanical Sciences and Engineering - Springer. He has several scientific publications in conferences and journals and some books. In addition to his professional experience, work has been carried out abroad: Delcam International plc. England; Institute - PTW, Technical University of Darmstadt, Germany; Technological Institute of Monterrey, Mexico. Member of the technical committee of Engineering Manufacturing of the Brazilian Association of Mechanical Sciences - ABCM.

\section{Title: Application of Hybrid Manufacturing Process (Machining and Additive Manufacture-SLM) for Tool-making Industry}

Abstract. Cooling is one of the most important phases at plastic injection molding process. It can affect the product mechanical properties, warpage and injection cycle time. Drilling machining is the most used method to manufacture the cooling channels, thus, only linear channels are possible to build. Therefore, in most of the cases, it is not possible to have a homogenous heat transfer, what injuries the product and the injection 
process. The industries have been dealing with these limitations so far. Today, with new metal additive manufacture techniques, such Selective Laser Melting (SLM), it becomes possible to manufacture molds with complex cooling channels. These channels are known as Conformal Cooling (CC) follows complex geometries of the products, resulting in a more efficient cooling system. To reduce the costs of SLM, this work presents an hybrid manufacture process, combining machining and SLM to manufacture molds with conformal cooling channels. The results shown the hybrid process reduced expressively the cost of the SLM without missing mechanical properties of the mold and the conformal cooling system reduced the molding process and improve the quality of the plastic parts.

Keywords: hybrid manufacturing; SLM; molds; conformal cooling. 


\section{KEYNOTE SPEAKER 4}

\section{Assoc. Prof. Ir. Dr. Julie Juliewatty Mohamed}

Director of the Intellectual Property and Commercialisation Division, Centre of Research and Innovation, Universiti Malaysia Kelantan, Malaysia.

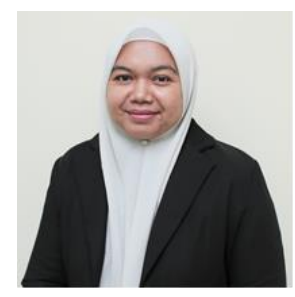

Associate Professor Ir Dr Julie Juliewatty Mohamed is Director of the Intellectual Property and Commercialisation Division, Centre of Research and Innovation, Universiti Malaysia Kelantan. Assoc Prof Ir Dr Julie Juliewatty holds a Bachelor of Materials Engineering (USM), MSc in Materials Engineering - Composite (USM) and $\mathrm{PhD}$ in Materials Engineering - Elctroceramic also from USM. She is Registered Professional Engineer, Board of Engineers Malaysia (BEM). She has published extensively in the area of advanced ceramic - electroceramic materials such as dielectric (CCTO, NiO), piezoelectric (KNN, PZT), and also traditional ceramic (Mambong Pottery, Singgora roof tile). She has published more than 100 journal. Her recent projects have focused on development of $\mathrm{CaCu} 3 \mathrm{Ti} 4 \mathrm{O} 12$ (CCTO) materials that has high potential to be used as supercapacitor, due to its giant dielectric constant behaviour.

Her impressive background both in research and academia landed her several prestigious awards which include Gold Medal in International Invention, Innovation and Technology Exhibition (ITEX) 2019, PECIPTA 2019, ITEX 2018, Malaysia Technology Expo (MTE) 2017, Carnival Research and Innovation (CRI) 2019, CRI 2018 and CRI 2017. She has won silver medal in ITEX 2019, MTE 2019, ITEX 2017, CRI 2018, and some other competition. She has achieved 20 awards in innovation competition. 


\title{
Title: Dielectric Loss (Tan $\Delta$ ) Reduction Of CaCu3Ti4O12 (CCTO) Via Various Addition Of Glasses
}

\begin{abstract}
Addition of various glasses has successfully reduced tan $\delta$ of CCTO- based ceramics. Less amounts $(0-1.0 \mathrm{wt} \%)$ of glasses $(\mathrm{BaO}-$ $\mathrm{SrO}-\mathrm{Nb} 2 \mathrm{O} 5-\mathrm{B} 2 \mathrm{O} 3-\mathrm{SiO} 2$ [BSNBS] and $\mathrm{SrO}-\mathrm{B} 2 \mathrm{O} 3-\mathrm{SiO} 2$ [SBS], respectively) were added into pure CCTO and sintered at $1040^{\circ} \mathrm{C}$ for 10 hours. The phase formation and microstructure of each sample were characterized using $\mathrm{X}$ - ray diffraction and scanning electron microscopy, respectively. The dielectric behavior of the samples was measured at 1 MHz. The addition of BSNBS and SBS glasses $(\leq 0.5 \mathrm{wt} \%)$ successfully reduced $\tan \delta$ of CCTO from 0.5 until 0.4 and 0.39 , respectively, and simultaneously increased $\varepsilon$. Smaller tan $\delta$ and $\varepsilon$ r were further obtained when the added glasses were more than $0.5 \mathrm{wt} \%$. These behaviors were due to segregation of glasses together with precipitation of $\mathrm{CuO}$ which decreased the grain size, and caused the presence of pores at grain boundaries. Therefore, small amount of various additions of glasses could modify the CCTO dielectric properties.
\end{abstract}




\section{KEYNOTE SPEAKER 5}

\section{Prof. Prof Hamzah Fansuri}

Department of Chemistry, Institut Teknologi Sepuluh Nopember (ITS) in Surabaya, Indonesia.

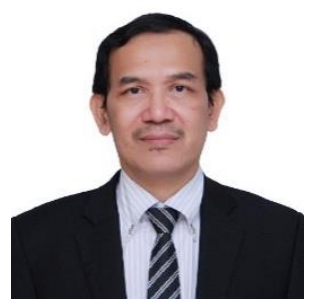

Hamzah Fansuri is a Professor at the Department of Chemistry and the Dean of Faculty of Science and Data Analytics, Institut Teknologi Sepuluh Nopember (ITS) in Surabaya, Indonesia. Hamzah's research interest is in Inorganic materials, particularly Geopolymer and Zeolite, Heterogeneous Catalyst for gas to liquid conversion and Inorganic membranes. His current research projects are: i) methane conversion to syn gas and other small hydrocarbon compounds by partial oxidation using membrane catalysts; ii) geopolymer from fly ash and bottom ash for building materials and heavy metal immobilization; and iii) ceramics and geopolymer membranes for wastewater treatment.

\section{Title: Geopolymers from power plant's fly ashes for immobilize heavy metal waste}

Abstract. Fly ash has been increasingly used as a geopolymer raw material for the construction industries. However, Fly ash is still classified as hazardous waste in Indonesia because it may contain heavy metals and other pollutant elements. In addition, the quality of fly ash varies greatly due to the diversity of coal sources, coal preparation and coal burning processes. Generaly, the geopolymer properties are determined by the ratio of $\mathrm{SiO} 2 / \mathrm{A} 12 \mathrm{O} 3, \mathrm{SiO} 2 / \mathrm{Na} 2 \mathrm{O}$ and $\mathrm{H} 2 \mathrm{O} / \mathrm{Na} 2 \mathrm{O}$. Setting these ratios can work well when kaolin is used as a raw material, but this is not the case when fly ash is used as a raw material. Due to the various properties of the geopolymer produced, many studies have been carried out to determine 
what factors play a very important role in controlling the properties of the fly ahs-based geopolymer products. Based on the results of research that we have conducted since 2008, the chemical composition of fly ash does not determine the quality of the geopolymer produced. The complex combination of physical properties, chemical properties and manufacturing / mixing methods determines the quality of the resulting geopolymer. Our research shows that the most important factors are morphology and particle size and reactivity of fly ash used. Apart from converting fly ash into geopolymers, attention to the content of dangerous heavy metals is also very important. Heavy metal content can be leached into the environment when geopolymers are used as construction materials. Our researchs using $\mathrm{Pb} 2+, \mathrm{Cd} 2+, \mathrm{Co} 2+$ and $\mathrm{Sr} 2+$, it can be concluded that there are three ways heavy metal ions interact/exist in the geopolymer, namely as neutralizing cations, encapsulation and becoming part of the structure. Variation of heavy metal interaction with geopolymer inside the geopolymer body cause differences in how heavy metal cations are immobilize in the geopolymer matrix. 


\section{KEYNOTE SPEAKER 6}

\section{Prof. Dr Nasir Shafiq \\ Department of Management \& Humanities, Universiti Teknologi \\ PETRONAS, Malaysia.}

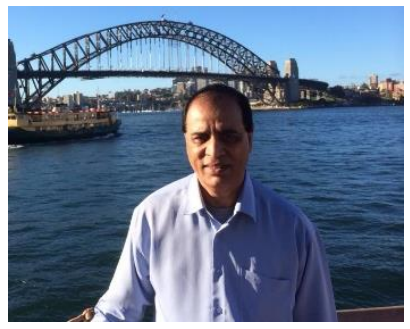

1999, $\mathrm{PhD}$ by University of Leeds

1987, Master in ME by Asian Institute of Technology Bangkok 2002, Degree in Bachelor of Arts by National University of Malaysia

He is a Professor in Structural Engineering and Sustainable development apart from research and academics I am actively involved in administrative position. Current portfolios include Director of Sustainable Resources Mission Oriented Research, Chairman Innovation Committee and Chief Editor of the Research Bulletin RESINEX. The administrative positions main KPIs are research management at MOR level, strategic and business planning, monitoring of IP filing, Research Commercialization and Technology Licencing.

\section{Title: Application of Hybrid Manufacturing Process (Machining and Additive Manufacture-SLM) for Tool-making Industry}

Abstract. Among the supplementary cementing material (SCM) criteria in concrete is to have a high content of reactive silica essential in pozzolanic reaction for concrete strength development. Indeed, it is proven that rice husk ash (RHA) contains a high amount of amorphous silica that is ubiquitous in SCM's pozzolanic reaction in concrete. However, the usage of conventional RHA is unfavorable in the current concrete industry. One of the reasons that hindered the utilization of conventional RHA nowadays is its properties inconsistency, namely chemical and mineralogical properties. 
In this regard, an improvement on the RHA properties by introducing thermochemical pretreatment before a burning procedure is an excellent way to reach the goal. In this paper, physicochemical characteristics details of pretreated rice husk ash were determined. Raw rice husk was pretreated using $0.1 \mathrm{~N}$ hydrochloric acid $(\mathrm{HCl})$ and heated at $80 \mathrm{oC}$. After that, the pretreated rice husk was mechanically activated by a high-energy planetary ball mill for 15 minutes at a speed of 300rpm and a ball-to-powder ratio (BPR) 15:1. The chemical composition, mineralogical properties, particle size analysis, specific surface area, and microstructure properties of ultrafine treated rice husk ash (UFTRHA) were investigated. The optimum sample's amorphous silica content was recorded as $98.60 \%$ incinerated at $600 \mathrm{oC}$ with four hours of pretreatment soaking duration. For studying the particle size and specific surface, it was also observed that burning temperature of $600 \mathrm{oC}$, pretreated at four hours were recorded to produce the well-refined size of UFTRHA; which was $\mathrm{d}(0.1), \mathrm{d}(0.5)$, and $\mathrm{d}(0.9)$ were obtained as $1.416 \mu \mathrm{m}, 4.364 \mu \mathrm{m}$, and $14.043 \mu \mathrm{m}$ respectively. The largest specific surface area value was obtained at $219.58 \mathrm{~m} 2 / \mathrm{g}$ with a similar pretreatment condition. Meanwhile, the strength activity of UFTRHA from the optimum pretreatment process was measured by testing the compressive strength of mortars. The highest compression value obtained was $50.17 \mathrm{MPa}$ with $3 \%$ UFTRHA replacement at 28 days. 


\title{
KEYNOTE SPEAKER 7
}

\section{Prof. Dr Abdellah El-Hadj}

Faculty of Technology, University of Medea, Algeria.

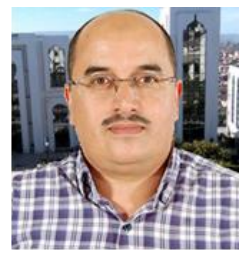

Pr. Abdellah ABDELLAH EL-HADJ is an Head of laboratory of mechanics, Physics, and Mathematical modelling, University of Medea, Algeria. His research interest is Fluid flow, injection moulding, Fluidstructure analysis, optimization and product design engineering.

\section{Title: Crititism of Low-Cost Mechanical Ventilators Using Multi- Physics Analysis}

\begin{abstract}
During this period of COVID-19 pandemic, the lack of medical equipment (like ventilators) leads to complications to arise in the medical field. A low-cost ventilator seems to be an alternative substitute to fill the lacking. This paper presents a numeri-cal analysis for predicting delivered parameters of low-cost mechanical ventilator. Based on several manufactured mechanical ventilators, two proposed designs are investigated in this study. Fluid-structure interaction (FSI) analysis is used for solving any problems with the first design, and computational fluid dynamic (CFD) analysis with moving boundary is used for solving any problems with the second design. For this purpose, Ansys workbench platform is used to solve the set of equations. Results showed that the Ambu-bag based mechanical ventilator exhibited difficulties in con-trolling ventilation variables, which certainly is going to cause serious health problems such as barotrauma. The mechanical ventilator based on pistoncylinder is more satis-factory with regards to delivered parameters to the patient. The ways to obtain pres-sure control mode (PCM) and volume control mode (VCM) are identified. Finally, the ventilator output is highly affected by inlet flow, length of cylinder, and diameter of piston.
\end{abstract}




\title{
KEYNOTE SPEAKER 8
}

\section{Assoc. Prof. Shayfull Zamree Abd Rahim}

Associate Professor Faculty of Mechanical Engineering Technology, Universiti Malaysia Perlis, Malaysia.

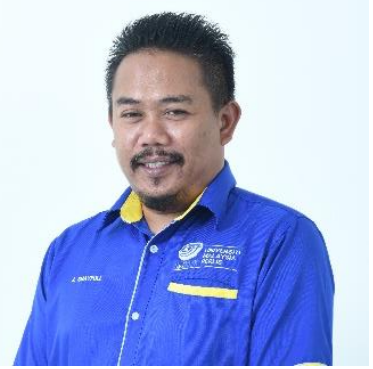

Ir. Dr. Shayfull Zamree Bin Abd Rahim is an Associate Professor at Faculty of Mechanical Engineering Technology, Universiti Malaysia Perlis, Malaysia. He is also a corporate member of The Institution of Engineers, Malaysia (IEM). He has published 171 articles with 729 citations and hindex of 17. His research interest is in materials processing, injection moulding, optimization and product design engineering.

\section{Title: Rapid Tooling Drives Innovation to Commercialization: A New Hybrid Mold Insert for Rapid Tooling Application}

\begin{abstract}
Recent years have shown such overwhelming uses of rapid tooling (RT) and Additive Manufacturing (AM) technologies in various field of industries. Various types of prototypes have been researched especially in the area of new product development. This research aims to develop a hybrid mold insert to increase the speed of tooling development and performance. An extensive review on the suitable development approach of a hybrid mold insert, material preparation and the filler effect on physical and mechanical properties have been conducted. Latest research indicates that it is feasible to develop a hybrid material using the combination of different shapes/sizes of filler particles. It is expected that this approach can improve the compressive strength and thermal conductivity, and consequently the hybrid mold performance (cooling time
\end{abstract}


and number of cycle) will be increased. Research works in RT for hybrid mold insert are still lacking as compared to the conventional manufacturing technology. One of the significant limitations is on identifying the right method to improve physical and mechanical properties due to its limited type, size and shape of materials. A new formulation of metal epoxy composite materials for the hybrid mold insert in injection molding application and rapid tooling for non-metal products will also be investigated. 


\section{KEYNOTE SPEAKER 9}

\section{Dr. Idawati Ismail}

Faculty of Engineering, Universiti Malaysia Sarawak, Malaysia.

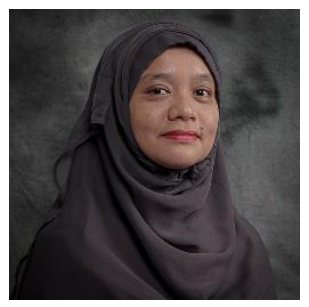

Dr Idawati Ismail is a senior lecturer at Universiti Malaysia Sarawak. She obtained her PhD from University of Melbourne, Australia, specializing in durability of alkali activated binders. Her field of expertise also includes materials characterization, particularly looking into the correlations between microstructural characteristics and performance of alkali activated materials and concretes. She has published several papers reporting different types of raw materials that have the potentials as alternative binders.

\section{Title: Can Artificial Intelligence Predict Durability of Alkali Activated Concretes?}

Abstract. Normal Portland cement concretes are commonly used in construction industry and its strength and durability performance are generally well understood. However, since there is a need in adopting sustainable materials, alkali activated concretes has gained more attention in the last 20 years. Due to the different controlling parameters in alkali activated concretes, it is also difficult to make prediction on their strength and durability. Machine learning is the scientific study of algorithms and statistical models that computer systems use to perform a specific task without using explicit instructions, but, relying on patterns and inference instead. This preliminary study is tackling on the correlation between microstructural characteristics of alkali activated binders and their performance, using machine learning techniques. We analyse the patterns pertaining to the data relating to alkali activated concrete microstructure, 
and estimate the concrete strength using various machine learning techniques such as artificial neural network, regression, and clustering.The main aim of this paper is to examine the possibility of using machine learning methodologies for tackling the concrete design problem.

Keywords: Alkali activated materials, concrete, machine learning 


\section{Part IV}

\section{INVITED SPEAKER}

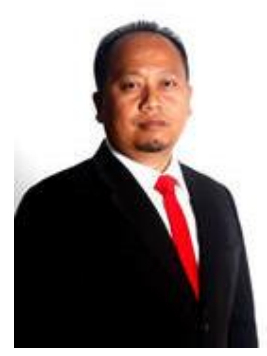

\section{Associate Professor Ts. Dr. Azhari Md}

\section{Hashim}

Faculty of Art and Design, Universiti

Teknologi MARA, UiTM Kedah, Malaysia.

Title: Intensify Creativity And Innovation In

Service Design To Establish An Excellence

Industrial Design Teaching Environment

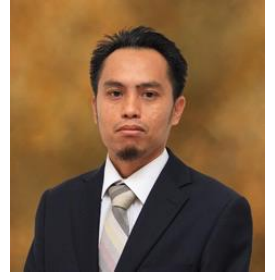

Dr. Abdul Rahman Hemdi

Faculty of Mechanical Engineering, Universiti Teknologi Mara, UiTM Penang, Malaysia.

Title: Methods and Tools for Integrating

Sustainability Perspective into Product Designs.

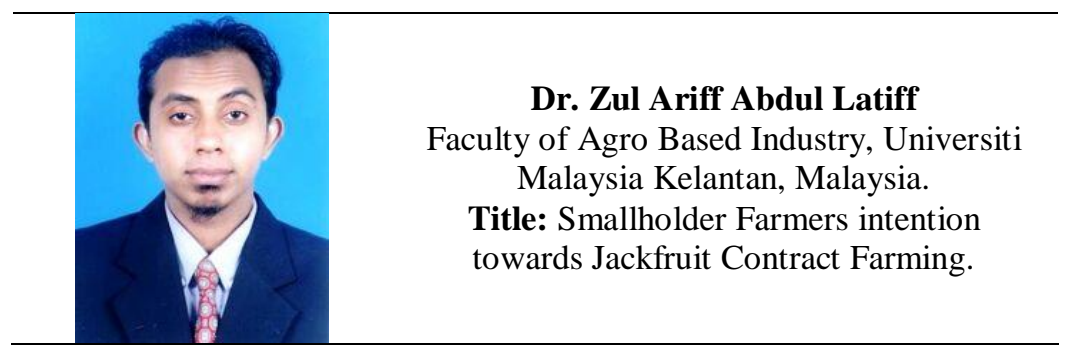




\section{Part V}

\section{CONFERENCE COMMITTEE}

\section{ICAMET \& MIGS 2020}

\section{Honorary-Chair:}

Prof. Dr. Mohd Mustafa Al Bakri Abdullah, Universiti of Malaysia Perlis

(UniMAP)

Assoc. Prof. Ir. Dr. Shayfull Zamree Abd. Rahim, Universiti Malaysia

Perlis (UniMAP), Malaysia

\section{Chairman:}

Dr. Rafiza Abdul Razak, Universiti of Malaysia Perlis (UniMAP),

Malaysia

\section{Technical and Organizing Committee}

Dr. Zarina Yahya, UniMAP, Malaysia

Dr. Wan Mastura Wan Ibrahim, UniMAP, Malaysia

Dr. Romisuhani Ahmad, UniMAP, Malaysia

Dr Ikmal Hakem Aziz, Universiti of Malaysia Perlis (UniMAP), Malaysia

Muhammad Faheem Mohd Tahir, UniMAP, Malaysia

Liyana Jamaludin, UniMAP, Malaysia

Nurul Aida Mohd Mortar, UniMAP, Malaysia

Liyana Ahmad Sofri, UniMAP, Malaysia

Rosnita, UniMAP, Malaysia 


\section{CONFERENCE COMMITTEE}

\section{ICDISST 2020}

\section{Co-organized by:}

World Invention Intellectual Property Associations (WIIPA), Taiwan

\section{Advisory Board:}

Professor Ts. Dr. Mohd Mustafa Al-Bakri Abdullah (UniMAP)

Professor Dr. Che Mohd Ruzaidi Ghazali, (UMT)

Assoc. Professor Ir. Dr. Shayfull Zamree Abd Rahim (UniMAP)

Assoc. Professor Ir. Dr. Mohd. Fathullah Ghazli@ Ghazali (UniMAP)

Chairman: Muhamad Farizuan Rosli

Co-Chairman: Mohd Effendi Muhammad Suandi

\section{Technical Committees:}

Professor Dr. Md Saidin Bin Wahab (UTHM)

Assoc. Professor Dr Huzili Bin Hussin (UniMAP)

Assoc. Professor Dr. Abdul Mutalib Leman (UTHM)

Assoc. Professor Norshahrizan Bt Nordin (UniMAP)

Assoc. Professor Tunku Salha Binti Tunku Ahmad (UniMAP)

Assoc Prof Dr Saiful Bahri Mohamed, Universiti Sultan Zainal Abidin

Prof. Madya Dr Mohammad Rusdi bin Mohd Nasir

Ir. Dr. Mohd Rashidi Bin Maarof (UMP)

Dr. Sharmini Binti Abdullah (UniMAP)

Drs. Suwardi Annas, M.Si., Ph.D, (Universitas Negeri Makassar, Indonesia)

Drs. Subaer, M.Phil, Ph.D (Universitas Negeri Makassar,Indonesia)

Dr. Khairu Bin Kamarudin (UTHM)

Dr. Julinawati Bt Suanda (UniMAP)

Dr. Ummi Naiemah Binti Saraih (UniMAP)

Dr. Rosmamuhamadani Ramli (UiTM)

Ir. Dr. Nik Ahmad Faris Bin Nik Abdullah (Politeknik Sultan Abdul Halim

Mu'adzam Shah - Polimas)

Ir. Mohd. Nasir Mat Saad (UniMAP)

Ir. Amarul Bin Talip (UniMAP)

Muhamad Ezran Bin Zainal Abdullah (UMK) 


\title{
CONFERENCE COMMITTEE
}

\section{INNOSTEC 2020}

\author{
Chairman: \\ President of INNOPA
}

\section{Co-Chairman:}

Director of Innovation and Development of INNOPA

\section{Technical Committees:}

Prof. Ts. Dr. Safian Sharif (Universiti Teknologi Malaysia) Assoc. Prof. Abdul Mutalib Bin Leman (Universiti Tun Hussein Onn

$$
\text { Malaysia) }
$$

Assoc. Prof. Dr. Zawawi bin Daud (Universiti Tun Hussein Onn

$$
\text { Malaysia) }
$$

Assoc. Prof. Dr. Ahmad Zia Ul-Saufie Mohamad Japeri (Universiti

Teknologi MARA)

Assoc. Prof. Ts. Dr. Aeslina Binti Abdul Kadir (Universiti Tun Hussein Onn Malaysia)

Assoc. Prof. Dr Mohd Remy Rozainy Mohd Arif Zainol (Universiti

$$
\text { Sains Malaysia) }
$$

Assoc. Prof. Dr. Ramadhansyah Putra Jaya (Universiti Malaysia

$$
\text { Pahang) }
$$

Dr Irna Farikhah (The University of PGRI Semarang)

Dr. Mohamad Anuar Kamaruddin (Universiti Sains Malaysia)

Dr Zuliahani Ahmad (UiTM Perlis)

Dr. Nurul Huda Osman (Universiti Putra Malaysia)

ChM. Dr. Nik Raihan Bt Nik Yusoff (Universiti Malaysia Kelantan)

Ts. Dr. Rosniza Hussin @ Isa (Universiti Tun Hussein Onn Malaysia)

Ts. Dr. Mohd Azlan Suhaimi (Universiti Teknologi Malaysia)

Dr. Ahmad Hamdan bin Ariffin (Universiti Tun Hussein Onn

$$
\text { Malaysia) }
$$

Dr. Khairul Anuar Abd Wahid (Universiti Kuala Lumpur)

Dr. Chen Ruey Shan (Universiti Kebangsaan Malaysia)

Dr. Md Rakibuddin (Yeungnam University)

Mohamed Syazwan Osman, B.Eng., M.Sc. (UiTM Pulau Pinang) 


\section{Part VI}

\section{GENERAL INFORMATION}

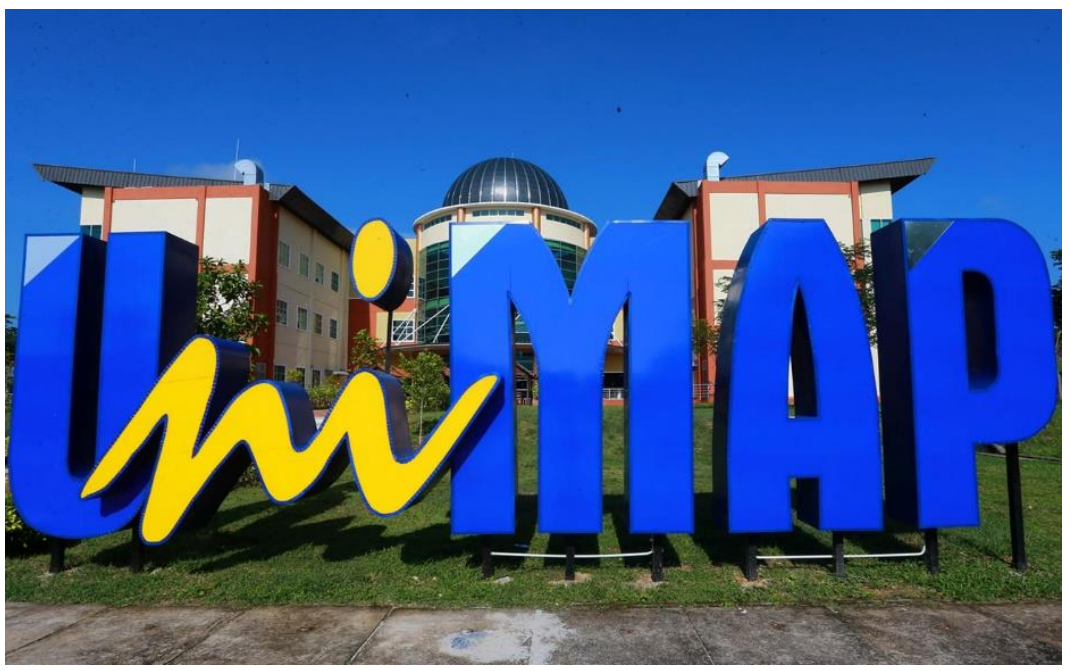

\section{About UniMAP}

Universiti Malaysia Perlis (UniMAP) is Malaysia's 17th public institution of higher learning. Approved by the Malaysian Cabinet in May 2001, it started off as a university college - Kolej Universiti Kejuruteraan Utara Malaysia (KUKUM). The institution's first intake comprised 116 engineering students who began classes in June 2002. In February 2007, KUKUM was upgraded to a full-fledged university and renamed Universiti Malaysia Perlis (UniMAP). The university is one of only four technical universities in Malaysia.

UniMAP's raison d'etre was to produce highly-skilled engineers to fulfil and support Malaysia's Industrial Blueprint (Pelan Induk Perindustrian Negara). Over the years, we have remained true to this mission, aiming to produce exemplary individuals who will contribute to the Nation's development and industry competitiveness agenda. 
We take pride in UniMAP being a leading technical university in the region, enhanced by its active engagement with leading industries in the region and globally. Our niche areas are Engineering, Engineering Technology, Technology, Science \& relevant areas, with emphasis on electronics. Our focus on TVET means that we are able to offer students with a range of programmes highly relevant to industry, including that of soft-TVET.

UniMAP students are nurtured to become competent practitioners in their area of specialization and to have the confidence to explore entrepreneurial possibilities upon graduation. They are expected to not only exhibit excellence in the knowledge and skills that are directly related to their specialized fields of study, but also to demonstrate outstanding proficiency in both communication and ICT skills, as well as possess unsurpassed traits of professionalism and patriotism. 

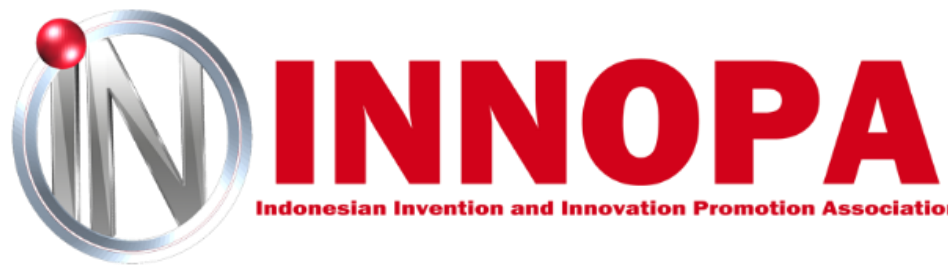

Indonesian Invention and Innovation Promotion Association

\section{About INNOPA}

Indonesian Invention and Innovation Promotion Association (INNOPA) is an association that concerns in the development and promotion of innovation in Indonesia. INNOPA has been established since 2011 and appointed as the one and only representation of Indonesian innovation association under the patronage of International Federation of Inventor's Association (IFIA) and World Invention Intellectual Property Association (WIIPA). Our aim is to help Indonesian innovators to show and promote their innovations to the International level. Over the years, INNOPA has been successfully maintain a harmonious and strong partnership with hundreds of overseas innovation associations or companies in many countries. INNOPA also broaden its network with some of public institutions or companies in Indonesia. As an association that commit in the development of innovation in Indonesia, INNOPA builds a strategic relationship with more than 10.000 innovators from students, teachers, and also individual researchers coming from Indonesia remarkable universities. To improve the quality of the inventors and maintain the good relationship among the associations, universities, and companies, we enabling our vision and missions.

\section{Vision}

Preparing Indonesian Innovators to Face Industrial Revolution 4.0 through the Development and Promotion of Innovation in International Level.

\section{Missions}

1. Conducting training and seminar of innovation.

2. Providing guidance to be a great innovator.

3. Providing information service about innovation to the society.

4. Making a great collaboration with certain community or institution aimed to improve skill of Indonesian innovators.

5. Promoting intellectual property rights. 
6. Helping innovators to promote their products in International market.

7. Linking innovators with potential investors. 


\section{PART VII}

\author{
List of Abstracts
}

$8^{\text {th }}$ International Conference on Advanced Material Engineering \& Technology (ICAMET 2020)

$1^{\text {st }}$ International Conference on Design Innovation, Social Science \& Technology (ICDISST 2020)

$1^{\text {st }}$ International Innovation on Science, Technology, and Engineering Conference (INNOSTEC) 2020

Malaysian-Indonesian Geopolymer Symposium (MIGS 2020) 


\section{Structural Analysis of $\mathrm{Ba}_{1-\mathrm{x}} \mathrm{Er}_{\mathrm{x}} \mathrm{TiO}_{3}$ $(0 \leq x \leq 0.02)$}

\section{*Nur Shahirah Zakaria1, Rozana Aina Maulat Osman ${ }^{1,3, a}$ and Mohd Sobri Idris ${ }^{2,3}$}

${ }^{1}$ School of Microelectronic Engineering, Universiti Malaysia Perlis, 02600 Arau, Perlis, Malaysia.

${ }^{2}$ School of Materials Engineering, Universiti Malaysia Perlis, 02600 Arau, Perlis, Malaysia.

${ }^{3}$ Center of Excellence Frontier Materials Research, Universiti Malaysia Perlis, 01000 Kangar, Perlis, Malaysia.

*rozana@unimap.edu.my

Abstract. Erbium doped $\mathrm{BaTiO}_{3}$ with the composition of $\mathrm{Ba}_{1-x} \mathrm{Er}_{x} \mathrm{TiO}_{3}$ for with $\mathrm{X}=0.0045,0.0085,0.01$, and 0.02 samples were prepared via the solid state reaction method. The samples were sintered at $1300^{\circ} \mathrm{C}$ and $1400^{\circ} \mathrm{C}$ in ambient air. The samples single phase tetragonal structure with the space group $\mathrm{P} 4 \mathrm{~mm}$. The phase pure of $\mathrm{Ba}_{1-\mathrm{x}} \mathrm{Er}_{\mathrm{x}} \mathrm{TiO}_{3}$ samples was confirmed using X-ray Diffraction (XRD) analysis. The crystal analysis for $\mathrm{Ba}_{1-x} \mathrm{Er}_{x} \mathrm{TiO}_{3}$ samples were simulated using Visualization for Electronic and Structural Analysis (VESTA) software. 


\section{The Structural Analysis of Calcium Doped $\mathrm{BaTiO}_{3}$}

\section{${ }^{*}$ Chow Chun Sam ${ }^{1}$, Rozana Aina Maulat Osman ${ }^{1,3, a}$, Mohd Sobri Idris ${ }^{2,3}$ and Yasmin Abdul Wahab ${ }^{4}$}

${ }^{1}$ Faculty of Electronic Engineering Technology, Universiti Malaysia Perlis, 02600 Arau, Perlis, Malaysia.

${ }^{2}$ Faculty of Chemical Engineering Technology, Universiti Malaysia Perlis, 02600 Arau, Perlis, Malaysia.

${ }^{3}$ Center of Excellence Frontier Materials Research, Universiti Malaysia Perlis, 01000 Kangar, Perlis, Malaysia..

${ }^{4}$ Nanotechnology \& Catalysis Research Centre, University of Malaya, 50603 Kuala Lumpur, Malaysia.

*rozana@unimap.edu.my

Abstract. A ceramic $\mathrm{BaTiO}_{3}$ was doped with $\mathrm{Ca}$ at the $\mathrm{A}$-site and $\mathrm{A}$ - and $\mathrm{B}$ site. The methods used to prepare the ceramics samples were using a conventional solid-state reaction route. This method was adopted because it allows obtaining powders of high purity and minimal impurities. In this study, the characterization of ca dope $\mathrm{BaTiO}_{3}$ ceramics using X-ray diffraction (XRD) and Rietveld analysis is carried out. The results revealed that the calcium ion incorporation had a significant effect on structural analysis of perovskite $\mathrm{BaTiO}_{3}$ at $\mathrm{A}$-site and no significant effect at $\mathrm{A}$ - and $\mathrm{B}$-site site doping. 


\title{
Effect of Temperature on The Structural Properties of Spinel LiNi $0.5 \mathrm{Mn}_{1.5} \mathrm{O}_{4}$ as Cathode Material for Rechargeable Lithium-ion Batteries
}

\section{*Siti Nur Adlina Norazman"1, 2, Rozana Aina Maulat Osman ${ }^{1,3}$ and Mohd Sobri Idris ${ }^{1,2}$}

${ }^{1}$ Center of Excellence Frontier Materials Research, Universiti Malaysia Perlis, 01000 Kangar, Perlis, Malaysia.

${ }^{2}$ School of Materials Engineering, Universiti Malaysia Perlis, 02600 Arau, Perlis, Malaysia.

${ }^{3}$ School of Microelectronic Engineering, Universiti Malaysia Perlis, 02600 Arau, Perlis, Malaysia.

*sobri@unimap.edu.my

\begin{abstract}
Cathode materials with composition of $\mathrm{LiNi}_{0.5} \mathrm{Mn}_{1.5} \mathrm{O}_{4}$ successfully prepared using conventional solid-state synthesis route. The sample was heat treated at 800,850 , and 900 for 12 hours to evaluate thermal stability of sample at high temperature. Results show the sample remained stable as spinel structure, but their lattice parameters and unit cell volume are slightly change as temperature increased. There is possibility of oxygen deficiency occurred as $\mathrm{LiNi}_{0.5} \mathrm{Mn}_{1.5} \mathrm{O}_{4}$ fired at high temperature for a long period of time that promoted the existence of secondary phase of $\mathrm{Li}_{x} \mathrm{Ni}_{1-\mathrm{x}} \mathrm{O}$ at $900{ }^{\circ} \mathrm{C}$.
\end{abstract}




\section{Indoor Environment Quality (IEQ): Lighting and Acoustics Factors toward Occupants Satisfaction}
* S N A M Noor ${ }^{1, a)}$, H H Ding $\left.2, b\right)$, S Saharuddin'1,c), N F M Yusof ${ }^{1, d)}$, F R M Roshdi ${ }^{1, e)}$ and N A Namandadin ${ }^{2, f)}$

${ }^{1}$ Department of Quantity Surveying, Faculty of Architecture, Planning and Surveying, Universiti Teknologi Mara, Cawangan Perak, Kampus Seri Iskandar, 32610, Perak, Malaysia.

${ }^{2}$ Department of Civil Engineering Technology, Faculty of Engineering Technology, Universiti Malaysia Perlis, Kampus UniCITI Alam, Sungai Chuchuh, 02100 Padang Besar, Perlis, Malaysia..

*sitinuraishah@gmail.com

Abstract. In Malaysia, the demand for green building kept rising from year to year. The design concept of the green building which provides better indoor environment to make occupant more comfortable and healthier. The Green Building Index (GBI) as a rating system in Malaysia was used to evaluate the environmental design and performance of a building by the occupant, due to that, it is used for this research to investigate the relationship between the indicator of the Indoor Environment Quality (IEQ) and occupant satisfaction's element in a private university in Sarawak. The building occupants are the most important feedback to determine the occupant's satisfaction level for IEQ within the campus. A quantitative method was applied to reach the objectives by using simple random sampling. A total of 254 copies of the questionnaire survey form were distributed to respondents at School of Business and Management (SBM) and School of Built Environment (SBE) in the university. However, there are only 238 responds are usable for this research. The result shows that the lighting (68.2.0\%) and the acoustics (42.2\%) in IEQ's indicator had moderate positive and significant relationship with visual comfort, and aural comfort respectively. 


\section{Electrical Properties of $\mathrm{Ba}_{0.8} \mathrm{Sr}_{0.2} \mathrm{Ti}_{0.94} \mathrm{Sn}_{0.06} \mathrm{O}_{3}$ Ceramics}

\section{* Nadia Nasika Nasir ${ }^{1,3}$, Rozana Aina Maulat Osman ${ }^{1,3, a)}$ and Mohd Sobri Idris 2,3}

${ }^{1}$ School of Microelectronic Engineering, Universiti Malaysia Perlis, 02600 Arau, Perlis, Malaysia.

${ }^{2}$ School of Materials Engineering, Universiti Malaysia Perlis, 02600 Arau, Perlis, Malaysia.

${ }^{3}$ Center of Excellence Frontier Materials Research, 01000 Kangar, Perlis, Malaysia.

*rozana@unimap.edu.my

Abstract. In this work, the synthesis of $\mathrm{Ba}_{0.8} \mathrm{Sr}_{0.2} \mathrm{Ti}_{0.94} \mathrm{Sn}_{0.06} \mathrm{O}_{3}$ (BSTS) from $\mathrm{BaCO}_{3}, \mathrm{SrCO}_{3}, \mathrm{TiO}_{2}$ and $\mathrm{SnO}_{2}$ is studied. $\mathrm{Ba}_{0.8} \mathrm{Sr}_{0.2} \mathrm{Ti}_{0.94} \mathrm{Sn}_{0.06} \mathrm{O}_{3}$ ceramic was prepared via conventional solid-state reaction in the air at $1400^{\circ} \mathrm{C}$. Samples were slowly cooled to room temperature. The X-ray diffraction (XRD) studies show that $\mathrm{Ba}_{0.8} \mathrm{Sr}_{0.2} \mathrm{Ti}_{0.94} \mathrm{Sn}_{0.06} \mathrm{O}_{3}$ ceramic has belonged to the cubic phase structure with space group Pm-3m. The ceramic's electrical properties show high dielectric constant, $\varepsilon r \sim 6445$ at room temperature measured at a frequency of $10 \mathrm{~Hz}$. The capacitance of the sample described the dielectric behavior was associated with the grain boundary effect $\left(C=10^{-8}\right.$ to $\left.10^{-10} \mathrm{~F}\right)$, $\mathrm{Ba}_{0.8} \mathrm{Sr}_{0.2} \mathrm{Ti}_{0.94} \mathrm{Sn}_{0.06} \mathrm{O}_{3}$ ceramic has a small dielectric loss and the conductivity in the range between semi - insulator and insulator material. 


\title{
Crystal Chemistry and Electrical Properties of La-doped $\mathrm{BaTiO}_{3}$
}

\section{* Tiong Yuan Zhe ${ }^{1}$, Rozana Aina Maulat Osman ${ }^{1,3, a)}$ and Mohd Sobri Idris ${ }^{2,3}$}

${ }^{1}$ School of Microelectronic Engineering, Universiti Malaysia Perlis, 02600 Arau, Perlis, Malaysia.

${ }^{2}$ School of Materials Engineering, Universiti Malaysia Perlis, 02600 Arau, Perlis, Malaysia.

${ }^{3}$ Center of Excellence Frontier Materials Research, 02600 Arau, Perlis, Malaysia.

*rozana@unimap.edu.my

\begin{abstract}
The effect of lanthanum doping with different concentrations of lanthanum to dope with barium titanate $\left(\mathrm{BaTiO}_{3}\right)$ was studied. All the samples of $\mathrm{Ba}_{1-x} \mathrm{La}_{\mathrm{x}} \mathrm{TiO}_{3}$ with $\mathrm{x}=0,0.0005,0.0010$ and 0.0030 are prepared through the conventional solid-state reaction. XRD is used to determine the purity and to evaluate crystal chemistry of the prepared samples. Impedance spectroscopy analysis is used to analyse the impedance data of the $\mathrm{Ba}_{1-x} \mathrm{La}_{x} \mathrm{TiO}_{3}$ and study the changes with different concentration of lanthanum doped after the samples are sintered at $1450^{\circ} \mathrm{C}$ for 4 hours. From the results, the dielectric constant is frequency-dependent where the higher the frequency, the lower the dielectric constant, and the Curie temperature, $T_{\mathrm{c}}$ is decreased from $393 \mathrm{~K}$ to $383 \mathrm{~K}$ by increasing the dopant concentration of lanthanum into $\mathrm{BaTiO}_{3}$.
\end{abstract}




\title{
Failure Analysis of Leaf Spring for Commercial Vehicle
}

\section{* W H Tan ${ }^{1, a)}$, W Faridah, $\left.2, \mathrm{~b}\right)$, A M Andrew $\left.3, \mathrm{c}\right)$, N A N Zainab $^{2, \mathrm{~d})}$, S Ragunathan ${ }^{2,4, \mathrm{e})}$ and A S N Amirah ${ }^{2, \mathrm{f})}$}

${ }^{1}$ School of Mechatronic Engineering, Universiti Malaysia Perlis, Kampus Tetap Pauh Putra, 02600 Arau, Perlis, Malaysia.

${ }^{2}$ School of Environmental Engineering, Universiti Malaysia Perlis, Kompleks Pusat Pengajian Jejawi 3, 02600, Arau, Perlis, Malaysia.

${ }^{3}$ Centre for Diploma Studies (PPD), Universiti Malaysia Perlis (UniMAP),S2-L1-26, KampusUniCITI Alam, Sungai Chuchuh, 02100 Padang Besar, Perlis, Malaysia. ${ }^{4}$ Center of Excellence Geopolymer and Green Technology (CEGeoGTech), School of Material Engineering, Universiti Malaysia Perlis (UniMAP), P.O. Box 77, D/A Pejabat Pos Besar, 01000 Kangar, Perlis, Malaysia.

*whtan@unimap.edu.my

\begin{abstract}
The objective of this study is to analysis the failure of leaf spring for the commercial vehicle. A given specification of leaf spring is modeled and analyzed using ANSYS software. The material used is 55Si2Mn90. The failure of leaf spring is performed using static analysis, modal analysis and harmonic response analysis. The effect of different loads on the stress, total deformation and frequency response are investigated. The result showed that the stress, total deformation and frequency response increase when load is increased. The failure occurred near the eye of master leaf of the leaf spring due to high stress generated. At the same, it is also observed that the peak response happened on the first mode of natural frequency.
\end{abstract}




\title{
Smart Android Based Health Diagnostic Shoe using Acupuncture Points
}

\author{
${ }^{*}$ A M Andrew ${ }^{1, a)}$, W Faridah, $\left.2, \mathrm{~b}\right)$, W H Tan ${ }^{3, c)}, \mathrm{S}$ \\ Ragunathan ${ }^{2,4, \mathrm{~d})}$, A S N Amirah",e), N A N Zainab ${ }^{2, \mathrm{ff}}$ and A \\ F M Tajudin ${ }^{1, g)}$
}

${ }^{1}$ Centre for Diploma Studies (PPD), Universiti Malaysia Perlis (UniMAP),S2-L1-26, KampusUniCITI Alam, Sungai Chuchuh, 02100 Padang Besar, Perlis, Malaysia.

${ }^{2}$ School of Environmental Engineering, Universiti Malaysia Perlis, Kompleks Pusat Pengajian Jejawi 3, 02600 Arau, Perlis, Malaysia.

${ }^{3}$ School of Mechatronic Engineering, Universiti Malaysia Perlis, Kampus Tetap Pauh Putra, 02600 Arau, Perlis, Malaysia.

${ }^{4}$ Center of Excellence Geopolymer and Green Technology (CEGeoGTech), School of Material Engineering, Universiti Malaysia Perlis (UniMAP), P.O. Box 77, D/A Pejabat Pos Besar, 01000 Kangar, Perlis, Malaysia.

*allanmelvin@unimap.edu.my

\begin{abstract}
Acupuncture is an ancient form of bodywork used originally in oriental medicine. This research enables the users to pre-check their body health condition using this shoe. This research is also intended to alert and pre- warn the users about the condition of their body parts before they get worse. Nowadays, a lot of money and time are spent in clinics and hospitals for health screening and body check- up. This system will be a great assistant to the end user to facilitate a pre- health check- up. Users need to wear the shoe and the vibration points in the different vibration points will send vibration signal to be analyzed by the microcontroller. Once the result is analyzed, the result of the simulation will be displayed on the special application developed. Based on the suggestion given, the user can seek further medical attention from professionals and medical assistants.
\end{abstract}




\title{
Smart SMS- Based Appointment Management System for Hospitals in Rural Area
}

\author{
* A M Andrew ${ }^{1, a)}$, N A N Zainab ${ }^{2, b)}$, A S N Amirah",c), S \\ Ragunathan ${ }^{2,4, \mathrm{~d})}$, W H Tan ${ }^{3, \mathrm{e})}$, W Faridah ${ }^{2, \mathrm{f})}$ and A A A \\ Asri ${ }^{1, g)}$
}

${ }^{1}$ Centre for Diploma Studies (PPD), Universiti Malaysia Perlis (UniMAP),S2-L1-26, KampusUniCITI Alam, Sungai Chuchuh, 02100 Padang Besar, Perlis, Malaysia.

${ }^{2}$ School of Environmental Engineering, Universiti Malaysia Perlis, Kompleks Pusat Pengajian Jejawi 3, 02600 Arau, Perlis, Malaysia.

${ }^{3}$ School of Mechatronic Engineering, Universiti Malaysia Perlis, Kampus Tetap Pauh Putra, 02600 Arau, Perlis, Malaysia.

${ }^{4}$ Center of Excellence Geopolymer and Green Technology (CEGeoGTech), School of Material Engineering, Universiti Malaysia Perlis (UniMAP), P.O. Box 77, D/A Pejabat Pos Besar, 01000 Kangar, Perlis, Malaysia.

*allanmelvin@unimap.edu.my

\begin{abstract}
Nowadays, many hospitals are seeking for smart managing their operations. Based on the discussion with a local private hospital in Penang, Malaysia, there are problems in managing the appointments of dialysis patients. The dialysis center staffs currently having manual management system, where the staffs will call the patients one by one to find out whether they are available to fill the empty slots for the dialysis for the day. It is indeed troublesome for the staffs and the patients. Patients at times are not ready for filling the slots even though they wanted the dialysis, may be due to last minute arrangement for timing and transports. Thus, there is a need to have a system which can manage the appointments for dialysis patients. The purpose of the research is to automate the existing manual appointment system by the help of computerized devices, and to develop a dialysis appointment management system which is user- friendly, simple, fast and cost - effective. The main function of the system is to make an appointment and to store patient details, which will be an easier retrieval for the attendants. The system will identify the empty slots available, and will contact the patients to check the availability. Based on the input from the patients through Short Messaging System (SMS), the appointment will be sorted. The administrators can login to the Smart Appointment Management System using an authorized username and password for viewing and making changes manually.
\end{abstract}




\title{
Development of Smart GPS- based Nurse Following Robot
}

\author{
${ }^{*}$ A M Andrew ${ }^{1, a)}$, W Faridah, $\left.2, b\right), W ~ H ~ T a n^{3, c)}, S$ \\ Ragunathan ${ }^{2,4, \mathrm{~d})}$, A S N Amirah",e), N A N Zainab ${ }^{2, \mathrm{f})}$, and \\ $T P Y i^{1, g)}$
}

${ }^{1}$ Centre for Diploma Studies (PPD), Universiti Malaysia Perlis (UniMAP),S2-L1-26, KampusUniCITI Alam, Sungai Chuchuh, 02100 Padang Besar, Perlis, Malaysia.

${ }^{2}$ School of Environmental Engineering, Universiti Malaysia Perlis, Kompleks Pusat Pengajian Jejawi 3, 02600 Arau, Perlis, Malaysia.

${ }^{3}$ School of Mechatronic Engineering, Universiti Malaysia Perlis, Kampus Tetap Pauh Putra, 02600 Arau, Perlis, Malaysia.

${ }^{4}$ Center of Excellence Geopolymer and Green Technology (CEGeoGTech), School of Material Engineering, Universiti Malaysia Perlis (UniMAP), P.O. Box 77, D/A Pejabat Pos Besar, 01000 Kangar, Perlis, Malaysia.

*allanmelvin@unimap.edu.my

\begin{abstract}
Hospital nurses regularly bring their medicines and healthcare items to the patients using trolley. They need to push or pull the cart to the patient's beds, and then, need to bring it back to the original position many times daily. It can be tiresome for nurses because in a day, they need to treat many patients in the hospital. Thus, many devices have been invented to assist the nurses in their daily work routines. This research is focusing on developing a nurse following mobile robot that follows and carries medical items. The mobile robot is integrated with microcontroller, Global Positioning System (GPS) module, digital compass module and Bluetooth module. To use the robot, the nurse firstly needs to connect her smartphone to the robot through Bluetooth connection. Once the connection is established, the robot will start to follow the nurse. The robot can carry a maximum load of $5 \mathrm{~kg}$ and uses two direct current geared motors and a caster wheel to move.
\end{abstract}




\title{
The Effect of Trans-Polyoctylene Rubber (TOR) as Compatibilizer on Polypropylene (PP)/ Recycled Acrylonitrile Butadiene Rubber (NBRr)/ Banana Skin Powder (BSP) Composite
}

\section{* A A Ghani ${ }^{1, a)}, \mathrm{N} \mathrm{Kasmuri}{ }^{3}$, S Ramasamy ${ }^{4,5}$, R Ahmad $^{2}$, S Ragunathan ${ }^{2,5}$ and N A Ismail ${ }^{1}$}

${ }^{1}$ Chemical Engineering Technology, Faculty of Engineering Technology, Universiti Malaysia Perlis, Campus of UniCITI Alam, 02100 Padang Besar, Perlis, Malaysia.

${ }^{2}$ School of Environmental Engineering, Universiti Malaysia Perlis, Kompleks Pusat

Pengajian Jejawi 3, 02600 Arau, Perlis, Malaysia.

${ }^{3}$ Faculty of Civil Engineering, Universiti Teknologi MARA, 40450 Shah Alam, Selangor, Malaysia.

${ }^{4}$ Faculty of Engineering Technology Universiti Malaysia Perlis (UniMAP), Aras 1, Blok S2, Kampus UniCITI Alam, Sungai Chuchuh, Padang Besar 02100 Perlis, Malaysia. 5Center of Excellence Geopolymer and Green Technology (CEGeoGTech), School of Material Engineering, Universiti Malaysia Perlis (UniMAP), P.O. Box 77, D/A Pejabat

Pos Besar, 01000 Kangar, Perlis, Malaysia.

*azlindaghani@unimap.edu.my

\begin{abstract}
In this study, effect tensile properties on Polypropylene (PP)/ Recycled Acrylonitrile Butadiene Rubber (NBRr)/ Banana Skin Powder (BSP) composite with addition of Trans-Polyoctylene (TOR) as compatibilizer was examined. The samples were prepared and mixed using heated two roll mills at $180^{\circ} \mathrm{C}$ for $50 \mathrm{rpm}$ of speed. The composites were compressed into $1 \mathrm{~mm}$ sheet by using GO-Tech Compression hot press machine before it was cut into dumbbell shape for tensile test. The results showed an increment on the tensile strength and Young's Modulus in the composite with TOR compared to the composite without TOR. However, for elongation at break, Eb the result showed a lower percentage for composite with TOR compared to the composite without TOR. Decreasing pattern in tensile strength and Young's Modulus and increasing pattern in Eb are the effect from the increasing of NBRr content in the formulation. In the water absorption studies, the result showed an increase of moisture content (\%) over time and a lower percentage of water absorption for the PP/NBRr/BSP composite with TOR than the composite without TOR.
\end{abstract}




\section{Chemical Treatment on Polypropylene (PP)/Recycled Acrylonitrile Butadiene Rubber (NBRr)/Banana Skin Powder (BSP) Composites using Epoxy Resin.}

\section{* A A Ghani ${ }^{1, a)}$, N Kasmuri², S Ramasamy ${ }^{3,5}$, R Ahmad $^{4}$, $S$ Ragunathan ${ }^{4,5}$ and N A Ismail ${ }^{1}$}

${ }^{1}$ Chemical Engineering Technology, Faculty of Engineering Technology, Universiti Malaysia Perlis, Campus of UniCITI Alam, 02100 Padang Besar, Perlis, Malaysia ${ }^{2}$ Faculty of Civil Engineering, Universiti Teknologi MARA, 40450 Shah Alam, Selangor, Malaysia

${ }^{3}$ Faculty of Engineering Technology Universiti Malaysia Perlis (UniMAP), Aras 1, Blok S2, Kampus UniCITI Alam, Sungai Chuchuh, Padang Besar 02100 Perlis, Malaysia.

${ }^{4}$ School of Environmental Engineering, Universiti Malaysia Perlis, Kompleks Pusat Pengajian Jejawi 3, 02600 Arau, Perlis, Malaysia

${ }^{5}$ Center of Excellence Geopolymer and Green Technology (CEGeoGTech), School of Material Engineering, Universiti Malaysia Perlis (UniMAP), P.O. Box 77, D/A Pejabat Pos Besar, 01000 Kangar, Perlis, Malaysia

*azlindaghani@unimap.edu.my

Abstract. Thermoplastic elastomers based on polypropylene (PP)/recycled acrylonitrile butadiene rubber (NBRr) /banana skin powder (BSP) was investigated. The aim is to study the effect of epoxy resin with fixed 5 phr to the different composite ratio $(70 / 0 / 30,70 / 5 / 30,70 / 10 / 30,70 / 15 / 30$, and 70/20/30). The samples were prepared using heated two roll mill, then compressed using hot press machine at $180^{\circ} \mathrm{C}$ for 11 minutes, then lastly were cut into dumbbell shape.Samples then were tested for functional group, and mechanical properties which include tensile strength, Young Modulus and elongation at break. The result show that the tensile strength and Young Modulus were found to be decrease with the increasing of $\mathrm{NBRr}$ content. Meanwhile, the elongation at break was found to be increasing with the increasing of NBRr content. The enhancement of tensile properties of $\mathrm{PP} / \mathrm{NBRr} / \mathrm{BSP}$-epoxy resin due to the better adhesion between the NBRr and epoxy resin. 


\title{
Catalytic Pyrolysis of Agricultural Waste using Waste Egg Shell
}

\author{
${ }^{*}$ Razi Ahmad ${ }^{1, a)}$, Norhafezah Kasmuri2,b), Shamala \\ Ramasamy ${ }^{3,4, c)}$, Ragunathan Santiagoo ${ }^{1,4, d)}$ and Nurul \\ Asmidar Mahadi ${ }^{1, \mathrm{e}}$
}

${ }^{1}$ School of Environmental Engineering, Universiti Malaysia Perlis, Kompleks Pusat Pengajian Jejawi 3, 02600 Arau, Perlis, Malaysia.

${ }^{2}$ Faculty of Civil Engineering, Universiti Teknologi MARA, 40450 Shah Alam, Selangor, Malaysia.

${ }^{3}$ Faculty of Engineering Technology Universiti Malaysia Perlis (UniMAP), Aras 1, Blok S2, Kampus UniCITI Alam, Sungai Chuchuh, Padang Besar 02100 Perlis, Malaysia. ${ }^{4}$ Center of Excellence Geopolymer and Green Technology (CEGeoGTech), School of Material Engineering, Universiti Malaysia Perlis (UniMAP), P.O. Box 77, D/A Pejabat Pos Besar, 01000 Kangar, Perlis, Malaysia.

*razi@unimap.edu.my

\begin{abstract}
The catalytic pyrolysis of agricultural waste by waste eggs shell had been studied in the fixed bed reactor. The objectives of this study were to investigate the potential use of waste eggs shell as catalyst in pyrolysis process and to determine the effect of pyrolysis product with various pyrolysis parameters which are temperature, heating rate and biomass size and to determine the effect of catalyst on bio oil production. The optimum parameter for maximum bio oil yield from this study were at temperature of $450^{\circ} \mathrm{C}$, heating rate of $50^{\circ} \mathrm{C} / \mathrm{min}$ and biomass size of $425 \mu \mathrm{m}$. In this study, the used of eggs shell as a catalyst produced the highest bio oil yields of $65.67 \%$.
\end{abstract}




\title{
Catalytic Pyrolysis of Biomass using Calcium-Based Catalysts
}

${ }^{*}$ Razi Ahmad1,a), Shamala Ramasamy2,4,b), Ragunathan Santiagoo ${ }^{1,4, \mathrm{c})}$, Norhafezah Kasmuri ${ }^{3, \mathrm{~d})}$ and Nor Amizah Saede ${ }^{1, e)}$

${ }^{1}$ School of Environmental Engineering, Universiti Malaysia Perlis, Kompleks Pusat Pengajian Jejawi 3, 02600 Arau, Perlis, Malaysia.

${ }^{2}$ Faculty of Engineering Technology Universiti Malaysia Perlis (UniMAP), Aras 1, Blok S2, Kampus UniCITI Alam, Sungai Chuchuh, Padang Besar 02100 Perlis, Malaysia.. ${ }^{3}$ Faculty of Civil Engineering, Universiti Teknologi MARA, 40450 Shah Alam, Selangor, Malaysia.

${ }^{4}$ Center of Excellence Geopolymer and Green Technology (CEGeoGTech), School of Material Engineering, Universiti Malaysia Perlis (UniMAP), P.O. Box 77, D/A Pejabat Pos Besar, 01000 Kangar, Perlis, Malaysia.

*razi@unimap.edu.my

\begin{abstract}
The catalytic pyrolysis of biomass in fixed bed reactor using calcium-based catalysts had been studied in fixed bed reactor. The objective of this study was to determine the influence of parameters on pyrolysis product and to determine the potential of calcium-based catalysts in pyrolysis of palm shell. The results were obtained with various temperature, biomass size and catalyst ratio. The maximum bio oil from this study were at the temperature of $500{ }^{\circ} \mathrm{C}$, biomass size of $425 \mu \mathrm{m}$ and percentages catalyst ratio of $20 \%$. In this study the use of Cryptomya Elliptica as a calcium-based catalyst produced the highest amount of bio oil yield of $32.71 \%$.
\end{abstract}




\title{
Catalytic Pyrolysis of Coconut Shell in Fixed- bed Reactor
}

\author{
${ }^{*}$ Razi Ahmad ${ }^{1, a)}$, Shamala Ramasamy ${ }^{2,5, b)}$, Ragunathan \\ Santiagoo ${ }^{1,5, \mathrm{c})}$, Norhafezah Kasmuri ${ }^{3, \mathrm{~d})}$, Rozanah \\ Abdullah $^{1, \mathrm{e})}$ and Nur Nasulhah Kasim ${ }^{4, \mathrm{f})}$
}

${ }^{1}$ School of Environmental Engineering, Universiti Malaysia Perlis, Kompleks Pusat Pengajian Jejawi 3, 02600 Arau, Perlis, Malaysia.

${ }^{2}$ Faculty of Engineering Technology Universiti Malaysia Perlis (UniMAP), Aras 1, Blok S2, Kampus UniCITI Alam, Sungai Chuchuh, Padang Besar 02100 Perlis, Malaysia.. ${ }^{3}$ Faculty of Civil Engineering, Universiti Teknologi MARA, 40450 Shah Alam, Selangor, Malaysia.

${ }^{4}$ Faculty of Applied Science, Universiti Teknologi MARA, Cawangan Perlis, 02600 Arau, Perlis, Malaysia.

${ }^{5}$ Center of Excellence Geopolymer and Green Technology (CEGeoGTech), School of Material Engineering, Universiti Malaysia Perlis (UniMAP), P.O. Box 77, D/A Pejabat Pos Besar, 01000 Kangar, Perlis, Malaysia.

*razi@unimap.edu.my

Abstract. Pyrolysis of coconut shell was investigated in a fixed-bed reactor to determine the effects of pyrolysis parameters (temperature and heating rate). The effect of zeolite and dolomite catalyst on the product yields and the qualities of the liquid product was investigated. The result showed that the optimal conditions for liquid (bio-oil) yield (48.03\%) were at pyrolysis temperature of $4500 \mathrm{C}$, heating rate of $50{ }^{\circ} \mathrm{C} / \mathrm{min}$, gas flow rate of $50 \mathrm{~L} / \mathrm{min}$ and particle size of $300 \mu \mathrm{m}$. The yield of bio-oil without catalyst is higher than with catalyst. However, the characterisation of bio-oil, indicated that the catalytic pyrolysis upgraded the bio-oil quality. The coconut shell showed that the bio-oil was highly oxygenated containing high fraction of phenol-based compounds. 


\title{
Characterization of Product Yield on Pyrolysis of Sawdust
}

\author{
${ }^{*}$ Razi Ahmad, a), Norhafezah Kasmuri2,b), Shamala \\ Ramasamy ${ }^{3,4, c)}$, Ragunathan Santiagoo ${ }^{1,4, d)}$ and Nur Ain \\ Yusoff ${ }^{1, e)}$
}

${ }^{1}$ School of Environmental Engineering, Universiti Malaysia Perlis, Kompleks Pusat

Pengajian Jejawi 3, 02600 Arau, Perlis, Malaysia.

${ }^{2}$ Faculty of Civil Engineering, Universiti Teknologi MARA, 40450 Shah Alam, Selangor, Malaysia.

${ }^{3}$ Faculty of Engineering Technology Universiti Malaysia Perlis (UniMAP), Aras 1, Blok S2, Kampus UniCITI Alam, Sungai Chuchuh, Padang Besar 02100 Perlis, Malaysia.. ${ }^{4}$ Center of Excellence Geopolymer and Green Technology (CEGeoGTech), School of Material Engineering, Universiti Malaysia Perlis (UniMAP), P.O. Box 77, D/A Pejabat Pos Besar, 01000 Kangar, Perlis, Malaysia.

*razi@unimap.edu.my

\begin{abstract}
In this study, pyrolysis of sawdust was investigated using a fixed bed reactor. The objectives of this project were to study the effect of pyrolysis parameters on production of bio-oil and bio-char and to analyze the characteristics of pyrolysis product. The variations of pyrolysis temperature are $450,500,550,600$ and $650^{\circ} \mathrm{C}$. The particle size was varied in the range of $>1.18 \mathrm{~mm}$ and $<1.18 \mathrm{~mm}$. The heating rate was at 40,50 and $60^{\circ} \mathrm{C} / \mathrm{min}$. The maximum product yield of bio-char was $49.28 \%$ obtained at $550{ }^{\circ} \mathrm{C}$, with heating rate of $50{ }^{\circ} \mathrm{C} / \mathrm{min}$ and particle size of $<1.18 \mathrm{~mm}$. The maximum bio-oil yield was $28.86 \%$ and the maximum gas yield was $68.83 \%$. The optimum gas was at the pyrolysis temperature of $450^{\circ} \mathrm{C}$, heating rates of $60^{\circ} \mathrm{C} / \mathrm{min}$ and particle size of $<1.18 \mathrm{~mm}$. Sawdust can be utilized as biomass feedstock to increase bio-char product. It has high lignin content which can increase yield of bio-char. The bio-char is potential source of renewable fuel and chemical feedstock.
\end{abstract}




\title{
Liquid Fuel Production from Co-pyrolysis of Rice Husk and Polystyrene Waste Mixture
}

\section{${ }^{*}$ Razi Ahmad ${ }^{1, a)}$, Ragunathan Santiagoo ${ }^{1,5, b)}$, Norhafezah Kasmuri ${ }^{2, c)}$, Shamala Ramasamy ${ }^{3,5, d)}$, Nurul Nafizah Salim ${ }^{1, e)}$ and Nur Nasulhah Kasim ${ }^{4, f)}$}

${ }^{1}$ School of Environmental Engineering, Universiti Malaysia Perlis, Kompleks Pusat Pengajian Jejawi 3, 02600 Arau, Perlis, Malaysia.

${ }^{2}$ Faculty of Civil Engineering, Universiti Teknologi MARA, 40450 Shah Alam, Selangor, Malaysia.

${ }^{3}$ Faculty of Engineering Technology Universiti Malaysia Perlis (UniMAP), Aras 1, Blok S2, Kampus UniCITI Alam, Sungai Chuchuh, Padang Besar 02100 Perlis, Malaysia..

${ }^{4}$ Faculty of Applied Science, Universiti Teknologi Mara, Cawangan Perlis, 02600 Arau, Perlis, Malaysia.

${ }^{4}$ Center of Excellence Geopolymer and Green Technology (CEGeoGTech), School of Material Engineering, Universiti Malaysia Perlis (UniMAP), P.O. Box 77, D/A Pejabat Pos Besar, 01000 Kangar, Perlis, Malaysia.

* razi@unimap.edu.my

\begin{abstract}
Rice husk and polystyrene waste were combined to obtain bio-oil through pyrolysis process. The bio-oil produced from mixtures of rice husk and polystyrene waste also potential to be used as fuel. The parameters were used for this study are ratios of mixture, temperature, particle sizes and holding time. High yield of bio-oil was obtained on a rice husk/polystyrene waste of 70:30, temperature of $4500 \mathrm{C}$, particle size of $300 \mu \mathrm{m}$ and holding time of 2 minutes. Results of bio-oil characterization from combination between rice husk and polystyrene proved that the hydrocarbons become increased and the content of acid was decreased. The bio-oil majority consisted of aliphatic and aromatic amines.
\end{abstract}




\title{
Characterization \& Comparison of Oil Palm Empty Fruit Bunch Fiber Composite with \& Without Stearic Acid As Compatibilizer In Polypropylene/Recycled Acrylonitrile Butadiene Rubber Matrices
}

\author{
${ }^{*} \mathrm{R}$ Santiagoo ${ }^{1,5, a)}$, N Kasmuri², S Ramasamy ${ }^{3,5}, \mathrm{R}$ \\ Ahmad $^{1)}$, A A Ghani $^{4)}$ and N Zahari1)
}

${ }^{1}$ School of Environmental Engineering, Universiti Malaysia Perlis, Kompleks Pusat Pengajian Jejawi 3, 02600 Arau, Perlis, Malaysia.

${ }^{2}$ Faculty of Civil Engineering, Universiti Teknologi MARA, 40450 Shah Alam, Selangor, Malaysia.

${ }^{3}$ Faculty of Engineering Technology Universiti Malaysia Perlis (UniMAP), Aras 1, Blok S2, Kampus UniCITI Alam, Sungai Chuchuh, Padang Besar 02100 Perlis, Malaysia.

${ }^{4}$ Chemical Engineering Technology, Faculty of Engineering Technology, Universiti

Malaysia Perlis, Campus of UniCITI Alam, 02100 Padang Besar, Perlis, Malaysia.

${ }^{5}$ Center of Excellence Geopolymer and Green Technology (CEGeoGTech), School of Material Engineering, Universiti Malaysia Perlis (UniMAP), P.O. Box 77, D/A Pejabat

Pos Besar, 01000 Kangar, Perlis, Malaysia.

*raguna@unimap.edu.my

Abstract. The effect of stearic acid (SA) as compatibilizer in polypropylene (PP)/ recycled acrylonitrile butadiene rubber (NBRr)/ oil palm empty fruit bunch (OPEFB) fiber composites were studied. The composites were prepared by mixing the PP/NBRr/OPEFB fibers using heated two roll mill at temperature of $180^{\circ} \mathrm{C}$ with speed of $15 \mathrm{rpm}$ within 9 minutes for six formulation (70/20/0, 70/20/5, 70/20/10, 70/20/15, 70/20/20, 70/20/30) phr. The effect of $\mathrm{SA}$ on tensile and morphological properties of PP/NBRr/OPEFB fibers composites were identified. The composites sample with treated OPEFB fibers have a better tensile strength and young modulus compared to the composites sample with untreated OPEFB fibers. Scanning electron microscopy showed better adhesion between OPEFB fiber and PP/NBRr matrices in the presence of SA. 


\title{
The Effect of Diglycidyl Ether of Bisphenol A (DGEBA) On Recycled Acrylonitrile Butadiene Rubber (NBRr)
}

\author{
${ }^{*}$ R Santiagoo ${ }^{1,5, a)}$, N Kasmuri², S Ramasamy ${ }^{3}, \mathrm{R}$ \\ Ahmad1, A A Ghani ${ }^{5}$ and N I Yusuf ${ }^{1}$
}

\begin{abstract}
${ }^{1}$ School of Environmental Engineering, Universiti Malaysia Perlis, Kompleks Pusat Pengajian Jejawi 3, 02600 Arau, Perlis, Malaysia.

${ }^{2}$ Faculty of Civil Engineering, Universiti Teknologi MARA, 40450 Shah Alam, Selangor, Malaysia.

${ }^{3}$ Faculty of Engineering Technology Universiti Malaysia Perlis (UniMAP), Aras 1, Blok S2, Kampus UniCITI Alam, Sungai Chuchuh, Padang Besar 02100 Perlis, Malaysia.

${ }^{4}$ Chemical Engineering Technology, Faculty of Engineering Technology, Universiti

Malaysia Perlis, Campus of UniCITI Alam, 02100 Padang Besar, Perlis, Malaysia.

${ }^{5}$ Center of Excellence Geopolymer and Green Technology (CEGeoGTech), School of Material Engineering, Universiti Malaysia Perlis (UniMAP), P.O. Box 77, D/A Pejabat

Pos Besar, 01000 Kangar, Perlis, Malaysia..
\end{abstract}

* raguna@unimap.edu.my

\begin{abstract}
Composite based on Polypropylene (PP)/Recycled Acrylonitrile Butadiene Rubber (NBRr)/Oil Palm Empty Fruit Bunch (OPEFB) has been studied. The composites were prepared by using a heated two- roll mill machine at temperature $180 \mathrm{oC}$ for 9 minutes period using $50 \mathrm{rpm}$ rotor speed. The compound was compressed by using a hot press machine at temperature 180 oC for 10 minutes period. The particle size of the OPEFB and NBRr powder used in this project is $150 \mu \mathrm{m}$. The effect of Diglycidyl Ether of Bisphenol A (DGEBA) on mechanical, morphological, chemical and water absorption properties was analyzed with different compositions. The results obtained showed that the tensile strength, Young's modulus and elongation at break for the treated composite were higher compared to the untreated composite. The morphological and chemical properties results support the tensile properties and these showed that the DGEBA compatibilizer has improved the interfacial adhesion between PP, NBRr, and OPEFB that leads to better attachment among them. For the water absorption test, the treated composite showed a lower water absorption compared to the untreated composite.
\end{abstract}




\title{
The Effect of Microwave Treatment with Trimethacrylate Propane Triacrylate (TMPA) On Oil Palm Empty Fruit Bunch (OPEFB) Fibre
}

\author{
* R Santiagoo 1,5,a), N Kasmuri², S Ramasamy ${ }^{3,5}, \mathrm{R}$ \\ Ahmad ${ }^{1}$, A A Ghani ${ }^{4}$ and S N F N Apindi ${ }^{1}$
}

${ }^{1}$ School of Environmental Engineering, Universiti Malaysia Perlis, Kompleks Pusat Pengajian Jejawi 3, 02600 Arau, Perlis, Malaysia.

${ }^{2}$ Faculty of Civil Engineering, Universiti Teknologi MARA, 40450 Shah Alam, Selangor, Malaysia.

${ }^{3}$ Faculty of Engineering Technology Universiti Malaysia Perlis (UniMAP), Aras 1, Blok S2, Kampus UniCITI Alam, Sungai Chuchuh, Padang Besar 02100 Perlis, Malaysia.

${ }^{4}$ Chemical Engineering Technology, Faculty of Engineering Technology, Universiti

Malaysia Perlis, Campus of UniCITI Alam, 02100 Padang Besar, Perlis, Malaysia.

${ }^{5}$ Center of Excellence Geopolymer and Green Technology (CEGeoGTech), School of Material Engineering, Universiti Malaysia Perlis (UniMAP), P.O. Box 77, D/A Pejabat Pos Besar, 01000 Kangar, Perlis, Malaysia.

*raguna@unimap.edu.my

Abstract. The effect of the microwave treatment with Trimethacrylate Propane Triacrylate as the compatibilizer on the mechanical and chemical properties of the Polypropylene (PP), Recycled Acrylonitrile Butadiene glove and Oil Palm Empty Fruit Bunch (OPEFB) fibre has been investigated. The composite were mixed together by using heated two roll mill according to six different formulation which is $(100 / 0 / 10,80 / 20 / 10,70 / 30 / 10,60 / 40 / 10$, $50 / 50 / 10,40 / 60 / 10 \mathrm{phr}$ ) with $4 \%$ of TMPTA. Then, the samples was undergo the microwave treatment with the constant temperature and time $\left(90^{\circ} \mathrm{C}\right.$ and 4 minutes). Result analyses revealed that the microwave-treated composite with TMPTA showed the improvement in tensile properties of the composite. The composite with TMPTA have higher tensile strength compared to without TMPTA. The presence of TMPTA in the PP/NBRr/OPEFB composite formed a better interaction through FTIR analysis. 


\title{
Compression Properties of Fly Ash /Rice Husk Geopolymer Hybrid Brick
}

\section{*Shamala Ramasamy ${ }^{1,2, a)}$, Razi Ahmad ${ }^{3}$, Norhafezah Kasmuri, ${ }^{4,5}$, Ragunathan Santiagoo ${ }^{3,5}$, Che Hanis Syafiqah Che Mat ${ }^{1,2}$, and Meor Ahmad Faris ${ }^{1,2}$}

${ }^{1}$ Faculty of Engineering Technology, Universiti Malaysia Perlis (UniMAP), P.O. Box 77, D/A Pejabat Pos Besar, Kangar, Perlis 01000, Malaysia.

${ }^{2}$ Center of Excellence Geopolymer and Green Technology, School of Material Enginering, Universiti Malaysia Perlis, Komplek Pengajian Jejawi 2, 02600 Arau, Perlis

${ }^{3}$ Sustainable Environment Research Group (SERG), Center of Excellence Geopolymer and Green Technology, School of Material Enginering, Universiti Malaysia Perlis, Komplek Pengajian Jejawi 2, 02600 Arau, Perlis

${ }^{4}$ Faculty of Civil Engineering, UniversitiTeknologi MARA, 40450 Shah Alam, Selangor, Malaysia

${ }^{5}$ Sustainable Environment Research Group (SERG), Center of Excellence Geopolymer and Green Technology, School of Material Enginering, Universiti Malaysia Perlis, Komplek Pengajian Jejawi 2, 02600 Arau, Perlis, Malaysia

*shamala@unimap.edu.my

\begin{abstract}
Geopolymer, an inorganic compound exhibit a wide variety of desirable properties especially in the field of construction. The use of new geopolymer sources materials such as fly ash and rice hush ash have potential as geopolymer bricks to reduce the emission of carbon dioxide caused by ordinary Portland bricks that also indirectly contributes to global environmental impact.The parameter for fly ash and rice hush ash geopolymer brick is by fixing the solid/liquid ratio at 2.0 while the ratio of $\mathrm{Na}_{2} \mathrm{SiO}_{3} / \mathrm{NaOH}$ is $2: 5$ and $\mathrm{NaOH}$ molarity of 12 During mixing process, sample is allowed to pre-cure at room temperature to allow completion of gelling phase and then at $70^{\circ} \mathrm{C}$ for 24 hours to get the reliable early strength. Samples are then subjected to mechanical testing, which is compressive strength to support findings of the best formulation. The best mix design for fly ash geopolymer brick was at 2.5 with highest compressive strength at $44.2 \mathrm{MPa}$. The best mix design also correlates with highest result obtained in water absorption study.
\end{abstract}




\title{
The Density-Morphology Relation: Rice Husk Filled Fly Ash Geopolymer Brick
}

\section{*Shamala Ramasamy ${ }^{1,2, a)}$, Ragunathan Santiagoo ${ }^{3,4}$, Razi Ahmad ${ }^{3}$, Norhafezah Kasmuri ${ }^{4,5}$, Meor Ahmad Faris $^{1,2}$, and Kangkana Bhaisya ${ }^{6}$}

${ }^{1}$ Faculty of Engineering Technology, Universiti Malaysia Perlis (UniMAP), P.O. Box 77, D/A Pejabat Pos Besar, Kangar, Perlis 01000, Malaysia.

${ }^{2}$ Center of Excellence Geopolymer and Green Technology, School of Material Enginering, Universiti Malaysia Perlis, Komplek Pengajian Jejawi 2, 02600 Arau, Perlis

${ }^{3}$ Sustainable Environment Research Group (SERG), Center of Excellence Geopolymer and Green Technology, School of Material Enginering, Universiti Malaysia Perlis, Komplek Pengajian Jejawi 2, 02600 Arau, Perlis

${ }^{4}$ Faculty of Civil Engineering, UniversitiTeknologi MARA, 40450 Shah Alam, Selangor, Malaysia

${ }^{5}$ Sustainable Environment Research Group (SERG), Center of Excellence Geopolymer and Green Technology, School of Material Enginering, Universiti Malaysia Perlis, Komplek Pengajian Jejawi 2, 02600 Arau, Perlis, Malaysia. ${ }^{6}$ Faculty of Engineering and Technology, Liverpool John Moores University, Cherie Booth Building, Byrom St, Liverpool, L3 3AF, United Kingdom

*shamala@unimap.edu.my

\begin{abstract}
Undeniable need of an alternative material for Ordinary Portland Cement has led to major focus of geopolymer source materials. 0.87 ton of carbon dioxide $(\mathrm{CO} 2)$ release for one ton of cement production. The use of new sources materials such as fly ash a have potential as geopolymer bricks plus can reduce the emission of carbon dioxide by ordinary Portland bricks which cause the environmental impact to the global. First part of this work is to determine the feasibility of using rice husk as a reinforcing material for fly ash geopolymer brick. Mix design of $2: 5 \mathrm{Na}_{2} \mathrm{SiO}_{3} / \mathrm{NaOH}$ ratio, $12 \mathrm{M}$ $\mathrm{NaOH}$ concentration and solid-to-liquid ratio of 2.0 with varying rice husk loading was tested and healed at room temperature then at $70^{\circ} \mathrm{C}$ for 24 hours to get stable early strength. The microstructure of fly ash geopolymer brick with rice husk ash were analysed for raw material (rice husk ash and fly ash) and geopolymer brick product. From morphology analysis, almost all particles has took part in geopolymerization process and compacted area has represent the form of geopolymer gel through microstructure analysis that has carried out both rice husk ash and fly ash in geopolymer brick. The best mix design also correlate with highest result obtained density analysis.
\end{abstract}




\title{
Compression Behavior in Correlation with Morphological Findings of Fly Ash Grout Material
}

\author{
*Shamala Ramasamy 1,2,a), Norhafezah Kasmuri \\ Ragunathan Santiagoo 2,4, Razi Ahmad4, Meor Ahmad \\ Faris $^{1,2}$ and Kazi Masuma Khatun ${ }^{3}$
}

${ }^{1}$ Faculty of Engineering Technology, Universiti Malaysia Perlis (UniMAP), P.O. Box 77, D/A Pejabat Pos Besar, Kangar, Perlis 01000, Malaysia

${ }^{2}$ Center of Excellence Geopolymer and Green Technology, School of Material

Engineering, Universiti Malaysia Perlis, Kompleks Pengajian Jejawi 2, 02600 Arau, Perlis, Malaysia.

${ }^{3}$ Faculty of Civil Engineering, Universiti Teknologi MARA, 40450 Shah Alam, Selangor, Malaysia.

${ }^{4}$ School of Environmental Engineering, Universiti Malaysia Perlis, Kompleks Pusat

Pengajian Jejawi 3, 02600, Jejawi, Pelis, Malaysia.

*shamala@unimap.edu.my

\begin{abstract}
The ordinary Portland cement (OPC) is the function as a binder for grout material. However, a massive used of OPC had caused pollution to the environment. Thus, the earlier research proposed the environmental friendly binder known as geopolymer. This new binder needs to be mixed between alkaline liquids and materials rich in silica and alumina. In this paper, fly ash class $\mathrm{C}$ was used as source material with alkaline activators such as sodium hydroxide $(\mathrm{NaOH})$ and sodium silicate $\left(\mathrm{Na}_{2} \mathrm{SiO}_{3}\right)$. This paper concluded that the concentration of $\mathrm{NaOH}$ solution and sodium silicate-to-sodium hydroxide $\left(\mathrm{Na}_{2} \mathrm{SiO}_{3} / \mathrm{NaOH}\right)$ ratios have a significant effect on compressive strength. The different concentration of $\mathrm{NaOH}$ solution ( $10 \mathrm{M}$ and $12 \mathrm{M}$ ) and sodium silicateto-sodium hydroxide $\left(\mathrm{Na}_{2} \mathrm{SiO}_{3} / \mathrm{NaOH}\right)$ ratios $(1.5,2.0,2.5$ and 3.0) were used in the production of geopolymer. The parameters such as curing and solid-toliquid $(\mathrm{S} / \mathrm{L})$ ratio were controlled in this paper. The main evaluation techniques in this study were compressive strength and optical microscopy (OM). The optimum compressive strength obtained was $15.5 \mathrm{MPa}$ for 28 days resulted from $12 \mathrm{M}$ of $\mathrm{NaOH}$ concentration and $\mathrm{Na}_{2} \mathrm{SiO}_{3} / \mathrm{NaOH}$ with ratio 2.5 .
\end{abstract}




\title{
Water-Solids Interaction of Fly Ash Based Geopolymer Grout
}

\section{*Shamala Ramasamy1,2,a), Razi Ahmad ,Norhafezah Kasmuri ${ }^{4,5}$, Ragunathan Santiagoo ${ }^{3,5}$, Sarah Diana Zulfiqar $^{1,2}$ and Meor Ahmad Faris ${ }^{1,2}$}

${ }^{1}$ Faculty of Engineering Technology, Universiti Malaysia Perlis (UniMAP), P.O. Box 77, D/A Pejabat Pos Besar, Kangar, Perlis 01000, Malaysia.

${ }^{2}$ Center of Excellence Geopolymer and Green Technology, School of Material Enginering, Universiti Malaysia Perlis, Komplek Pengajian Jejawi 2, 02600 Arau, Perlis

${ }^{3} 5$ School of Environmental Engineering, Universiti Malaysia Perlis, Komplek Pusat Pengajian Jejawi 3, 02600, Jejawi, Pelis, Malaysia

${ }^{4}$ Faculty of Civil Engineering, UniversitiTeknologi MARA, 40450 Shah Alam, Selangor, Malaysia

${ }^{5}$ Sustainable Environment Research Group (SERG), Center of Excellence Geopolymer and Green Technology, School of Material Enginering, Universiti Malaysia Perlis, Komplek Pengajian Jejawi 2, 02600 Arau, Perlis, Malaysia.

*shamala@unimap.edu.my

\begin{abstract}
The focus of current research work is to investigate the water to solids interaction and characteristic of geopolymer grout material. Previous researchers proposed fly ash as an environmentally friendly binder material known as geopolymer. This new binder needs to be mixed between alkaline liquids and materials rich in silica and alumina. Fly ash class $\mathrm{C}$, used as source material with alkaline activators such as sodium hydroxide $(\mathrm{NaOH})$ and sodium silicate $\left(\mathrm{Na}_{2} \mathrm{SiO}_{3}\right)$. This paper concluded that the concentration of $\mathrm{NaOH}$ solution and sodium silicate-to-sodium hydroxide $\left(\mathrm{Na}_{2} \mathrm{SiO}_{3} / \mathrm{NaOH}\right)$ ratios have a significant effect on water absorption behavior of geopolymer end product. The different concentration of $\mathrm{NaOH}$ solution (10 $\mathrm{M}$ and $12 \mathrm{M}$ ) and sodium silicate-to-sodium hydroxide $\left(\mathrm{Na}_{2} \mathrm{SiO}_{3} / \mathrm{NaOH}\right)$ ratios $(1.5,2.0,2.5$ and 3.0) were used in the production of geopolymer. The parameters such as curing and solidto-liquid (S/L) ratio were controlled in this paper. The main evaluation techniques in this study were water absorption and optical microscopy (OM). The optimum water absorption percentages were observed on samples with $10 \mathrm{M}$ of $\mathrm{NaOH}$ concentration as compared to $12 \mathrm{M} \mathrm{NaOH}$ concentration. Based on the OM image, geopolymer grout showed fewer poresand denser structure on samples with $10 \mathrm{M} \mathrm{NaOH}$ concentration after 28 days.
\end{abstract}




\title{
Performance of Concrete Gravity Dam with Various Height of Dam Based on Static Pushover Analysis
}

\author{
${ }^{*}$ N A N Zainab ${ }^{1, a)}$, W Faridah ${ }^{1}$, A M Andrew ${ }^{3}$, S \\ Ragunathan ${ }^{1,4}$, A S N Amirah ${ }^{1}$ and W H Tan ${ }^{2}$
}

${ }^{1}$ School of Environmental Engineering, Universiti Malaysia Perlis, Kompleks Pusat Pengajian Jejawi 3, 02600 Arau, Perlis, Malaysia.

${ }^{2}$ School of Mechatronic Engineering, Universiti Malaysia Perlis, Kampus Tetap Pauh Putra, 02600 Arau, Perlis, Malaysia.

${ }^{3}$ Centre for Diploma Studies (PPD), Universiti Malaysia Perlis (UniMAP),S2-L1-26, KampusUniCITI Alam, Sungai Chuchuh, 02100 Padang Besar, Perlis, Malaysia. ${ }^{4}$ Center of Excellence Geopolymer and Green Technology (CEGeoGTech), School of Material Engineering, Universiti Malaysia Perlis (UniMAP), P.O. Box 77, D/A Pejabat

Pos Besar, 01000 Kangar, Perlis, Malaysia.

* nikzainab@unimap.edu.my

\begin{abstract}
The study was related to the performance of the concrete gravity dam with a various height of dam based on static pushover analysis. Based on the concepts of nonlinear static pushover analysis, a lateral incremental load is applied to the dam body after exerting gravitational and hydrostatic loads. In a concrete gravity dam, inertia loads and hydrodynamic loads are the types of lateral loads generated in earthquakes. The four concrete dams of various height had been analyzed by using ABAQUS. For each model, there were 10 trials analysis of increasing lateral load until the dam reached its limit state. The four finite elements of the concrete gravity dam with various height will be designed. The various height of concrete gravity dam has been specified to $50 \mathrm{~m}, 75 \mathrm{~m}, 100 \mathrm{~m}$ and $125 \mathrm{~m}$. The analysis had been run and the limit state of concrete gravity dam such as cracking will be determined. The magnitude of lateral pushover load will be increased consequently until the dam reached its limit state.
\end{abstract}




\title{
Water Distribution System at Residential Area at Taman Seri Wang in Arau, Perlis
}

\author{
${ }^{*}$ N Amirah Abu Seman ${ }^{1, a)}$, W H Tan ${ }^{2, b)}$, W Faridah ${ }^{1, c)}$, A M \\ Andrew $^{3, \mathrm{~d})}$, N A N Zainab ${ }^{1, \mathrm{e})}$ and S Ragunathan ${ }^{1,4, \mathrm{f})}$
}

${ }^{1}$ School of Environmental Engineering, Universiti Malaysia Perlis (UniMAP), Kompleks Pusat Pengajian Jejawi 3, 02600 Arau, Perlis, Malaysia

${ }^{2}$ School of Mechatronic Engineering, Universiti Malaysia Perlis, Kampus Tetap Pauh Putra, 02600 Arau, Perlis, Malaysia.

${ }^{3}$ Centre of Diploma Studies (PPD), Universiti Malaysia Perlis (UniMAP), S2-L1-26, Kampus UniCITI Alam, Sg.Chuchuh, 02100 Padang Besar, Perlis, Malaysia.

${ }^{4}$ Center of Excellence Geopolymer and Green Technology (CEGeoGTech), School of Material Engineering, Universiti Malaysia Perlis (UniMAP), P.O. Box 77, D/A Pejabat Pos Besar, 01000 Kangar, Perlis, Malaysia.

* noramirah@unimap.edu.my

\begin{abstract}
Water distribution system is considered successful if it can supply water at the required quantity and quality with the minor loss. Complex network of pipes that has a lot of connections will increase head loss in the water distribution system. Therefore, it is important to identify the head loss occurred in the water distribution network of Taman Seri Wang in Arau, Perlis. Hardy-Cross method is selected to calculate the head loss in the looped water distribution network. Since Taman Seri Wang consists of terrace houses, the water demand is 225 liters/person/day. About 16 loop networks are considered, for Taman Seri Wang water distribution system. All the simulation is carried out for 24 - hours analysis. Based from the analysis shows the actual flow demand is $24.03 \mathrm{~L} / \mathrm{s}$ which is three times higher than consumer need demand value $(5.89 \mathrm{~L} / \mathrm{s})$. The flow rate shows a decreasing value at nodes $42,34,54$, and 46 after 0700 hours analysis. While higher percentage of head loss is detected mainly in link 1 of water intake point and link 15 at water tank near study area.
\end{abstract}




\title{
Impact of Solvent Selection on the Extraction of Total Phenolic Content and Total Flavonoid Content from Kaffir Lime Leaves: Ultrasonic Assisted Extraction (UAE) and Microwave Assisted Extraction (MAE)
}

\author{
${ }^{*}$ A Anuar ${ }^{1, a)}$, M A Awang ${ }^{2, b)}$ and H F Tan ${ }^{1}$ \\ ${ }^{1}$ Faculty of Egineering Technology, Universiti Malaysia Perlis, Kampus UniCITI Alam, \\ Sungai Chuchuh, Padang Besar, 02100, Perlis, Malaysia. \\ ${ }^{2}$ Ganofarm R\&D SDN BHD, Sky-Pod Square, Persiaran Puchong Jaya Selatan, \\ Bandar Puchong Jaya, 47100 Puchong,Selangor, Malaysia. \\ *adilahanuar@unimap.edu.my
}

\begin{abstract}
Kaffir lime is one form of the aromatic plants which is well-known in the field of medicinal, food and perfumery industry. The key aim of the research to study the effect of specific solvent extraction use both Ultrasonic assisted extraction (UAE) and Microwave assisted extraction (MAE) techniques. Solvents were analyzed using distilled water $\left(\mathrm{H}_{2} \mathrm{O}\right), 50 \%$ ethanol and $50 \%$ methanol, respectively. The biological activity of the extract was measured using total phenolic content (TPC) and total flavonoid content (TFC) for both extraction methods. The findings revealed that $50 \%$ of ethanol was the best solvent to obtain the highest TPC, while $50 \%$ of methanol was the best solvent to obtain the highest TFC in the UAE process. Nevertheless, $50 \%$ ethanol was the perfect solvent to achieve the highest levels of TPC and TFC using MAE techniques. For this analysis, the UAE was more successful than the MAE, as the UAE had higher TPC and TFC than the MAE.
\end{abstract}




\title{
The Use of Media Filters in Treatment of Runoff Pollution
}

\author{
${ }^{*}$ N Amirah Abu Seman ${ }^{1, a)}$, S Ragunathan ${ }^{1,4, b)}$, N A N \\ Zainab $^{1, \mathrm{c})}, \mathrm{W}$ H Tan ${ }^{2, \mathrm{~d})}, \mathrm{M} \mathrm{Andrew}^{3, \mathrm{e})}$ and W Faridah ${ }^{1, \mathrm{f})}$
}

${ }^{1}$ School of Environmental Engineering, Universiti Malaysia Perlis (UniMAP), Kompleks Pusat Pengajian Jejawi 3, 02600 Arau, Perlis, Malaysia

${ }^{2}$ Mechanical Engineering Programme, School of Mechatronic Engineering, Universiti Malaysia Perlis (UniMAP), Kampus Pauh Putra, 02600 Arau, Perlis, Malaysia.

${ }^{3}$ Centre of Diploma Studies (PPD), Universiti Malaysia Perlis (UniMAP), S2-L1-26, Kampus UniCITI Alam, Sg.Chuchuh, 02100 Padang Besar (U), Perlis, Malaysia. ${ }^{4}$ Center of Excellence Geopolymer and Green Technology (CEGeoGTech), School of Material Engineering, Universiti Malaysia Perlis (UniMAP), P.O. Box 77, D/A Pejabat Pos Besar, 01000 Kangar, Perlis, Malaysia.

* noramirah@unimap.edu.my

\begin{abstract}
The main aim of this research is to enhance the efficiency of water quality. The present study is to examine the capacity of recycled aggregate and sand to treat domestic water in a manner that reduces the rate of environmental pollution. The sample was taken from Wang Ulu agricultural district, Jejawi industrial area and Taman Desa Katong residential area. Water quality research was carried out in order to obtain the characteristics of wastewater such as suspended solids, BOD, COD and TSS. This operating system included the use of three values of precipitation intensity, which is $5 \mathrm{~L}$ / min as low-intensity rainfall, $12.5 \mathrm{~L}$ / min as average rainfall intensity, and $22.5 \mathrm{~L} / \mathrm{min}$ as high-intensity rainfall, which consists of recycled aggregate and sand with high absorption capacity. Experimental findings indicate that the recycling of aggregates and sand filters has a positive effect on water in rural, industrial and residential areas. It shows that the use of recycled aggregates as a drainage bed can increase the permeability of the region by reducing erosion, preventing flooding and promoting natural infiltration.
\end{abstract}




\title{
Structural and Impedance Analysis of $\mathrm{Ba}_{0.9925} \mathrm{Er}_{0.0075} \mathrm{TiO}_{3}$ for Microelectronic Application
}

\section{* Teo Yao Guan ${ }^{1,3}$, Rozana Aina Maulat Osman ${ }^{1,3, a)}$, Mohd Sobri Idris ${ }^{2,3}$ and Yasmin Abdul Wahab ${ }^{4}$}

${ }^{1}$ Faculty of Electronic Engineering Technology, Universiti Malaysia Perlis, 02600 Arau, Perlis, Malaysia.

${ }^{2}$ Faculty of Chemical Engineering Technology, Universiti Malaysia Perlis, 02600 Arau, Perlis, Malaysia.

${ }^{3}$ Center of Excellence Frontier Materials Research, 01000 Kangar, Perlis, Malaysia.

${ }^{4}$ Nanotechnology \& Catalysis Research Centre, University of Malaya, 50603 Kuala Lumpur, Malaysia

*rozana@unimap.edu.my

\begin{abstract}
The $\mathrm{Ba}_{0.9925} \mathrm{Er}_{0.9975} \mathrm{TiO}_{3}$ ceramics that were prepared via solid-state reaction route were found to be phase pure at the final sintering temperature of $1350^{\circ} \mathrm{C}$. The highest value of the dielectric constant is about 9000 measured at $10 \mathrm{~Hz}$ and decreases to about 1000 at the Curie temperature at much higher frequencies. The $\mathrm{Ba}_{0.9925} \mathrm{Er}_{0.9975} \mathrm{TiO}_{3}$ is found to be of high-K dielectric materials with properties a thousand times greater than $\mathrm{SiO}_{2}$. At room temperature application, the $\mathrm{Ba}_{0.9925} \mathrm{Er}_{0.9975} \mathrm{TiO}_{3}$ exhibits a dielectric constant value from 1000 to 2500 , depending upon the frequencies. The conductivity and activation energy of the $\mathrm{Ba}_{0.9925} \mathrm{Er}_{0.9975} \mathrm{TiO}_{3}$ lies in the semiconductor region. The dielectric loss is a very low and very suitable candidate for microelectronic applications.
\end{abstract}




\title{
Impedance and Modulus Spectroscopy of Polycrystalline $\mathrm{Ba}_{0.9995} \mathrm{La}_{0.0005} \mathrm{TiO}_{3}$ for Multilayer Ceramic Capacitor
}

*Tiong Yuan Tze ${ }^{1,3}$, Rozana Aina Maulat Osman ${ }^{1,3, a)}$, Mohd Sobri Idris ${ }^{2,3}$, Ku Noor Dhaniah Ku Muhsen ${ }^{1,3}$, Nurul Izza Mohd Nor ${ }^{1}$, Yasmin Abdul Wahab ${ }^{4}$, Suresh Sagadevan ${ }^{4}$, Tutu Sebastian ${ }^{5}$ and Ruiz LeÓn Domingo Arturo $^{6}$

${ }^{1}$ Faculty of Electronic Engineering Technology, Universiti Malaysia Perlis, 02600 Arau, Perlis, Malaysia.

${ }^{2}$ Faculty of Chemical Engineering Technology, Universiti Malaysia Perlis, 02600 Arau, Perlis, Malaysia.

${ }^{3}$ Center of Excellence for Frontier Materials Research, Universiti Malaysia Perlis, 01000 Kangar, Perlis, Malaysia.

${ }^{4}$ Nanotechnology \& Catalysis Research Centre, University of Malaya, 50603 Kuala Lumpur, Malaysia

${ }^{5}$ EMPA, Materials Science and Technology, Laboratory for High Performance Ceramics, Überlandstrasse 129, 8600 Dübendorf, Switzerland

${ }^{6}$ Chemistry Materials Department, Universidad de Santiago de Chile, Av. Libertador Bernardo O'Higgins no 3363, Santiago, Chile

*rozana@unimap.edu.my

\begin{abstract}
Ba} 0.9995 \mathrm{La}_{0.0005} \mathrm{TiO}_{3}$ ceramics prepared via solid-state reaction route was found to be phase pure at the final sintering temperature of $1300^{\circ} \mathrm{C}$ for 16 hours. The dielectric constant was varied from 1900 to 2800 from $10 \mathrm{~Hz}$ to $100 \mathrm{kHz}$. Impedance spectroscopy is a powerful technique to study the complexities of ceramic materials such as homogeneity and inhomogeneity of materials that being process during production of most electronic materials. An electronic ceramic component can be visualized as a grain, grain boundary and electrode system. Impedance spectroscopy is being widely used to separate out contribution of the bulk and the grain boundary to the overall equivalent circuit models. Fixed frequency plots of dielectric constant versus temperature for $\mathrm{Ba}_{0.9995} \mathrm{La}_{0.0005} \mathrm{TiO}_{3}$ ceramics shows typical perovskite response with Curie temperature, $T_{c}$ about $115^{\circ} \mathrm{C}$ and fit with the equivalent circuit which contributed by bulk and grain boundary response.
\end{abstract}




\title{
Properties of $\mathrm{CeO}_{2}$ o-doped with Trivalent Dopants
}

\section{*S S C Abdullah ${ }^{1,3, a)}$, L K Siang ${ }^{1, b)}$, S H Salleh ${ }^{1,4, c)}$ and I H W Nordin',d)}

${ }^{1}$ School of Materials Engineering, Universiti Malaysia Perlis, 02600 Arau, Perlis, Malaysia.

${ }^{2}$ School of Mechatronics Engineering, Universiti Malaysia Perlis, Kampus Tetap Pauh, 02600 Arau, Perlis, Malaysia.

${ }^{3}$ Center of Excellent Frontier Materials Research, Universiti Malaysia Perlis, 01000

Kangar, Perlis, Malaysia

${ }^{4}$ Centre of Excellence Geopolymer and Green Technology, Universiti Malaysia Perlis, 02600 Arau, Perlis, Malaysia.

*salmie@unimap.edu.my

\begin{abstract}
This paper reports on the synthesis of $\mathrm{CeO}_{2}$ with $\mathrm{Sm}$ and $\mathrm{Fe}$ as double dopants via solid state reaction methods. The composition of the samples were $\mathrm{Ce}_{0.8-\mathrm{x}} \mathrm{Fe}_{\mathrm{x}} \mathrm{Sm}_{0.2} \mathrm{O}_{2-\delta},(0<\mathrm{x}<2.0)$, where concentration of $\mathrm{Sm}$ was fixed at $20 \mathrm{~mol} \%$ and concentration of Fe varies from $5-20 \mathrm{~mol} \%$. Samples were sintered at $1450^{\circ} \mathrm{C}$ with holding time of 5 hours after pelletized under $150 \mathrm{MPa}$. Phase structure, morphology, densification and hardness were characterized. Single phase has been obtained only from samples with concentration of $\mathrm{Fe}$ up to $5 \mathrm{~mol} \%$. The relative density of samples is in the range of $92-97 \%$. Irregular needle-shape particles was observed on the samples with larger Fe concentration. Hardness value was increased with $\mathrm{Fe}$ concentration.
\end{abstract}




\title{
Physical and Mechanical Properties of Coconut Shell Concrete (CSC)
}

* Mustaqqim Abdul Rahim ${ }^{1, a)}$, Shao-Wen Cheah ${ }^{1, b)}$, Afizah Ayob ${ }^{1, c)}$, Norlia Mohamad Ibrahim ${ }^{1, d)}$, Shamilah Anudai@Anuar ${ }^{1, e)}$, Nor Faizah Bawadi ${ }^{1, f)}$, Shahiron Shahidan ${ }^{2, g)}$ and Ahmad Nur Aizat Ahmad ${ }^{3, h}$ )

${ }^{1}$ School of Environmental Engineering, University Malaysia Perlis, 02600, Arau, Perlis, Malaysia.

${ }^{2}$ Faculty of Civil and Enviromental Engineering, UniversitiTun Hussein Onn, 86400, BatuPahat,Johor, Malaysia.

${ }^{3}$ Faculty of Technology Management and Business, UniversitiTun Hussein Onn, 86400, BatuPahat, Johor, Malaysia

*mustaqqim@unimap.edu.my

\begin{abstract}
The use of waste products as partial replacement for the material in concrete can help to reduce the environmental and economic problem. Coconut shell (CS) is one of the agricultural waste that suitable to use as and coarse aggregates replacement due availability of CS which not only can help to decrease the cost of the concrete and reduce the environmental problem, it also can maintain the properties of the concrete. In this study, the compressive strength of the concrete has been chosen to be investigated. Three different types concrete cube have been casted in this study; $0,10 \%$, $15 \%, 20 \%$ of CS to replace for coarse aggregates. The size of the cube samples to be casted is $100 \times 100 \times 100 \mathrm{~mm}$ and were cured for 7 and 28 days. The study shows that the optimum percentage for CS concrete is $10 \%$ due to in this percentage of replacement, it gives the highest compressive strength value compare to other percentage at 28 days.
\end{abstract}




\section{Review on the $\mathrm{Al}_{2} \mathrm{O}_{3}$ Nanoparticle Reinforcement Effect on Thermal and Mechanical Properties of SAC Alloys}

${ }^{*}$ Ervina Efzan ${ }^{1, a)}$, Hana Abdalla1,b) and Umer Nirmal ${ }^{1, c)}$

${ }^{1}$ Faculty of Engineering and Technology, Mechanical Engineering Department, Multimedia University Melaka, Bukit Beruang, 75450, Melaka, Malaysia.

*ervina.noor@mmu.edu.my

Abstract. This paper presents a short summery on the effect of the addition and doping of Sn-Ag-Cu or commonly known as SAC alloys with Aluminum oxide (Al2O3) nanoparticles. The paper introduce initially the background of the lead free solders as well as establish the concept of nanoparticle reinforcement composite lead free solder alloys. Then a short summery on the effect of the two nanoparticle reinforcement on the sac solder in the sections of Thermal properties and mechanical properties is presented. For instance some reported with $\mathrm{Sn}-0.3 \mathrm{Ag}-0.7 \mathrm{Cu}$ (SAC0307) when alloyed with $0.12 \mathrm{Al}_{2} \mathrm{O}_{3}$ it showed an improved shear force of thermal cycling when it came to the mode of ductile fracture in comparison to the original alloy which possess a mode of fracture that presented a mixture between ductile and brittle. 


\title{
Effect of Salinity, Light and Fertilizer on Caulerpa lentillifera Under Culture Conditions
}

\author{
* I M Fakhrulddin ${ }^{1, a)}$, Z Muta Harah",b), R D Shiamala ${ }^{3, c)}$ \\ and $\mathrm{A}$ M Azrie ${ }^{4, d)}$
}

${ }^{1}$ Institute of Aquaculture and Aquatic Sciences (I-AQUAS), Universiti Putra Malaysia (UPM), Teluk Kemang, 71050 Port Dickson, N. Sembilan, Malaysia.

${ }^{2}$ Faculty of Agriculture, Universiti Putra Malaysia, 43400 UPM Serdang, Selangor Darul Ehsan, Malaysia

${ }^{3}$ Faculty of Agriculture and Food Sciences, Universiti Putra Malaysia Bintulu Campus, 97008 Bintulu, Sarawak, Malaysia.

${ }^{4}$ Ganofarm R\&D SDN BHD, Sky-Pod Square, Persiaran Puchong Jaya Selatan, Bandar Puchong Jaya, 47100 Puchong, Selangor, Malaysia.

*m_fakhrulddin@upm.edu.my

\begin{abstract}
Seaweed was commonly consumed across the worldwide. In Malaysia, Caulerpa lentillifera or known as latok is increasingly popular with as an additional diet by local peoples. The different dietary qualities, minerals and nutrients are of concern to the food industry. This also has potential in pharmaceutical, nutraceutical, bioremediation and agriculture sectors. Despite its complex habitat adaptations, majority of Caulerpa lentillifera in the market has been harvested from the wild, contributing to natural habitat disruptions. Therefore, the purpose of this research was to investigate selected parameters such as salinity, light, and fertilizer of Caulerpa lentillifera under cultivation in Malaysia. The Caulerpa lentillifera showed better growth under salinity above 25 psu and 30 psu, which also provide sufficient light for a period of 10 hours. The optimum growth rate of Caulerpa lentillifera under cultivation conditions can be obtained by adding fertilizer such as conway and von stock media e.g $17.55 \%$ SGR and $13.50 \%$ SGR respectively. This study indicates parameters, including salinity, light and fertilizer that contribute to the growth of Caulerpa lentillifera culture.
\end{abstract}




\title{
Determination of Fruit Maturation and Ripening Potential on Postharvest Quality of Passiflora quadrangularis $\mathrm{L}$
}

\author{
${ }^{\star}$ N. M. Zahari ${ }^{1}$, S. S. M. Razali ${ }^{1}$, Nurhanani A. \\ Aziz $^{3}$, F. Nurhikmah ${ }^{3}$, M. H. Zawawi ${ }^{1}$, A. Syamsir ${ }^{1,4}$ \\ and M. R. Isa ${ }^{2}$
}

${ }^{1}$ Faculty of Agriculture and Food Sciences, Universiti Putra Malaysia Bintulu Campus, 97008 Bintulu, Sarawak, Malaysia.

${ }^{2}$ International Institute of Aquaculture and Aquatic Sciences (I-AQUAS), Universiti Putra Malaysia, 71050 Port Dickson, Negeri Sembilan, Malaysia.

${ }^{3}$ Ganofarm R\&D Sdn. Bhd. Sky-Pod Square, Persiaran Puchong Jaya Selatan, Bandar Puching Jaya, 47100 Puchong, Selangor, Malaysia.

*shiamala@upm.edu.my

\begin{abstract}
Passiflora quadrangularis commonly known as giant granadilla bear largest fruit $(\sim 1-3 \mathrm{~kg})$ with edible fleshy rind in its genus. In recent years, this fruit has gained popularity and planted together with the well-known purple passion fruit. Despite its expansion, scientific research has not upheld with the pre- and postharvest handling of this fruit. Theherefore, the aim of the present study is to investigate the optimum harvest maturity and ripening potential of $P$. quadrangularis. The optimum harvesting period of this fruit was 55 to 60 days after anthesis (DAA). Fruits harvested on day 55 are suitable for cooking as vegetables as melon species. However, fruits harvested at day 60 were ideal for consumption as fresh, both mesocarp and pulp. At ripening (day 60) the mesocarp fruit firmness was $3.33 \pm 0.10 \mathrm{~N}$, with total soluble solid of the pulp was $14.57 \pm 0.33^{\circ}$ Brix. Pulp and mesocarp $\mathrm{pH}$ also increased slightly at maturation, $3.76 \pm 0.21$ and $5.14 \pm 0.02$, respectively. Passiflora quadrangularis also known to be non-climacteric fruit as it cannot ripen after being picked from the vine. At storage fruits that harvested from day 50 and 55 after anthesis that treated with ethylene were enhanced surface yellow pigmentation after 47 days of treatment. The present study documented detailed pre-harvesting stages for $P$. quadrangularis which are crucial for provide optimum marketable qualities of this fruit as well as export purposes.
\end{abstract}




\title{
Characteristics and Properties of Styrene Butadiene Rubber/Reclaimed Nitrile Glove (SBR/rNBRg) Blend
}

\author{
${ }^{*}$ S Husain ${ }^{1, a)}$, N Munirah Rohaizad ${ }^{1, b)}$, A M Nasir ${ }^{1, c)}$ and \\ $\mathrm{N} \mathrm{H}$ Ishak ${ }^{1, \mathrm{~d})}$
}

${ }^{1}$ Faculty of Engineering Technology, Universiti Malaysia Perlis, Kampus UniCITI Alam, Sungai Chuchuh 02100 Padang Besar, Perlis, Malaysia.

*normunirah@unimap.edu.my

Abstract. In this study, the waste nitrile gloves were reclaimed by using mechano-chemical method to form reclaimed nitrile glove (rNBRg). The significance of reclaiming waste nitrile gloves is to protect the environment. This reclaiming process is carried out at constant concentration of tetra methyl thiuram disulfide (TMTD) and different milling time. The performance of rNBRg then was evaluated by measurement of sol content and crosslink density at different milling time times. It shows that, the best milling time was at 40 minutes. Then, nitrile gloves were then reclaimed at highest milling time which is 40 minutes before underwent rubber compounding. The process of rubber compounding is proceeding by blending all additives and styrene butadiene rubber (SBR) with reclaimed nitrile gloves at different formulation and blend ratio to form SBR/rNBRg blend. This rubber blend then undergoes several characterizations such as cure characteristics, mechanical and physical properties of SBR/rNBRg blend at different SBR/rNBRg blend ratio. The cure time and scorch time are decreases as the composition of rNBRg increases. Maximum and minimum torque is increases and decreases respectively with the increasing of rNBRg loading. It is also observed that as the loading of rNBRg increases, the hardness and modulus at $100 \%$ elongation are increases, while the tensile strength and elongation at break are decreases. 


\title{
Mechanical and Morphological Characteristics of Eggshell Filled Polymer Matrix Composite: A Review
}

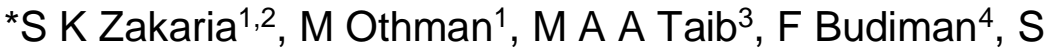 Z Salleh ${ }^{2}$ and $\mathrm{P}$ T Teo,a)}

${ }^{1}$ Department of Manufacturing and Materials Engineering, Kulliyyah of Engineering, International Islamic University Malaysia (IIUM), Gombak, Malaysia.

${ }^{2}$ Advanced Materials Research Cluster, Faculty of Bioengineering and Technology, Universiti Malaysia Kelantan, Jeli Campus, 17600 Jeli, Kelantan, Malaysia.

${ }^{3}$ Division of Advanced Ceramic Materials Technology, Advanced Technology Training Center (ADTEC) Taiping, 34600 Kamunting, Perak, Malaysia.

${ }^{4}$ School of Electrical Engineering, Telkom University, Jl. Telekomunikasi No. 1, Bandung 40257, West Java, Indonesia.

*teopaoter@umk.edu.my

\begin{abstract}
Eggshell waste has become one of the main environmental problems be it from egg industry or as municipal solid waste. Researchers have been debating over the utilization of eggshell in the polymer matrix composite. With the current knowledge, it is possible to bring out the full potential of eggshell waste as filler in polymer matrix composite be it to reduce the weight of material or helps in degradation of polymer as compared to neat polymer products. Therefore, this paper aims to review on the current application of eggshell in polymer matrix composite and to evaluate the factors affecting the properties of the composite from mechanical and morphological point of view. The factors such as weight percentage of filler, particle size of filler, treatment of filler and addition of binder will be thoroughly reviewed.
\end{abstract}




\section{A Review: Effect of Nanoparticles Addition on the Properties of Sn-Ag-Cu Lead Free Solder Alloy}

*M N Ervina Efzan ${ }^{1, a)}$ M M Nur Haslinda',b) M M Al Bakri Abdullah2,c)

${ }^{1}$ Faculty of Engineering and Technology, Multimedia University, 75450 Ayer Keroh, Malacca, Malaysia

${ }^{2}$ Center of Excellence Geopolymer and Green Technology (CEGeoGTech), School of Materials Engineering, Universiti Malaysia Perlis, 01000 Kangar, Perlis, Malaysia.

*ervina.noor@mmu.edu.my

Abstract. Sn-Ag-Cu lead-free solder alloy containing nanoparticles has been extensively developed as replacement for the conventional tin-lead $(\mathrm{Sn}-\mathrm{Pb})$ solder in electronic packaging industry. $\mathrm{Sn}-\mathrm{Ag}-\mathrm{Cu}$ solder alloy has been receiving a lot of attention with its good reliability and mechanical properties. Addition of nanoparticles in $\mathrm{Sn}-\mathrm{Ag}-\mathrm{Cu}$ solder with appropriate content provides remarkable improvements on the properties of $\mathrm{Sn}-\mathrm{Ag}-\mathrm{Cu}$ solder. Thus, this paper reviews the effects of addition of nanoparticles on the properties of Sn-Ag-Cu lead free solder alloy. 


\title{
Fatty Acid Composition Between Capra Aegagrus hircus and Bos taurus Milk from Commercial and Fresh Milk Product in Malaysia using Gas Chromatography-Mass Spectrometry (GC-MS)
}

\author{
*Nurdalila A'wani Aziz'1,a), Hakim Zamani1,b), Tg. Ainul \\ Farha Tg. Abdul Rahman ${ }^{1, c)}$, Mohd Zuhaifah Mohamed \\ Jamil $^{2, d)}$ and Dzulfadli Rosli2,e) \\ ${ }^{1}$ Halal Action Laboratory, Kolej GENIUS Insan, Universiti Sains Islam Malaysia, \\ Bandar Baru Nilai, 71800 Nilai, Negeri Sembilan, Malaysia \\ ${ }^{2}$ International Fatwa and Halal Centre, Universiti Sains Islam Malaysia, Bandar Baru \\ Nilai, 71800 Nilai, Negeri Sembilan, Malaysia \\ *nurdalila.awani@usim.edu.my
}

\begin{abstract}
Capra Aegagrus hircus's milk and Bos taurus's milk are considered fundamental nutrition sources of the human diet. Fatty acid content in milk is one of the most important contribution towards milk quality. Hence, objectives of this study are to profile fatty acid composition of Capra Aegagrus hircus's milk and Bos taurus's milk, then to compare the fatty acid content in both the Capra Aegagrus hircus's milk and Bos taurus's milk. Fresh and commercialized milk from each of the species; Capra Aegagrus hircus and Bos Taurus, were collected from three different farms and three different commercialized brands. All samples were done in triplicates and analyzed for fatty acid composition of the milk using Gas Chromatography-Mass Spectrometry (GC-MS). The data obtained from GC-MS were calculated relatively in percentage of peak area (\%) and analyzed using principle component analysis (PCA). The fatty acid detected were grouped into three classes: (1) saturated fatty acid (SFA), (2) monounsaturated fatty acid (MUFA), and (3) polyunsaturated fatty acid (PUFA). There are significant differences in terms of SFA between fresh and commercial Capra Aegagrus hircus's milk and Bos taurus's milk, but almost similar results for MUFA and PUFA. Results obtained from this study have confirmed that fresh and commercial Capra Aegagrus hircus's milk is better than fresh and commercial Bos taurus's milk. Thus, Capra Aegagrus hircus's milk consumption should be taken into consideration, hence contribute as part of a complete nutrition for the well-being of society.
\end{abstract}




\title{
Optimization of Encapsulated Neem Extract for Releasing Rate Studies
}

\author{
${ }^{*}$ N.H.M. Salleh, N. A. Aziz and A.R. Mohamed \\ ${ }^{1}$ Department of Chemical Engineering Technology, Faculty of Engineering \\ Technology, Universiti Malaysia Perlis, 01000 Kangar. Malaysia \\ *hasyierah@unimap.edu.my
}

\begin{abstract}
The application of synthetic pesticide contributes to the environmental issues, insect resistance, marketing opportunities and detrimental health effect. To this end, the application of biopesticide from neem leaves offers a great potential as biopesticide due to its active ingredient namely azadirachtin. However, the compound is not stable under harsh environment. Encapsulation technique helps to increase the delivery efficiency. The studies focus on the optimization of encapsulation of neem extract which involved three parameters namely concentration of sodium alginate, A (1.5-2.5\%), volume of neem extract, B $(5-15 \mathrm{ml})$ and exposure time, $C$ (30-90 min) by using Central Composite Design (CCD). The model was significant with $\mathrm{B}$ and $\mathrm{C}$ displayed the potent parameters in the releasing neem extract to the surrounding. The optimum conditions were found to be $2.02 \%$ of $A, 11.88 \mathrm{ml}$ of $B$ and 68.35 min of $C$ which released $7.34 \%$ of neem extract to the surrounding. The encapsulation of neem extract showed a good potential to be used in agriculture sector.
\end{abstract}




\title{
Electrical properties of $\mathrm{Ba}_{0.85} \mathrm{Sr}_{0.15} \mathrm{TiO}_{3}$ ceramics for microelectronic devices
}

\section{*Nadia Nasika Nasir ${ }^{1,3}$, Rozana Aina Maulat Osman ${ }^{1,3, a)}$ and Mohd Sobri Idris 2,3}

${ }^{1}$ Faculty of Electronic Engineering Technology, Universiti Malaysia Perlis, 02600 Arau, Perlis, Malaysia.

${ }^{2}$ Faculty of Chemical Engineering Technology, Universiti Malaysia Perlis, 02600 Arau, Perlis, Malaysia.

${ }^{3}$ Center of Excellence Frontier Materials Research, 01000 Kangar, Perlis, Malaysia

*rozana@unimap.edu.my

\begin{abstract}
Barium strontium titanate $\left(\mathrm{Ba}_{0.85} \mathrm{Sr}_{0.15} \mathrm{TiO}_{3}, \mathrm{BST}\right)$ ceramic has been prepared by conventional solid -state reaction in air at $1200^{\circ} \mathrm{C}$, followed by slow cooling to room temperature at the end of the reaction. The X-ray diffraction (XRD) studies show that these ceramic are belongs to tetragonal phase structure with space group P4mm. The electrical properties of the ceramic shows maximum dielectric constant was about $\varepsilon_{r}=1094.52$ of this sample has resulted at the Curie temperature, $\mathrm{T}_{\mathrm{C}}=80^{\circ} \mathrm{C}$ measured at a frequency of $1 \mathrm{kHz}$. The capacitance of the sample described the dielectric behavior was associated with bulk ferroelectric $\left(C=10^{-9}\right.$ to $\left.10^{-10} \mathrm{~F}\right)$. Besides, $\mathrm{Ba}_{0.85} \mathrm{Sr}_{0.15} \mathrm{TiO}_{3}$ ceramic has conductivity in the range between semi - insulator and insulator material and the samples shows small PTCR effect above the Tc.
\end{abstract}




\title{
Design and Development of an Automated Temperature of Volvariella Mushroom Controlled Room
}

\author{
*Mariam Majid ${ }^{1, a)}$, Rakin $^{1}$, M Afendi',b), M S Abdul \\ Majid $^{3, c)}$ and M J M Ridzuann ${ }^{2, d)}$
}

${ }^{1}$ School of Engineering Technology, Universiti Malaysia Perlis, KampusUniCITI Alam, Sungai Chuchuh, 02100 Padang Besar, Perlis, Malaysia.

${ }^{2}$ School of Mechatronic Engineering, Universiti Malaysia Perlis, Kampus Tetap Pauh Putra, 02600 Arau, Perlis, Malaysia.

${ }^{3}$ School of Manufacturing Engineering, Universiti Malaysia Perlis, Kampus Tetap Pauh Putra, 02600 Arau, Perlis, Malaysia.

*mariam@unimap.edu.my

\begin{abstract}
The most important factors that affect the output of mushroom productivity is temperature. From that, this paper presents the design and simulation of an Automatic Control Room Heater system for Agricultural industry. This system allows the user to set a desired temperature for control room and fruiting phase which has been set between $34^{\circ} \mathrm{C}-32{ }^{\circ} \mathrm{C}$ and 28 ${ }^{\circ} \mathrm{C}-32{ }^{\circ} \mathrm{C}$, respectively. The process was developed by the responds of the system by turning $\mathrm{ON}$ any of loads (fan or a heater) automatically depending on the temperature difference. The system was designed and simulated using solid works and Arduino software, respectively. As a result, the planted mushroom that used automated handling method was advantageous in morphology features compared with manual handling method. In addition, the total yield of mushroom for automated was higher than manual handling.
\end{abstract}




\title{
Evaluation of Kenaf/Glass Fibre Reinforced Composites for Bolted Single Lap Joints under Tension Loading
}

\author{
${ }^{*}$ Mariam Majid ${ }^{1, a)}$, A W S Zainab ${ }^{1}$, M Afendi2,b), M S \\ Abdul Majid ${ }^{3, c)}$ and M J M Ridzuan ${ }^{2, d)}$
}

${ }^{1}$ School of Engineering Technology, Universiti Malaysia Perlis, KampusUniCITI Alam, Sungai Chuchuh, 02100 Padang Besar, Perlis, Malaysia.

${ }^{2}$ School of Mechatronic Engineering, Universiti Malaysia Perlis, Kampus Tetap Pauh Putra, 02600 Arau, Perlis, Malaysia.

${ }^{3}$ School of Manufacturing Engineering, Universiti Malaysia Perlis, Kampus Tetap Pauh Putra, 02600 Arau, Perlis, Malaysia..

*mariam@unimap.edu.my

\begin{abstract}
Experimental studies have been presented in this paper on dissimilar material metal/fibre laminates to investigate the fatigue response under tension-tension loading. The testing was evaluated on single lap joints (SLJs) with different joint technique; fastener bolted, adhesive bonded and hybrid (combination of bolted and bonded) joint with dimension of $160 \mathrm{~mm}$ length, $40 \mathrm{~mm}$ width and $3 \pm 0.5 \mathrm{~mm}$ thickness. The dynamic testing were subjected into constant frequency and stress ratio of $5 \mathrm{~Hz}$ and 0.1 , respectively. The range of applied load level were defined in between $30 \%$ to $90 \%$. Theoretically, significant improvements in fatigue strength can be obtained by adopting long overlap length which used in the study, $64 \mathrm{~mm}$. From the experimental study, the hybrid joint of dissimilar material reached highest load cycles followed by adhesive bonded and bolted joint
\end{abstract}




\title{
Tensile Properties of Hybrid Composites Based on Kenaf and Glass Fibre with the Effect of Stacking Sequence: Water Absorption Behaviour
}

\author{
${ }^{*}$ Mariam Majid ${ }^{1, a)}$, U Khairiah ${ }^{1}$, M Afendi ${ }^{2, b)}$, M S Abdul \\ Majid $^{3, c)}$ and M J M Ridzuan',d)
}

${ }^{1}$ School of Engineering Technology, Universiti Malaysia Perlis, KampusUniCITI Alam, Sungai Chuchuh, 02100 Padang Besar, Perlis, Malaysia.

${ }^{2}$ School of Mechatronic Engineering, Universiti Malaysia Perlis, Kampus Tetap Pauh

Putra, 02600 Arau, Perlis, Malaysia.

${ }^{3}$ School of Manufacturing Engineering, Universiti Malaysia Perlis, Kampus Tetap Pauh

Putra, 02600 Arau, Perlis, Malaysia.

*mariam@unimap.edu.my

\begin{abstract}
In this research, the aim of the study is to investigate the mechanical properties of eco-hybrid natural polymer of kenaf and glass fibre. The specimens were fabricated using vacuum infusion technique and joining into single lap bolted joint. The mechanical fasteners of Huck lock bolt were used as joining method with the bondline length of $64 \mathrm{~mm}$. The investigation was conducted under two different conditions of dry and wet of $50^{\circ} \mathrm{C}$ for water immersion of 20 days. The effect of moisture was defined in bolted joints materials. The tensile test with a speed rate of $1 \mathrm{~mm} / \mathrm{min}$ was conducted for both condition using $100 \mathrm{kN}$ load cell until total failure of specimen. The experimental results were plotted into load displacement and stress strain curve for each environment.
\end{abstract}




\title{
Study on dissolution behaviour and quantification of Gallic acid as a chemical marker in Kacip Fatimah herbal medicinal products
}

\author{
*Z Noorazwani',a), M A Nazurah ${ }^{2, b)}$, M N A Mohd Eeyad \\ Arief ${ }^{3, c)}$ and $Y$ Harisun ${ }^{1, d)}$ \\ ${ }^{1}$ Institute of Bioproduct Development (IBD), Universiti Teknologi Malaysia (UTM), \\ 81310, Skudai,Johor Bahru, Malaysia. \\ ${ }^{2}$ Universiti Teknologi MARA, Faculty of Chemical Engineering, Pasir Gudang, 81750, \\ Masai, Malaysia. \\ ${ }^{3}$ Faculty Bioresources and Food Industry, University Sultan Zainal Abidin, 21300, \\ Kuala Terengganu, Malaysia. \\ *azwani@ibd.utm.my
}

\begin{abstract}
Dissolution behaviour of active ingredients has an important effect on their pharmacological function. In reality, predicting their bioavailability is considered to be one of the most critical quality control tests. In this study dissolution behaviour was carried out using model independent included fit factors which comply with the FDA guidelines. The parameters of test ratio are the fit factors which include difference factor $\left(f_{1}\right)$ and similar factor $\left(f_{2}\right)$. These parameters were employed to compare in-vitro dissolution behaviour which were tested using different media; $0.1 \mathrm{M} \mathrm{HCl}, 30 \% \mathrm{EtOH}$, acetate buffer $(\mathrm{pH}$ 4.8) and phosphate buffer pH 6.8. Three brands of Kacip Fatimah (I,II,III) were compared and brands $V$ is a pure Kacip Fatimah used as a benchmark. The active ingredients namely galic acid in all samples was also quantified using a reverse-phase HPLC. Results obtained indicate that the dissolution efficiency for active ingredients for all brands were not significantly different however, gallic acid in all brands showed the highest solubility in $0.1 \mathrm{M} \mathrm{HCl}$ compared to the other three media used. Meanwhile, product I showed the highest amount of galic acid released compared to product II and product III. Using fit factors, only brands 1 and brand $\mathrm{V}$ showed similarity in results. Contents of the Gallic acid for brand I and brand V analysed via HPLC were the highest. Both results from in-vitro dissolution and HPLC test could be applied for quality control of gallic acid for Kacip Fatimah as herbal medicinal products available in markets.
\end{abstract}




\title{
Steering System Improvement for Formula SAE Car Using Ackermann Principle
}

\author{
*M T A Rahman ${ }^{1, a)}$, A Rahman ${ }^{1, b)}$ and S S Halim,c) \\ ${ }^{1}$ School of Mechatronics Engineering, Universiti Malaysia Perlis, Kampus Tetap Pauh \\ Putra, 02600 Arau, Perlis, Malaysia. \\ *tasyrif@unimap.edu.my
}

\begin{abstract}
Formula Society of Automotive (FSAE) car is a lightweight and low velocity racing car made for SAE competitions. A suitable steering system is important for the maneuverability and cornering during the competition since steering systems are supposed to be adjusted based on the vehicle type. Unsuitable steering system will result in stiff controls and skidding during a turn. Ackermann steering principle is commonly used for low speed and tight turning with no skidding by reducing the turning angle from geometrical turning of the wheels. Ackerman steering geometry can be designed by using the rack and pinion method. The method for improving the steering system is split into two stages, theoretical calculation, and experimental testing. The results will be compared with the past year FSAE competition entry to check its validity. Significant dimension changes had been done to the vehicle parts that influence the stiffness of the steering controls. The results validated that an improved steering mechanism was developed for UniART's Formula SAE car.
\end{abstract}




\title{
Air Flow Quality Analysis in Optimizing MODENAS GT128 Engine Performance
}

\author{
${ }^{*}$ M T A Rahman ${ }^{1, a)}$, A Rahman ${ }^{1, b)}$, N S Ahmat ${ }^{1, c)}$ and G E \\ Suhri ${ }^{1, d)}$
}

${ }^{1}$ School of Mechatronic Engineering,Mechanical Engineering Programme, Universiti Malaysia Perlis, Pauh Putra Campus, 02600, Arau, Perlis, Malaysia.

*tasyrif@unimap.edu.my

\begin{abstract}
This study introduces the method of engine performance optimization for more effective combustion of engines by improving the air flow quality that entering the combustion chamber. The main restriction that limits the air flow into the combustion chamber is due to the intake passage geometry. The intake passage of the engine is usually made using a mold and some small areas tolerant may be ignored. Usually, the small diameter of the intake passage acts as a restriction at the intake port, which will reduce the flow of air into the combustion chamber. To allow more air to enter the combustion chamber and to support the combustion process, the porting process was performed to enlarge the intake passage diameter and valve lift opening is modified. The engine efficiency can therefore be increased as more air can enter the combustion chamber in the meantime. This study covers two design types with the diameter of the intake passage and the valve lift opening act as parameters. Two types of analysis; simulation works and experimental works were undergone to test the validity of the modification. The results validated that the suitable intake passage diameter and valve lift opening was developed to optimize the performance of the engine.
\end{abstract}




\title{
Structural Analysis of Car Chassis Design
}

\author{
*M T A Rahman'1,a), A Rahman'1,b), M A M Temizi ${ }^{1, c)}$ and N \\ S Roslan ${ }^{1, d)}$
}

${ }^{1}$ School of Mechatronic Engineering,Mechanical Engineering Programme, Universiti Malaysia Perlis, Pauh Putra Campus, 02600, Arau, Perlis, Malaysia.

*tasyrif@unimap.edu.my

\begin{abstract}
Formula Society of Automotive Engineers (FSAE) car is a singleseat race car that travels with a high velocity in a short time. A chassis is the skeletal framework of a vehicle on which most of the mechanical parts like tires, axle assemblies and the engine are fastened. It is the most significant part of any vehicle as it is the source of strength and stability for the car under any conditions. A poor chassis design may lead to a failure in supporting loads and endanger the driver. The aim for this study is to improve the existing FSAE car chassis in order to optimize the performance of the car during the competition. A total of eight designs have been proposed and undergo analysis tests which are the main roll hoop test, front roll hoop test, static shear test, and static torsional loading test to obtain the Von-Mises Stress and the total deformation. Both of the processes are conducted in CATIA software. From the results obtained, the newly selected chassis design which is considered as the new improved design had a reduction of $57.315 \%$ for static shear stress in terms of Von-Mises Stress. The total deformation reduced more than half for all tests except for the front roll hoop test. The total deformation shows an increment of $6.89 \%$ for the front roll hoop test. The results had validated that an improved chassis design was successfully developed.
\end{abstract}




\title{
Characteristic of Local Robusta Cherries upon Fermentation and Roasting during Wet Coffee Processing
}

\section{*Z Noorazwani',a), A H Siti Nurfittrah"2,b), O Norzalina3,c), R Soleh $^{1, d)}$, M Siti Alyani ${ }^{1, e)}$ and S Norasiah ${ }^{1, f)}$}

\author{
${ }^{1}$ Institute of Bioproduct Development (IBD), Universiti Teknologi Malaysia (UTM), \\ 81310, Skudai, Johor Bahru, Malaysia. \\ ${ }^{2}$ Faculty of Medicine and Health Science, Universiti Putra Malaysia (UPM), \\ 434000, Serdang, Selangor, Malaysia.
}

${ }^{3}$ Innovation Centre in Agritechnology for Advanced Bioprocessing, Universiti Teknologi Malaysia, 84600, Pagoh, Johor, Malaysia.

*azwani@ibd.utm.my

\begin{abstract}
The unique chemical composition in coffee cherry offers a unique quality when it is processed. This study aimed to evaluate the characteristic of local Robusta coffee cherry when submitted to fermentation and roasting process via wet process. Local Robusta coffee cherry were divided to three groups namely Green B, Fermented and Roasted. Commercial samples namely Green N, Kopi Luwak and Green Z were also analysed as a benchmarking which representing the process involved. All the samples were evaluated for their antioxidant activity (AA) using ABTS and DPPH method including TPC analysis. Its organic acid, caffein and chlorogenic acid were also analysed using HPLC equipped with PDA detector. The AA values for both ABTS and DPPH methods showed similar trends and aligned with TPC results where Green $\mathrm{N}$ possessed the highest antioxidant value $\left(\mathrm{IC}_{50}\right.$ $160.6 \pm 1.6 \mu \mathrm{g} / \mathrm{ml}, \mathrm{IC}_{50} 2007.5 \pm 10.5 \mu \mathrm{g} / \mathrm{ml}$, ABTS and DPPH respectively). The acetic acid concentration is in the range between $0.03-1.13$ (\%dry matter) while lactic acid concentration is in the range between 0.01-0.79 (\%dry matter). Caffeine content was found at a higher concentration in Roasted (3.78 $\pm 3.5 \mathrm{mg} / \mathrm{g})$ followed by Kopi Luwak $(2.75 \pm 0.5 \mathrm{mg} / \mathrm{g})$ and Fermented $(2.68 \pm$ $0.8 \mathrm{mg} / \mathrm{g}$ ) while chlorogenic acid was found at the highest concentration in Green B $(0.40 \pm 0.2 \mathrm{mg} / \mathrm{g})$. Sample submitted to fermentation prior to roasting process gave impact on acetic acid, lactic acid, caffeine and CGA content. Acetic acid, lactic acid, caffeine and CGA are components that affect the quality of coffee as such offer a special characteristic of local Robusta coffee cherry.
\end{abstract}




\title{
Evaluating the Colloidal Stability of Graphene Oxide Nanosheet in Heat Transfer Fluids
}

\author{
*Yi Xiang Phan ${ }^{1}$, Wee Siang Koh¹ and Swee Pin Yeap",a)
}

${ }^{1}$ Department of Chemical and Petroleum Engineering, UCSI University, Cheras, 56000, Kuala Lumpur, Malaysia.

*yeapsw@ucsiuniversity.edu.my

Abstract. Adding small amount of graphene oxide (GO) into heat transfer fluids has been found to enhance thermophysical properties of the fluids. Nevertheless, the efficiency a GO-based nanofluid for heat transfer application is depending on ability of the GO to stay disperse in the base fluid. Realizing this, the present study investigated the long-term colloidal stability (up to 2 days) of GO upon added into different types of commonly used heat transfer fluids. Results showed that GO can be dispersed in distilled water, ethylene glycol, propylene glycol, and ethanol upon subjected to sonication. However, rapid agglomeration and sedimentation of the GO in ethanol medium rendering it a less effective heat transfer nanofluid. On the other hand, GO nanoparticles were observed to be highly stable in both ethylene glycol and propylene glycol, possibly due to protic nature of these two base fluids. In fact, the GO nanoparticles were found to be $\sim 100 \%$ and $>82 \%$ stable in ethylene glycol and propylene glycol-rich medium, respectively; a condition much better than the one dispersed in distilled water medium. Interestingly, it was found that the GO failed to disperse in engine oil which made up of nonpolar hydrocarbon chain, hence, suggested its poor compatibility with this type of heat transfer fluid. It is envisaged that outcome from the present work can provide a proper guideline on the selection of suitable fluid for making GObased heat transfer fluid. 


\title{
Study on Chip Formation when Machining Aluminum Alloy 7075-T6 with Carbide Tools under High-Speed Machining
}

\author{
*M S Ahmad Yasir',a), M Z A Yazid², M Z A Khairul \\ Azreen $^{2}$, Z Karim $^{1}$ and Gusri Akhyar Ibrahim ${ }^{3}$
}

${ }^{1}$ Department Mechanical and Manufacturing, Universiti Kuala Lumpur Malaysia France Institute, UniKL MFI, Malaysia.

${ }^{2}$ Department of Manufacturing, Universiti Kuala Lumpur Malaysia Italy Design Institute, UniKL MIDI, Malaysia.

${ }^{3}$ Depart of Mechanical Engineering, Lampung University, Bandar Lampung, Indonesia

*yasir@unikl.edu.my

\begin{abstract}
This paper discusses the effect of cutting parameters on the chip formation when machining Aluminum Alloy 7075-T6 with carbide tools under high-speed machining. The cutting condition applied in this study were dry and near dry conditions. Full factorial design with 3 factors and 2 level was used. The cutting speed, feed rate and axial depth of cut used are $500 \mathrm{~m} / \mathrm{min}$ and $600 \mathrm{~m} / \mathrm{min}, 0.12 \mathrm{~mm} /$ tooth and $0.15 \mathrm{~mm} /$ tooth and $1.40 \mathrm{~mm}$ and $1.70 \mathrm{~mm}$ respectively. The near dry cutting is also known as Minimum Quantity of Lubricant (MQL). The flow rate applied was $100 \mathrm{~mL} / \mathrm{H}$. This experiment shows that the size of chip much depends on the feed rate and depth of cut. Smaller chip was observed at lower feed rate and lower depth of cut. Cutting speed has no significant impact on the size of chip. Chips produced under MQL machining have less burn marks. This is a strong evidence that the MQL can reduce the heat generated at the cutting zone.
\end{abstract}




\title{
Characterization of Force Factor on Voice Coil Actuator for Active Vibration Isolation System
}

\author{
${ }^{*}$ Muhajir Ab. Rahim ${ }^{1}$ \\ ${ }^{1}$ School of Mechatronic Engineering, Universiti Malaysia Perlis, Perlis, Malaysia \\ *muhajir@unimap.edu.my
}

\begin{abstract}
In this paper, the effects of the force factor of a voice coil actuator for active vibration isolation system is investigated. Two sets of experiments are conducted to characterize the actuating force of the actuator. The first experiment is concerned on the value of force factor when the voice coil is excited at different low frequencies with a constant stroke length. Meanwhile, the effect of varying the distance of the permanent magnet from the electrical coil is studied in the second experiment. The results has showed the significant influence of force factor in generating the driving force for an active vibration isolation system.
\end{abstract}




\title{
Correlation of Polymer Concentration with the Membrane Performance of Polyethersulfone Membrane for Humic Acid Removal
}

\author{
${ }^{*} \mathrm{~N} N \operatorname{Tan}^{1}, \mathrm{Q}$ H Ng${ }^{1, a)}$, SK Enche AB Rahim ${ }^{1, b)}$, C W \\ Heah $^{1}$, S H Shuit ${ }^{2}$, P Y Hoo ${ }^{1}$, and Y P Teoh ${ }^{3}$
}

${ }^{1}$ Faculty of Chemical Engineering Technology, Universiti Malaysia Perlis, Kampus UniCITI Alam, Sungai Chuchuh, Padang Besar, 02100, Perlis, Malaysia.

${ }^{2}$ Department of Chemical Engineering, Lee Kong Chian Faculty of Engineering \& Science, Universiti Tunku Abdul Rahman, Sungai Long Campus, Jalan Sungai Long,

Bandar Sungai Long, Cheras 43000, Kajang, Selangor, Malaysia.

${ }^{3}$ Department of Petrochemical Engineering, Faculty of Engineering and Green

Technology, Universiti Tunku Abdul Rahman, Jalan Universiti, Kampar, Perak, Malaysia

*qhng@unimap.edu.my

\begin{abstract}
In this study, the effect of the polyethersulfone (PES) polymer concentration toward the membrane filtration performance was studied. Moreover, the synthesized membrane was characterized with porosity measurement followed by the determination of pure water flux as well as humid acid $(\mathrm{HA})$ rejection. The results showed an increase in the percentage of $\mathrm{HA}$ rejection and flux recovery ratio (FRR) value and a decrease in membrane permeate flux was due to an increase in the concentration of polymers. Furthermore, the results showed that complete blocking was the dominant fouling mechanism in this study except for $12 \mathrm{wt} \%$ PES membrane. For the $12 \mathrm{wt} \%$ PES membrane, the mechanism was controlled by the standard blocking mechanism which was well predicted the flux decline of PES membrane. Indeed, 15 wt\% PES membrane has been chosen as the best membrane in this study, since its shown outstanding performance in terms of both HA rejection and membrane permeate flux.
\end{abstract}




\title{
Design Analysis of High-Pressure Pure Water Jet Nozzle for Cutting Industry
}

\author{
*S N L Roselita1,a), A Rahman ${ }^{1, b)}$, M T A Rahman ${ }^{1, c)}$, N S \\ Kamarrudin ${ }^{1, \mathrm{~d})}$ and N A M Amin ${ }^{1, \mathrm{e})}$
}

${ }^{1}$ Faculty of Mechanical Engineering Technology, Universiti Malaysia Perlis, Kampus Alam Pauh Putra, 02600 Arau, Perlis, Malaysia.

*anasrahman@unimap.edu.my

\begin{abstract}
The increasing demand for cut quality has led to the emergence of new processing technologies, especially when many alloys are considered quite difficult to be cut. One of the most advanced technology is water jet cutting. The problem was the low efficiency in the cutting process using a water jet that not only can cut metals but also food products without contaminating them. The objective of this study is to optimize the cutting process in relation to the nozzle diameter as the observed parameter. The pure water jet was chosen instead of an abrasive water jet to avoid contamination of food products. Computational fluid dynamics (CFD) were used as the solver to visualize how the liquid flows. Some parameters were taken from the previous study as references and were optimized for observation. The pressure and nozzle diameter used are 200, 400 and 600 $\mathrm{MPa}$ and $0.15,0.2$ and $0.3 \mathrm{~mm}$ respectively. After the analysis, it is found that as the pressure of the water jet increase, the water velocity is increasing. Moreover, as the diameter of the nozzle hole increase, the spray of water become wider. The most suitable parameters were found to be $200 \mathrm{MPa}$ and $0.15 \mathrm{~mm}$ of pressure and nozzle diameter respectively. This will allow for the intended food cutting process with a stand-off distance around $8 \mathrm{~mm}$.
\end{abstract}




\title{
Study of Indoor Air Quality (laq) using One- Way Anova
}

\author{
${ }^{*}$ M I S M Anuar ${ }^{1, a)}$, N H Mardi 1, b) N Zaini ${ }^{1, c)}$ and N M \\ Zahari ${ }^{1, d)}$
}

${ }^{1}$ Department of Civil Engineering, Universiti Tenaga Nasional (UNITEN), 43000 Kajang, Selangor Darul Ehsan, Malaysia.

*mirfnsyhmi@gmail.com

\begin{abstract}
This study assessed the physical and chemical parameters related to indoor air quality (IAQ) at Universiti Tenaga Nasional (UNITEN) and the $I A Q$ of selected campus buildings were compared with guidelines provided by DOSH. This study is especially important as students spend most of their time indoors thus making them more vulnerable to exposure to indoor contaminants. Seven sampling locations around the UNITEN campus were selected which all have different layout. The method of data collection is based on Industry Code of Practice on Indoor Air Quality 2010 (ICOP). The indoor contaminants were recorded using real-time monitoring method and the parameters of interest are the Particulate Matter (PM2.5 and PM10), Total Volatile Organic Compound (TVOC), relative humidity and temperature. Results show that the parameters of IAQ level in UNITEN is at a safe level as it is well below the DOSH permissible limit. One-way ANOVA analysis was used to identify whether or not the mean of the IAQ parameters specifically PM2.5, PM10 and TVOC are the same and belongs to the same population. Statistical analysis also shows that there was no significant difference in IAQ level between all sampling locations $(P \leq 0.05)$.
\end{abstract}




\title{
Optimization of Encapsulated Neem Extract for Releasing Rate Studies
}

\author{
${ }^{*} \mathrm{~N} \mathrm{H} \mathrm{M} \mathrm{Salleh}{ }^{1, a)}, \mathrm{N}$ A Aziz ${ }^{1}$ and A R Mohamed ${ }^{1}$
}

${ }^{1}$ Faculty of Chemical Engineering Technology, University Malaysia Perlis, Kampus UniCITI ALAM, Sungai Chuchuh 02100 Padang Besar, Perlis, Malaysia.

* hasyierah@unimap.edu.my

\begin{abstract}
The application of synthetic pesticide contributes to the environmental issues, insect resistance, marketing opportunities and detrimental health effect. The application of biopesticide from neem leaves offers a great potential as biopesticide due to its active ingredient namely azadirachtin. However, the compound is unstable under harsh environment. Encapsulation technique helps to increase the delivery efficiency. The studies focus on the optimization of encapsulation of neem extract which involved three parameters namely concentration of sodium alginate, $\mathrm{A}(1.5-2.5 \%)$, volume of neem extract, B $(5-15 \mathrm{ml})$ and exposure time, C (30-90 $\mathrm{min})$ by using Central Composite Design (CCD). The model was significant with $B$ and $C$ displayed the potent parameters in the releasing neem extract to the surrounding. The optimum conditions were found to be $2.02 \%$ of $A, 11.88 \mathrm{ml}$ of $B$ and 68.35 min of $C$ which released $7.34 \%$ of neem extract to the surrounding. The encapsulation of neem extract showed a good potential to be used in agriculture sector.
\end{abstract}




\title{
Characteristics of Film Bulk Acoustic Wave Resonator using Different Electrode Materials
}

\author{
${ }^{*}$ N.I.M. Nor ${ }^{1, a)}$, N. Khalid ${ }^{1, b)}$ and Y.W. Jing ${ }^{1, c)}$ \\ ${ }^{1}$ School of Microelectronic Engineering, Universiti Malaysia Perlis, Kampus Tetap \\ Pauh Putra, 02600 Arau, Perlis, Malaysia. \\ *izza@unimap.edu.my
}

\begin{abstract}
Film bulk acoustic wave resonator (FBAR) is a device that consists of a thin-film piezoelectric, where the piezoelectric thin film is sandwiched between the top and bottom electrodes. The FBAR has widely used in radio frequency (RF) communication circuits such as RF filters due to its advantages of high quality $(Q)$ factor. The performance of FBAR is highly related to the piezoelectric material. Based on the literature review, the piezoelectric material such as aluminum nitride (AIN) and zinc oxide ( $\mathrm{ZnO})$ are commonly used in bulk acoustic wave (BAW) technology. Other than piezoelectric material, another important element in designing an FBAR is the electrode materials. Different electrode materials affect the performance of FBAR in terms of $Q$ factor and coupling coefficient $\left(k^{2}\right.$ eff $)$ due to their material properties. Therefore, in this work, FBAR working at frequency $5 \mathrm{GHz}$ to 10 $\mathrm{GHz}$ by using AIN as the piezoelectric material with two types of electrode materials, which are molybdenum (Mo) and aluminum (Al) are compared in terms of $Q$ factor and $k^{2}$ eff. Based on the results, the $Q$ factor of FBAR with Mo as electrodes has achieved the highest value of 16667 at $5 \mathrm{GHz}$ while the $Q$ factor of FBAR with Al as electrodes achieved 14092 at $5 \mathrm{GHz}$. On the other hand, the $\mathrm{k}^{2}$ eff of FBAR with $\mathrm{Al}$ as electrodes achieved the highest percent with $6.71 \%$ at $7 \mathrm{GHz}$ compared to FBAR with Mo as electrodes have its highest coupling coefficient with $5.78 \%$ at $6 \mathrm{GHz}$.
\end{abstract}




\title{
Design of Experiment of Redispersible Spray Dried Powder of Fatty Acid-Nanostructured Lipid Carriers using a $2^{3}$ Full Factorial Design
}

\author{
${ }^{*} \mathrm{~N}$ M Noor ${ }^{1, a)} \mathrm{N}$ A Anuar ${ }^{2, b)}, \mathrm{Z}$ I Abd-Rasid ${ }^{1, \mathrm{c})}, \mathrm{N}$ \\ Mohtar ${ }^{3, d)}, \mathrm{R}$ Hasham ${ }^{2,4, e)}$
}

${ }^{1}$ Cosmeceutical and Fragrance Unit, Institute of Bioproduct Development (IBD- N22), Universiti Teknologi Malaysia, 81310 UTM Johor Bahru, Johor, Malaysia

${ }^{2}$ Universiti Tun Hussein Onn Malaysia, Hub Pendidikan Tinggi Pagoh, Jalan Panchor, 84600 Pagoh, Muar, Johor, Malaysia.

${ }^{3}$ Department of Pharmaceutical Technology, School of Pharmaceutical Sciences, Universiti Sains Malaysia, 11800 Minden, Pulau Pinang.

${ }^{4}$ School of Chemical and Energy Engineering, Faculty of Engineering, Universiti

Teknologi Malaysia, 81310 UTM Johor Bahru, Johor, Malaysia.

*norhayati@ibd.utm.my

\begin{abstract}
Fatty acid such as lauric and oleic acid have been used extensively either in cosmeceutical or pharmaceutical products as an emollient or moisturiser. In this study, fatty acids which combine lauric and oleic acid have been prepared into nanostructured lipid carriers (FA-NLCs) system in order to improve physical stability hence, it could enhance the topical effectiveness. In order to prolong the stability of the nanodispersion of the FA-NLCs, spray drying technique has been applied to produce FA-NLCs in powder form. The work currently describes the design of experiment of lipid-based nanosystems with spray dried powder to acquire nanosystems after redispersion. FA-NLCs were prepared using melt-dispersion ultrasonication method. Three parameters were optimized with respect to spray drying; intake temperature, flow rate and feed concentration by $2^{3}$ Full Factorial Design. The response evaluated was the powder yield output, moisture content and size of the redispersed nanoaggregates. Results showed that the inlet temperature, flow rate and feed concentration were significant factors in achieving high powder yield, low moisture content and small redispersed nanoaggregates size which reflected to Standard Order No 6. In conclusion, spray dried FA-NLCs was successfully prepared with smallest nanoaggregate size, higher powder yield and lowest moisture content for cosmetic ingredients.
\end{abstract}




\title{
Boom Stiffening Effect on Long Arm Excavator Performance under Maximum Breakout Condition
}

\author{
*Mohamad Syafiq A. Rashid ${ }^{1, b)}$, Chee-MingChan ${ }^{1, a)}$, \\ Muhammad Farid Shaari, ${ }^{1, c)}$ and Allen Liew ${ }^{2, d)}$ \\ ${ }^{1}$ Faculty of Engineering Technology, Universiti Tun Hussein Onn Malaysia, Johor, \\ Malaysia. \\ ${ }^{2} \mathrm{NTL}$ Masters Sdn. Bhd. \\ *chan@uthm.edu.my
}

\begin{abstract}
The boom is considered the most critically affected part of Long Arm Excavators in severe work conditions, where high forces and unpredictable environmental elements at the worksite could severely affect the machine's overall performance. A potential solution to improve the boom's robustness is via stiffening. As an industrial collaborative project, the present study examined the performance of an existing machine via simulated improvement of the boom with such an approach, i.e. incorporation of stiffeners on the boom. Simulation works were carried out with Ansys Workbench 19.2 to assess the boom's performance in terms of resulting stress, strain and deformation under a series of stiffening configurations, which included varying the dimensions and positions of the stiffeners on the boom. The improved conditions were Improvement I: stiffener's thickness reduction to $10 \mathrm{~mm}$, Improvement II: a combination of different stiffener's thickness reduction to 10 and $8 \mathrm{~mm}$ at critical and non-critical parts of the boom, Improvement III: removal of half intermediate $12 \mathrm{~mm}$ thick stiffeners, and Improvement IV: removal of half intermediate $8 \mathrm{~mm}$ thick stiffeners. From the analysis, it was found that the maximum equivalent stress of the boom decreased with the number of stiffeners incorporated. The combination of different stiffener's thickness could also increase the boom's strength while decreasing the maximum equivalent stress. The lowest maximum equivalent stress of the boom was achieved via Improvement II with a reduction of $26.1 \%$. Removal of non-critical part stiffeners also kept stress values under the designated stress limits against fatigue failure, i.e. $44 \mathrm{MPa}$. In summary, performance optimisation appeared to be achievable with improvement II.
\end{abstract}




\title{
Physical properties of Garcinia atroviridis powder extract using pilot scale spray dryer
}

\author{
${ }^{*} \mathrm{M}$ Z Taher ${ }^{1}$, I M Yusoff ${ }^{1}$ and A Idris $\mathrm{A}^{2,3}$ \\ ${ }^{1}$ Herbal and Phytochemical Processing Unit, Institute of Bioproduct Development, \\ Universiti Teknologi Malaysia, 81310 Skudai , Johor, Malaysia. \\ ${ }^{2}$ Institute of Bioproduct Development, Universiti Teknologi Malaysia, 81310 Skudai , \\ Johor, Malaysia. \\ ${ }^{3}$ School of Chemical and Energy Engineering, Faculty of Engineering, Universiti \\ Teknologi Malaysia, 81310 Skudai , Johor, Malaysia.
}

*zarani@ibd.utm.my

\begin{abstract}
The paper presents the physical property of plant based extract food powder during processing. The effect of drying on the Garcinia atroviridis powder extract under pilot scale spray dryer was performed. The physical attributes to the powder including particles properties (particle size, size distribution) and bulk powder (porosity) were discussed. The results showed that particles size obtained under volume mean diameter and Sauter mean diameter were approximately $215 \mu \mathrm{m}$ and $111 \mu \mathrm{m}$, respectively with good porosity. The data showed that Garcinia atroviridis powder extract under pilot scale spray dryer may promotes the potential of the Garcinia atroviridis powder extract in food application as well as ingredient in pharmacological products.
\end{abstract}




\title{
A Simulation Study on the Mechanical Performance of Natural Fibre Reinforced Polymer Composite Material
}

\author{
${ }^{*}$ S N Morshidi1,a), M R Isa1,b), O S Zaroog ${ }^{2, c)}$ \\ ${ }^{1}$ Department of Mechanical Engineering, Universiti Tenaga Nasional, Jalan IKRAM- \\ UNITEN, 43000 Kajang, Selangor, Malaysia. \\ ${ }^{2}$ Faculty of Engineering, Sohar University, Sultanate of Oman, Oman \\ *asyikinmorshidi@gmail.com
}

\begin{abstract}
Natural fiber had recently been used as reinforcement with polymer in a composite is increasing, due to benefits. The benefits in natural fiber is the lightweight, low cost, environmentally friendly with a good specific mechanical property. However, several factors need to take into account to affecting the mechanical properties of natural fiber reinforced polymer, such as fiber fraction, fiber condition and fiber orientation. This study presents the simulation study on the mechanical properties of different natural fiber reinforced in a diagonal orientation and to compare the mechanical properties such as tensile and bending properties of Kenaf Fiber, PALF, and Ramie reinforced polymer composites. This study of mechanical properties will be investigated using ANSYS 18.1. The composites are designed in different natural fiber with fiber orientation in direction of $45^{\circ}$ and $135^{\circ}$ alternately in five layers. Tensile and bending test are analyze based on ASTM standard to determine the effect of stacking sequence and fiber orientation on the composites. The results show that fiber orientation have affect the mechanical properties of the composite materials.
\end{abstract}




\title{
Characterization of Mechanical Properties of Hybrid Natural Fibre Reinforced Polymer Composite
}

\author{
${ }^{*} \mathrm{G} B$ Goh ${ }^{1, a)}, \mathrm{M}$ R Isa ${ }^{1, b)}$, O S Zaroog ${ }^{2, \mathrm{c})}$ \\ ${ }^{1}$ Department of Mechanical Engineering, Universiti Tenaga Nasional, Jalan IKRAM- \\ UNITEN, 43000 Kajang, Selangor, Malaysia. \\ ${ }^{2}$ Faculty of Engineering, Sohar University, Sultanate of Oman, Oman \\ *gohgwenneolean@gmail.com
}

\begin{abstract}
Natural fibre reinforce polymer composite is gaining attention from researchers worldwide due to its potential as a replacement for synthetic fibre. Its main properties which are environmental-friendly and lightweight make is suitable to be used in many industries such as automotive industry. However, it has low mechanical properties compared to synthetic fibre composite. Hence, to improve its mechanical properties, researchers started to hybridised natural fibre which has proven that this method maximise the mechanical properties of natural fibre composite. This paper investigated the mechanical properties of hybrid pineapple/kenaf fibre reinforced polymer composite with three different fibre loading which are, 3\%, 6\% and $9 \%$. The method of fabrication is solvent casting method and the matrix used is epoxy resin. The results obtained shows that, for impact strength and hardness, higher fibre loading has higher impact strength and hardness. In the other hand, for tensile test, lower fibre loading has higher tensile strength.
\end{abstract}




\title{
Mixed Shear Mode and Compression Mode Magnetorheological Elastomer Isolator
}

\author{
${ }^{*}$ A. N. Azman ${ }^{1, a}$, M. F. Jaafar ${ }^{1,2, b}$ \\ ${ }^{1}$ College of Engineering, Universiti Tenaga Nasional, Kampus Putrajaya, 43000 \\ Kajang, Selangor, Malaysia. \\ ${ }^{2}$ Department of Aerospace Engineering, Universiti Putra Malaysia, 43400 Serdang, \\ Selango, Malaysia \\ *anasnajmiii@gmail.com
}

\begin{abstract}
The work presents the investigation on mixed mode MRE isolator to study the behavior of the smart magnetorheological elastomer (MRE) material. The study involves from the fabrication of the samples to the testing of the complete isolator. The fabrication of the MRE samples is also important to show the necessary materials and tools needed to produce a sample that is applicable for a both shear and compression testing. The casing for the isolator as well as the mould are produced beforehand to allow flexibility and more time to focus on the items needed for the fabrication process. Once the casing and samples are well integrated, the complete MRE isolator will go through the testing process. NI LabVIEW NXG 5.0 is the software used to receive data from the testing equipment and from there onwards, the data are manipulated for comparisons. The comparison of the graphs will then be related to the previous studies to allow a deeper understanding on the project.
\end{abstract}




\title{
Experimental Investigation on The Dispersion Stability of $\mathrm{Al}_{2} \mathrm{O}_{3}-$ Cuo Hybrid Nanofluid Using Ultraviolet (UV)-visible spectroscopy and Zeta Potential Analyzer
}

\author{
${ }^{*}$ R Wizal Zulkafli 1,b), V Vicki Wanatasanappan²,a) \\ ${ }^{1}$ College of Engineering, , Universiti Tenaga Nasional, Jalan IKRAM-UNITEN, 43000 \\ Selangor, Malaysia \\ ${ }^{2}$ Institute of Power Engineering, Universiti Tenaga Nasional, Jalan IKRAM-UNITEN, \\ 43000 Selangor, Malaysia. \\ *vignesh@uniten.edu.my
}

\begin{abstract}
This paper focuses on an experimental investigation on the dispersion stability of $60: 40$ water and ethylene glycol based $\mathrm{Al}_{2} \mathrm{O}_{3}-\mathrm{CuO}$ hybrid nanofluids. The volume and concentration of hybrid nanofluids were set to be $30 \mathrm{ml}$ and $0.5 \%$. Three different surfactants (PVP, CTAB, and SLS) with different surfactant ratios (1:10 and 5:10) were used to ensure the nanofluids remained homogenous for a longer period. Dispersion stability is studied using several methods such as sedimentation observation, zeta potential, and UVVis. FESEM testing is conducted to study the morphological behavior of the nanoparticles powder, including particle size and structure. Visual inspection showed that only pure $\mathrm{Al}_{2} \mathrm{O}_{3}-\mathrm{CuO}$ and $\mathrm{Al}_{2} \mathrm{O}_{3}-\mathrm{CuO}-\mathrm{PVP}$ (1:10) remained homogenous without any visible separation layer. As for UV-Vis spectroscopy, the absorbance value for all samples was below than $1 \%$. Thus, to further investigate the stability $\mathrm{Al}_{2} \mathrm{O}_{3}-\mathrm{CuO}$ hybrid nanofluid, the Zeta potential test is also conducted. Analysis of Zeta potential indicated that PVP with surfactant ratio 1:10 provided better result on the nanofluid stability. The $\mathrm{pH}$ value for sample with the PVP dispersant is then measured to be 7.7 which is slightly further from the IEP $(\mathrm{pH}$ 9.7-10)
\end{abstract}




\title{
Effectiveness of Ethanolic and Methanolic Morus nigra Extracts on Microbial Strains
}

\section{* M A Sokri ${ }^{1}$, M M Hussin ${ }^{1,2}$, K A K Pahirulzaman ${ }^{1 a)}, \mathrm{N} \mathrm{H}$ Saidan ${ }^{1}$}

${ }^{1}$ Faculty of AgroBased Industry, Universiti Malaysia Kelantan, Jeli Campus, 17600 Jeli, Kelantan, Malaysia.

${ }^{2}$ Industrial Biotechnology Research Centre (IBRC), SIRIM Berhad, 1, Persiaran Dato' Menteri, Section 2, 40000 Shah Alam, Selangor.

* khomaizon@umk.edu.my

\begin{abstract}
The effectiveness of Morus nigra as natural antimicrobial agents were assessed by the ability of the crude extract to inhibit the growth of Escherichia coli, Staphylococcus aureus, Aspergillus brasiliensis, and Candida albicans. Different parts (fruit, root, leaves and stem) of $M$. nigra were extracted by maceration using different solvents; ethanol and methanol. The antimicrobial assays were carried out by paper disc diffusion method. M. nigra of all part extracted in ethanol were able to inhibit the growth of test microorganisms compared to, when extracted in methanol. Root and fruit extracts of $M$. nigra were able to inhibit the test microorganisms. The analytical analysis using HPLC-DAD was able to identify the presence of flavonoids rutin, quercetin, apigenin and kaempferol in crude extracts that correspond to inhibition zones observed. Hence, the results suggested that crude extracts from $M$. nigra root and fruit have antimicrobial properties to prevent the growth of test microorganisms.
\end{abstract}




\title{
Conceptual Solid Desiccant Cooling Cycle with New Dehumidifier Configurations
}

\author{
${ }^{*}$ M A Ahamat ${ }^{1, a)}$, O Y Chieh ${ }^{1, b)}$, E N Roslin", c) and R \\ Abidin', d)
}

${ }^{1}$ Universiti Kuala Lumpur Malaysia France Institute, 43650 Bandar Baru Bangi, Selangor, Malaysia.

${ }^{2}$ Universiti Pertahanan Nasional Malaysia, Kuala Lumpur, Malaysia.

*asmidzam@unikl.edu.my

\begin{abstract}
Desiccant cooling cycle utilizes waste heat as energy source. In this paper, a conceptual solid desiccant cooling cycle with lower increase in air temperature during dehumidification is presented. The ratio of temperature rise during dehumidification at desiccant bed is proposed. It is predicted that a lower ratio of temperature rise may improve the ability of the cycle to reduce the temperature of supply air. Then, three configurations of dehumidifier/desiccant bed that could mitigate the rise in air temperature are briefly discussed. Although this paper does not include any mathematical models to predict the performance of those proposed configurations, the conceptual strategies presented may contribute to a breakthrough in desiccant cooling cycle.
\end{abstract}




\title{
Refurbishing Damaged Surfaces of Nickel- Aluminum Bronze Propellers: A robotic approach using Gas Metal Arc Welding and Friction Stir Processing
}

\author{
${ }^{*}$ Azman ahmad ${ }^{1}$ \\ ${ }^{1}$ Department of Mechanical and Manufacturing, University of Kuala Lumpur-Malaysia \\ France Institute, Bandar Baru Bangi 43650 Selangor DE, Malaysia \\ *azmanahmad@unikl.edu.my
}

\begin{abstract}
Gas Metal Arc Welding (GMAW) are well known due to its cost effective and easy accessibility. The technique is commonly used in shipping maintenance to repair corrosion and erosion affected propeller blades. Recently, studies of the Friction Stir Process (FSP) have shown its capability to generate a very fine microstructure and enhancement of the metal surface properties. This paper proposes an integrated approach for repairing larger sized nickel-aluminum bronze (NAB) components using a single robotic system. The process includes surface cleaning, weld deposition (WD), welding deposition Friction Stir Process (WD-FSP), surface and contour finishing. The mechanical properties, including hardness, cavitation erosion and corrosion performance, are tested on as-cast NAB, WD and WD-FSP surfaces. The weld deposition and WD-FSP surfaces showed an enhancement in hardness compared to as-cast NAB. As for cavitations erosion and corrosion, the weld deposition and WD-FSP sample exhibited an improvement in the cumulative mass loss and shifting of the electrode potential to the more noble section signifying that using the proposed approach is feasible for $\mathrm{NAB}$ repair.
\end{abstract}




\title{
Seismic Isolator based on Multilayer Magnetorheological Elastomer
}

\author{
${ }^{*} \mathrm{~S} \operatorname{Kumar}^{1, \mathrm{a}}$, M. F. Jaafar ${ }^{1,2, b}$ \\ ${ }^{1}$ College of Engineering, Universiti Tenaga Nasional, Kampus Putrajaya, 43000 \\ Kajang, Selangor, Malaysia. \\ ${ }^{2}$ Department of Aerospace Engineering, Universiti Putra Malaysia, 43400 Serdang, \\ Selangor, Malaysia. \\ *sarvin.uniten97@yahoo.com
}

\begin{abstract}
Magnetorheological Elastomer, which is also known as MREs, has multiple usage of application as it has the ability to isolate the vibration by varying the stiffness with the presence of magnetic field. Based on this research, it explains about the fabrication of the isolator for multilayer MRE, in order to be tested for vibration isolation by obtaining graphs of time domain and frequency domain for isotropic and anisotropic MRE based on multilayer configuration with the aid of LabVIEW NXG. The samples of the MREs were prepared in a mold and cured for about 4 hours or over a night to have the best result of the sample. Both types of MRE samples were tested with variable configuration in order to analyse the differences in time domain and frequency domain graphs at different percentage of carbonyl iron particle (CIP) used in the MRE that was mixed with silicone rubber. Variable distance of curing was also implemented for anisotropic arrangement, in order to test the performance of the MRE for different magnetic field strength intensity.
\end{abstract}




\title{
A Review of Biomechanical Modelling of Trabecular Bone On Estimation of Bone Quality Effected By Cracks and Stress Fracture
}

\author{
* M S N Nadiah ${ }^{1, a)}$, N Najwa Mansor 1,b) \\ ${ }^{1}$ Faculty of Engineering Technology, Universiti Malaysia Perlis, Kampus UniCITI \\ Alam, Sungai Chuchuh, 02100 Padang Besar, Perlis, Malaysia.. \\ *nae96_1603@yahoo.com
}

\begin{abstract}
Dental implant is one of the methods used to restore the natural functionality and appearance. Upon proceeding the dental implants, many factors should be taken as to avoid failures about the surgery. Therefore, in this paper review, there are compilations of research about bones that are related to dental implant such as fractures. Strength of the bones, fracture toughness and bone fatigue playing role in maintaining the stability of the bones for the dental implant. Those factors have different effects on clinical fracture. Besides, fibrous dysplasia of bone is an uncommon skeletal disorder resulting in deformity, fractures, pain and functional impairment. Patients have to undergo several procedures before performing the dental implant surgery as this disease can give implications. The failures of dental implant usually because of lack of osseointegration. By performing the coating implant surfaces with organic components, it activates and catalyzes the osseointegration process. In addition, there are explanation about the characteristics of bones and the relationship between osseointegration and the bone-implant interface. Lastly, the osteoclasts had roles in bone remodelling around implant biomaterials as well as the soft tissue adhesion contributes to implant stability.
\end{abstract}




\title{
Analysing the Macroeconomic Impact of GST Implementation for Malaysian Economy: Evidence of CGE Model
}

\author{
${ }^{*}$ S Suriyani ${ }^{1, \text { a) }}$ and $\mathrm{H}$ Mukaramah", b) \\ ${ }^{1}$ School of Economic Finance and Banking, Universiti Utara Malaysia, 06010 Sintok, \\ Kedah, Malaysia. \\ ${ }^{2}$ School of Economic,Finance and Banking, Universiti Utara Malaysia, 06010 Sintok, \\ Kedah, Malaysia. \\ *suri_1402@yahoo.com
}

\begin{abstract}
Goods and Services Tax (GST) is a general consumption tax imposed on goods and services. In the face of an increasingly challenging economic performance, the government's deteriorating revenue and stagnant investment levels have resulted in a deficit. Besides reliance on oil and gas revenue, Malaysian therefore has implemented GST at 6 per cent in April 2015. In this paper, we use a generally equilibrium model (CGE) to examine the wider macroeconomic impact on this GST policy. We found that while GST increased government revenue and brings about 2 per cent increase in real Growth Domestic Product (GDP), it manages to handle investment levels. Additionally, GST leads to increase the fixed investment and in real consumption and the welfare through declining of consumer price index by 0.2 per cent. As GST is excluded from exports of domestically manufactured products, the impact of six per cent of GST is increased by the export of goods and services produced domestically. On the other hand, a decline in real production is inevitable, provided a decrease in personal disposable earnings, real investment and consumption, the food and beverages and accommodation sector will see the greatest decrease in production by -0.34 per cent and the information and communication 0.24 per cent. While the import impact of GST, we can see the percentage of changes are slightly small rather than export. This statement coincides with the results found showing that imports are exceeding the exports. In this highlight, the ideas on the implementation of GST is to upgrade the government tax collecting mechanism and beneficially to contribute to national GDP.
\end{abstract}




\title{
Development of Instrumentation for a Study on Relationship between Integrated Management System and Innovation Performance in Malaysia Green Building Industry
}

\section{${ }^{*} \mathrm{~N}$ Z Zainol ${ }^{1, a)}, \mathrm{M}$ S Jusoh ${ }^{2, \mathrm{~b})}, \mathrm{F}$ A Ibrahim ${ }^{1, \mathrm{c})}$, and N Hamidin ${ }^{1, d)}$}

\author{
${ }^{1}$ Faculty of Civil Engineering Technology, Universiti Malaysia Perlis, Malaysia \\ ${ }^{2}$ Faculty of Applied Sciences and Humanities, Universiti Malaysia Perlis, Malaysia \\ * norrazman@unimap.edu.my
}

\begin{abstract}
A questionnaire is a vital research instrument consisting of a series of questions for the purpose of gathering information from respondents. Most psychological research required an instrument that shall be valid and reliable to investigate that particular study's intended variables. Eventually, such an instrument that fits the study is very rare. So, a need was felt to develop a suitable and reliable tool for the same purpose. Aim: To develop an instrument for measuring variables, i.e., Integrated Management System and Innovation Performance, and to test its reliability and validity. Methods: A draft of the 59item scale was developed, which comprises 14 items in the demographics section and 45 measurement items. The tool's content validity was established by accepting items that range in between $75 \%$ to $90 \%$ of the validity index for each item. To test the instrument's reliability, a pilot study was conducted where the instrument is applied to 30 respondents representing 30 different organisations involved in building construction. Results: The instrument passes the content validity with an index of .78 while it has no significant face validity issues. Statistical analyses showed excellent internal consistency by Cronbach's alpha which all variables are above 0.8. Conclusion: The instrument has acceptable properties (i.e., valid and reliable) and is suitable for measuring the intended variables, i.e., IMS and IP. It is recommended to be further tested for construct validity.
\end{abstract}




\title{
Design and Analysis of Rectangular Microstrip Patch Antenna at 2.4 and $5 \mathrm{GHz}$
}

\section{*Hamza Abbasi ${ }^{1}$, Muhammad Nihal Naseer ${ }^{1 *}$, Yasmin Abdul Wahab ${ }^{2 *}$, Muhammad Mobin Siddiqi ${ }^{1}$, Rozana Aina Maulat Osman ${ }^{3,4}$, Nurul Ezaila Alias ${ }^{5}$, Hanim Hussin $^{6}$}

\author{
${ }^{1}$ Nanotechnology \& Catalysis Research Centre, University of Malaya, 50603 Kuala \\ Lumpur, Malaysia 1National University of Sciences and Technology (NUST), 44000- \\ Islamabad, Pakistan \\ ${ }^{2}$ Nanotechnology \& Catalysis Research Centre, University of Malaya, 50603 Kuala \\ Lumpur, Malaysia \\ ${ }^{3}$ Faculty of Electronic Engineering Technology, Universiti Malaysia Perlis, 02600 Arau, \\ Perlis, Malaysia \\ ${ }^{4}$ Center of Excellence Frontier Material Research, 01000 Kangar, Perlis, Malaysia \\ ${ }^{5}$ School of Electrical Engineering, Faculty of Engineering, Universiti Teknologi \\ Malaysia \\ ${ }^{6}$ Faculty of Electrical Engineering, Universiti Teknologi MARA,40450 Shah Alam, \\ Malaysia. \\ *nihal.me@pnec.nust.edu.pk
}

\begin{abstract}
The principle of the photogrammetry techniques is the electromagnetic radiant imagery taken by drone to record, measure and interpret photographic images. This paper presents the application of photogrammetry techniques for the inspection of buildings and structures. The aim of this research is to assess the application of Unmanned Aerial Vehicle (UAV) by using drone to develop a three-dimensional mapping model, that can be used for health infrastructure monitoring. The test was conducted at College of Engineering building in Universiti Tenaga Nasional (UNITEN). The picture captured using high-resolution camera that have been attached to the drone was used and processed using Agisoft Software. The best resolution of three-dimensional mapping using Agisoft software was compared in order to identify surface defect occurs on College of Engineering buildings. As consequence, the surface defect has been found and further analysis was conducted. Findings stated that, building surface defect monitoring using photogrammetry method can be used as one of methods to conduct the building inspection and monitoring..
\end{abstract}




\section{The Dielectric Behaviour of $\mathrm{Ba}\left(\mathrm{Sn}_{0.05} \mathrm{Zr}_{0.01} \mathrm{Ti}_{0.94}\right) \mathrm{O}_{3}$ Ceramic by Impedance Spectroscopy Analysis}

\section{Ku Noor Dhaniah Ku Muhsen $13^{*}$, Rozana Aina Maulat Osman ${ }^{1,3}$, Mohd Sobri Idris 2,3}

${ }^{1}$ Faculty of Electronic Engineering Technology, Universiti Malaysia Perlis, 02600 Arau, Perlis, Malaysia.

${ }^{2}$ Faculty of Chemical Engineering Technology, Universiti Malaysia Perlis, 02600 Arau, Perlis, Malaysia.

${ }^{3}$ Center of Excellence Frontier Materials Research, Universiti Malaysia Perlis, 01000 Kangar, Perlis, Malaysia.

*kunoordhaniah@gmail.com

Abstract. In this work, the $\mathrm{Ba}\left(\mathrm{Sn}_{0.05} \mathrm{Zr}_{0.01} \mathrm{Ti}_{0.94}\right) \mathrm{O}_{3}$ ceramic has been synthesized by using conventional solid state reaction route sintered at 1450 ${ }^{\circ} \mathrm{C}$. The X-ray diffraction analysis shown that the sample exhibited tetragonal structure at room temperature. The dielectric constant shows that there are two phase transition temperatures around $46{ }^{\circ} \mathrm{C}\left(T_{0-t}\right)$ and $70{ }^{\circ} \mathrm{C}\left(T_{\mathrm{c}}\right)$. The dielectric constant reached maximum at $T_{\mathrm{c}}$ about 3200 . The electrical properties of the sample were dominated by the grain effect. An incomplete semicircle arc was observed in the complex impedance and electric modulus plot. The dielectric loss remained similar value around room temperature, $T_{0-t}$ and $T_{\mathrm{c}}$. 


\section{Synthesis and Characterization on Garnet- type Structure $\mathrm{Li}_{7} \mathrm{La}_{3} \mathrm{Ce}_{2} \mathrm{O}_{12}$ and its Electrical Properties}

\section{Nazerah Yaacob ${ }^{1,2}$, Siti Nur Adlina Norazman ${ }^{1,2}$, Rozana Aina Maulat Osman ${ }^{1,3}$, Mohd Sobri Idris ${ }^{1,2^{*}}$ and Ku Noor Dhaniah Ku Muhsen 1,3}

${ }^{1}$ Center for Frontier Materials Research, Universiti Malaysia Perlis, 02600 Arau, Perlis, Malaysia.

${ }^{2}$ Materials Engineering Programme, Faculty of Chemical Engineering Technology, Universiti Malaysia Perlis, 02600 Arau, Perlis, Malaysia.

${ }^{3}$ Faculty of Electronic Engineering Technology, Universiti Malaysia Perlis, 02600 Arau, Perlis, Malaysia.

*sobri@unimap.edu.my

Abstract. In this work, we report a garnet-type lithium-ion conductor with the chemical formula of $\mathrm{Li}_{7} \mathrm{La}_{3} \mathrm{Ce}_{2} \mathrm{O}_{12}$ that prepared by conventional solid-state synthesis route. A pure phase of cubic garnet-type $\mathrm{Li}_{7} \mathrm{La}_{3} \mathrm{Ce}_{2} \mathrm{O}_{12}$ was obtained at $900^{\circ} \mathrm{C}$ for 12 hours with intermittence grindings. Purity of the samples were confirmed by using X-ray diffraction (XRD) technique. The electrical properties of the samples wereanalyzed using Impedance Spectroscopy (IS) technique. Results show that the electrical conductivity in $\mathrm{Li}_{7} \mathrm{La}_{3} \mathrm{Ce}_{2} \mathrm{O}_{12}$ is dominated by bulk effects. 


\title{
The effect of lithium excess toward synthesis of $\mathrm{Li}_{7} \mathrm{La}_{3} \mathrm{Zr}_{2} \mathrm{O}_{12}$ cubic garnet-type as solid electrolyte for all solid-state rechargeable batteries
}

Siti Nur Adlina Norazman ${ }^{1,2}$, Nazerah Yaacob ${ }^{1,2}$, Rozana Aina Maulat Osman ${ }^{1,3}$, Mohd Sobri Idris ${ }^{1,2^{*}}$ and Ku Noor Dhaniah Ku Muhsen ${ }^{1,3}$

${ }^{1}$ Center for Frontier Materials Research, Universiti Malaysia Perlis, 02600 Arau, Perlis, Malaysia.

${ }^{2}$ Materials Engineering Programme, Faculty of Chemical Engineering Technology, Universiti Malaysia Perlis, 02600 Arau, Perlis, Malaysia.

${ }^{3}$ Faculty of Electronic Engineering Technology, Universiti Malaysia Perlis, 02600 Arau, Perlis, Malaysia.

* sobri@unimap.edu.my

\begin{abstract}
In this work, we report a low temperature biopolymer sol-gel route to synthesise these garnet materials using Agar, with the formation of the garnet phase at temperatures $1000^{\circ} \mathrm{C} \sim 1100^{\circ} \mathrm{C}$, with single phase samples of cubic $\mathrm{Li}_{7} \mathrm{La}_{3} \mathrm{Zr}_{2} \mathrm{O}_{12}$. XRD measurement shows that the complete formation of cubic $\mathrm{Li}_{7} \mathrm{La}_{3} \mathrm{Zr}_{2} \mathrm{O}_{12}$ with $10 \%$ excess of lithium is at $1000^{\circ} \mathrm{C}$, which is $\sim 100^{\circ} \mathrm{C}$ lower than the addition of $30 \%$ excess lithium which is at $1100^{\circ} \mathrm{C}$. However, the conductivity plot shows the conductivity of the $\mathrm{Li}_{7} \mathrm{La}_{3} \mathrm{Zr}_{2} \mathrm{O}_{12}$ with $30 \%$ lithium excess contributed in high $\mathrm{Li}^{+}$conductivity compared with $\mathrm{Li}_{7} \mathrm{La}_{3} \mathrm{Zr}_{2} \mathrm{O}_{12}$ with $10 \%$.
\end{abstract}




\title{
Structural and dielectric properties of $\mathrm{Ba}_{0.8} \mathrm{Sr}_{0.2} \mathrm{Ti}_{0.96} \mathrm{Sn}_{0.04} \mathrm{O}_{3}$ ceramics
}

\author{
Nadia Nasika Nasir ${ }^{1,3}$, Rozana Aina Maulat Osman ${ }^{1,3}$ \\ Mohd Sobri Idris ${ }^{2,3^{*}}$ and Ku Noor Dhaniah Ku Muhsen ${ }^{1,3}$
}

${ }^{1}$ Center for Frontier Materials Research, Universiti Malaysia Perlis, 02600 Arau, Perlis, Malaysia.

${ }^{2}$ Materials Engineering Programme, Faculty of Chemical Engineering Technology, Universiti Malaysia Perlis, 02600 Arau, Perlis, Malaysia.

${ }^{3}$ Faculty of Electronic Engineering Technology, Universiti Malaysia Perlis, 02600 Arau, Perlis, Malaysia.

* sobri@unimap.edu.my

Abstract. Perovskite type ceramics $\mathrm{Ba}_{0.8} \mathrm{Sr}_{0.2} \mathrm{Ti}_{0.96} \mathrm{Sn}_{0.04} \mathrm{O}_{3}$, a relaxor composition prepared through solid state reaction route and calcinated at temperature is $1400^{\circ} \mathrm{C}$ for 3 hours with intermediate mixing. The room temperature XRD study suggests that all the samples have the tetragonal symmetry with space group p $4 \mathrm{~mm}$. The pellets were sintered at $1400^{\circ} \mathrm{C}$ for 3 hrs. The dielectric measurements at different frequency show that dielectric constant increases near $T_{c}$. Loss factor was decreased with increasing temperature but continue to increase as the temperature further increase above $100^{\circ} \mathrm{C}$. 


\title{
Factors Associated with Stress among Academic Staff at a Malaysian Public University
}

\author{
*K Isa1, H Kadir@Shahar² \\ ${ }^{1}$ Center for General Studies and Co-curricular, Universiti Tun Hussein Onn Malaysia, \\ 86400 Parit Raja, BatuPahat, Johor, Malaysia. \\ ${ }^{2}$ Center for Language Studies, Universiti Tun Hussein Onn Malaysia, 86400 Parit \\ Raja, Batu Pahat, Johor,Malaysia \\ *nesa@uthm.edu.my
}

\begin{abstract}
Workers who have stress at workplace will experience a few changes on their emotions and attitudes which negatively affect their own health and productivity. This research was conducted to measure the factors that lead to stress among academic staff at one of the Malaysian Public Universities. Academicians were selected in this study since motivational aspects and level of stress among them will affect the holistic development of students. A survey was conducted through questionnaires that were given randomly to 150 respondents. The sample of this study was selected based on a purposive sampling. The study used focus group discussion for data collection and open-ended questions as the main instruments. All the data collected were descriptively analysed. Findings have shown that there are four prominent factors which contribute to stress including heavy workload, negative working environment, administration and management problems and lack of rewards or appreciation. The highest frequency factors fall onto the two factors- heavy workload and negative working environment. Most workers complained that they were overloaded with work tasks in addition to having had to be in a less conducive working environment. Thus, this research suggests some potential ways for organisations to reduce the stress among their workers by being alert about what the workers actually need at their workplace.
\end{abstract}




\title{
Knowledge of Smoking Implications and Acceptance of Smoking Ban at Food Premises
}

\author{
${ }^{*} \mathrm{~K}$ Isa ${ }^{1}$, J Jamin², S T Palpanadan ${ }^{3}$ and M Mizad ${ }^{4}$ \\ ${ }^{1}$ Center for General Studies and Co-curricular, Universiti Tun Hussein Onn Malaysia, \\ 86400 Parit Raja, Batu Pahat, Johor, Malaysia. \\ ${ }^{2}$ Faculty of Technical and Vocational Education, 86400 Parit Raja, Batu Pahat, Johor, \\ Malaysia \\ ${ }^{3,4}$ Center for Language Studies, Universiti Tun Hussein Onn Malaysia, 86400 Parit \\ Raja, Batu Pahat, Johor, Malaysia \\ *nesa@uthm.edu.my
}

\begin{abstract}
Smoking has become a comman practice in society today. Various initiatives have been taken to reduce smoker populations in the country but almost all doesn't work. The introduction and imposition of a ban on smoking in public spaces especially on food premises introduced by the Ministry of Health Malaysia have received positive and negative responses from consumers. This study was conducted to determine the level of consumers' awareness of the implications of smoking on health; and the level of consumers' acceptance of smoking ban instructions on food premises. At the same time, the study also aimed at determining the food premis owners' perceptions of no smoking instructions at food premises. A total of 500 consumers at the food premises and 50 food premis owner were selected as a sample. Findings indicate that the level of knowledge about the implications of smoking on health was high (mean $=3.54$ ) and that respondents' level of acceptance of smoking ban instructions was also high (mean $=3.13$ ). The analysis also showed that there was a significant relationship between the level of respondents' knowledge of the implications of smoking and the prohibition of smoking imposed on food premises with a value of $r=0.728$ at a significant level $p=0.000$ level. Meanwhile, most food premis owners say that smoking bans on food premises do not affect their business performance, and Pearson's correlation findings also indicate that there is a weak relationship between smoking bans and business performan.
\end{abstract}




\title{
Learning Style Tendencies Based on Fleming's VARK Learning Style among TVET Students
}

\section{Razali, N.S.M. ${ }^{1}$, ${ }^{*}$ Ahmad F. ${ }^{1}$, Hamzah N. ${ }^{1}$, Wan Hassan W.A.S. ${ }^{1}$ and Baharudin S.M. ${ }^{2}$}

${ }^{1}$ Faculty of Technical and Vocational Education, Universiti Tun Hussein Onn Malaysia, Malaysia

${ }^{2}$ School of Educational Studies, Universiti Sains Malaysia

*muhdfazrulhelmi@gmail.com

\begin{abstract}
This study aims to identify learning style tendencies based on the Fleming's VARK learning style of TVET students. This study uses a questionnaire approach to assess TVET students' learning styles based on Fleming's visual, auditory, writing or reading and kinesthetic learning styles. The study population is technical students of FPTV, UTHM and the selected sample consists of 53 students from various fields namely General Machining (BBA), Welding and Metal Fabrication (BBD), Electrical \& Electronics (BBE) and Creative Multimedia (BBF) who took the subject BBD10803 Information Technology in Education at Universiti Tun Hussein Onn Malaysia. The results of this study indicate that the most preferred Fleming's VARK learning style is a visual learning style.
\end{abstract}




\title{
COVID-19 Pandemic: Non-Quarantined Residential College Students' Perceptions of Communicative Importance
}

\section{${ }^{*}$ S T Palpanadan ${ }^{1}, \mathrm{M}$ S Idris ${ }^{1}, \mathrm{H}$ Harun ${ }^{1}, \mathrm{~A}$ H Shahron ${ }^{1}, \mathrm{M}$ Z M Bosro ${ }^{1}$ and $M$ Y Ibrahim ${ }^{1}$}

${ }^{1}$ Universiti Tun Hussein Onn Malaysia, 86400 Parit Raja, Johor, Malaysia

*sarala@uthm.edu.my

\begin{abstract}
The implementation of Movement Control Order (MCO) method to break COVID-19 chain to save the nation has affected the daily routine of the residential college students at the universities. Those who were not infected by the disease were categorized as the Non-quarantined students where they had to undergo certain rules and regulations during the crisis. This study aims to identify the perceptions of that the Non-Quarantined students at the residential colleges of a Malaysian technical public university towards communicational service provided during the COVID-19 pandemic. A total of 520 students residing at the residential colleges participated in the study. Five main aspects of communication at the residential college were studied: instant updates; platforms; availability of information; admin responses; and counselling service. The analysis conducted using Statistical Package for The Social Science Version 25.0 (SPSS 25) showed that the mean score for the highest aspect was on the instant updates (4.11) provided to the nonquarantined students during the Covid-19 crisis. The findings indicated that majority of the respondents were satisfied with the communication service provided where the mean score was 3.99. The respondent provided the lowest mean score (3.87) for the aspect of counselling service. Thus, this study would recommend that the residential colleges of the universities should upgrade the service of counselling sections and make them known to the students for them to utilize the services to the maximum.
\end{abstract}




\title{
Behavioural Intention to Adopt Blockchain Technology in Bangladeshi Banking Companies
}

\author{
M R Kabir ${ }^{1,2}$ and ${ }^{*}$ M A Islam ${ }^{1}$ \\ ${ }^{1}$ School of Business, Innovation and Technopreneurship, Universiti Malaysia Perlis, \\ Malaysia. \\ ${ }^{2}$ School of Business Administration, East Delta University, Chittagong Bangladesh. \\ *amin@unimap.edu.my
}

\begin{abstract}
Banking is a business of trust and transparency. Unfortunately, recent financial scams in the banking industry of Bangladesh have thrown a big question in terms of reliability and transparency. On the other hand, the emergence of blockchain technology has created new hope in terms of ensuring transparency in the baking system. However, before implementing any new technology, it is essential to understand the stakeholders' intention to adopt it. This study is an attempt to explain the factors driving the intention to adopt blockchain in the banking industry. Though, there much behavioural theory to explain technology adoption, extended Technology Acceptance Model (TAM) is used in this research because of its proven record in explaining technology acceptance. The research is conducted with the bank employees as the respondents. A total of 300 questionnaires have been distributed while 215 useable questionnaires were found for the analysis of this study. Two internal factors, as seen in the original TAM called perceived usefulness and ease of use, are found significant in describing the intention to adopt blockchain. On the other hand, two additional external variables called social influence and trust are analyzed. Trust is found to be significant, while the social influene was not statistically significant in this regard. The four independent variables together explain $48 \%$ variation in the intention to adopt blockchain technology for the banking industry. The implication of this research is significant. If the banks intend to adopt and operate blockchain, this research will provide them with a good picture of what managerial actions are essential for its adoption.
\end{abstract}




\title{
Extension of TAM Explaining the Determinants of I-banking Adoption: Bangladesh Perspective
}

\author{
M R Kabir ${ }^{1,2}$ and *M A Islam ${ }^{1}$ \\ ${ }^{1}$ School of Business, Innovation and Technopreneurship, Universiti Malaysia Perlis, \\ Malaysia. \\ ${ }^{2}$ School of Business Administration, East Delta University, Chittagong Bangladesh. \\ *amin@unimap.edu.my
}

\begin{abstract}
The advancement of technology and rapid growth in the number of internet users throughout the world has been pushing people to do all sorts of transactions online. This move towards digitization requires banking services to be automated and online. With its dream to become a digital nation by 2021, Bangladesh is striving hard to enter into the world market online. Hence, though late, banks in Bangladesh have started their I-banking services. However, the acceptance level of users is essential to understand before its full-fledged implementation. Thus, this study aims at explaining the determinants of internet banking with extended Technology Adoption Model (TAM) as the base. Though a good number of studies have already been undertaken using TAM, the study is justified in the sense that it would mitigate the research gap considering two country-specific variables like security and privacy risk. The variables are selected on the backdrop concerning the absence of a strict regulation for the use of the internet and a much-talked issue of internet speed and quality in Bangladesh. A questionnaire survey has been conducted among the internet users to identify the determinants of the intention to use I-banking (IUIB) and hence the adoption of it. A total of 200 questionnaires have been administrated using three different forms called an inperson survey, postal mail and google form. Out of 200 questionnaires, 150 fully completed and usable questionnaires have been received with a success rate of $75 \%$. All the independent variables called perceived usefulness; perceived ease of Use, perceived enjoyment, access to information, security and privacy (S.P.) and quality of internet connection (QIC) are found to be significant in explaining the users' IUIB. The IUIB is also found to be highly significant to explain the -banking Adoption by the users. The country-specific variable like the S.P. has a negative impact on I-banking adoption while the QIC found to have a positive impact in Bangladesh context. Hence, the study recommends the policymakers of Bangladesh to initiate strong laws for protecting the security of data over the internet with a special urge to the telecommunication regulatory authority and telecom companies to ensure technology infrastructure for high speed and smooth internet services.
\end{abstract}




\title{
Factor Influencing Youth in Aquaculture Industry in Kelantan
}

\author{
${ }^{*} \mathrm{~A}$ L Zul Ariff ${ }^{1}$ and M Nursalwani ${ }^{1}$
}

${ }^{1}$ Faculty of Agro Based Industry, University Malaysia Kelantan, Kampus Jeli, 17600 Jeli, Kelantan, Malaysia.

*zulariff@umk.edu.my

\begin{abstract}
For as one can remember, aquaculture has been considered as an important activity and sector nowadays even though it is not one of the demanding and an attractive alternative to other work sectors like public sector employment. In the beginning of 1920's, the aquaculture activity in Malaysia has developed rapidly and become as one of an important activity. Aquaculture is becoming important as a way of increasing local production for food security and increasing export revenues. The main purpose of this research is to identify the factors that influence youth interest to become an aquaculture entrepreneur. In this context, 40 youth in University Malaysia Kelantan (UMK) has been selected as respondents. This study used two methods which are qualitative and quantitative as the best way to address the issue of aquaculture entrepreneurship. The simple random sampling technique was applied to collect the data. The respondents selected are those who have interest in the aquaculture business.
\end{abstract}




\title{
The Effect of Frozen Food to Health: A Case Study among Consumers in Kelantan
}

\author{
${ }^{*} \mathrm{~A}$ L Zul Ariff ${ }^{1}$ and M Nursalwani ${ }^{1}$
}

${ }^{1}$ Faculty of Agro Based Industry, University Malaysia Kelantan, Kampus Jeli, 17600 Jeli, Kelantan, Malaysia.

*zulariff@umk.edu.my

\begin{abstract}
The demand for frozen food shows an increasing growth as more people involved in workforce. Consumers prefer frozen food for various reasons as it is more convenient and offer health claims that fit consumers' preferences. However, some frozen food contains harmful ingredients that may affect consumers' health. Consumers hardly distinguish nutrient content, structure-function and health claims. Thus consumers' awareness towards health effect from frozen food is somewhat questionable. The study indicates that knowledge, attitude and practice have an impact toward the effect of frozen food towards health. Self-administered survey was conducted and 60 people in Kelantan randomly were asked to complete the questionnaire based on knowledge, attitude and practice towards the effect of frozen food to consumer health. The finding indicate that knowledge, attitude and practice have an impact toward the effect of frozen food to health. Awareness among consumers regarding health issue caused by frozen food should be a concern from government and media.
\end{abstract}




\title{
A Synthesis of Tree Retention Studies: A Systematic Review
}

\section{${ }^{*}$ K Hassan ${ }^{1}$, W S N W Mohamad ${ }^{1}$, M R M Nasir ${ }^{1}$, N D Mustapa $^{1}, \mathrm{R}$ Hasan $^{1}$ and S N Harun ${ }^{2}$}

${ }^{1}$ Faculty of Architecture and Ekistics, Universiti Malaysia Kelantan, 16300 Bachok, Kelantan, Malaysia.

${ }^{2}$ Faculty of Architecture, Planning and Surveying, Universiti Teknologi MARA, 40450 Shah Alam, Malaysia

*khalilah.h@umk.edu.my

\begin{abstract}
The demand for frozen food shows an increasing growth as more people involved in workforce. Consumers prefer frozen food for various reasons as it is more convenient and offer health claims that fit consumers' preferences. However, some frozen food contains harmful ingredients that may affect consumers' health. Consumers hardly distinguish nutrient content, structure-function and health claims. Thus consumers' awareness towards health effect from frozen food is somewhat questionable. The study indicates that knowledge, attitude and practice have an impact toward the effect of frozen food towards health. Self-administered survey was conducted and 60 people in Kelantan randomly were asked to complete the questionnaire based on knowledge, attitude and practice towards the effect of frozen food to consumer health. The finding indicate that knowledge, attitude and practice have an impact toward the effect of frozen food to health. Awareness among consumers regarding health issue caused by frozen food should be a concern from government and media.
\end{abstract}




\title{
Participation of Youth in Integrated Crops of Corns and Tapioca in Kelantan: Pre-Test
}

\author{
${ }^{*}$ A L Zul Ariff ${ }^{1}$, M Nursalwani ${ }^{1}$ and A Mohammad Amizi ${ }^{1}$ \\ ${ }^{1}$ Faculty of Agro Based Industry, University Malaysia Kelantan, Kampus Jeli, 17600 \\ Jeli, Kelantan, Malaysia. \\ *zulariff@umk.edu.my
}

\begin{abstract}
This study is aimed to identify the level of effectiveness of cultivation of integrated crops of corns and tapioca in Kelantan beside to determine the participation of youth in integrated crops of corns and tapioca in Kelantan. A self-administered survey was conducted using a structured questionnaire to collect data from the survey respondents. 78 respondents were involved in this study. A random sampling technique was applied in collecting data. The data were then analyzed using SPSS version 21.0. The descriptive analysis was used to analyses the information gathered from the questionnaires. The results illustrate that respondents have high level of effectiveness of cultivation of integrated crops of corns and tapioca in Kelantan. The findings also revealed that respondents participate in cultivation of integrated crops of corns and tapioca in Kelantan because they want to generate their second income sources and to become entrepreneurs.
\end{abstract}




\title{
Malaysian Public University Students' Challenging Skills to Pass Malaysian University English Test (MUET)
}

\author{
M Z M Bosro1, *H Harun', S T Palpanadan'1, M Y \\ Ibrahim ${ }^{1}$, N A Mohd Sohaimi ${ }^{1}$ and N A Abdul Latif \\ Jannaton ${ }^{1}$
}

${ }^{1}$ Universiti Tun Hussein Onn Malaysia, 86400 Parit Raja, Johor, Malaysia.

*hairuddin@uthm.edu.my

\begin{abstract}
The Malaysian University English Test (MUET) was introduced in 1999 to bridge the gap between secondary and tertiary English language needs, primarily in English language competency. MUET examination consists of four language skills and some of the skills become a great challenge for students to pass. Apparently, it is compulsory for students to pass MUET examination with at least Band 3 before entering tertiary education system. However, many students were found to struggle with this requirement. Thus, this study aimed to investigate the most challenging skill that affects the students to obtain the minimum requirement. The study employed probability sampling method involving undergraduates from Faculty of Technical and Vocational Education (FPTV), Universiti Tun Hussein Onn Malaysia (UTHM), Johor. Data was collected from 500 students whose did not achieve Band 3 score from their previous MUET examination through an online questionnaire where 217 of them responded. Based on the frequency and percentage of the data analysis, 180 students $(83 \%)$ of the population were very weak in speaking skills followed by 150 students who were weak in writing skills. However, 109 students were good in reading skills but there were 100 out of 217 students who were weak in listening skills. Thus, speaking skill was found to be the main challenge of MUET examination followed by writing skills. Meanwhile, listening skill is the third most difficult skill and followed by reading skill at the last place for MUET examination among UTHM students. Based on the findings, sufficient effort must be taken by the educational system to improve the speaking skills competency of the students. In fact, it is relevant to investigate in detail the way English language proficiency could help the Malaysian students during their tertiary education.
\end{abstract}




\title{
Employability skills: what employers need?
}

\author{
*Khairul Azhar Mat Daud', Nik Zulkarnaen Khidzir', \\ Balakrishnan Parasuraman², Ena Bhattacharyya ${ }^{3}$, K.S. \\ Savita $^{4}$, Pasupuleti Visweswara Rao ${ }^{5}$, Jayaraj Vijaya \\ Kumaran $^{6}$, Nik Muhammad Sabri Nik Hassan ${ }^{1}$, and \\ Rahimah Aris $^{3}$
}

${ }^{1}$ Faculty of Creative Technology and Heritage, Creative, Universiti Malaysia Kelantan, Malaysia

${ }^{2}$ Faculty of Entrepreneurship and Business, Universiti Malaysia Kelantan, Malaysia

${ }^{3}$ Management Humanities Department, Universiti Teknologi PETRONAS, Malaysia

${ }^{4}$ Computer and Information Sciences Department, Universiti Teknologi PETRONAS, Malaysia

${ }^{5}$ Faculty Of Medicine And Health Science, Universiti Malaysia Sabah, Malaysia ${ }^{6}$ Faculty of Earth Science, Universiti Malaysia Kelantan, Malaysia

*azhar.md@umk.edu.my

\begin{abstract}
This paper will be discussed critically according on the need of employers on graduates employability skills. The emerging of new digital technologies tremendously leads a new way to doing a job. To cope with a need of client almost all jobs in all sectors looking for a new skills to retrain and reskilling their employees. Employers also seeking a fresh graduates whose are meets with their requirement. In current issues, almost all higher education providers doing a research and still explored a particular skills are need to provide to their students, which is meets with employers need. This paper will explain specifically about what are employers needed on graduate employability skills. This is preliminary research to looking a specific skill are very crucial and needed by the employers currently. Sixteen (16) related to employers' perception toward trait of employability skills in digital era being analysis. According to this analysis, have four main skills are need by an employers, there are [1] basic academic skills, [2] high order thinking skills, [3] technical skills and, [4] employability skills. Through literature review analysis from this study, it's found 29 attributes must be concentrates to gains employability skills among graduates at higher education institutions. Communication skills is a first priority are concern by employers when they looking a new workers. The second employability skill preferred by employers is problem solving skills and the third priority is critical thinking skills. By validating the construct of employability skills, this study is aimed at providing a general guide to researchers and scholars who would like to embark on similar employability skills studies. The findings also aim provides the holistic view of current trend of global employability skills needed by the graduates which match with the requirement of the industries. Thus, it will minimize the gap between employability skills offered by graduates and the required skills expected by employers in industry.
\end{abstract}




\title{
Investigation of chemical analysis and physical properties of bio-polymer waste banana peel fibre composites.
}

\author{
${ }^{\star}$ Nik Alnur Auli Nik Yusuf ${ }^{1}$ and Mahani binti Yusoff ${ }^{1}$ \\ ${ }^{1}$ Faculty Bio-engineering and Technology (FBKT), University Malaysia Kelantan \\ (UMK), UMK Jeli Campus, 17600, Jeli, Kelantan. \\ *alnurauli@umk.edu.my
}

\begin{abstract}
The present work has investigate the conversion of waste banana peel fiber (WBP) a raw a material in the form of food industry wastes into value added bio-polymer which can be replaced synthetic plastics. WBP represent around $85 \%$ of the total byproducts generated from the brewing industry and is available in large quantities throughout the year; however its primary application has been limited to animal feed. Despite this, due to its chemical composition, it has value as lignocellulosic rich material. In this paper, raw WBP has undergone physical and chemical characterisation to determine the composition analysis of extractives, cellulose and lignocellulose of WBP. WBP fiber contains a high moisture content (approx. 75 wt. \%). Then, it will be process into form of composite by added of variety glycerol content $(0,10,20,30$ and 40 grams) mixed on a dry weight basis of WBP. The solution was premixed and then heated from room temperature to $80 \mathrm{oC}$, where it was maintained for $1 \mathrm{~h}$ while being constantly mixing. The solution was then allowed to cool at $40 \mathrm{oC}$, and then, the glycerol was added to the gelatinized suspension. The suspension was then vigorously mixing for 45 min. The mixed suspensions were immediately poured onto a aluminium-nylon mesh mold to form a composite thin film. The films were then pressed with heat press machine at $1200 \mathrm{C}$ for 5 minutes. The composites will dried for $24 \mathrm{~h}$ in an ambient room temperature in dessicator at about $37 \mathrm{oC}$ until they reached a constant weight. The thickness of the films was controlled by the addition of the same weight of suspension into a dish of same size. The finial thickness of the film was about $0.20 \mathrm{~mm}$. This research were focus on the chemical analysis of WBP fiber where it can determine the extractives, halocellulose, lignin and $\alpha$-cellulose. Then, the WBP fiber composite film were tested for physical properties analysis which were the thickness and density, moisture content, water solubility, water absorption and thickness swelling, porosity and contact angle (CA). This work shows that glycerol can strongly affect the functional properties of WBP fiber based composite.
\end{abstract}




\title{
Social Engineering (SoE) Attacks Towards Network Security in Higher Learning Institute: The Partial Least Squares Path Modeling Approach
}

\author{
${ }^{*}$ Nik Zulkarnaen Khidzir ${ }^{1}$,Shekh Abdullah-Al-Musa \\ Ahmed2, Tan Tse Guan ${ }^{1}$ and Khairul Azhar Mat Daud ${ }^{1}$ \\ ${ }^{1}$ Faculty of Creative Technology and Heritage, University Malaysia Kelantan, \\ Malaysia
}

\begin{abstract}
The basic network security issues have changed very little over the past decade. Protecting the confidential institutional information, preventing unauthorized access defending the network against SoE attacks remain primary concerns of network security professional toady. Widespread remote access by the high number of increasing sophisticated SoE attacks is making network security significantly more challenging in the institute . Confidential information can reside in two states on a network. It can reside on institutional physical storage media, such as a hard drive or memory, or it can reside in transit across the physical network wire in the form of packets. These two information states present multiple opportunities for SoE attacks from users in higher leaning institute internal network, as well as those users on the internet. Given the dramatic rise in external security threats, couples with the rising cost of network intrusions. Institution are more pressured than ever to define and protect their network perimeter. There is no choice for the institute but to keep abreast of large number of security issues confronting in today's world.
\end{abstract}




\title{
The Designing and Development of Gendang Kecapi as Bamboo-Based Musical Instruments on Eco-Tourism Activities
}

\author{
*Mohd Aswawi Isa1, Khairul Azhar Mat Daud', Mohd \\ Hilmi Harun ${ }^{1}$, Wan Mohd Faizal Wan Ishak², Shaipuddin \\ Muhammad ${ }^{1}$, Muhammad Hawari Berahim ${ }^{1}$, Ros Dalilah \\ Abd Ghani ${ }^{3}$, Siti Nur Anis Muhammad Apandi ${ }^{1}$, Sudirman \\ Kiffli ${ }^{1}$ and Farrah Atikah Saari ${ }^{1}$
}

${ }^{1}$ Faculty of Creative Technology and Heritages, University Malaysia Kelantan, Lock Beg No 1, 16300 Bachok, Kelantan, Malaysia.

${ }^{2}$ Faculty of Bio Engineering \& Technology, University Malaysia Kelantan Jeli Campus, Jeli, Kelantan.

${ }^{3}$ Centre of Language Studies \& Generic Developmen, University Malaysia Kelantan Lock Beg No 1, 16300 Bachok, Kelantan, Malaysia.

*aswawi@umk.edu.my

\begin{abstract}
This paper was developed to reveal the finding of studies related to musical heritage of Malay-based bamboo. The study was conducted in several districts in the state of Kelantan such as Tanah Merah, Pasir Puteh and Pasir Mas. The data was obtained via a series of interview with a bamboo traditional musician. The finding shows that there are several types of bamboo-based musical instruments that are almost extinct in Kelantan. Among the musical instruments are the gendang kecapi, the serunai, Kertok Buluh, the instrument music can duplicate voice kijang, burung wakwak, rusa, burung sitar, napoh or kancil and ayam hutan. All of these musical instruments are almost extinct and are no longer recognized by a new generation. From this study, the findings also show that the development of bamboo-based musical instruments has high potential to stimulate the growth of eco-tourism activities in Malaysia. In this regard, this paper will explore and reveal the findings of this study so that bamboo-based musical instrument will be known to all future generations. It's also can be used as one of the most exciting eco-tourism activities through organizing workshop to making bamboo-based musical instruments.
\end{abstract}




\title{
Differences in the Types of Kelingkan Shawls in Malaysia
}

\author{
*Norhasliyana Hazlin Zainal Amri ${ }^{1}$ and Hamdzun Haron² \\ ${ }^{1}$ Universiti Malaysia Kelantan, Kampus Bachok, Beg berkunci No. 01, 16300 Bachok, \\ Kelantan,Malaysia \\ ${ }^{2}$ Pusat Citra Universiti, Universiti Kebangsaan Malaysia, 43600 UKM Bangi, Selangor \\ Darul Ehsan,Malaysia \\ *hazlin.za@umk.edu.my
}

\begin{abstract}
The art of kelingkan embroidery is a valuable traditional heritage for women. Kelingkan shawls are still worn in the community during important ceremonies, especially weddings. This heritage is a Malay handicraft that is pioneered by women and kelingkan is still made on a small scale in the states of Sarawak, Selangor, and Kelantan. Understanding regarding the types of kelingkan shawls is important for the community, especially those who are kelingkan shawl enthusiasts, so that this form of traditional kelingkan shawl will endure, though some changes have occurred in the creation of kelingkan due to modernization. To conclude this problem, two questions have emerged - What are the types of kelingkan shawls in Malaysia and What are the differences between traditional and modern kelingkan shawls? This study applies the descriptive qualitative approach through fieldwork such as observations, collection studies in Malaysia, specifically the Malay Peninsula in Kuala Lumpur, Selangor, Kelantan and Terengganu, as well as in Kuching, Sarawak, where interviews were held with embroiderers and library research was conducted. As a result, this study has found that traditional kelingkan shawls can be divided into two types, namely square or rectangular ones, using silver or gold kelingkan thread. Meanwhile, modern kelingkan shawls can be divided into 3 types - square, rectangle and triangle, which all still use silver and gold kelingkan thread, as well as colorful metal strips. The implications of this study is that it can provide knowledge and understanding to the community, especially those who are interested in or are studying kelingkan shawls in Malaysia. It will encourage them to know more about the changes that are happening to Malay artistic heritage and how it can be sustained in Malaysia.
\end{abstract}




\title{
Rhetorical Manifestation through the Language of Visuals during Japanese Occupation in Malaya
}

\author{
*Sharulnizam Ramli ${ }^{1}$ and Saiful Akram Che Cob² \\ ${ }^{1}$ Faculty of Creative Technology and Heritage, Universiti Malaysia Kelantan, Malaysia \\ ${ }^{2}$ Faculty of Art \& Design, Universiti Teknologi Mara, Malaysia \\ *sharulnizam@umk.edu.my
}

\begin{abstract}
The writing was aimed at researching and analyzing the rhetoric of image visualization which was found in the Japanese occupation period in Malaya from 1942 until 1945. Visual has its own role and appeal in delivering the message through the charm of dramatic images, radical and full of rhetoric. The rhetoric visual during Japanese occupation was tracked in newspapers, magazines, books, posters and disseminated at general locations such as government buildings, villages, mosques, schools and community-focused areas throughout Malaya. The Malays were the majority race in Malaya and the least accepted the effect of cruelty, stress, terrorism by the Japanese regime. Images that have been identical to the Malay race in the rhetoric visual can be detected on the aspect of clothing, social activities, Islamic institutions and religious, cultural and literature. Therefore, all these scenario in terms of rational was far from real. The language of visual with rhetorical and metaphor message by Japanese authority has become one of the strongest medium of communication in that era. This is how Nippon in Malaya change local mind set especially Malays from resistance to support.
\end{abstract}




\title{
Verification of Nonlinear State Observer System for RazakSAT using Extended Kalman Filter
}

\section{${ }^{*} \mathrm{H}$ Nor Hazadura ${ }^{1}$, J Ahmad Kadri ${ }^{1}, \mathrm{H}$ Mohd Zamri² and T Vilcherd ${ }^{3}$}

${ }^{1}$ Institute of Engineering Mathematics, Universiti Malaysia Perlis, Kampus Tetap Pauh Putra, 02600 Arau, Perlis, Malaysia.

${ }^{2}$ School of Engineering Technology, Universiti Malaysia Perlis, Kampus UniCITI Alam, Sungai Chuchuh, 02100 Padang Besar, Perlis, Malaysia.

${ }^{3}$ School of Mechatronic Engineering, Universiti Malaysia Perlis, Kampus Tetap Pauh Putra, 02600 Arau, Perlis, Malaysia.

*hazadura@unimap.edu.my

\begin{abstract}
This paper verifies an observer system of satellite attitude estimation via Extended Kalman Filter. This work can contribute as a backup or an alternative system during unavailable sensor measurements due to malfunction sensor or for cost reduction by reducing the number of sensors for future mission. In this work, the observability test for any possible combination of output measurements is carried out using Lie derivative technique. Then, verification of the observer system is performed through full state observer by using real in-flight telemetry data of RazakSAT.
\end{abstract}




\title{
Potential Impacts in the Conservation of Old Shophouse towards its Heritage Values
}

\section{${ }^{*}$ Farrah Atikah Saari', Mohammad Rusdi Mohd Nasir², Sahrudin Mohamed Som ${ }^{1}$, Ayub Awang ${ }^{2}$, Sudirman Kiffli ${ }^{1}$ and Izati Nabila Marzuki ${ }^{1}$}

${ }^{1}$ Fakulti Teknologi Kreatif dan Warisan, Universiti Malaysia Kelantan 16300 Bachok, Kelantan, Malaysia

${ }^{2}$ Fakulti Senibina Dan Ekistik, Universiti Malaysia Kelantan 16300 Bachok, Kelantan, Malaysia

*atikah.s@umk.edu.my

\begin{abstract}
Efforts in conserving the architectural inheritance of old shophouses are quite challenging due to the condition and age of the buildings nowdays. In Kota Bharu, there are many old shophouse structures and buildings that are left unattended even though the city is still recognized for its unique cultural values. The factors that led to the negligence of these old shophouses are due to the financial problem, lack of awareness in the importance of heritage conservation, decreasing rate in business prospect, no continuity in heritage ownership and business operation. This situation leads to failure in conserving these buildings where some of the old shophouses started to collapse. Thus, this study aims to identify the unique characteristics in the architectural designs and heritage of the old shophouses for the conservational purpose as well as acknowledging the significance of its heritage values. This is a qualitative research that employs structured observation and structured interview methods. The outcomes from the observation method found that the shophouse buildings in Kota Bharu still exhibit its unique design in architectural heritage and the modifications are still minimum. Meanwhile, the research outcomes from the interview method stated a higher percentage of respondents who agree on the significance and importance of the old shophouse's architectural structure conservation effort. Therefore, the old shophouses have a high potential to be conserved due to their contribution to heritage values. As the outcome, this research could provide an opportunity to the authorized bodies to see its potential to be recognized as a gazetted city or heritage site as well as improving the Cultural Zone area, Kota Bharu.
\end{abstract}




\title{
Developing A Framework of Edible Garden Concept for Horticultural Therapy for The Elderly People
}

\author{
*M S A Sham¹, M R M Nasir ${ }^{1}$, W S N W Mohamad"1, K \\ Hassan ${ }^{1}$, M A M J Noordin ${ }^{1}$ and R Hassan²
}

${ }^{1}$ Faculty of Architecture and Ekistics, Universiti Malaysia Kelantan, Kampus Bachok, 16300 Bachok, Kelantan, Malaysia.

${ }^{2}$ Klinik Kesihatan Kuala Besut, Jln Melawi - Semerak, Kampung Pachakan, 22300

Besut, Terengganu

*mohdsyazsham@gmail.com

\begin{abstract}
Nowadays horticulture therapy become worldwide practice and have been identified that it is a successful treatment mostly towards all types of abilities and ages where have been practices within the various type of institutional. Edible landscaping also puts forward a productive landscaping option as this type of landscape integrates food-producing plant selection to be applied to conventional landscape designs. The purpose of this research is to investigate the effects of horticultural therapy on the psychological, physical, cognitive function, and quality of life among elderly in Pusat Aktiviti Warga Emas (PAWE) Kemumin, Kelantan. A new landscape plan for the green space at Pusat Aktiviti Warga Emas (PAWE) Kemumin is designed which is aimed at having beneficial effects towards elderly people especially on the scope of horticultural therapy through edible garden concept. Besides, the site study is analyzed by carrying out the checklist through the elements of horticultural therapy in the edible garden which are classified into three main topics including physical attributes, biological attributes, and also social attributes indirectly, those findings are considered and also being incorporated in the landscape project proposal. The main idea of the project is to developing and design a regular feeling in the essential area of the garden which indirectly is an alternative for spare time prevails, the therapy processes within nature, and also to gain the memories of the elderly people's lives. New master planning of edible garden for horticultural therapy towards the Pusat Aktiviti Warga Emas (PAWE) Kemumin being produced in a way to achieve the main point that being carry on from the aims and objectives of the study. Other than that, the layout of the garden created in a clear and simple layout, also visible and clear view while, the design eases the disorientation and creates a series of activities that can boost the senses which the users can experience at the center of PAWE.
\end{abstract}




\title{
Influence of Hate Speech Messages on Voters' Choice of Candidate in Kwara State 2019 Gubernatorial Election
}

\author{
*Sholola Yusuf Ajani ${ }^{1}$, Ahmed Kamaldeen Arikewuyo ${ }^{1}$ \\ Azeez Adesina Lukuman², Adisa Rasaq Muhammad², \\ Omoloso Aisha Imam², Ahmad Fahmi Mahamood³, Abdul \\ Rahman Abdul Manaf ${ }^{3}$, Junainor Hassan ${ }^{3}$ \\ ${ }^{1}$ Department of Mass Communication, Summit University, Irra Road, P.M.B 4412,Offa, \\ Kwara State, Nigeria \\ ${ }^{2}$ Department of Mass Communication, University of Ilorin, 240003 Ilorin, Nigeria \\ ${ }^{3}$ School of Human Development \& Technocommunication, Universiti Malaysia \\ Perlis,02600 Arau Perlis,Malaysia \\ *yushofficial@gmail.com
}

\begin{abstract}
The Nigerian and some Asia country's media landscape over the years has projected numerous political campaigns that are hate speeches directed at the perceived opposition candidates and political party. This study examined the influence of hate speech messages on voters' choice of candidate in Kwara State, Nigeria in 2019 GE and was anchored on the agenda-setting theory. The study used a survey research design with a single cross-sectional research method. The study generated 464,393 registered voters as the study population. Using cluster sampling and purposive respectively to select 400 samples. The study, therefore, discovered that social media is the most channel of exposure by respondents on hate speech messages during the 2019 gubernatorial election in Kwara State with 66\%. The study also found that the use of hate speech undermines the importance of political candidates with $72 \%$ in any given election. The study further discovered that the use of hate speech during elections influenced the voters by making them change from one candidate to the other with $82 \%$ thereby encouraging more votes against the opposition party. The implication of these findings has a strong influence on the way electorates undermine the importance of political issues and as such rendered political candidates and parties irrelevant with a critical effect on the credibility, fairness, and smooth running of any political landscape and the conduct of Nigerian elections in general. The paper proposes critical political education to electorates on voting behavior to promote good governance.
\end{abstract}




\title{
Horticulture Therapy Through Edible Garden Project
}

\author{
*M R M Nasir ${ }^{1}$, I H Salleh², M S A Sham¹, W S N W \\ Mohamad $^{1}$, K Hassan ${ }^{1}$ and $\mathrm{R}$ Hassan $^{3}$
}

\begin{abstract}
${ }^{1}$ Faculty of Architecture and Ekistics, Universiti Malaysia Kelantan, Kampus Bachok, 16300 Bachok, Kelantan, Malaysia.

${ }^{2}$ Faculty of Architecture, Planning \& Surveying, UiTM Cawangan Perak, Kampus Seri Iskandar, 32610 Seri Iskandar, Perak, Malaysia

${ }^{3}$ Klinik Kesihatan Kuala Besut, JIn Melawi - Semerak, Kampung Pachakan, 22300
\end{abstract}

Besut, Terengganu

*rusdi.mn@umk.edu.my

\begin{abstract}
The Edible Garden Project is a special group innovation project designed for the patients at Klinik Kesihatan Tanjung Malim (KKTM) under the Psychosocial Rehabilitation Program (PSR) especially individuals with mental health problems, elderly and disabled. The project can be looked as a module and useful alternative therapy for PSR in order to speed up the recovery process, including self-expression, sensory stimulation, social interaction as well as practicing fine and gross motor skills along with eye-hand coordination. In addition, this project will also aim to develop the potential for KKTM as a reference hub in innovation therapy as well as being a recreational or social activities related to the surrounding community. The program is based on the involvement of community volunteers consisting of lectures and students, employees and patients undergoing treatment in KKTM along with an expert from the Malaysian Agricultural Research and Development Institute (MARDI) to share and disseminate knowledge on edible garden and their innovation on therapeutic benefits. The main emphasis of the project was given to the development of an attractive and well-planned edible garden design as well as to promote horticulture therapy benefits with the selection of plant species through short-term crop rotation between one to six months. Overall, the program seeks to create a community agent of transformation towards a more dynamic and quality in line with the objectives outlined in 3Qs Perak Amanjaya.
\end{abstract}




\title{
Needs Assessment for The Development of Competency Heating Ventilation and Air Conditioning (HVAC) Supervisor and Technician in Oil and Gas Industry Malaysia
}

\author{
*M.M. Syafiq Syazwan ${ }^{1}$, Fatimah Yusop ${ }^{1}$, Mohd Bekri \\ Rahim $^{2}$, Kamarul Aini Mohd Sari ${ }^{1}$, Nurdalila Saji ${ }^{1}$ and \\ Norshuhaila Mohamed Sunar ${ }^{1}$
}

${ }^{1}$ Faculty of Engineering Technology, University Tun Hussein Onn,84600 Pagoh, Muar, Johor, Malaysia

${ }^{2}$ Faculty of Technical and Vocational Education, University Tun Hussein Onn, 86400 Parit Raja, Batu Pahat, Johor, Malaysia

*mohdsyafiq@uthm.edu.my

\begin{abstract}
Lack of study towards support services in oil and gas (O\&G) industry triggered to understanding the heating, ventilating and airconditioning (HVAC) maintenance and competency of executor personnel in this particular area. HVAC system provide comfort for occupants at offshore platform and onshore plant and serve suitable ambient temperature for the critical rooms that are equipped with sensitive electrical equipment. This study discussed the finding of needs assessment which has been conducted to identify the perception for development of competency in HVAC maintenance for supervisor and technician in O\&G industry. HVAC system and maintenance also have been described to understanding the HVAC system in O\&G. Online survey questionnaire have been used as instrument and 58 respondents were involved in this study. Mean score was obtained for every question text in the questionnaire. Descriptive survey classified in three categories and the results show all categories very high agreed based on mean score interpretation. The authors add several insights for future studies based on the result obtained from needs assessment.
\end{abstract}




\title{
Conservation of Historic Buildings in Kota Bharu, Kelantan: A Preliminary Review of Adaptive Reuse Approach
}

\author{
*Daeng Haliza Daeng Jamal', Nasirin Abdillah, \\ Sahrudin Mohamed Som ${ }^{1}$ \\ and Norazlinda Mohamed Rosdi ${ }^{1}$
}

${ }^{1}$ Department of Heritage Studies, Faculty of Creative Technology \& Heritage Universiti Malaysia Kelantan, Malaysia.

*haliza.j@umk.edu.my

\begin{abstract}
Acceptance of modern design and architecture is potentially seen contributing to the redevelopment of towns or cities. This may have resulted in the negligence of historic buildings in these places. Among methods or approaches in conserving and preserving historic buildings against disastrous threats and modernisation is through adaptive reusing of the buildings, or better known as the adaptive reuse approach. It is commonly known that many historic buildings conserved are reused or turned into museums, business premises, offices, restaurants, hotels, boarding houses and other public amenities. In Malaysia, this approach has been applied in various cities and towns, including Kota Bharu, Kelantan. This type of application, however, needs to be comprehensively understood by all parties involved so as to achieve the objectives of conservation. This study aims at surveying and reviewing several historic buildings that have been reused in Kota Bharu, Kelantan. In addition, this paper will also discuss the involvement of local authorities in the conservation and preservation of historic buildings in Kota Bharu, Kelantan. The research methods employed in the data collection of this study are the library research and a fieldwork involving observations. It is found in this study that several historic buildings in Kota Bharu, Kelantan have been reused with new functions. Another finding also discovers that the restored historic buildings are mainly located in the city centre of Kota Bharu and they have become tourist attractions. In this context, the adaptive reuse approach seems to have helped sustain the heritage of historic buildings in Kota Bharu. It can be concluded that there have been comprehensive efforts by the local authorities in conserving and 'resurrecting' the historic buildings through their new functions.
\end{abstract}




\title{
Effects Of Roadside Tree Species On Malaysıa Driver's Emotions Associated With Vehıcle Crashes
}

\section{${ }^{*} \mathrm{R}$ Hasan $^{1}$, W S N W Mohamad ${ }^{1}, \mathrm{~K} \mathrm{Hassan}^{1}, \mathrm{~N} \mathrm{Ramlee}^{1}$ and F C Sulaiman²}

\author{
${ }^{1}$ Department of Landscape Architecture, Universiti Malaysia Kelantan, Kampus \\ Bachok, 16300 Bachok, Kelantan, Malaysia. \\ ${ }^{2}$ Centre of Studies for Park and Amenity Management, Faculty of Architecture, \\ Planning \& Surveying, Universiti Teknologi MARA, 40450 Selangor, Malaysia
}

*ramly.h@.umk.edu.my

\begin{abstract}
This research aims to study the effects of roadside tree species selection on driver's emotions. The research objectives of this paper are (i) to determine the driver's emotions when passing through the roadside tree species (ii) To examine the relationship between roadside tree species and the driver's emotions. This research used a mixed-method using survey and interviews. Interviews were conducted in a public place such as at rest stops and restaurant around the side of the highway. A set of questionnaires including demographic background and illustration of seven tree shapes along the roadside shown for reference. Ten positive and negative drivers' emotions have been identified and described by the respondents when passing through the road that has different types of trees shapes. Columnar shape tree indicated the first rank for the suggestions of roadside trees species. Parameter joy displayed a very strong relationship that was statistically very high positive correlation with conical shape trees (tau- $b=0.89<0.01)$. The research expanded the present body of knowledge in the area of the selection of appropriate roadside tree species in urban areas and taking into account the drivers' emotional factors.
\end{abstract}




\title{
Students' Feedback on Learning Skills to Enhance MUET Results
}

\author{
N.A Mohd.Sohaimi ${ }^{1},{ }^{*} \mathrm{H}$ Harun${ }^{1}$, S. T Palpanadan${ }^{1}$, M Z M \\ Bosro', \\ M Y Ibrahim ${ }^{1}$ and N A Abdul Latif Jannaton ${ }^{1}$
}

${ }^{1}$ Universiti Tun Hussein Onn Malaysia, Parit Raja, 86400 Batu Pahat, Johor, Malaysia

*hairuddin@uthm.edu.my

\begin{abstract}
The Ministry of Education has initiated an official directive for every student to sit for the Malaysian University English Test (MUET) as a way to ensure they meet the minimum level set for their language proficiency in English. Similarly, at University of Tun Hussein Onn Malaysia (UTHM), the method of using the results of MUET would be used as a measure of student competence, admission requirements as well as placement in various academic programs. Thus, this study was conducted to identify the most suitable approaches to improve the performance in MUET based on the university students' feedback for the related skill. This research employed quantitative method involving undergraduates from the Faculty of Technical and Vocational Education (FPTV), UTHM, Johor. 217 students answered the questionnaire and gave opinion through an online questionnaire. The data analysis showed that the majority of respondents chose the speaking component with a frequency of $30 \%$ as the most difficult components of MUET followed by reading component with a percentage of $25 \%$. Meanwhile, the writing and listening components recorded a frequency of $25 \%$ and $21 \%$ respectively. The paper also presented the suggestions provided by the respondents where they were very positive to improve their learning in English especially in speaking. The findings could help the FPTV students at UTHM enhance scores and obtain a better result in MUET in the future.
\end{abstract}




\title{
Edge Decorative Motif (Kok): Kelingkan Embroidery of Kelantan
}

\section{*Norhasliyana Hazlin Zainal Amri ${ }^{1}$, Azwady Mustapha ${ }^{2}$, Hanisa Hassan ${ }^{3}$ and Hamdzun Haron ${ }^{4}$}

\author{
${ }^{1}$ Universiti Malaysia Kelantan, Kampus Bachok, Beg berkunci No. 01, 16300 Bachok, \\ Kelantan, Malaysia \\ ${ }^{2}$ Universiti Malaysia Kelantan, Kampus Bachok, Beg berkunci No. 01, 16300 Bachok, \\ Kelantan, Malaysia \\ ${ }^{3}$ Pusat Citra Universiti, Universiti Kebangsaan Malaysia, 43600 UKM Bangi, Selangor \\ Darul Ehsan, Malaysia \\ *hazlin.za@umk.edu.my
}

\begin{abstract}
Kelingkan is an art of embroidery using metal ribbon threads coated with gold, silver embroidered on a soft fabric surface. Kelingkan requires high precision and uses the expertise of embroiders. Recall this is the handcraft led by Malay women for a long time in nature, namely Malays in Sarawak, Kelantan and Selangor. Each of these states has a different design motif identity and reflects its own state and identity through the use of flora and fauna motifs. In Kelantan, the art of embroidery is still done on a small scale although it is less well known Sarawak and Selangor but the market demand still continues due to the uniqueness of the edge decoration (kok) different between the states that are active in Kelingkan embroidery. The question is what is the origin of Kelantan embroidery and how is the decorative motif (kok) depicted in Kelantan embroidery? To answer this question, a qualitative study was conducted through field study methods, Such as observation of dry embroidery artifacts and interviews with embroidery markers. The study found that a history of embroidery kelingkan in Malaysia evolved since the existence of the trading system in Malaya. Only three states Sarawak, Selangor and Kelantan still have embroiders that are actively conducing it. The development of kelingkan embroidery in Malaysia started in the palace and developed through hereditary family relationships and incubator program while there are two side decorative motifs (kok) depicted in Kelantan kelingkan embroidery, namely 3 points and 5 points or also known as etok is shell. In conclusion, the results of this study should be seen as a continuing source for the Malay community art treasures to be preserved and maintained at the younger generation so that no time wasted. Through this study, kelingkan embroidery can also explain the variety of kelingkan available in Malaysia, Kelantan, Selangor and Sarawak which are still actively doing this embroidery in textile and clothing.
\end{abstract}




\title{
English Lecturers' Self-Efficacy Beliefs in Open and Distance Learning (ODL): Substantive Implications
}

\author{
*A A A Aziz'1, N A Norwahi², N A Nordin², N Zaini², S \\ Shaidin 1 , S B H J Azhar ${ }^{2}$ and A A Aziz ${ }^{1}$ \\ ${ }^{1}$ Akademi Pengajian Bahasa, Universiti Teknologi MARA, UiTM Melaka Kampus Alor \\ Gajah, 78000 Alor Gajah, Melaka, Malaysia. \\ ${ }^{2}$ Akademi Pengajian Bahasa, Universiti Teknologi MARA, UiTM Melaka Kampus \\ Jasin, 77300 Merlimau, Melaka, Malaysia. \\ *ameirul@uitm.edu.my
}

\begin{abstract}
The enforcement of Movement Control Order (MCO) in Malaysia due to COVID-19 pandemic has affected the education sector where the teaching and learning process is instructed to practice open and online distance learning (ODL). The purpose of this qualitative case study is to explore the English language lecturers in one Malaysian public university describe their self-efficacy beliefs in ODL practice. Purposive sampling method was used to recruit prospective participants. Semi-structured interviews were used as the primary data collection method. The data gathered were then analysed using thematic data analysis. The results indicate that despite having the compulsory implementation of ODL within a short notice, the participants disclosed that their sense of self-efficacy beliefs varied depending on context-specific nature based on several domains including self-assurance, technological pedagogical content knowledge (TPCK), teaching preparation, intrinsic motivation and administration support. The present study also reveals that participants utilised emotion-driven selfefficacy beliefs to overcome ODL challenges and eventually developed socialemotional rewards for staying positive in ODL practices. It was also found that self-efficacy beliefs contributed to students' positive performance, and this has become a factor in heightening participants' self-efficacy beliefs. The results have provided enlightenment on participants' self-efficacy beliefs in ODL practices and offer recommendations for improvement in tertiary educational practices to bring positive impacts on teaching and learning.
\end{abstract}




\title{
Kinetic Study of Photocatalytic Degradation of Reactive Black 5
}

\author{
Nur 'Aliaa Razali and *Siti Amira Othman \\ ${ }^{1}$ Department of Physics and Chemistry, Universiti Tun Hussein Onn Malaysia, 84600 \\ Pagoh, Johor, Malaysia. \\ *sitiamira@uthm.edu.my
}

\begin{abstract}
The wastewater discharged from industries consist several of harmful chemicals. These chemicals will affect the water resource and it is necessary to maintaining the water quality. Photocatalysis is highly effective and economical process because it can complete the mineralization of the pollutants, only involving UV or solar light, and operate near room temperature have become the advantages of this process. Despites of all the advantages of this photocatalyst, titanium dioxide is capable to act as sensitizer for light which will reduce the redox process due to their electronic structure. The best part is that the titanium dioxide can be chemically activated by light, thus in the industry, self-cleaning for the building often used titanium dioxide which helps the cleaning process become easier. Nitrogen and magnesium will be used as dopants because doping of $\mathrm{TiO} 2$ generally found will enhance the photocatalytic activity of the catalyst. Hence, this study is significant in order to improve the present method of photocatalysis in treating the wastewater treatment. In effort to find the viable and reliable ways for wastewater treatment, it is necessary to conduct research and study on this issue.
\end{abstract}




\title{
Formulating Post-Pandemic Design Factors In Creating Safe Shopping Experience Within Retail Fashion Stores In Malaysia
}

\author{
*J Azri ${ }^{1}$ and B Azizi ${ }^{2}$ \\ ${ }^{1}$ School of Architecture and Ekistics, Universiti Malaysia Kelantan, 16310 Bachok, \\ Kelantan, Malaysia \\ ${ }^{2}$ School of Housing, Building and Planning Universiti Sains Malaysia,11800 USM, \\ Penang, Malaysia \\ *mohdazrijain89@gmail.com
}

\begin{abstract}
The physical fashion retail is one of the hardest-hit industries by the Covid-19 outbreak in 2020. As to recover, retailers need to seek alternative way to add shopping value to increase sales while following the government issued standard operating procedure (SOP). Available past international and Malaysia's retail studies had identified several customers-oriented on store environment attributes effect consumers behavior. However, until today there are no specific guidelines on the fashion retail stores environment context in Malaysia after the post-pandemic available. Therefore, the purpose of this study is to examine, discuss and established the influences of various postpandemic design factors towards provide safe fashion retail stores environment and to study their impact on customer's behavior. The study used a case study as part of its qualitative research methodology which employed observation and interviews, on a selected fashion retail store. The results revealed that these four groups of design factors; exterior, interior, ambient and health safety were important for retailers in creating unique and safe postpandemic shopping experiences the that induced the behavior intentions among customers included store choice and purchasing. However certain elements need to adjust to accommodate SOP health safety as stated by the government. These design elements were all connected to one another and supportive in creating a pleasant and safe environment shopping experience. Therefore, it was vital for retailers to give attention to these design elements to stay advantages in today's competitive market.
\end{abstract}




\title{
Learning about English Language Lecturers' Resilience: Identification of Stress and Coping Strategies of Open and Distance Learning (ODL)
}

\author{
A A A Aziz1, *S Shaidin', N Zaini², N A Nordin², N A \\ Wahi' ${ }^{2}$ S B H J Azhar', and A A Aziz
}

${ }^{1}$ Academy of Language Studies, Universiti Teknologi MARA, Kampus Alor Gajah, 78000 Alor Gajah, Melaka, Malaysia.

${ }^{2}$ Academy of Language Studies, Universiti Teknologi MARA, Kampus Jasin, Kampung Seri Mendapat, 77300 Merlimau, Melaka, Malaysia.

${ }^{3}$ Faculty of Computer Science and Mathematics, Universiti Teknologi MARA, Kampus Jasin, Kampung Seri Mendapat, 77300 Merlimau, Melaka, Malaysia.

*sumayyah@uitm.edu.my

\begin{abstract}
The physical fashion retail is one of the hardest-hit industries by the Covid19 outbreak in 2020. As to recover, retailers need to seek alternative way to add shopping value to increase sales while following the government issued standard operating procedure (SOP). Available past international and Malaysia's retail studies had identified several customers-oriented on store environment attributes effect consumers behavior. However, until today there are no specific guidelines on the fashion retail stores environment context in Malaysia after the post-pandemic available. Therefore, the purpose of this study is to examine, discuss and established the influences of various post-pandemic design factors towards provide safe fashion retail stores environment and to study their impact on customer's behavior. The study used a case study as part of its qualitative research methodology which employed observation and interviews, on a selected fashion retail store. The results revealed that these four groups of design factors; exterior, interior, ambient and health safety were important for retailers in creating unique and safe post-pandemic shopping experiences the that induced the behavior intentions among customers included store choice and purchasing. However certain elements need to adjust to accommodate SOP health safety as stated by the government. These design elements were all connected to one another and supportive in creating a pleasant and safe environment shopping experience. Therefore, it was vital for retailers to give attention to these design elements to stay advantages in today's competitive market.
\end{abstract}




\title{
Role of Design and Innovation to Enhance New Product Development among Malaysian Small and Medium
}

\author{
${ }^{*}$ M Y Nur Haizal ${ }^{1}$, I. Marzuki ${ }^{1}$ and A. Mohamad Hariri² \\ ${ }^{1}$ Faculty of Innovative Design and Technology, Universiti Sultan Zainal Abidin, \\ Kampus Gong Badak, 21300 Kuala Nerus, Terengganu, Malaysia \\ ${ }^{2}$ Majlis Rekabentuk Malaysia (MRM), Lot 5285, Lebuhraya Sungai Besi-Puchong, \\ 57000 Bukit Jalil, Malaysia \\ *haizal@unisza.edu.my
}

\begin{abstract}
The role of design and innovation through NPD process can be a good platform for Malaysian SMEs to enhance their competitiveness. However, less study has been conducted to examine how the process has been implemented by SMEs. NPD process requires a proper planning and commitment from the company. Managing the NPD proses by utilise design as a source of innovation will improve the quality of the product. But, many of the SMEs not utilise the potential of design and innovation as their sources to gain competitiveness. Therefore, there are gaps on how the process has been conducted by SMEs such as how they implementing, managing and who are the parties should be involved in the process. The objective of this paper is to explore the process of new product development conducted by small and medium manufacturing industries (SMEs) through design and innovation in creating added value to a product, based on an empirical study covering product, furniture, and automotive manufacturing industries in Malaysia. A mixed-method was applied consist of 450 respondents for questionnaire survey and 12 selected participants from different group\&\#39;s namely industrial designers, marketers, and decision- makers. The results reveal the positive effects of managing design and innovations in the industries are important to improve product value and to enhance company performance through product development processes.
\end{abstract}




\title{
Rediscovering Local 'third places' of Kota Bharu, Kelantan Malaysia: The Study of Kedai Pati
}

\author{
${ }^{*} \mathrm{~N} \mathrm{H}$ Anuar, Y Mohd Faudzi, N Md Alwi, S N A Mohd \\ Nasir, M R Mohd Nasir and M H K Mhd Zain
}

Faculty of Architecture \& Ekistics, Universiti Malaysia Kelantan, Kampus Bachok Kelantan, Malaysia..

*norhafizah@umk.edu.my

\begin{abstract}
This paper attempts to rediscover the temporalities of Kedai Pati and its unchanging relationship with the old city of Kota Bharu, Kelantan. Much of the existence of this locally renowned 'third place' interfaces between work and life due to its direct connection with urban development. Kedai pati ('pigeon stall') is said to be part of the locality in Kota Baru township for more than fifty years, providing a distinctive experience of nostalgia. Kedai Pati is perceived as a valuable space for the local working men to informally attend on the regular or irregularly. At present day, Kedai Pati still survives with its signature theatrical-service pantry operation, seller-buyer social setting, that is part of a unique ambience considered as Kelantan's cultural heritage. Mapping the remaining locations of the kedai pati around the urban settings of current Kota Bharu Town Centre will indicate the strategic foci of nodal gastronomic places for the public to have access to. Information derived from this work can be useful for future planning and development in both urban and rural Malaysian context.
\end{abstract}




\title{
Intelligent Fall Detection System using Traditional and Non-traditional Machine Learning Algorithm based on MQTT
}

\section{Y Cheong ${ }^{1},{ }^{*}$ C C Lim ${ }^{1,2}$, Y F Chong ${ }^{1,2}$ and V Vikneswaran ${ }^{1,2}$}

\begin{abstract}
${ }^{1}$ School of Mechatronic Engineering, Universiti Malaysia Perlis, Kampus Tetap Pauh Putra, 02600 Arau, Perlis, Malaysia.

${ }^{2}$ Sport Engineering Research Centre (SERC), Universiti Malaysia Perlis, Kampus Tetap Pauh Putra, 02600 Arau, Perlis, Malaysia.
\end{abstract}

*cclim@unimap.edu.my

\begin{abstract}
The population of elderly people exposed to the risk of fall increases each year as reported by World Health Organization (WHO). Fall detection system presented normally is high cost, large size and not efficient. Wearablebased sensor fall detection system developed in this project which were small size, portable and low-cost. The concept of Message Queuing Telemetry Transport (MQTT) applied in this fall detection system to ease the process of data transmission from motion sensor to Raspberry Pi for classification via Wi$\mathrm{Fi}$. A small size and lightweight microcontroller (Wemos D1 mini ESP 8266) integrated with MPU6050 motion sensor to sense and publish the motion data. Raspberry Pi 3 Model B applied to carry out classification of the motion data. Machine learning algorithms used for classification in comparison were kNearest Neighbors (k-NN) and Long Short-Term Memory (LSTM) of Recurrent Neural Network (RNN). LSTM achieved better result at $97 \%$ than k-NN at $94 \%$. Smartphone used to publish the notification via an application known as Blynk.
\end{abstract}




\title{
Twin Deep Convolutional Neural Network Approach for RGB-D Face Recognition
}

\section{*P Shunmugam 1 , K Kamarudin ${ }^{1,3}$, L M Kamarudin²,3, A Zakaria $^{1,3}$ and $\mathrm{H}$ Nishizaki ${ }^{4}$}

\begin{abstract}
${ }^{1}$ School of Mechatronic Engineering, Universiti Malaysia Perlis, Kampus Tetap Pauh Putra, 02600 Arau, Perlis, Malaysia.

${ }^{2}$ School of Computer Engineering, Universiti Malaysia Perlis, Kampus Tetap Pauh Putra, 02600 Arau, Perlis, Malaysia.

${ }^{3}$ Centre of Excellence for Advanced Sensor Technology (CEASTech), Universiti Malaysia Perlis, 01000 Kangar, Perlis, Malaysia.

${ }^{4}$ Graduate School of Medicine and Engineering, University of Yamanashi, 4 Chome-437 Takeda, Kofu, Yamanashi 400-8510, Japan.
\end{abstract}

*puvenes1994@gmail.com

\begin{abstract}
Two-dimensional face recognition has been researched for the past few decades. With the recent development of Deep Convolutional Neural Network (DCNN) deep learning approaches, two-dimensional face recognition had achieved impressive recognition accuracy rate. However, there are still some challenges such as pose variation, scene illumination, facial emotions, facial occlusions exist in the two-dimensional face recognition. This problem can be solved by adding the depth images as input as it provides valuable information to help model facial boundaries and understand the global facial layout and provide low-frequency patterns. RGB-D images are more robust compared to RGB images. Unfortunately, the lack of sufficient RGB-D face databases to train the DCNN are the main reason for this research to remain undiscovered. So, in this research, new RGB-D face database is constructed using the Intel RealSense D435 Depth Camera which has $1280 \times 720$-pixel depth. Twin DCNN streams are developed and trained on RGB images at one stream and Depth images at another stream, and finally combined the output through fusion soft-max layers. The proposed DCNN model shows an accuracy of $95 \%$ on a newly constructed RGB-D database.
\end{abstract}




\title{
Expansion of Heritage Mosques in Malaysia: Issues and Challenges
}

\author{
*Sahrudin bin Mohamed Som¹, Mohammad Rusdi bin \\ Mohd Nasir'2, Wan Saiful Nizam bin Wan Mohamad² and \\ Farrah Atikah binti Saari ${ }^{1}$
}
${ }^{1}$ Faculty of Creative Technology and Heritage, Universiti Malaysia Kelantan, 16300
Bachok, Kelantan, Malaysia.
${ }^{2}$ Faculty of Architecture and Ekistics, Universiti Malaysia Kelantan, 16300 Bachok, Kelantan, Malaysia.
*sahrudin.ms@umk.edu.my

\begin{abstract}
The expansion of the mosque is a common practice that aims to provide additional space for the increase in congregation members as well as to improve the facilities of the mosque. However, there are some issues and challenges that have to be faced in the expanding of heritage mosques. Some mosques in Malaysia have been designated as heritage sites and have been gazetted under the National Heritage Act 2005 (Act 645). Act 645 has stipulated that any new development including expansion must comply with certain conditions as a heritage site. Department of National Heritage (DNH) has provided guidelines related to new developments at heritage sites in the Heritage Building Conservation Guidelines 2017. Although guidelines have been made available, reports from $\mathrm{DNH}$ indicate that issues involving the expansion works of heritage mosques continue to arise. There is dissatisfaction among the community of heritage mosques over the restriction made by DNH upon their expansion proposal. While DNH sees the expansion as potentially affecting the heritage value of the mosque, in contrary the mosque community sees it as important in continuation of using it. The purpose of this study is to discuss the issues and challenges surrounding the problems in the expansion of heritage mosques in Malaysia. This is a library based study, follows qualitative approach by analysing laws and guidelines in Malaysia that govern heritage sites development. The study results found that the conflict of values involving various stakeholders on the heritage mosque, the absence of clear criteria in the existing guidelines and the absence of community involvement in the evaluation process are the factors in the issue of expanding heritage mosques in Malaysia.
\end{abstract}




\title{
Minimising Operational Costs during COVID- 19 Pandemic: Leveraging Crowdsourcing Business Model for Enhancing SMEs' Performance
}

\section{*Mohd Fitri Mansor ${ }^{1}$, Hasliza Abdul Halim², Noor Hazlina Ahmad², Noor Hidayah $\mathrm{Abu}^{3}$, and Khairun Nisa' Khairuddin ${ }^{1}$}

${ }^{1}$ Faculty Applied \& Human Sciences, Universiti Malaysia Perlis, 01000 Kangar, Perlis, Malaysia.

${ }^{2}$ School of Management, Universiti Sains Malaysia, 11800 USM, Penang, Malaysia.

${ }^{3}$ School of Technology Management and Logistics Universiti Utara Malaysia, 06010

Sintok, Kedah, Malaysia

*fitrimansor@unimap.edu.my

\begin{abstract}
Uncertain business environment particularly during COVID 19 outbreak forced many enterprises including Small and Medium Enterprises (SMEs) need to change the business model. This rampant situation creates 'rubbing salt into the wound' for many enterprises in order to survival and sustain in the market. Enterprises should alter the business strategy from the traditional way of running the business to the new phenomenon of business strategy i.e. crowdsourcing practices. In view of the above, the aim of this study is to investigate how the SMEs could minimise the operating costs in order to boost business performance mainly COVID 19 pandemic. Specifically, the objectives of this study are to examine the impacts of crowdsourcing practices, crowdsourcing cost reduction towards business performance for SMEs in Malaysia. The findings revealed that, the crowdsourcing practices and crowdsourcing cost reduction positively significantly to the SMEs in Malaysia in order to enhance the business performance. This study also highlights practical and theoretical contributions, significant of study; limitations and future study as well as conclude the entire study.
\end{abstract}




\title{
Mechanical and Electrical Performances of Different Silicone Rubber Content in Polyurethane Elastomer/Silicone Rubber/Graphene Nano-platelets Conductive Material
}

\author{
${ }^{*}$ C W Heng, P L Teh, N A Abdul Rahim and C K Yeoh \\ ${ }^{1}$ School of Material Engineering, University Malaysia Perlis, Kompleks Pusat \\ Pengajian Jejawi 2, Taman Muhibbah, 02600, Arau, Perlis, Malaysia.
}

*weiwei5501@gmail.com

\begin{abstract}
Immiscible polyurethane elastomer (PUE)/silicone rubber/graphene nano-platelets blend composites filled with different PUE/silicone rubber blend ratio were synthesised by using solution casting technique. In this work, two different types of silicone rubber: liquid silicone rubber (LSR) and powdered silicone rubber (PSR) were used as secondary matrix based on double percolation concept to construct an immiscible blend that has a balance electrical conductivity and mechanical properties. The electrical conductivity has increased gradually, but the mechanical properties of the composites shows a remarkable decline when silicone rubber loading increases up to 20 vol\% for both blend systems. The well balance of electrical conductivity and performance is achieved at $15 \mathrm{vol} . \%$ of silicone rubber loading. Overall, PUE/PSR/GnPs at 15 vol. \% of silicone rubber content has higher electrical conductivity and mechanical strength as compared to PUE/LSR/GnPs blend system.
\end{abstract}




\title{
A Review of Traditional and Deep Learning Approaches on RGB-D Face Recognition
}

\section{*P Shunmugam 1 , K Kamarudin ${ }^{1,3}$, L M Kamarudin²,3, A Zakaria $^{1,3}$ and A N Abdullah ${ }^{1,3}$}

\author{
${ }^{1}$ School of Mechatronic Engineering, Universiti Malaysia Perlis, Kampus Tetap Pauh \\ Putra, 02600 Arau, Perlis, Malaysia. \\ ${ }^{2}$ School of Computer Engineering, Universiti Malaysia Perlis, Kampus Tetap Pauh \\ Putra, 02600 Arau, Perlis, Malaysia. \\ ${ }^{3}$ Centre of Excellence for Advanced Sensor Technology (CEASTech), Universiti \\ Malaysia Perlis, 01000 Kangar, Perlis, Malaysia.
}

*puvenes1994@gmail.com

\begin{abstract}
Uncertain business environment particularly during COVID 19 outbreak forced many enterprises including Small and Medium Enterprises (SMEs) need to change the business model. This rampant situation creates 'rubbing salt into the wound' for many enterprises in order to survival and sustain in the market. Enterprises should alter the business strategy from the traditional way of running the business to the new phenomenon of business strategy i.e. crowdsourcing practices. In view of the above, the aim of this study is to investigate how the SMEs could minimise the operating costs in order to boost business performance mainly COVID 19 pandemic. Specifically, the objectives of this study are to examine the impacts of crowdsourcing practices, crowdsourcing cost reduction towards business performance for SMEs in Malaysia. The findings revealed that, the crowdsourcing practices and crowdsourcing cost reduction positively significantly to the SMEs in Malaysia in order to enhance the business performance. This study also highlights practical and theoretical contributions, significant of study; limitations and future study as well as conclude the entire study.
\end{abstract}




\title{
A Review on Malay Vernacular Architecture Ventilation Design Elements Effectiveness and Its Application. Comparative Case Study: Rumah Kutai Tiang 12 (Vernacular) and Rumah Selangorku (Contemporary)
}

\author{
${ }^{*}$ K Rizal ${ }^{1}$ I Ismi ${ }^{1}$, A Azli ${ }^{1}$, A Izzati ${ }^{1}$ and W Julaihi ${ }^{2}$ \\ ${ }^{1}$ School of Architecture And Ekistics, Universiti Malaysia Kelantan, Kampus Kota \\ Pengkalan Chepa, 16100 Kota Bharu. Kelantan. \\ ${ }^{2}$ Faculty of Built Environment, Universiti Malaysia Sarawak, Universiti Malaysia \\ Sarawak 94300 Kota Samarahan, Sarawak, Malaysia \\ *rizal.k@umk.edu.my
}

\begin{abstract}
Thermal comfort and ventilation needs of occupants have been achieved successfully with the perfect solution by means of Malay vernacular architecture design. Ventilation have always been a major design element that needs to be thoroughly planned especially in Malay vernacular architecture in order to provide thermal comfort to the occupants. Amongst the various factors that affects ventilation in Malay vernacular architecture are the availability of multiple windows and openings, orientation of the building, roof design as well as variety of floors that contributes to further enhance the thermal comfort of the occupants. Thus, modern development needs to incorporate the suitable elements and applications for ventilation based on the design solutions provided by the Malay vernacular architecture into their designs. A study on vernacular ventilation assists in reinstating the relevance of its application in providing the most efficient thermal comfort to the occupants. The main focus of this research paper is to investigate the applications and significance of ventilation in Malay vernacular architecture as it could further assists designers in the future to provide modern developments that are more feasible in its design specifically on its thermal comfort. This research will provide adequate case studies and ethnographic observations to further enhance the understanding of Malay vernacular architecture ventilation elements whereby the researcher would act as a participant during the process. This research is aimed to change future architects and designers approach in planning and designing more feasible ventilated contemporary buildings.
\end{abstract}




\title{
Efficiency Management of Quality Working Environment in Construction Industry
}

\author{
${ }^{*} \mathrm{~N}$ Ishak and M A Azizan
}

Faculty of Engineering Technology (Civil), Universiti Malaysia Perlis, Kampus UniCITI Alam, Sungai Chuchuh, 02100 Padang Besar, Perlis, Malaysia.

*nurfadzillah@unimap.edu.my

\begin{abstract}
Construction industry is difficult to control the working management in company or at site. For example, construction sector have many project site to manage, different site have different way to control. Scientific management approach has the rigid mechanistic in organization. All work processes could be analyzed into discrete tasks. Each job was broken down into component parts and each part time. Increased interest in job design has been associated with the development of a broader social concern for the quality of working life (QWL). Qualities of working life focus on providing a work environment conducive to the satisfaction of individual needs. This research was conducted to investigate perceptions about the working management method in organization due to study the information based on experience and to find the knowledge and information in search of the efficient working management approach. The findings show the efficiency management of working environment in the organizations due to improve the employee's performance and satisfaction.
\end{abstract}




\title{
Measuring Residents' Satisfaction on Quality of Low-Cost Affordable Housing Projects: An Empirical Investigation
}

\author{
M K Musa1, *M A A Rahman'1, M N A Azman², R Lip³, \\ and $\mathrm{N} \mathrm{Hashim}^{4}$
}

${ }^{1}$ Faculty of Engineering Technology, Universiti Tun Hussein Onn Malaysia (UTHM), Pagoh Campus, 84600 Pagoh, Muar, Johor, Malaysia.

${ }^{2}$ Faculty of Technical and Vocational Education, Universiti Pendidikan Sultan Idris (UPSI), 35900, Tanjung Malim, Perak, Malaysia.

${ }^{3}$ Muar Community College, 27 - 37, Jalan Sulaiman, Kampung Dato Bentara Luar, 84000 Muar, Johor, Malaysia.

${ }^{4}$ Faculty of Social Sciences and Humanities, Universiti Teknologi Malaysia, 81310

UTM Skudai, Johor, Malaysia.

*ashrafr@uthm.edu.my

\begin{abstract}
The construction of low-cost affordable housing in Malaysia is getting high in demand. Even though, the quality of the houses were reported not conforming with generally accepted standards of respectable. Survey through questionnaires on residences at three newly-completed low-cost affordable houses in Johor, Malaysia showed that quality of the housing was at an unsatisfactory level. Despite the existence of standard requirements in determining quality, there is still a significant scope for improvement in Malaysia. These issues are related to verification of application of construction code of practice, building risk and safety, building health, building energy and environmental and eco construction. From the findings, several recommendations have been suggested as measures for improvement the quality of low-cost affordable housing in the future.
\end{abstract}




\title{
Construct Validity and Reliability of Higher Order Thinking Skills in Design and Technology Course: A Rasch Measurement Model Approaches for Pilot Study
}

\author{
${ }^{*}$ N. Hashim ${ }^{1}$, M S Saud ${ }^{1}$, S A Abdullah ${ }^{1}$, D S A Jafar ${ }^{1}$ and \\ M A A Rahman ${ }^{2}$
}
${ }^{1}$ Faculty of Social Sciences and Humanities, Universiti Teknologi Malaysia, 81310 UTM Skudai, Johor, Malaysia.
${ }^{2}$ Faculty of Engineering Technology, Universiti Tun Hussein Onn Malaysia (UTHM), Pagoh Campus, 84600 Pagoh, Muar, Johor, Malaysia.

*zalinahashim84@gmail.com

\begin{abstract}
This pilot study aims to produce empirical evidence of item validity and reliability of best practice instrument for Higher Order Thinking Skills (HOTS) for Design and Technology course. This pilot study instrument consists of 30 items and has been distributed to 150 respondents who are Design and Technology teachers of primary school in Muar and Batu Pahat district in the state of Johor. This instrument was developed to measure seven HOTS constructs namely 1) curriculum; 2) assessment; 3) pedagogy; 4) cocurriculum; 5) community and private sector support; 6) resources and 7) capacity building. The validity and reliability of this HOTS instrument was analyzed through the Rasch Measurement Model using Winstep V.3.69.1.11 software. Analysis was made on the aspects of reliability and separation of item-respondents, polarity item that measures the constructs, item fit as well as standard residual correlation values. The results of the analysis conducted found that there is no item that need to be dropped and all 30 items have been identified as suitable items to be use in measuring seven HOTS constructs. Findings from the study clearly show that the instruments developed have a high level of validity and reliability and are capable of being used in measuring Higher Order Thinking Skills in Design and Technology Course.
\end{abstract}




\title{
Analysis of Biophilic Design in Communal Space of an Office Building. Case Study: Pertubuhan Arkitek Malaysia (PAM) Centre
}

\section{*Ismi Ibrahim¹, Rizal Khairuddin¹, Azli Abdullah¹, Izzati M Amin $^{1}$ and Julaihi Wahid ${ }^{2}$}

${ }^{1}$ Faculty of Architecture and Ekistics, Universiti Malaysia Kelantan, Kampus Bachok, 16310 Kelantan, Malaysia.

${ }^{2}$ Faculty of Built Environment, Universiti Malaysia Sarawak, 02100 Kota Samarahan, Sarawak, Malaysia.

*hamadi.i@umk.edu.my

\begin{abstract}
Biophilic design is an innovative way of designing a space to bring about sense of connection to nature through various mean of approaches. Today, there are various studies and researches done with proven empirical evidences to examine the benefits and impacts of biophilic design to our health and well-being. With growing interest in biophilic design, increase in its usage can be seen implemented abundantly in spaces and buildings nowadays. Aim of this study is to examine various biophilic design that can be used in communal spaces of office building based on existing researches from other countries and to observe how biophilic design elements and attributes are implemented and adapted to address the climatic context of the selected case study in Malaysia and occupant's perception on its effects towards them with possible identification of preferred biophilic design in the tropical climate context. The study will focus on selected case study of office building, which is Pertubuhan Arkitek Malaysia (PAM) Centre at Bangsar, Kuala Lumpur. The findings show that visual connection with nature attribute in biophilic design of a space is the one most agreed to provide the best outcome towards the occupants through its implementation in a space, based on survey study conducted.
\end{abstract}




\title{
Pico-Hydro System as an Alternative Energy Generator
}

\author{
*Mariah Awang ${ }^{1}$, Muhamad Adnan Bin Zulkanai ${ }^{1}$, Nor \\ Hapira Nadia Binti Nafrizon'1, M A A Rahman'1, M M \\ Syafiq Syazwan ${ }^{1}$, Mohd Shahril Abdul Rahman², Mohd \\ Kamaruzaman Musa ${ }^{1}$, Nuramidah Hamidon ${ }^{1}$ and \\ Fatimah Yusop ${ }^{1}$
}

${ }^{1}$ Faculty of Engineering Technology, University Tun Hussein Onn,84600 Pagoh, Muar, Johor, Malaysia.

${ }^{2}$ Faculty of Built Environment and Surveying, Universiti Teknologi Malaysia, Skudai, Johor, Malaysia.

*mariah@uthm.edu.my

\begin{abstract}
Pico-hydro system is a renewable energy source which uses a small motor or generator that is connected to turbines to generate electricity without relying on any non-renewable energy sources. The power generated by the pico-hydro system is less than $5 \mathrm{~kW}$. Currently, the distribution of fuel consumption for electricity generation is $44.7 \%$ using coal, $42.5 \%$ gas-based, $3.7 \%$ oil-based, and $5.7 \%$ hydro-based. The Malaysian government has set a clear goal and strategy that small hydropower (mini, micro, and pico) will contribute up to $500 \mathrm{MW}$ to the national power grid/electricity generation in 2020. In this study, the model built is the pico-hydro system with the operating system powered by pumps with a $10 \mathrm{~W}$ solar panel. The purpose of this study is to build a model of a pico-hydro system as an alternative energy generator, to gauge the energy produced by this pico-hydro model, and to analyse the performance and effectiveness of the pico-hydro system in terms of power and output. Among the tests performed were testing on battery charger controllers and battery charging time rates, water flowrate testing, system efficiency, and relationship analysis between the head height, rotation, and output of power. This model produced the maximum flow of $0.22 \mathrm{~A}$ from the generator to the charger controller with a head height of $0.63 \mathrm{~m}$. The hydraulic efficiency test showed that the system had an efficiency.
\end{abstract}




\title{
The Implementation of Thai Art in Five-Star Hotels in Thailand: An Evaluation Study of Central and Northern Region of Thailand on Hotel Lobby Decorations
}

\author{
Muhammad Faizal Bin Abdul Rani
}

Department of Architecture, Faculty of Built Environment and Surveying, Universiti Teknologi Malaysia, UTM Skudai, 81310 Johor, Malaysia.

*tanjak_melayu@yahoo.com

\begin{abstract}
Thailand is a country with a long and rich history due to its strategic location. The Thai people have their own unique and distinctive art as well as cultural heritage. These were brought about through each generation by the many episodes of social and cultural adaptations, evolution, and development over the centuries. The heritage has been passed down and carried on until today. However, the rapid progress in technology and communications brought about by the era of globalization has also resulted in some drawbacks to this. In addition, Thailand has also struggled to balance between rapid development while maintaining traditional values in the modern context. In the construction field, the country has developed in many aspects. These include designs, resources, construction procedures, needs and demands, purposes, and images. This article attempts to distinguish how current buildings and structures had implemented Thai art to reflect a local image and identity. This article aims to evaluate Bangkok's and Chiang Mai's five-star hotels in terms of their implementation of Thai art as decorations in their respective lobbies. Qualitative data was set through this research, with direct observation being applied in the hotel lobbies. It was found that Thai art was applied more into the decorative aspect than for other purposes. Some of the architects and designers had been reluctant to use Thai art in their designs due to their feeling that heritage is not relevant to current needs. It was also found that the Thai people remain respectful of the values of Thai Buddhism in their daily life..
\end{abstract}




\title{
The Relationship of Perceived Behavioural Control toward Intention of Consumer in Application of Organic Fertilizers in Selangor
}

\author{
${ }^{*}$ A L Zul Ariff, M Nursalwani and A Mohammad Amizi \\ Faculty of Agro Based Industry, Universiti Malaysia Kelantan, Kampus Jeli, 17600 Jeli, \\ Kelantan, Malaysia. \\ *zulariff@umk.edu.my
}

\begin{abstract}
The purpose of this study is to identify the relationship between perceived behaviour control of consumers towards intention of consumer toward the application of organic fertilizers in Selangor. A simple random sampling technique was applied in selecting 86 consumers at MAHA event located at MAEPS, Serdang, Selangor. The consumers were asked to answer the questionnaire which distributed to them to get the data. The data were then analysed by using the software of SPSS version 21.0. Based on the result of statistical tests, the perceived behaviour control had a statistically significant association with the intention of consumers toward application of organic fertilizers in Selangor. From this study, it shows that the consumer is more intent to use healthy product such as organic fertilizers in order to choose a healthy lifestyle on themselves and also on the environment.
\end{abstract}




\title{
SME Performance towards Marketing Halal Products
}

\section{${ }^{*}$ A L Zul Ariff, M Nursalwani and A Mohammad Amizi}

Faculty of Agro Based Industry, Universiti Malaysia Kelantan, Kampus Jeli, 17600 Jeli, Kelantan, Malaysia.

*zulariff@umk.edu.my

\begin{abstract}
Halal products concerned and attracts variety of consumers all around the world. SMEs is an acronym for Small and Medium-sized Enterprises that contribute to development of the country's economy. This research related to halal product and issues among SME performance toward marketing of halal product in Malaysia. There were 40 respondents from SMEs in Malaysia that conducted in this survey. Data was collected through the online survey, which is KAP Survey, questions pertaining to relationship between perception of SMEs and income level toward halal product in Malaysia. Analysis of the result was done by using SPSS. The result showed that majority of SMEs agreed on Halal product to improve their business. Moreover, the knowledge of SMEs toward marketing of halal products showed $100 \%$ of SME know about the Halal product that used quality, clean and healthy ingredient to consumer buy the products. Then, to study the most influence factors towards marketing of the halal product among SMEs there was not statistically relationship between perceptions in Halal product because respondent SMEs has many various races and religion. All the factors have strong relationship toward marketing Halal products. These results suggest that SMEs should ensure to hire workers from totally selfemployed to awareness on their Halal certification products.
\end{abstract}




\title{
Youth Perception towards Being an Orchid Entrepreneur
}

\author{
*A L Zul Ariff, K Fatimah, Z Suhana, I Akmal Adillah, T A \\ $B$ Tengku Halimatun Sa'adiah, and A Mohammad Amizi
}

Faculty of Agro Based Industry, Universiti Malaysia Kelantan, Kampus Jeli, 17600 Jeli, Kelantan, Malaysia.

*zulariff@umk.edu.my

\begin{abstract}
Orchid is a valuable exotic flower species and this floricultural industry is profitable in our country. It creates lots of business opportunity and employment as this industry is widely concerned by the government and nongovernment organisations. As these species are able to grow well in Malaysia, their production feed the cut flower industry, tourism market in Sabah, orchid hybridization and the most importance is the entrepreneurial business in this industry. However, orchid flowers are sensitive to external conditions, so research and development is needed for a mature yet productive orchid industry. This is because this industry is showing an increasing trend of economic status. Still, Malaysians especially the youths are less intended to become an orchid entrepreneur while they are also less aware of its commercial potential. Theory of perceived behaviour (TPB) is used in this research study to identify demographic factors such as income, entrepreneurial knowledge and social norms of the youths are studied to review the relevancy and validity among the youths who have income. Both primary data and secondary data are gathered by collecting a sampling of 122 youth with income of their information through questionnaires and referring previous studies. Lastly, data analyses are done by performing descriptive analysis, reliability test, chi-square test, factor analysis and variances are explained.
\end{abstract}




\title{
Self-Esteem and Perceived Academic Control Towards Well-Being Emotion Among Wellness Students
}

\author{
Md Zaki Muhamad Hasan, *Noorshella Che Nawi, Azwan \\ Abdullah, Anis Amira Ab Rahman and Mahathir \\ Muhamad
}
Faculty of Entrepreneurship and Business, UMK City Campus, Pengkalan Chepa, 16100 Kelantan Malaysia
*norshella@umk.edu.my

\begin{abstract}
The purpose of this study is to investigate the self-esteem and perceived academic control towards well-being emotions among wellness students and the most factors affecting the well-being emotions among wellness students at Uni X. A total of 250 Wellness students been surveyed and data was analyzed using SPSS software. The findings of this study are aligned with the past studies which are there is a relationship between selfesteem and academic perceived control towards well-being emotion among wellness students. In addition, this study also revealed that self-esteem is the most influencial factor compared to perceived academic control towards wellbeing emotion among wellness student.
\end{abstract}




\title{
Online Student Engagement (OSE) In Entrepreneurship Course During Covid-19 Pandemic Period
}

\author{
*W L Koe ${ }^{1}, \mathrm{M} \mathrm{H}$ Mahphoth ${ }^{1}, \mathrm{P}$ D Dirgantari² and Y M \\ Hidayat $^{2}$
}

${ }^{1}$ Faculty of Business and Management, Universiti Teknologi MARA, Cawangan Melaka, 75300 Melaka, Malaysia.

Universitas Pendidikan Indonesia, Kota Bandung, Jawa Barat 40154, Indonesia.

*koeweiloon@yahoo.com

\begin{abstract}
Online learning is a new trend in Education 4.0. The COVID-19 pandemic has forced universities to adopt e-learning. As such, entrepreneurship course has turned to use online learning platform in many learning institutions. Student engagement remains as an issue in online learning because the setting in online learning is different from traditional classroom learning. However, online student engagement (OSE) is still considered a relatively new concept and studies are scarcely available. As such, this study aimed to analyze the level of OSE in terms of skills, emotion and participation in entrepreneurship course. It carried out a questionnaire survey to collect the desired information. A total of 290 students from a public university in Malaysia have participated in the survey. Analysis revealed that students demonstrated high level of skill in listening and reading carefully, high level of emotion in putting forth effort in learning and high level of participation in helping fellow students. Overall, participation was rated as the top component in OSE. It can be concluded that student participation played a crucial role in ensuring student engagement in online learning environment. Therefore, building a good rapport and getting to know each other among learners and, designing enjoyable course outline are important in online learning environment. This study enriches the knowledge of important component of OSE and provides suggestions to enhance learners OSE in university.
\end{abstract}




\section{Overview Of Psychological Well-Being Among Malaysıan Society Durıng Covid-19 Outbreak}

\section{*Siti Mariam and Noraini Saro}

Center for Islamic Philanthropy and Social Finance, Faculty of Business Management, Universiti Teknologi MARA, Cawangan Melaka, KM 26, Jalan Lendu, 78000, Alor Gajah, Melaka.

*smali@uitm.edu.my

Abstract. Covid-19 pandemic has caused havoc worldwide. Malaysia is also going through a challenging situation, as the number of infected/positive cases is increasing day by day. The Government of Malaysia enforced a Movement Control Order starting on March 18, 2020 to break the chain of COVID-19. The COVID-19 pandemic has far- reaching effects on the psychological wellbeing of individuals in society. This article uses secondary data such as journals, newspapers, websites, and government records. The objective of this article mainly focused on the psychology effects among Malaysian society during the COVID-19 outbreak. This discovery shows that pandemic COVID19 leads to several psychological effects on Malaysian society, such as anxiety, stress, depression and others. This article also shows the efforts of the government to ensure the psychological well-being of Malaysian society. 


\title{
Preference of Consumer toward Halal Base Product in Vending Machine in Selangor
}

\author{
${ }^{*} \mathrm{~A} L$ Zul Ariff, H Zulhazman, M Nursalwani and A \\ Mohammad Amizi
}

Faculty of Agro Based Industry, University Malaysia Kelantan, Kampus Jeli, 17600 Jeli, Kelantan, Malaysia

*zulariff@umk.edu.my

\begin{abstract}
Vending machines have been developed since 1880s and has been continued to be customized to suit the taste and needs of consumers. Vending machines serves automatically, with a specific currency. Vending machines has become a multipurpose machine that not only able to serve food and snacks, but also serve ready to go meal and some are also equipped with microwave to heat the food and can be readily eaten right after purchase. Suppliers are becoming more efficient in placing vending machines so that consumers can have access to the particular vending machines. Globalization has brought Islamization with Vending machines. Hence many halal-based products are available, with the innovation of Halal vending machine, competing with Kosher-based product. Japan, Brunei and Malaysia are the pioneers that open the market as to the growing numbers of Muslim consumers. Fake logos and too many certified Halal logos have done nothing but increasing the doubt among the Muslim consumers and community. This study uses Knowledge Attitude and Practice (KAP) Survey Model to keep track of the behaviour of the consumer. (KAP) Survey Model questionnaire was distributed to 100 consumers to study the behaviour and perception towards vending machines that sell Halal-based products.
\end{abstract}




\title{
Access Security System in University Tun Hussein Onn Malaysia (Pagoh Campus)
}

\author{
*Mariah Awang ${ }^{1}$, Ina Syazwani Hamzah"1, M A A \\ Rahman', Mohd Kamaruzaman Musa ${ }^{1}$, M M Syafiq \\ Syazwan ${ }^{1}$, Fatimah Yusuf ${ }^{1}$, Nuramidah Hamidon ${ }^{1}$, Mohd \\ Shahril Abdul Rahman ${ }^{2}$ and Wilson Rangga Anak \\ Anthony Jiram ${ }^{2}$
}

${ }^{1}$ Faculty of Engineering Technology, University Tun Hussein Onn,84600 Pagoh, Muar, Johor, Malaysia.

${ }^{2}$ Faculty of Built Environment and Surveying, Universiti Teknologi Malaysia, Skudai, Johor, Malaysia.

*mariah@uthm.edu.my

\begin{abstract}
The study of access security system in University Tun Hussein Onn Malaysia (UTHM) in Pagoh branch is literally a research that enclosed to the safety research that involves in the entrance of the buildings to avoid any threats upcoming that can contribute to the loss of property and economic part. University is the place that involves in strong protection of security guided and commonly we all know that this system works 24 hours per day. Thus, we will be found out in this study on how the access security system is working on the campus and what are the implements that they want to obtain from working out this system. The objectives of this project are to determine the type of access security system in UTHM Pagoh campus and to study the user's awareness about the access security system in UTHM Pagoh campus. This research study is completed by applying qualitative of research method to achieve the first objective and using quantitative method which is this project will use the questionnaire to complete and achieve the second objective. These data are then analyzed to exploit with the Statistical Package for Social Science (SPSS) version 19 and Microsoft Excel software. The data will be processed and presented in the form of chart and percentage by using this software. Last but not least, this project will find out the types of access security system available in the campus and to figure the user's awareness of the access security in UTHM Pagoh campus.
\end{abstract}




\title{
Panic Buying During Covid-19 in Malaysia
}

\author{
*A R Ridzuan"1, A Luthfia², R S Mohideen"1, \\ S N S Allam¹, N A Karim Zamri ${ }^{1}$, A Zulkarnain², \\ S Ismail ${ }^{1}$, A F Ramlan ${ }^{1}$ and R A Aryanti W \\ Puspokusumo ${ }^{2}$
}

${ }^{1}$ Universiti Teknologi MARA, Cawangan Melaka, Kampus Alor Gajah, Melaka, Malaysia.

${ }^{2}$ Bina Nusantara University, Jakarta, Indonesia

*abdulrauf@uitm.edu.my

\begin{abstract}
One of Covid-19 side effects was movement control order (MCO). Panic buying can be defined as the action of buying large quantities of a particular product or commodity due to sudden fears and a lockdown announcement from the government just adds fuel to the flames. This study has been done to identify the level of panic buying during movement restricted order (MCO). Panic buying is chosen as the research's topic because it is the most obvious reaction that was shown from the public when MCO was announced and wanted to know did they practice this behavior or not. The researcher used questionnaire form to survey the level of panic buying during MCO. Google form was also used to determine the survey and the link was distributed to all social media platforms. From the survey, we gained 411 respondents, starting from age 18 and above that involved various ethnic in Malaysia. The findings show that the level of panic buying among Malaysian is very low $(\mathrm{m}=2.13)$.
\end{abstract}




\title{
Towards Developing Economic Community Development And Sustainability Model Of The Asian Clam (Etok) Industry In Kelantan, Malaysia
}

\section{${ }^{*}$ Mohammad Ismail ${ }^{1}$, Y Mohd Rafi ${ }^{1}, \mathrm{H}$ Zulhazman², Z Mohd Nazri ${ }^{1}$, A R M Rooshiban Merican ${ }^{1}$, E R Aweng ${ }^{2}$, A L Zul Ariff ${ }^{3}$ and M R Wan Siti Farizan ${ }^{1}$}

${ }^{1}$ Faculty of Entrepreneurship and Business, Universiti Malaysia Kelantan, Kelantan, Malaysia.

${ }^{2}$ Faculty of Earth Science, Universiti Malaysia Kelantan, Kelantan, Malaysia.

${ }^{3}$ Faculty of Agro Based Industry, University Malaysia Kelantan, Kelantan, Malaysia.

\section{*mohammad.i@umk.edu.my}

\begin{abstract}
This research examines the business profiling of Asian clam (etok) sellers in Kelantan, which has been considered as the food heritage of the state. The study was conducted in order to understand a deep insight into business activities as an initial stage for further investigation to develop a sustainable etok business model. These include etok branding, marketing and proposing the new strategy on promoting and sustaining this heritage food. A total of 108 Etok sellers from ten districts in Kelantan which are Gua Musang, Bachok, Kota Bharu, Pasir Mas, Tumpat, Tanah Merah, Machang, Kuala Krai, Pasir Puteh and Jeli involved in the study. The data were analysed using Statistical Package for the Social Sciences (SPSS) version 24. The descriptive study reveals that the majority of respondents (55.6\%) involved in the business for more than ten years and inherited (58.4\%) from their parents and ancestors. Most of them (84.3\%) are running etok business as a full-time employment. Majority of them (71.3\%) earned a steady daily profit of approximately RM 100.00 or 25.00 USD. This signifies that the industry is still viable and provides a substantial income to those involved in the business. Expectantly, this study will pave a way of comprehensive exploration of etok business in proposing better strategy, promoting and sustaining business in the state of Kelantan
\end{abstract}




\title{
Examining the Relationship between Facility, Teaching Quality and Administration Towards Student Satisfaction
}

\author{
${ }^{*}$ A F Arham ${ }^{1}$, N S Norizan ${ }^{1}$, Z F Ahmad ${ }^{1}$, H D Md Isa ${ }^{1,2}$, N \\ $\mathrm{N}$ Kamarulzaman ${ }^{1}$, A F Arham ${ }^{3}$
}

${ }^{1}$ Faculty of Business \& Management, Universiti Teknologi MARA, Kampus Bandaraya Melaka, 75300 Melaka, Malaysia.

${ }^{2}$ Oriental Nilam College of Nursing and Health Sciences, 75200, Melaka, Malaysia.

${ }^{3}$ Pusat Citra Universiti, Universiti Kebangsaan Malaysia, Bangi, 43600, Selangor, Malaysia.

*ahmad490@uitm.edu.my

\begin{abstract}
Today, enhancing and providing the best learning experience and top-quality education are now being embedded into the strategic thrusts of higher learning institutions. Previous research also has contemplated to investigate the factors affecting student satisfaction. However, the focus towards nursing college in the country is still lacking. As Malaysia is now moving towards becoming a hub for medical tourism, the enhancement and improvement on the nursing college is deemed important. In this study, three factors were proposed to influence student satisfaction significantly. Based on 148 samples of respondents, the results indicated that, collectively, the level of satisfaction among students is good. The result of mean analysis also indicated that the respondents perceived teaching quality as the most important factor for their satisfaction, followed by administrative and facility. The results from Pearson Correlation also showed support for all three hypotheses proposed, in which facility, teaching quality and administrative were found to significantly influence student satisfaction. Implications of the study are also discussed.
\end{abstract}




\title{
Effectiveness of the Implementation of Geography Field Study Among Form Six Students
}

\section{*H Mahat ${ }^{1}$, N A A Wan Pauzan 1 , M Hashim¹,, Y Saleh ${ }^{1}, \mathrm{~N}$ Nayan $^{1}$, S B Norkhaidi ${ }^{1}$ and Suhendro ${ }^{2}$}

${ }^{1}$ Department of Geography and Environment, Faculty of Human Science, Universiti Pendidikan Sultan Idris, Malaysia.

${ }^{2}$ Postgraduate Geography Education Candidate, Universitas Pendidikan Indonesia, Indonesia.

* hanifah.mahat@fsk.upsi.edu.my

\begin{abstract}
This study aims to look at the effectiveness of Geography fieldwork study among form six students in Machang, Kelantan. A quantitative approach was applied in this study by using a questionnaire as an instrument. A simple random sampling method was used for the selection of respondents and the total number of respondents was 80 form six students who were taking Geography in some selected schools in the Machang district in Kelantan. Four study variables were used, namely interest, understanding, skills and effectiveness, in the implementation of the Geography fieldwork study. Descriptive analysis was used to examine the level of each variable I, II, III and IV, and inferential analysis (Pearson's correlation and regression) was used to examine the relationships and influential contributions of each study variable. The findings showed that all of the variables, namely interest $(M=2.89, S P=0.32)$, understanding $(M=2.87$, $\mathrm{SP}=0.32)$, manipulative skills $(\mathrm{M}=2.33$, $\mathrm{SP}=0.50)$, soft skills $(\mathrm{M}=2.75, \mathrm{SP}=0.44)$ and the effectiveness of the implementation $(\mathrm{M}=2.90, \mathrm{SP}=0.30)$ were at a moderate level. The results of the Pearson's correlation analysis also found that there was a significant positive relationship between the interest and understanding variables $(r=$ $0.538, p<0.005)$, understanding and manipulative skills $(r=0.556, p<0.005)$, manipulative skills and soft skills $(r=0.595, p<0.005)$ and soft skills with effectiveness $(r=0.677, p<0.005)$. In addition, regression analysis showed that soft skills had the highest impact on the effectiveness of the Geography field study by $45.8 \%$ with $\mathrm{R}^{2}=$ $0.581, \mathrm{~F}(26.030)=0.324, \mathrm{P}<0.05$. The implementation of Geography field study in schools can bring about change among students, and indicates that an effective Geography field study can enhance students' interest, understanding and skills in the subject of Geography and is able to give students the opportunity to be more innovative and to think creatively.
\end{abstract}




\title{
Problematic Review on Water Tariff-Pricing Model and its Relation with Environment and Climate Change
}

\author{
*Mohammad Fadzli Ramli', Tan Kim Hek ${ }^{1,2}$, Hamzah \\ Abdul Hamid ${ }^{1}$ and Mohd Syafarudy Abu ${ }^{1}$
}

\footnotetext{
${ }^{1}$ Institut Matematik Kejuruteraan, Fakulti Sains Gunaan dan Kemanusiaan, Universiti Malaysia Perlis, Kampus Pauh Putra, 02600 Arau, Perlis, Malaysia.

${ }^{2}$ Institut Bina Bisnes Indonesia (IBBI), Jalan Sei Deli No. 18, 20114 Medan, Kelurahan Silalas, Kecamatan Medan Barat, Sumatera Utara, Indonesia.
}

*mfadzli@unimap.edu.my

\begin{abstract}
The issue of water security, environment degrade and climate change has becoming more severe today and emergence actions are needed to mitigate the problem. The variability in climate change affected the water resources thus contributes to unstable and uneconomic water price. This problem is worsened by environmental and pollution impact thus led to irrational water tariff and price. Existing model only considers econometric values, but environmental and climate change is neglected from overall structure of water tariff and price. Furthermore, the non-structured water pricing model fails to educate water consumers about excessive use and water scarcity. Therefore, water tariff and pricing mechanisms need to accommodate the changing in environmental degradation and climate change for more rationale and relevant water tariff and price.
\end{abstract}




\title{
The Relationship between Career Satisfaction and Turnover Intention among Malaysian ICT Employees
}

\section{${ }^{*}$ C S Lim and U N Saraih}

Faculty of Applied Science and Humanities, Universiti Malaysia Perlis, Jalan KangarAlor Setar, 01000, Kangar, Perlis, Malaysia.

*limcheesin93@gmail.com

\begin{abstract}
Researchers paid attention on career satisfaction as predictor of turnover intention in response to request for future study about antecedent of turnover intention. This study determined the relationship between career satisfaction and turnover intention among the Malaysian information and communication technology (ICT) employees. This study also contributed to the Social Exchange Theory (SET) literature in examining the relationship between career satisfaction and turnover intention. This study used simple random sampling approach to collect data from 214 ICT employees from several organizations in Selangor, Malaysia. SPSS 23 statistical software is used to test the formulated hypotheses. This study revealed empirical findings on negatively significant relationship between career satisfaction and turnover intention. This study offered practically guidance on managerial side in ICT organizations to pay more attention on development of new skills, promotion chances and career goal of ICT employees after understanding the predictor of turnover intention. Therefore, it is expected that turnover intention decreased as career satisfaction increased; while, lack of Malaysian ICT employees' problem is thought out as well retaining those top performers in the industry.
\end{abstract}




\title{
The Groundwater Quality Assessment for Domestic Use in Malaysia: A Case Study of Sabah Rural Area
}

\author{
${ }^{*}$ M Hashim ${ }^{1}$, H M Japiring ${ }^{1}$, D L Setyowati ${ }^{2}, \mathrm{H}_{\text {Mahat }}{ }^{1}, \mathrm{~N}$ \\ Nayan ${ }^{1}$, Y Saleh ${ }^{1}$, S B Norkhaidi ${ }^{1}$ and M S Zahid ${ }^{3}$ \\ ${ }^{1}$ Department of Geography \& Environment, Faculty of Human Sciences, Universiti \\ Pendidikan Sultan Idris, 35900 Tanjong Malim, Perak, Malaysia. \\ ${ }^{2}$ Department of Geography, Faculty of Social Science, Semarang State University, \\ Sekaran Gunungpati Semarang, 50229 Indonesia. \\ ${ }^{3}$ Department of Biology, Faculty of Science \& Mathematics, Universiti Pendidikan \\ Sultan Idris, 35900 Tanjong Malim, Perak, Malaysia.
}

*mohmadisa@fsk.upsi.edu.my

\begin{abstract}
In rural areas of Sabah, Malaysia, the groundwater source is the only water supply for domestic consumption. Therefore, the monitoring of groundwater quality is essential to adhere to the standards by Malaysia's Department of Environment. This article seeks to evaluate the groundwater quality through the quantitative analysis, and the sampling carried out between January and March 2019. Among national water quality standards sampled including dissolved oxygen, $\mathrm{pH}$, ammonia nitrogen, and total suspended solids. The result showed that the chemical oxygen demand was above the standards, $>197 \mathrm{mg} / \mathrm{l}$ (Station 5) and fall into Class V. However, the index of water quality for all stations indicate Class II with the lowest in Station 5 ( 80 per cent) and the highest in Station 6 (90 per cent). All stations showed clean category except for Station 5 (moderately polluted). This study also implicates that the water quality assessment could act as a tool in monitoring the groundwater.
\end{abstract}




\title{
The Link Between Seller and Supplier for Creating Business Model of Etak - The Heritage Food Revival Sustainability in Kelantan, Peninsular Malaysia
}

\author{
${ }^{*}$ Z Mohd Nazri ${ }^{1}$, Y Mohd Rafi ${ }^{1}$, A R M Rooshihan \\ Merican ${ }^{1}$, M R Wan Siti Farizan ${ }^{1}$, Mohammad Ismail ${ }^{1}$, \\ $\mathrm{H}$ Zulhazman $^{2}$, A L Zul Ariff ${ }^{3}$ and E R Aweng ${ }^{2}$
}

${ }^{1}$ Faculty of Entrepreneurship and Business, Universiti Malaysia Kelantan, Kelantan, Malaysia.

${ }^{2}$ Faculty of Earth Science, Universiti Malaysia Kelantan, Kelantan, Malaysia.

${ }^{3}$ Faculty of Agro Based Industry, Universiti Malaysia Kelantan, Kelantan, Malaysia.

*mnazri.z@umk.edu.my

\begin{abstract}
This study examines the creating business model of Asian clam (etok) from seller's perspective and their link with supplier in Kelantan, which has been considered as the food heritage of the state. The research was conducted in order to understand a deep insight into business activities as an initial stage for further investigation to develop a sustainable etok business model. These include etok branding, marketing and proposing the new strategy on promoting and sustaining this heritage food. A total of 108 Etok sellers from ten districts in Kelantan which are Gua Musang, Bachok, Kota Bharu, Pasir Mas, Tumpat, Tanah Merah, Machang, Kuala Krai, Pasir Puteh and Jeli involved in the study. The data were analysed using Statistical Package for the Social Sciences (SPSS) version 24. The descriptive of study found that the majority of respondents agree that they have difficulty in getting etak from supplier. Most of the seller get the etak from the outside of Kelantan. They also have to booked etak from supplier earlier to get the etak for their business with a reasonable price, good etak quality and quantity also punctual when supply the etak to them. This signifies that the industry is still viable and provides a substantial income to those involved in the business. Expectantly, this study will pave a way of comprehensive exploration of etok business in proposing better strategy, promoting and sustaining business in the state of Kelantan.
\end{abstract}




\title{
Malaysians' Reactions Towards Government's Crisis Management During Covid-19
}

\author{
${ }^{*}$ Rosilawati Sultan Mohideen, Abdul Rauf Ridzuan, Siti \\ Nurshahidah Sah Allam, Siti Aminah Abd Wahab, llya \\ Yasnorizar llyas, Norena Abdul Karim Zamri, and Aini \\ Faezah Ramlan
}

Universiti Teknologi MARA, Cawangan Melaka, Kampus Alor Gajah, Melaka,
Malaysia.

*rosilawati729@uitm.edy.my

\begin{abstract}
The whole world is alerted with the Covid-19 pandemic outbreak as it is lethal and spread easily. The government have to take quick and effective action for the crisis management and Malaysia is not excluding in taking its own action to ensure the crisis is managed well. Therefore, this study is done to study on reaction of satisfaction level of Malaysians towards government's crisis management during Covid-19. This study was conducted by using random sampling technique where it involves 200 respondents from Malaysia. A structured questionnaire was used for data collection. The questionnaire of the research were divided into 4 sections consists of demographic profile, daily press conference, enforcement of Movement Control Order and mandatory quarantine. For the ordinal measurement questions, Likert Scale from strongly agree, agree, neutral, disagree and strongly disagree were used. The questions, an online survey, were created in Google Forms and distributed through social media such as Whatsapp Messenger, Instagram and Facebook. All the variables analysed by using descriptive analysis.
\end{abstract}




\title{
Optimization of Wear Behavior on Unreinforced/Glass Fiber Reinforced Plastic Injection Moulded Gear via Integration of Taguchi Method and Principal Component Analysis
}

\author{
${ }^{*}$ N M Mehat ${ }^{1}$, Z Syazani $^{1}$ and S Kamaruddin ${ }^{2}$ \\ ${ }^{1}$ Faculty of Mechanical Engineering Technology, Universiti Malaysia Perlis, Uniciti \\ Alam Campus, Sungai Chuchuh, 02100, Padang Besar, Perlis, Malaysia. \\ ${ }^{2}$ Mechanical Engineering Department, Universiti Teknologi PETRONAS, 32610 Seri \\ Iskandar, Perak Darul Ridzuan, Malaysia. \\ *nikmizamzul@unimap.edu.my
}

\begin{abstract}
To date, plastic gears are continuing to displace metal gears in a widening arena of applications. Plastic gears are presently not just being used for light-stacked applications but also in automotive starter gears, turbo actuators, and electronic throttle control. Despite of the benefits of plastic gears including noiseless operation, low weight, and working without lubrication, the occurrence of wear in plastic gears limit its application particularly in higher contact force during the operation. Therefore, in this study an attempt has been made to study the applicability and practical ability of using glass fiber in plastic gear in order to reduce the wear failure in plastic gear. The integration of Taguchi Method and Principal Component Analysis (PCA) optimization were implemented to investigate the effects of controlled parameters (gear combinations, speed, running time and load) on the wear behavior, tooth thickness and addendum circles measurement of glass fiber reinforced plastic gear.
\end{abstract}




\title{
The Effect of New Online Learning Readiness on Perceived Usefulness of Open Distance Learning Implementation during Covid-19 Outbreak
}

\section{*S A Siti Nurshahidah"1, H Mohd Sufiean², R Abdul Rauf", Y Fatimah Yazmin ${ }^{1}$, A W Shafezah ${ }^{1}$ and I Hamidah ${ }^{3}$}

\begin{abstract}
${ }^{1}$ Faculty of Communication and Media Studies, Universiti Teknologi MARA, Melaka Branch, Kampus Alor Gajah, Km 26 Jalan Lendu,78000 Alor Gajah, Melaka, Malaysia.

${ }^{2}$ Faculty of Social Sciences, Kolej Universiti Islam Melaka, Batu 28, Kuala Sungai Baru, 78200 Melaka, Malaysia.

${ }^{3}$ Faculty of Computer Science and Mathematics, Universiti Teknologi MARA, Melaka Branch, Kampus Alor Gajah, Km 26 Jalan Lendu,78000 Alor Gajah, Melaka, Malaysia.
\end{abstract}

*shahidah321@uitm.edu.my

\begin{abstract}
A decrease in student readiness in Open Distance Learning (ODL) is among frequently observed problems, especially during a pandemic outbreak. And these issues could reduce students perceived usefulness of ODL implementation and reflect on academic performance. This study comes out with a new cluster in measuring readiness to perceived usefulness of ODL implementation that little study mentions; 1) computer/Internet readiness (CIL), 2) self-directed learning readiness (SDL), and 3) motivational of learning readiness (MOL). The current study explored the impact of $\mathrm{ClL}$, MOL, and SDL readiness on the perceived usefulness of ODL implementation. A survey method was conducted $(n=656)$ among full-time undergraduate students in UiTMCM. Using descriptive statistical analysis, this study found that technological readiness and sociological readiness among undergraduate students were a strong significant predictor of perceived usefulness of ODL implementation, while psychological readiness reported no significant predictor of perceived usefulness of ODL implementation. This study has a twofold significance. Firstly, the findings highly towards higher education institutions, especially for developing countries who experience ODL implementation. Besides, the findings presented to the Academic Affairs, UiTMCM to guide the lecturers in preparing the best ODL course design, implementation, and measurement so that students are will experience the best practice of the ODL approach.
\end{abstract}




\title{
Aftermath of Pandemic Covid-19 on Tourism Industry: A Review on Virtual Tourism Platform
}

\author{
* N Z A Rahim ${ }^{1}$, N I S Nasaruddin ${ }^{1}$, N B A Shah ${ }^{1}$, F H \\ Halim¹, K A F A Samah¹, F I Saman¹, S F M Rum \\ ${ }^{1}$ Faculty of Computer and Mathematical Sciences, Universiti Teknologi MARA \\ Cawangan Melaka Kampus Jasin, 77300 Merlimau, Melaka, Malaysia \\ *nurul1867@uitm.edu.my
}

\begin{abstract}
Tourism is considered one of the hardest hit sectors during Covid19 as it impacts both demand and tourism supply in various aspects. In the aftermath of the pandemic crisis, significant actions have been made to encourage people back to travel by shifting the advertising of tourist attractions via virtual tourism. It can be helpful in attracting and navigating travellers to the desired places. Some of the most exciting advancements in technology aim to maximizing the travel quality by providing valuable information to travellers before the places of interest are reached and businesses will have incredible marketing tool by promoting interactive marketing experience. Therefore, the purpose of this study is to analyse several virtual and interactive platforms in tourism which includes the virtual reality (VR), augmented reality (AR), 360-degree video and hologram. The result of the research provides an insight for the tourism industry to revolve due to the aftermath of the pandemic Covid-19. Both advantages and disadvantages of these platforms in enhancing audience experience and engagement are discussed.
\end{abstract}




\title{
Automatic Chili Seeds Remover for Household and Small-Medium Enterprises as an Alternative of Hand Cutting Method
}

\author{
${ }^{*}$ A. Ghazali ${ }^{1}$, S. M. Sharun ${ }^{1}$, S. H. Y. S. Abdullah¹, F. A. \\ Halim Yap ${ }^{1}$ and N. H. Ariffin ${ }^{1}$
}

${ }^{1}$ Faculty of Computer and Mathematical Sciences, Universiti Teknologi MARA

Cawangan Melaka Kampus Jasin, 77300 Merlimau, Melaka, Malaysia

*azierara20@gmail.com

\begin{abstract}
Chili is the main ingredient and one of the spices that is widely used to improve flavor in the meal. Spicy meals provided with dried chili make some people feel spicy yet delicious and they become more desirable to be eaten. Naturally, chili contains a large number of seeds and it became more challenging to separate the seeds from the chili. It takes longer time and a lot of manpower to prepare dried chili paste manually. Hence to reduce meal preparation time, some people opted for the use of instant chili paste in their cooking. However, the chili paste contains additional preservatives to ensure longer shelf life. This situation is unfavorable for the consumer's health. On the other hand, the existing chili seed remover is large and expensive and only suitable for the large food industry application. The purpose of this study is to design and develop a beta prototype of an automatic dried chili seed remover machine (ADCSRM) which is ergonomic and portable and can be tested with different weights of dried chili per operation. It is also can help the small industry and the housewife to optimize their works. ADCSRM is designed to cut dried chili and remove the seeds by using specifically designed blade. This machine has seven main parts and used a blender motor with adjustable speed function. The result of this study showed that the ADCSRM machine can separate a minumum of $50 \mathrm{~g}$ up to $250 \mathrm{~g}$ of dried chili per operation. The maximum time for each operation is around 40-45 s depending on the weight of dried chili input. The machine was invented in a small size with a simple mechanism and easy to use. In conclusion, by using ADCSRM it can reduce the meal preparation time, number of labor as well as the cost of chili paste preparation.
\end{abstract}




\title{
Implications of Covid-19 Outbreak Spread on Small Traders in Bachok District, Kelantan
}

\author{
${ }^{*}$ D Mohamad ${ }^{1}$, A N A Rashid ${ }^{1}$, N Ahmad'1, M E Z \\ Abdullah', S N D Sukri1, J Jaafar1, M H Harun ${ }^{1}$ and M Y \\ $\mathrm{M} \mathrm{Naser}^{1}$
}

${ }^{1}$ Department of Creative Technology, Faculty of Creative Technology \& Heritage, Universiti Malaysia Kelantan, 16300 Bachok, Kelantan, Malaysia.

*darliana.m@umk.edu.my

\begin{abstract}
Tourism is considered one of the hardest hit sectors during Covid19 as it impacts both demand and tourism supply in various aspects. In the aftermath of the pandemic crisis, significant actions have been made to encourage people back to travel by shifting the advertising of tourist attractions via virtual tourism. It can be helpful in attracting and navigating travellers to the desired places. Some of the most exciting advancements in technology aim to maximizing the travel quality by providing valuable information to travellers before the places of interest are reached and businesses will have incredible marketing tool by promoting interactive marketing experience. Therefore, the purpose of this study is to analyse several virtual and interactive platforms in tourism which includes the virtual reality (VR), augmented reality (AR), 360-degree video and hologram. The result of the research provides an insight for the tourism industry to revolve due to the aftermath of the pandemic Covid-19. Both advantages and disadvantages of these platforms in enhancing audience experience and engagement are discussed.
\end{abstract}




\title{
Improving Occupational Safety and Health (OSH) Enforcement Among Employers in Manufacturing Sector in Kelantan
}

\author{
${ }^{*} \mathrm{R}$ Hassan $^{1}, \mathrm{~A}$ R Ismail ${ }^{1,2}, \mathrm{~N} \mathrm{~K}$ Makhtar ${ }^{3}$ and N Jusoh ${ }^{1}$ \\ ${ }^{1} 1$ Faculty of Creative Technology \& Heritage, Universiti Malaysia Kelantan, 16300 \\ Bachok, Kelantan, Malaysia \\ ${ }^{2}$ Centre for Management of Environment, Occupational Safety and Health (CMeOSH), \\ Universiti Malaysia Kelantan, 16300 Bachok, Kelantan, Malaysia \\ ${ }^{3}$ Department of Educational Planning and Research, Institute of Teacher Education, \\ Campus Kota Bharu, Kota Bharu, Kelantan, Malaysia \\ *ramli_h@mohr.gov.my
}

\begin{abstract}
Compliance to occupational safety and health (OSH) laws in Malaysia is enforced by the Department of Occupational Safety and Health (DOSH), Ministry of Human Resource. The acts involved are the Occupational Safety and Health Act 1994 (OSHA) and the Factory and Machinery Act 1967 (FMA). Actions were taken against employers who breached the laws are either persuasive or punitive. From the statistics, it is clear that the OSH enforcement officers use more persuasive strategy compared to a punitive strategy, which leads to enforcement deficit. The objective of the study is to study the factors hindering $\mathrm{OSH}$ enforcement officers towards imposing punitive action against errant employers. The study used questionnaires developed after a thorough literature review on enforcement factors. The questionnaires were distributed to the selected population, i.e. DOSH Kelantan's officers. The data was analysed using SPSS version 25 software. The study shows that knowledge, understanding and expertise of $\mathrm{OSH}$ officers in investigation and preparation of IP followed by officers' attitude towards the preparation of IP and the availability of records, database, procedures and equipment are the prominent factors that have to be taken care of to improve OSH enforcement in Kelantan.
\end{abstract}




\title{
Urban B40 Secondary School Student Creatıvity Versus Their Rural Counterparts
}

\section{* M A Yahyaawal ${ }^{1}, \mathrm{M}$ Ibrahim², $\mathrm{H} \mathrm{Omar}^{2}$, I Abdullah² and S A Tajuddin²}

${ }^{1}$ Faculty of Innovative Design and Technology, Universiti Sultan Zainal Abidin,Gong Badak Campus,21300 Kuala Nerus, Terengganu, Malaysia.

${ }^{2}$ Faculty of Innovative Design and Technology, Universiti Sultan Zainal Abidin,Gong Badak Campus,21300 Kuala Nerus, Terengganu, Malaysia.

*afiq_mr@yahoo.com

\begin{abstract}
Creativity is an important asset to our nation Malaysia as the need for "creative" workforce is increasing. In a report by Sinar Harian, Malaysia was ranked 35th in the Global Innovation Index (GII) and resides among middle income countries endeavouring to close the innovation gap. Following this fact, this research was proposed with the main objective of identifying real creativity level of B40 Malaysian students. The research instrument was a questionnaire modified according to Torrance Creative Thinking Test, where its Verbal Test and Figural Test were fashioned to measure creativity based on the four measuring indexes proposed by Yong, namely Originality, Fluency, Flexibility, and Elaboration. Datas procured were analyzed via descriptive statistics; from it several creativity aspect suggestions that could be implemented in Malaysia were brought forward. The findings of this research can be leveraged by stakeholders when planning the social system, education, work, economy, and improving Malaysia's standings in the Global Creativity and Global Creative Class indexes to similar heights as other Asia Pasific countries.
\end{abstract}




\title{
The Influence of Nature in the Design of 'Kelarai' Woven Mat Patterns Produced by the Malay Community in the East Coast of Malaysia
}

\author{
${ }^{*}$ I Mariam ${ }^{1}$ and I Marzuki \\ ${ }^{1}$ Faculty of Inovative Design and Technology, Universiti Sultan Zainal Abidin, Kampus \\ Gong Badak, 21300 Kuala Terengganu, Terengganu, Malaysia. \\ ${ }^{2}$ Faculty of Inovative Design and Technology, Universiti Sultan Zainal Abidin, Kampus \\ Gong Badak, 21300 Kuala Terengganu, Terengganu, Malaysia.
}

*mariamidris154@gmail.com

\begin{abstract}
The kelarai woven mat patterns is a common woven art form practised by Malays in the East Coast of Malaysia. The kelarai weave is denoted by the simple arrangement of squares to produce patterns on the mat. It is produced to show the beauty in the art of mat weaving. Each mat produced uses the 'kelarai' design, which is inspired by the elements of nature, as highlighted in the Malay philosophy and culture. This study aims to identify the use of kelarai pattern design, which is still largely not understood by some fractions of the public. This study will describe the types of kelarai pattern designs found on woven mats and the philosophy used, to enhance understanding and appreciation of art. This study is important because the art of kelarai mat weaving has been gradually forgotten, and there is uncertainty on the fate of this Malay art heritage. This is because the younger generation has little interest in continuing this traditional art form. This study is a qualitative study that uses field research method. It will descriptively describe the design of the motif and translate the nature elements highlighted in the design. The study's findings show that the Malays are highly skilled in producing kelarai woven mats despite having no formal education. These crafters have a high knowledge and skills in the arts, especially in using the woven arts to glorify the attributes of Allah S.W.T.
\end{abstract}




\title{
The Satisfaction of Residents of Residential Homes in Jordan Over Atrium Daylight
}

\author{
${ }^{*}$ Marzuki Ibrahim ${ }^{1}$ and Haytham Jaradat ${ }^{2}$ \\ ${ }^{1}$ Faculty of Innovative Design and Technology, Universiti Sultan Zainal Abidin, Gong \\ Badak Campus,21300 Kuala Nerus, Terengganu, Malaysia. \\ ${ }^{2}$ Faculty of Innovative Design and Technology, Universiti Sultan Zainal Abidin,Gong \\ Badak Campus,21300 Kuala Nerus, Terengganu, Malaysia. \\ *marzukiibrahim@unisza.edu.my
}

\begin{abstract}
This research was conducted to measure the level of satisfaction of residential occupants who use atrial roof architecture with daylight in terms of interior design suitability, thermal comfort, and internal visual comfort. The quantitative research method using this survey question involved 355 residential residents in Amman, Jordan. Respondents consisted of 40.3\% women and $59.7 \%$ men aged 25 to 50 years and above. Findings from this research show that ridge roofs recorded the highest percentage overall as compared to other types of roofs listed in this study (68.2\%). The collected data were coded, and SPSS version 23 was used to analyze all the data. The conclusions from this study indicate that Jordanians are satisfied with daylight on their atrium roof in terms of interior design suitability, thermal comfort, and interior visual comfort. Findings from the study suggest that daylight illumination in the atrium in Jordanian residential buildings is essential to analyze and it is also very closely related to the factors that have been identified; interior design, thermal comfort as well as visual comfort. All these factors have helped in giving exposure to the housing contractors involved in the aspects that need to be given special attention when doing the design work and manufacture of a product.
\end{abstract}




\title{
The Impacts of Education Level, Gender and Age Differences on Internet Use among Employees during the Movement Control Order (MCO) in Malaysia
}

\author{
`Z A Yazid ${ }^{1}$, S M Amin ${ }^{1}$, N M Taib ${ }^{1}$ and H Harun ${ }^{1}$ \\ ${ }^{1}$ Faculty of Business and Management, Universiti Teknologi MARA Cawangan \\ Melaka, Malaysia. \\ *zarinah320@uitm.edu.my
}

\begin{abstract}
The aim of this paper is to investigate the impacts of education levels, genders and age on employees' internet use in Malaysia during the Movement Control Order (MCO) in Malaysia. An online survey was used to collect primary data from 505 internet users among employees from public and private organizations in Malaysia. Data collected were analysed using SPSS 20.0. The results indicated that gender and education level had a positive impact on employees' internet usage while age did not have any significant impact on employees' internet usage. These findings should be useful for policymakers in setting up strategies to promote internet use among employees. Implications of the study are also discussed.
\end{abstract}




\title{
Determinants for Sustainable Green Product Consumption: A Glimpse from Peninsular Malaysia
}

\author{
${ }^{*}$ F W Rian ${ }^{1}$, N Gusman ${ }^{1}$ and M Fatimah ${ }^{1}$ \\ ${ }^{1}$ Faculty of Industrial Management, Universiti Malaysia Pahang, Lebuhraya Tun \\ Razak, 26300 Gambang, Pahang, Malaysia. \\ *rianfatra98@gmail.com
}

\begin{abstract}
The increase of economic growth changes the lifestyle and consumption patterns. It may also have excessive impact on environmental. One of solution that can be offered is the development of environmentalfriendly production and consumption systems. In this study, the perception will be used as initial hypotheses that consumption values are the driving for sustainable green product consumption. Consumption values used are value for money, social value, conditional value, and epistemic value. Environmental attitude which is an independent variable is made as the only first-order construct. The data collection method used in this study is to use a structured questionnaire. To test the hypotheses in this study Structural Equation Modeling (SEM) with SmartPLS 3.3.2 was used. The results shows that the environmental attitude will affect the level of consumption values. More importantly, sustainable green product consumption is not directly affected by social value, and the social value does not mediate the effect of environmental attitudes on sustainable green product consumption. Implication of the research will be discussed.
\end{abstract}




\title{
Does Financial Support Improve the Well- being of the Elderly?
}

\author{
*S N Mohd Fadzil', I Osman², S Ismail², M J Mohd \\ Hashim $^{3}$ and M R Khamis ${ }^{3}$
}

\begin{abstract}
${ }^{1}$ Faculty of Business and Management, Universiti Technologi MARA, Shah Alam Selangor, Malaysia

${ }^{2}$ Faculty of Business and Management, Universiti Technologi MARA, Cawangan Melaka, Kampus Bandaraya Melaka, Malaysia

${ }^{3}$ Faculty of Business and Management, Universiti Technologi MARA, Cawangan Selangor, Kampus Puncak Alam, Selangor, Malaysia
\end{abstract}

*hanisfadzil874@gmail.com

\begin{abstract}
The increase in the aging population in the ages of above 60 years old has given huge impact on the socioeconomic, growth and human development of a country. Meanwhile, poor well-being initiatives in a nation contribute more on neglect of elderly welfare, and mental and physical abuse affecting better life quality and satisfaction. Approximately 703 million persons aged 65 years old in the world in year 2019, and it is projected to double to 1.5 billion in 2050. Millions of senior citizens are exposed to two main problems, physical and mental health, and financial capacity. Financial poverty, particularly, is the core in an ageing society due to lack of regular income, the death of a spouse, mounting medical bills, and poor planning for retirement among elderly people. Thus, the main aim of this article is to review the role of financial support in improving elderly well-being. The main implication of this article reacts to government authorities in planning and providing initiatives or assistance for the elderly financially. Therefore, proper welfare, policy and legal services for the elderly require a deeper understanding of the relationship between the individual characteristics of adults and preferred financial components to improve elderly well-being and life satisfaction. For future recommendations, studies through observations, interviews, and empirical investigations would provide evidence the real demand of financial support and its components towards improving elderly well-being.
\end{abstract}




\title{
Effects of Gender, Age, and Internet Competency on Internet Usage among Academicians during the Movement Control Order (MCO) in Malaysia
}

\author{
${ }^{*}$ N M Taib ${ }^{1}$, S M Amin¹, Z A Yazid ${ }^{1}$ and H Harun ${ }^{1}$ \\ ${ }^{1}$ Faculty of Business and Management, Universiti Teknologi MARA Cawangan \\ Melaka, Malaysia. \\ *norraeffa@uitm.edu.my
}

\begin{abstract}
The Coronavirus Disease (COVID-19) has caused various unprecedented impacts to the whole world. In relation to this, Malaysia has enforced the Movement Control Over (MCO) starting on 18 March 2020 in order to fight the global COVID-19 pandemic. COVID-19 has claimed hundreds of thousands of lives and caused socio-economic shocks that left no one untouched. The pandemic also has forced all employees, including academicians, to practice Work from Home (WFH). In relation to this, the implementation of e-learning may incur academicians' acceptance that might be influenced by their attitudes towards internet connection, utilizing electronic equipment, and others to ensure an effective e-learning process. This study is aimed to examine the effects of gender, age, and internet competency on internet usage among academicians during the MCO. A total of 223 respondents participated in this study through a purposive sampling method which was conducted among academicians using an online questionnaire. Chi-square analysis was performed to examine the association among genders, age groups, and internet competency with internet usage. The results of the study revealed that there is a significant relationship between the respondents' genders and internet competency on internet usage among academicians during the MCO $\left(\chi^{2}=0.002, p<0.05\right)$. However, it was found that there is no significant relationship between the respondents' age and their internet usage $\left(\chi^{2}=0.665, p>0.05\right)$. In a situation where the country is facing the COVID-19 pandemic and the MCO, the use of the internet has become very important. This study also found that there are differences in internet usage among respondents of different genders and levels of efficiency. But when the online learning method was implemented, all academicians were no exception. Therefore, the age difference of academicians was found not to affect the use of the internet. Future studies by adding more respondents among teachers and those from private institutions are recommended, other than focusing on attitudes and perceptions which will benefit various parties, especially the academicians.
\end{abstract}




\title{
Youth Attitudes towards an Informal Roadside Metalwork Fabrication Apprenticeship Practice
}

\section{*H Awang ${ }^{1}$, J D Kankia², Z Daud³, R Roddin ${ }^{1}$ and A Abd Rahman $^{1}$}
${ }^{1}$ Faculty of Technical and Vocational Education, Universiti Tun Hussein Onn, 86400 Parit Raja, Batu Pahat, Johor, Malaysia.
${ }^{2}$ Hassan Usman Katsina Polytechnic Katsina State Nigeria, Nigeria.
${ }^{3}$ Faculty of Civil Engineering and Built Environment, Universiti Tun Hussein Onn, Malaysia.

*halizah@uthm.edu.my

\begin{abstract}
In the informal roadside metalwork fabrication apprenticeship practice, which is now commonly practiced in north western Nigeria, the lack of right attitude were evident in the case of the apprentice. These attitudes range from; attitudes towards facilities mishandling, tools, equipment, co-workers, client and crafts master. These lacks of right attitudes hinder better services rendered to the society. The purpose of this research was to identify those right attitudes needed for the informal roadside metalwork fabrication apprenticeship practice in Nigeria. To this effect an investigation was carried out through survey research, using questionnaire instrument and interview as entailed by methodological triangulation. The research was survey using 140 population of master craft persons from sampled workshops in seven states of North West geo-political zone of Nigeria, using structured questionnaire instrument. Interviews were conducted involving ten participants, randomly selected from, Industry-based trainers, lecturers and instructors within the seven states in north western Nigeria. The interviews were to have a balance result. Series of coding were made to obtain the results which were interpreted as they complemented the descriptive results as known by the methodological Triangulation method. To validate the results obtained from methodological triangulation, eleven Delphi panel of experts were engaged. Binary analysis and Kendall's coefficient of concordance (Kendall's Wa) were used to measure and determine the consensus of the Delphi panel of experts on the Attitude items. Results obtained were positive because, the level of consensus between the panelist was strong, the Attitude needed items score was 0.716 . The result also indicated an inter-judge reliability. Suggestions were made for the improvement of the practice, as the right Attitudes needed were outlined and validated.
\end{abstract}




\title{
The Use of Character-driven in Educational Comics to Promote Engagement in Classroom
}

\author{
${ }^{*}$ S M Nasir ${ }^{1,2}$, H Hamid $^{1,4}$, T F T Anuar ${ }^{3}$, I N Marzuki ${ }^{1,4}$ M \\ A Ariffin ${ }^{5}$ and T S Guan ${ }^{6}$
}

${ }^{1}$ Fakulti Teknologi Kreatif dan Warisan, Universiti Malaysia Kelantan, Kampus Bachok, 16300 Bachok, Kelantan, Malaysia.

*suraya.mn@umk.edu.my

\begin{abstract}
Engagement with students during teaching and learning process is vital to ensure effective communication in virtual classes. However, students with limited internet access face problems in participating the sessions. While teachers are adapting to the new normal in education, creative approach to teaching has been introduce in class by using educational comics. A case study has been conducted on 30 respondents through trial usage of comics and questionnaire. The findings reveal the effectiveness in using educational comics as introductory material in weekly lessons. The employment of teachers-inspired characters in comics has also contributed to students' engagement during non-face-to-face classes. Additionally, teachers-inspired comics can help diversify learning tools used by lecturers as effective teaching/learning strategies.
\end{abstract}




\title{
Microcontroller based MPPT Solar Charge Controller
}

\author{
${ }^{*}$ N H Baharudin ${ }^{1}$, T M N T Mansur ${ }^{1}$, T L Cong ${ }^{1}$, N F A \\ Sobri ${ }^{1}$ and $\mathrm{R}$ Ali $^{1}$
}

${ }^{1}$ Faculty of Electrical Engineering Technology, University Malaysia Perlis, Kampus Tetap Pauh Putra, 02600 Arau, Perlis, Malaysia.

*norhanisahbaharudin@gmail.com

\begin{abstract}
This paper deals with the Arduino based MPPT Solar Charge Controller. The maximum PV power extracted using maximum power point tracking (MPPT) algorithm. Whilst there are many of MPPT charge controllers available in the market, the Arduino based MPPT solar charge controller is an attractive method for MPPT controller due to its adaptable, simple, cheap, and durable that have a good performance and does the job well and has the profitable advantage that it can be set up in rural areas with a cheaper cost than conventional MPPT charge controllers. This system ensure maximum rated power is drawn from the PV panel and delivered it to the battery charging in healthy mode which prolong the battery life, increase efficiency of the PV panel under varying environment condition such as variation of the solar irradiation. To assess the performance, the Perturb and Observe (P\&O) algorithm methods are simulated using an Arduino based MPPT controller model for the PV system. The test result has shown the performance of the MPPT solar charge controller in tracking the maximum power point and extracting the optimum available power whilst charging the battery in the healthy mode.
\end{abstract}




\title{
Vernacular Graphic Design: Interactive Logos for Tourism Terengganu
}

\author{
${ }^{*}$ M S Ahmad ${ }^{1}$, S A M Alharahsheh¹, M Ibrahim¹, I \\ Abdullah ${ }^{1}, \mathrm{M} \mathrm{H} \mathrm{Omar}^{1}$
}

${ }^{1}$ Faculty of Innovative Design and Technology, Universiti Sultan Zainal Abidin, Gong Badak Campus, 21300 Kuala Nerus, Terengganu, Malaysia

*musophist@unisza.edu.my

\begin{abstract}
The tourism industry is one of the most important sectors for the economic development of a country around the world. Therefore, most countries use a variety of approaches including interactive graphic design to attract the attention of visitors traveling to their respective countries. In Malaysia, for example, most of the organizations involved in the tourism industry have strengthened their advertising towards interactive graphic design approach, especially the state tourism departments. One of the states in Malaysia that is actively developing tourism advertising and infrastructure is the state of Terengganu, which located on the east coast of peninsular Malaysia. In fact, the state of Terengganu has its own tourist attraction. There are many tourist attractions listed in the state. Among the organizations responsible for operating and promoting the tourism industry in the state is known as Terengganu Tourism. The Terengganu Tourism is an exemplary organization in the production of positive tourism advertisements, where a variety of creative and innovative tourism advertisements have been widely produced, and easily seen everywhere around the state. However, there are some matters related to the interactivity of the tourism ads that need to be improved, especially the identity of the logos. This study is conducted is to identify the main vernacular capacity found in the existing tourism logos, to analyse side-vernaculars for improvement to the existing tourism logos, and to recommend to Terengganu Tourism about the findings of new interactive graphic tourism logo design for their future tourism promotion use. This study was conducted based on qualitative research methods through time sampling observations and semi structured interviews. In addition, thematic analysis is also used to ensure that the theme of the study is coherent, consistent and distinctive. The findings of the study, which is the new interactive graphic tourism logo design, do have strong vernacular elements, such as diversity of culture, icon and heritage of the state of Terengganu. All efforts from Terengganu Tourism towards creative advertising, improvement in market segmentation, and innovative promotional campaigns at the national and international levels will be appreciated.
\end{abstract}




\title{
The Attitude of Property Owners Toward The Imposement of Assessment Tax
}

\author{
${ }^{*}$ M R Abdul Wahab ${ }^{1}$, S Abdullah², M H Hanafi ${ }^{1}$, \\ M N Mat Nah ${ }^{1}$ and A Abdul Razak ${ }^{1}$
}

${ }^{1}$ School of Housing, Building \& Planning, Universiti Sains Malaysia, Pulau Pinang, Malaysia

${ }^{2}$ Faculty of Architecture and Ekistics, Universiti Malaysia Kelantan, Kelantan, Malaysia

*shardy.a@umk.edu.my

\begin{abstract}
Attitude is a key component that can influence taxpayers' decisions whether to pay a tax or not. In the context of assessment tax, the issue of endless arrears requires careful study to be carried out on the actual attitude of taxpayers. It is because the result of the study will able to be utilized by the relevant agencies in order to develop certain actions that can form a positive attitude among the taxpayers. Therefore, this study has been conducted with the aim of identifying the actual attitude of property owners toward the assessment tax payment imposed on them. Through the survey approach, a total of 384 questionnaires were distributed to the respondents of this study. The data obtained were analyzed using descriptive statictic. The results of the study found there are 7 statements related to the attitude of assessment taxpayers where it revolves around two main elements, namely awareness and morality.
\end{abstract}




\title{
Sources of Brand Equity: An Investigation In Smes Context
}

\author{
${ }^{*} \mathrm{~N} \mathrm{H}$ AbdGhani ${ }^{1,2} \mathrm{~N}$ C Nawi ${ }^{1}$ and A A A Rahman ${ }^{1}$
}

\begin{abstract}
${ }^{1}$ Faculty of Entrepreneurship and Business, Universiti Malaysia Kelantan (UMK), Kampus Kota, Karung Berkunci 36, 16100 Pengkalan Chepa, Kota Bharu, Kelantan, Malaysia.
\end{abstract}

2Center of Universiti Quality Management, Universiti Malaysia Kelantan (UMK), 16300

Bachok, Kelantan, Malaysia.

*hasmini.ag@umk.edu.my

\begin{abstract}
Brand equity is considered to be one of the most important organizational resources. The importance of brand equity is not only agreed by large companies but SMEs also can build brand equity to ensure strength of their companies. Brand equity is critical to any organization including in SMEs as it conceptualized based on marketing and financial perspective. Obviously, higher brand equity can increase revenue, lower costs and greater profits. Thus, exploring the sources of brand equity become critical. This study will explore three main long-term branding strategies, which referring to brand experience, brand innovation and brand relationship in developing brand equity. These strategies majority investigated in larger company context previously. However, in this study these strategies are explored in the context of SMEs. Particularly, there are three main objectives in this study that refer to: 1 - to investigate the relationship between brand experience and brand equity; 2 - to investigate the relationship between brand innovativeness and brand equity; and, 3- to investigate the relationship between brand relationship and brand equity. Interestingly, the result of this study supported the previous study and enhance the importance of brand experience, brand innovativeness, and brand relationship in SMEs brand equity context.
\end{abstract}




\title{
Recruitment Framework of Academic Staff as Institutional Process at Public Universities in Bangladesh
}

\author{
${ }^{*}$ Dr. Jabunnesa ${ }^{1}$ and Dr. Md. Aminul Islam² \\ ${ }^{1}$ Department of Public Administration, Jahangirnagar University, Bangladesh \\ ${ }^{2}$ Faculty of Applied and Human Sciences, Universiti Malaysia Perlis \\ *jebunjupa@gmail.com
}

\begin{abstract}
Higher Education in Bangladesh has become a most-talked issue due to questions arises on its quality. Public university exercises its highest freedom in appointing faculty member recruitment preferring voter rather than teacher based on political consideration rather than merit and quality. The study is primarily finished with the secondary data collected from the different journals, newspaper, books, reports and supplementary exploring qualitative in nature. The study finds out that no specific rules and regulation even though unified policy are survived for recruitment process at the public universities in Bangladesh. Government tries to formulate unified recruitment policy but all efforts nipped in the buds due to massive hindrance from the public universities. The study shows that corruption, favoritisms, nepotism, patronage and political consideration are the major aspect of recruitment process that affects the whole higher education system in Bangladesh.
\end{abstract}




\title{
The Roles of Trust and Perceived Risks on Online Self-Disclosure
}

\author{
${ }^{*}$ A Ismail ${ }^{1}, \mathrm{M} \mathrm{R}$ Hamzah $^{1}$ and $\mathrm{H}$ Hussin ${ }^{1}$ \\ ${ }^{1}$ Faculty of Applied and Human Sciences, Universiti Malaysia Perlis, Pengkalan Jaya, \\ Jalan Alor Setar - Kangar, 01000 Kangar, Perlis, Malaysia. \\ *adilaismail@unimap.edu.my
}

\begin{abstract}
With the vast use of the Internet and specifically social media, a large number of online interaction and sharing of personal information on social media networking sites has raised new privacy issues. Against this concern, this paper will provide a conceptual understanding on the moderating factors towards online self-disclosure, which are trust and perceived risks. Trust is hypothesized to increase self-disclosure online, meanwhile perceived risks is suggested to decrease the activity. Based on the proposed framework, propositions are formulated as a basis for the study that will follow.
\end{abstract}




\title{
H.E.L.P Model as A Framework of Intervention in Redressing Domestic Violence: A Qualitative Approach
}

\author{
${ }^{*}$ M A Ghani ${ }^{1}$, A Mohamad ${ }^{2}$ and N A Ahmad ${ }^{1}$ \\ ${ }^{1}$ School of Applied Psychology, Social Work and Policy, Universiti Utara Malaysia, \\ 06010 Sintok, Kedah, Malaysia. \\ ${ }^{2}$ Faculty of Mechanical Engineering Technology, Universiti Malaysia Perlis, Kampus \\ Pauh Putra, 02600 Arau, Perlis, Malaysia \\ *mariny@uum.edu.my
}

\begin{abstract}
Domestic violence is often described as a family-centered problem and generally understood as patterns of abusive and coercive behavior which may cause physical injuries, psychological and emotional disturbances, sexual intimidation as well as financial oppression of the victim. The real magnitude of domestic violence problem in Malaysia has remained unclear due to the absence of comprehensive and well documented statistical data on violence against women as well as the issue of under-reporting cases of domestic violence. The study aims to be of significant use in gathering new and valuable data from the abused women's perspective and the professionals who work directly with them in offering help. The study employed qualitative approach using face-to-face; semi-structured interview with seven respondents consist of abused women and professionals who involved in managing the shelter homes. Current practices in the country show that information and records regarding domestic violence are non-integrated and separated from one another. Therefore, the research aspires to offer contributions on such issues as data sharing with governmental and nongovernmental agencies can be beneficial to abused women, their children, family, friends, and the society at large. A significant discovery from this study is one of the intervention framework for domestic violence victims and survivors known as H.E.L.P Model. This model enlightens that seeking assistance for abused women required four important components which include medical aid (healthcare support systems), social welfare efforts, legal advisory services as well as spiritual guidance and support while dealing with domestic violence experiences in the relationships.
\end{abstract}




\title{
Formation of Citizen-Centric Public Service Satisfaction Model During Pandemic Crisis in Malaysia: An Ideology
}

\author{
${ }^{*}$ S H M Amin ${ }^{1}$, A J M Ali ${ }^{1}$, A Abdullah ${ }^{1}$ and S D M \\ Wahid $^{1,2}$ \\ ${ }^{1}$ Faculty of Administrative Science \& Policy Studies, Universiti Teknologi Mara, 40450 \\ Shah Alam, Selangor, Malaysia. \\ ${ }^{2}$ Faculty of Business Management, Universiti Teknologi Mara, 78000 Alor Gajah, \\ Melaka, Malaysia. \\ *hajjar@uitm.edu.my
}

\begin{abstract}
The aim of this study is to produce a citizen-centric public service satisfaction model during the pandemic crisis in Malaysia. To develop the model, this study has gone through exploratory analysis using previous literature. Four components have been proposed that can benefit the supply side in conducting requirement gathering and designing of citizen-centric public service satisfaction model. This study can be useful in conceptual studies analysing the cognitive perspective of citizen satisfaction pertaining to the public administration during the pandemic crisis. This study provides a new integrative model reflecting citizen-centric public service satisfaction during a pandemic crisis. This study provides a new integrative model reflecting citizen-centric public service satisfaction during a pandemic crisis.
\end{abstract}




\title{
Pest Disturbance In Edıble Bırd Nest Swiftlet House
}

\author{
*Wan Khairy, W.I', Munirah A.R ${ }^{2}$, Nur Fatihah Nabilah \\ A.J' Zulhazman, $\mathrm{H}^{3}$ and M.R Yaacob ${ }^{1}$
}
${ }^{1}$ Faculty of Entrepreneurship and Business, Universiti Malaysia Kelantan, Kampus Kota, Pengkalan Chepa, 16100, Kota Bharu, Kelantan.

${ }^{2}$ Voel Enterprise, Lot 1417, Jalan Taman Purnama, Tok Adis, Kuala Ibai, 20400, Kuala Terengganu.

${ }^{3}$ Faculty of Earth Science, Campus Jeli Universiti Malaysia Kelantan, Locked Bag 100, 17600 Jeli, Kelantan.

*khairy.wi@umk.edu.my

\begin{abstract}
Many entrepreneurs are very interested to start Edible Bird Nest (EBN) production. However, many of them lack knowledge in pest distrubance in swiftlet house. They suffered losses because they are not concerned about pest disturbance in swiftlet house. This study aimed to identify pest in swiftlet house and to establish pest distrubance in swiftlet house. This research was conducted through field study. Field studies were conducted in nine swiftlet houses from three different areas namely, town, coastal and forested areas. Based on the field study, ants were the biggest pest problem in EBN swiftlet houses where about 69 observations of the houses were infested with the insects at one point or another. Cockroaches were the second biggest problem with 30 observations of the houses infested and rats were found in 18 observations of the houses. Pest disturbance in swiftlet house was the main cause of failure in the swiftlet ranching business. The results showed that there are no significant difference between pest disturbance in swiftlet house with location of swiftlet house. In the management of swiftlet houses, less pest disturbance can be assured to be productive and profitable ranching venture swiflet.
\end{abstract}




\title{
Suitable Habitat And Environmental Conditions For Successful Edible Bird Nest Swiftlet Houses
}

\author{
*Wan Khairy, W.I', Munirah A.R², Nur Fatihah Nabilah \\ A.J ${ }^{1}$, Zulhazman, $\mathrm{H}^{3}$ and M.R Yaacob ${ }^{1}$
}

${ }^{1}$ Faculty of Entrepreneurship and Business, Universiti Malaysia Kelantan, Kampus Kota, Pengkalan Chepa, 16100, Kota Bharu, Kelantan.

${ }^{2}$ Voel Enterprise, Lot 1417, Jalan Taman Purnama, Tok Adis, Kuala Ibai, 20400, Kuala Terengganu.

${ }^{3}$ Faculty of Earth Science, Campus Jeli Universiti Malaysia Kelantan, Locked Bag 100, 17600 Jeli, Kelantan.

*khairy.wi@umk.edu.my

\begin{abstract}
Many entrepreneurs are very interested to start Edible Bird Nest (EBN) production. However, many of them lack knowledge in suitable habitat and environmental conditions for EBN swiftlets. They suffered losses because they are not concerned about providing the management of the suitable habitat and environmental conditions before building their EBN swiftlet house. This study aimed to identify and establish the list of habitat and environmental conditions for successful of edible bird nest swiftlet ranching. This study comprised of interview questions and field study. Questionnaires were distributed 100 players in EBN industry in Terengganu. For the field study, air and surface temperatures, relative humidity, light intensity, and sound level were recorded in nine EBN swiftlet houses in three different areas, the forested, the coastal and the town areas. From the questionnaires, we found that the most popular area (67\%) to build EBN swiftlet houses was the forested area. This was followed by, the coastal area $(26.7 \%)$ and town area $(6.7 \%)$. Based on field study results, forested areas were the best and most productive to build EBN swiftlet house. The mean EBN and individual swiftlet population from the different areas were as follows: 78 nests and 263 individuals in forested, 51 nests and 133 individuals in the coastal and 25 nests and 65 individuals in the town area. From the environmental parameters collected it was shown that houses built in the forested area had the most suitable range for swiftlet adaptation. Air and surface temperatures were $31 \mathrm{oC}$, relative humidity was $82 \%$, light intensity $0.16 \mathrm{LUX}$, sound level $50 \mathrm{~dB}$ (internal) and $65 \mathrm{~dB}$ (external). The results showed that EBN production was significantly higher in swiftlet houses with suitable habitat and environmental conditions. In the management of swiftlet houses, only suitable habitat and environmental conditions can be assured to be productive and profitable ranching venture swiflet.
\end{abstract}




\title{
The Roles of Mosque in Sympathising the Kariah Members During the Movement Control Order (MCO) Period
}

\author{
*J M Salleh ${ }^{1}$, M S Karim¹, N A Kedin² and S B Sulaiman² \\ ${ }^{1}$ Fakulti Perakaunan, Universiti Teknologi MARA, Cawangan Melaka, 78000 Alor \\ Gajah, Melaka, Malaysia. \\ ${ }^{2}$ Fakulti Sains Komputer dan Matematik, Universiti Teknologi MARA, Cawangan \\ Melaka, 78000 Alor Gajah, Melaka, Malaysia.
}

*jismi@uitm.edu.my

\begin{abstract}
A mosque is a special place of worship for the Muslims and it plays various significant roles including in managing the economic affairs of the community. The strong association between the mosque and the Muslim society could not be denied as a mosque is regarded as the pillar and centre of Muslim activities (Wahab et al, 2016). In handling the impact of the pandemic of covid-19 or coronavirus which hit the world in 2020, the government of Malaysia had enforced the Movement Control Order (MCO) in April 2020. The implementation of MCO had directly affected a majority of residents in the country due to the discontinuation of certain economic activities. In dealing with the difficult situation, there is a question of whether the mosque had duly provided its kariah members with the necessary financial support and other assistance. In relation to the issue, research was carried out with the main objective of studying the effectiveness of the roles played by the mosque in taking care of the affairs of their kariah members during the period of MCO. Suggestions for improvements that should be duly considered by the mosque were also highlighted. A field study was undertaken by using questionnaires developed by the researchers. The questionnaires were distributed by using a random sampling technique to the respondents in the state of Melaka. Analysis of the data obtained from the questionnaires was made quantitatively, and it was also supported by qualitative explanations in order to enable the strengths, weaknesses, and recommendations for improvements to be described in detail. Besides providing feedback to the management of mosque, the study would also enlighten the opportunities for other researches to be carried out on the possibilities that mosque might need to improve on its existing functions and roles in sympathising the poor and needy group of the society.
\end{abstract}




\title{
Covid-19: Masjıd-Youth Engagement Inıtıatıves And Communicatıon Barriers
}

\author{
${ }^{*}$ M A Mahat ${ }^{1}, \mathrm{~N}$ A Kedin², J M Salleh ${ }^{1}$ and M H M Omar ${ }^{3}$
}

${ }^{1}$ Faculty of Accountancy, UiTM Melaka, Kampus Alor Gajah, 78000 Melaka, Malaysia

${ }^{2}$ Faculty of Computer and Mathematical Sciences, UiTM Melaka, Kampus Alor Gajah, 78000 Melaka, Malaysia

${ }^{3}$ Faculty of Art \& Design, UiTM Melaka, Kampus Alor Gajah, 78000 Melaka, Malaysia

*mohda229@uitm.edu.my

\begin{abstract}
Masjid is regarded as one of the most important institutions in Islam. During the post-Hijra phase of Muslim community in Madinah, masjid has been established as the centre for the ummah which significantly contributed to the arisen of Muslim civilitation in the past. Nowadays, most masjid however seem to have narrowed down its function for merely worshipping purposes. Notably, this institution is facing challenges to engage the whole segment of the society particularly Muslim youth, the failure of which would jeopadize the effort to instil the necessary Muslim characters and values in them. Covid-19 pandemic which had started in the first quarter of the year 2020 has further worsen the situation. If this problem persists, the future of masjid as the basic foundation of the ummah is threatened, uncertain and will continue to be less relevant in a community. The primary objective of this study is to analyse the initiatives taken in engaging Muslim youth with masjid before and during Covid-19 pandemic. A online survey was distributed to Muslim youth nationwide and a total of 556 responses were received and analysed. This study found that the initiatives taken to engage Muslim youth with masjid before and during Covid-19 pandemic are barely sufficient and need further improvement. A possibility of serious communication gap between masjid and the Muslim youth was also highlighted. This is the first large scale study on Covid-19 and its implications on the engagement of Muslim youth with masjid. The findings are regarded as relevant and beneficial to all relevant parties particularly the State Religious Authorities in their effort to improve the engagement of Muslim youth with masjid as well as to revive masjid as a prominent institution in the Muslim community in Malaysia.
\end{abstract}




\title{
The Design and Evaluation of Interactive Learning Media Using Augmented Reality (AR) Technology for Equilibrium Phase Diagram
}

\section{${ }^{*} \mathrm{~S} N$ Khairunnisa ${ }^{1}, \mathrm{H}$ N Ismalina ${ }^{1}$ and T Amarul ${ }^{2,3}$}

\begin{abstract}
${ }^{1}$ Mechanical Engineering Department, Politeknik Tuanku Syed SIrajuddin, 02600 Arau, Perlis, Malaysia.

${ }^{2}$ Green Design and Manufacture Research Group, Centerof Excellence Geopolymer and Green Technology (CEGeoGTech), Universiti Malaysia Perlis, 01000 Kangar, Perlis, Malaysia.

${ }^{3}$ Faculty of Mechanical Engineering Technology, Universiti Malaysia Perlis, KampusUniCITI Alam, Sungai Chuchuh, 02100 Padang Besar, Perlis, Malaysia.
\end{abstract}

*nisa1811@gmail.com

\begin{abstract}
This research study is about the design and evaluation of interactive learning media using Augmented Reality (AR) application for learning the Equilibrium Phase Diagram. Augmented reality gives better approaches for users to rapidly getting information which comes "alive" instantly to help and attract the students to learn equilibrium phase diagram effectively. Augmented Reality also was found helpful in reducing the problems of visualization in the topic of Equilibrium Phase Diagram. In order to ensure the learning process is successful, the instructional design model: ADDIE Hybrid Model, has been used in the development of the interactive learning media using augmented reality to learn the equilibrium phase diagram. There were five phases involved to make sure that the process of before, during and after using the interactive learning media with augmented reality applications has achieved the objectives.
\end{abstract}




\title{
The influence of Entrepreneurial Orientation on SMEs Performance in Ghana: The role of Social Capital and Government Support Policies
}

\section{*S G Zaato', M Ismail'1, S Uthamaputhran¹, W Owusu- Ansah² and J Owusu²}

\begin{abstract}
${ }^{1}$ Faculty of Entrepreneurship and Business, University Malaysia Kelantan, City Campus, 16100 Kota Bharu, Kelantan, Malaysia.

${ }^{2}$ Department of Marketing \& Corporate Strategy, Kwame Nkrumah University of Science and Technology (KNUST), Ghana.
\end{abstract}

*zagso2012@gmail.com

\begin{abstract}
The primary aim of this current study is to propose a research framework on the influence of Entrepreneurial Orientation (EO) on SMEs performance in Ghana: The role of Social Capital (SC) and Government Support Policies (GSPs). The study reviewed existing literature pertaining EO, SC and GSPs by using the five EO dimensions of Lumpkin and Dess, (1996) to further ascertain the mediating and moderating effect of SC and GSPS in relation to SMEs performance and in Ghana and used measures of SC, and GSPs. A questionnaire will be administered to 380 registered SME-owners of Ghana based on Ghana Statistical Survey, (2016) using simple random sampling technique, and the data will be analysed by the Partial Least SquareStructural Equation Modelling (PLS-SEM) approach to determine the emerged hypothesis. This study would be hinged on the resource-based view and the social capital theories stressing the need for SMEs to focus more on their unique internal and external resources that existed within their social capital network based on their reciprocal relations. This novel study would further provide new insight to practitioners to understand and appreciate the role of SC in explaining the EO of SMEs and how GSPs can enhance the EO and SMEs performance relationship.
\end{abstract}




\title{
Evaluation of Coronavirus Covid-19's Impact on Malaysian -Based Global Companies
}

\author{
S Uthamaputhran ${ }^{1}$, 'S.G Zaato ${ }^{1}, \mathrm{H}$ Hasan${ }^{1}, \mathrm{~N}$ R Zaind ${ }^{1}$, \\ M I Aziz ${ }^{1}$ and $\mathrm{N} \mathrm{H} \mathrm{Hamsani}^{1}$
}

${ }^{1}$ Faculty of Entrepreneurship and Business, University Malaysia Kelantan, City Campus, 16100 Kota Bharu, Kelantan, Malaysia.

*zagso2012@gmail.com

\begin{abstract}
The coronavirus outbreak has created a massive chaos and affected the domestic and global opportunities of Malaysian economy. Majority of the businesses affected in Malaysia are micro, small and medium sized enterprises. The aim of this article is to rewind back the impact of COVID-19 outbreak on Malaysian-based global companies and provide recommendations for policymakers to focus on main agenda that are very important during post-COVID-19 that is needed mainly to reduce business losses and survival throughout this crisis.
\end{abstract}




\title{
All Eyes on Me?: University Student's Speaking Anxiety in Relation to Gender
}

\author{
${ }^{*}$ N A Nordin², N F Dellah¹, F H Amanah², N Zabidin' and \\ M A Atan²
}

${ }^{1}$ Academy of Language Studies, Universiti Teknologi MARA Melaka, Km 26 Jalan Lendu, 78000 Alor Gajah, Melaka Bandaraya Bersejarah

${ }^{2}$ Academy of Language Studies, Universiti Teknologi MARA Melaka, Jalan Lembah Kesang 1/1-2, Kampung Seri Mendapat, 77300 Merlimau, Melaka

*afifanordin@uitm.edu.my

\begin{abstract}
A cardinal skill in acquiring a second language is speaking. Oral communication skill is perceived to be the most daunting especially for students of low proficiency since assessments and practices require them to speak in public or in front of peers. The purpose of conducting this study was to assess speaking anxiety in English oral presentations among UiTM diploma students in correlation to speaking anxiety levels and gender. A set of questionnaires consisting of 33 items adapted from Foreign Language Classroom Anxiety Scale (FLCAS) was disseminated to 257 students and analysed using statistical analysis (SPSS). The result depicted that male students have higher speaking anxiety across three domains (communication apprehension, fear of negative evaluation and test anxiety) compared to their female counterparts. However, further analysis using the independent sample t-test revealed that there was no significant difference between genders. Therefore, the results of this study have implications for ESL educators and could offer suggestions in adopting effective educational practices to help mitigate speaking anxiety among students and improve students' learning, proficiency and confidence in speaking English.
\end{abstract}




\title{
From The King's Speech to the Classrooms: Tertiary Students' Speaking Anxiety and Language Proficiency
}

\author{
${ }^{*}$ N Zabidin"1, M A Atan², N F Dellah¹, N A Nordin² and F H \\ Amanah ${ }^{2}$ \\ ${ }^{1}$ Academy of Language Studies, Universiti Teknologi MARA Melaka, KM 26 Jalan \\ Lendu, 78000 Alor Gajah, Melaka Bandaraya Bersejarah \\ ${ }^{2}$ Academy of Language Studies, Universiti Teknologi MARA Melaka, Jalan Lembah \\ Kesang 1/1-2, Kampung Seri Mendapat, 77300 Merlimau, Melaka \\ *nursyafiqah@uitm.edu.my
}

\begin{abstract}
Second language or foreign language learners commonly experience anxiety when they have to speak using the target language. This is made even more apparent when they are required to present during a speaking assessment or speak in front of their peers. Thus, this study was done with the aim to measure UiTM students' speaking anxiety in English oral presentations in relation to their level of language proficiency. 244 students from four different faculties in UiTM Melaka were given a set of questionnaires that consisted of 33 items adapted from Foreign Language Classroom Anxiety Scale (FLCAS). The data collected through the questionnaires was then analysed using statistical analysis (SPSS). The results showed that the participants experienced high level of speaking anxiety in English oral presentations in all three of the speaking anxiety dimensions. Pearson Correlation test also revealed that there was a significant inverse relationship between their level of language proficiency and speaking anxiety, particularly in terms of fear of negative evaluation and test anxiety. Hence, the results from this study concluded that the students' language proficiency was significant in examining their speaking anxiety and subsequently, can help provide an understanding on how to tackle the issue of language learners' speaking anxiety.
\end{abstract}




\title{
Optimization of Rhodamine 6G Removal from Aqueous Solution Using Box-Behnken Design
}

\author{
*A Huda ${ }^{1}, \mathrm{~K}$ W Lim${ }^{1}$, B Jayanthi ${ }^{1}$, S A Palsan ${ }^{1}$, M A S N \\ Huda $^{1}$, T Y S Leony ${ }^{1}$, A L Zul Ariff ${ }^{1}$ and A M Amizi
}

${ }^{1}$ Faculty of Agro Based Industry, Universiti Malaysia Kelantan, Jeli Campus, 17600 Jeli Kelantan, Malaysia

*hudaawang@gmail.com

\begin{abstract}
Batik industry is a growing textile industry in Kelantan. Improper treatment of wastewater from manufacture units leads to water pollution. One of the most abundant and harmful pollutants found in the batik industries effluents is Rhodamine 6G. A nanomagnetic adsorbent composite (NMAC) was used in this study to remove the Rhodamine $6 \mathrm{G}$ from aqueous solution. In this study, Box-Behnken Design is applied to obtain a model for optimum conditions for dye removal. A maximal dye removal (99.03\%) was attained with optimum conditions; intial dye concentration of $26.12 \mathrm{mg} \mathrm{L}^{-1}$, contact time of $14.33 \mathrm{~min}$, adsorbent dose of $0.05 \mathrm{~g}$, particle size of $190.26 \mu \mathrm{m}$ and $\mathrm{pH}$ of 6.54. A quadratic equation was validated with $99.97 \%$ fit between predicted and experimental outcomes.
\end{abstract}




\title{
Transformation of Thinking-Aloud in Assessing Hands-on Psychomotor: A pilot study
}

\author{
*ZB Razali ${ }^{1}$, NSS Mizam¹, MH Daud ${ }^{1}$ and MMMA Kader ${ }^{1}$ \\ ${ }^{1}$ Faculty of Electrical Engineering Technology, Universiti Malaysia Perlis, \\ KampusUniCITI Alam, 02100 Padang Besar, Perlis, Malaysia.
}

*zolbahri@unimap.edu.my

\begin{abstract}
Evaluation of laboratory experiences of engineering and engineering technology students has led to an increasing in the attention being paid to the development of students' psychomotor skills. One of the reasons that psychomotor seems to be less important in the past is because of the lack of suitable measuring tools despite it is important in the engineering and engineering technology course. Furthermore, a current assessment which is using report and test to evaluate the experience of student practice in the laboratory only help in assessing students' knowledge in cognitive skill. Thus, a new study method is needed to focus on evaluating engineering technology students in terms of their understanding of the component called 'hands-on practical experience' during their practical skill classes or experiment. The existing technique for evaluating psychomotor abilities that have emerged from attempts to improve selection in recruitment processes may provide a potentially useful tool for such a purpose. The point of this study is to create a new approach to test a change in practical experience to assess unintentional learning related to classic psychomotor skills in engineering technology laboratory classes. The methodology used to build up the instrument is portrayed and the empirical data collected to support its validity is presented. Thus, this research aims to find a way to measure the practical skill involve in a psychomotor change in an engineering laboratory class.
\end{abstract}




\section{Impact of Participation on Rabbit Farming Entrepreneurship for Beginners Module among B40}

*R K Raja lli Airina ${ }^{1}$, M S Nazhiifah Amiirah ${ }^{1}$, Z Suhana $^{1,2}$,
M N Maryana ${ }^{1,2}$ and T A B Tengku Halimatun Sa'adiah

${ }^{1}$ Faculty of Agro-Based Industry, Universiti Malaysia Kelantan, Jeli, Kelantan, Malaysia ${ }^{2}$ Institute of Food Security and Sustainable Agriculture Research (IFSSA), Universiti Malaysia Kelantan, Jeli, Kelantan, Malaysia

*airina@umk.edu.my 


\title{
Normally-Off GaN HEMT for High Power and High-Frequency Applications
}

\author{
${ }^{*}$ A. Z. Musa ${ }^{1,2}$, M. Mohamad Isa ${ }^{2,3}, S$. Taking ${ }^{2}$, N. \\ Ahmad $^{2}$ and F. A. Musa ${ }^{2}$
}

\begin{abstract}
${ }^{1}$ Politeknik Tuanku Syed Sirajuddin, Pauh Putra, 02600 Arau, Perlis, Malaysia.
${ }^{2}$ Faculty of Electronic Engineering Technology, Universiti Malaysia Perlis, Kampus Tetap Pauh Putra, 02600 Arau, Perlis, Malaysia
\end{abstract}

*azfadli@gmail.com

\begin{abstract}
This paper presents a review of a Gallium Nitride (GaN) High Electron Mobility Transistor (HEMT) technology appropriate in high-power and high-frequency applications. GaN, as wide bandgap materials (WBG) has demonstrated superior material properties such as improved thermal conductivity and excellent electrical properties, has become an attractive candidate for the next generation of high-power and high-frequency applications. The occurrence of the two-dimensional electron gas (2DEG) channel at $\mathrm{AIGaN} / \mathrm{GaN}$ heterostructures interface makes GaN HEMTs intrinsically Normally-on devices. However, the Normally-off operation is often desired in many power electronics applications. Several methods had been explained to obtain Normally-off devices. Therefore, Normally-off GaN-based HEMTs with a p-GaN gate method is among the most promising and the only commercially available today. First, this paper would summarize the physical properties and device performance of $\mathrm{GaN}$ material over Silicon (Si) and Gallium Arsenide (GaAs) and related to other WBG material. Then, a normally-on and normally-off configuration are explored. After that, the most relevant technological issues for normally-off HEMTs focusing on the $p-G a N$ gate are discussed. Finally, the $p-G a N$ interface's role and the impact of the thermal processes on the electrical characteristics are widely discussed.
\end{abstract}




\title{
The Application of Batik Block Motifs and Marbling Technique as Pattern Designs in Contemporary Batik
}

\author{
${ }^{*}$ G N Hafiza ${ }^{1,2}$, I Marzuki ${ }^{1,2}$ and W M Z Soliana ${ }^{3}$ \\ ${ }^{1}$ Faculty of Art\& Design, Universiti Technologi MARA, Cawangan Machang, 18500 \\ Machang, Kelantan, Malaysia \\ ${ }^{2}$ Faculty of Innovative Design and Technology,Universiti Sultan Zainal Abidin, uniSZa, \\ Terengganu, Malaysia \\ ${ }^{3}$ Faculty of Art\& Design, Universiti Technologi MARA, Cawangan Machang, 18500 \\ Machang, Kelantan, Malaysia \\ *nhafiza@uitm.edu.my
}

\begin{abstract}
Marbling is a pattern design created using inks that can float on the surface of water. The marbling technique is based on forming patterns on the surface of a liquid by manipulating floating paints. This pattern design possesses its own aesthetical value, that is the uniqueness of marbling pattern itself. Marbling can only be created once; it could not be repeated to recreate the same pattern for the second time. This is due to the influence of factors like the movement of air, water, and dye. Marbling was first introduced in $12^{\text {th }}$ century Japan. It was known as "suminagashi" or inks floating on water surface that resulted in circular patterns. In the $15^{\text {th }}$ century, the marbling technique started to flourish in Turkey and Persia, where it was known as "ebru" or "cloud art". Apart from inks, other materials involved in marbling creation includes oil paint and 'goughe'. The marbling technique continues to develop and reaches the United Kingdom, France, Germany, Holland, and Italy around the $17^{\text {th }}$ century. The researcher combined two techniques to create marbling, namely the creation of block batik through the use of wax and marbling pattern design using reactive dye, that is remazol dye mixed with alginate that functions as a dye movement control agent. Block batik (batik terap) or (batik pukul) is one of Malaysia's renown traditional craft. It is created through waxing and dyeing. Batik production in Malaysia expanded in the $15^{\text {th }}$ century. Its fame started in the East Coast states, namely Kelantan and Terengganu. The research founds that by combining marbling and block batik motifs, a new design in batik production process can be achieved. Marbling patterns were created on a silicate surface that replaced water. The silicate cured the resulting colour and pattern. From the research, it was found that silks and cottons are the most suitable for accurate dye and pattern absorption. This material could produce vibrant and orderly colours. In addition, marbling works splendidly with craft items and interior design decorations like curtains and pillowcases. The application of marbling on block batik motifs was found to be practical for entrepreneurs and students who wishes to enhance creativity in batik production. However, a continuous research is needed to simplify the process and technique for marbling and block batik production. The researcher has come up with a new application by combining block batik technique and marbling in contemporary batik creation.
\end{abstract}




\title{
Product quality evaluation: Selection among the Women Buyers in Kelantan
}

\author{
${ }^{*}$ N S M Anuar ${ }^{1}$, M Z Daud ${ }^{1}$, M Ibrahim² \\ ${ }^{1}$ Faculty of Art and Design, Universiti Teknologi MARA Cawangan Kelantan, 18500 \\ Machang, Kelantan, Malaysia. \\ ${ }^{2}$ Faculty of Innovative Design and Technology, Sultan Zainal Abidin (UniSZA), 21300 \\ Gong Badak, Terengganu, Malaysia. \\ *syafinaz342@uitm.edu.my
}

\begin{abstract}
Kelantan is one of the states that have been focusing on jewellery buyers. The features of Kelantan jewellery can be seen through a unique design, traditional concept and offered at a very reasonable price. Therefore, this study is aimed at identifying the level of knowledge and quality evaluation of jewellery products that are often judged by more than one quality feature. Quantitative methods are used to achieve this goal. The main data were collected through questionnaire survey method by interviewing 210 respondents. Respondents consist of Malay women buyers around gold shop in Kota Bharu city. Data collected and analyzed using a simple percentage method is descriptive statistics (frequency distribution and mean) and translated into table form. The collected data include demographic profiles, knowledge of jewellery and evaluation of jewellery products. The result of this research is used as a scientific reference to the parties involved directly or indirectly in this field. With the information and data obtained it can contribute to further developing the local jewellery industry.
\end{abstract}




\title{
Visitors Perception on the Facilities Management: A Preliminary Survey at Handicraft Museum Kota Bharu, Kelantan
}

\section{*S Sukri', Nordiana A J1 , S N Apandi ${ }^{1}$, A N E George ${ }^{1}$, M $\mathrm{Sim}^{1} \mathrm{M}$ Nagalingam ${ }^{1}$ and $\mathrm{M} A$ Rahni ${ }^{1}$}

${ }^{1}$ Faculty of Creative Technology and Heritage, Universiti Malaysia Kelantan, Beg

Berkunci No.01

16300 Bachok, Kelantan

*suraya@umk.edu.my

\begin{abstract}
This paper focuses on the tourist perception of facilities management at the Handicraft Museum Kota Bharu Kelantan. The museum plays a vital role in educating, managing, and identifying the communities cultural heritage because it connects to their collective memories and identities in provoking their sense of attachment and belongingness. Due to limited of scientific information in the related field, this study argues the significance of facilities management in enhancing tourists and communities experience as well as connection with their identities of the past in the handicraft museum in Kota Bharu, Kelantan. This research uses quantitative research methods, which is a survey method on tourist perception. The survey was randomly disseminated through google form to respective visitors who had visited the museum. Results show that most visitors visited the museum once in their lifetime due to the poor facility management due to three categories of facilities management. The paper also suggests few aspects of improvisation in museum management such as to hire more staffs, visible information's guidelines, sufficient public amenities, visible marketing strategies and promotions. This research also highlights its concern on the existence of an open restaurant in the museum establishments, which affects the structure and façade of the museum in the future. This study contributes to the importance of facilities management in enhancing tourist and communities experience in learning and connecting to their past and identities, which eventually invokes their sense of belongingness and attachment to their cultural heritage.
\end{abstract}




\title{
Factors influencing perception towards agriculture field in high level education among public university students in East Coast Region
}

\author{
${ }^{*}$ R Fazidah', T A B Tengku Halimatun Sa'adiah",3, A M \\ Mohd Afiq ${ }^{2}$, Z Suhana ${ }^{2,3}$ And M Z Norhafizah² \\ ${ }^{1}$ Faculty of Plantation and Agrotechnology, Universiti Teknologi MARA Pahang, \\ Malaysia. 26400 Bandar Tun Razak Jengka, Pahang, Malaysia. \\ ${ }^{2}$ Faculty of Agro Based Industry, Universiti Malaysia Kelantan, Jeli, Kelantan, \\ Malaysia \\ ${ }^{3}$ Institute of Food Security and Sustainable Agriculture Research (IFSSA), Universiti \\ Malaysia Kelantan, Jeli, Kelantan, Malaysia \\ *fazidahrosli@uitm.edu.my
}

\begin{abstract}
The agriculture sector has been the backbone of economy especially for producing agricultural products, food security, and the employment generation. However, sadly the intake patent for agriculture field in the public university in Malaysia shows the lowest number. Most youths are not interested in agriculture education in university due to their perception that agriculture courses are not as attractive as other courses. This study is aimed at determining the factors influencing the perception towards the agriculture field in high level education among public university students from across the East Coast Region, in Malaysia. Data that were collected through a questionnaire were analysed using descriptive analysis to achieve the aim of the study. The findings demonstrated that attitude was the most significant factor influencing the perception towards agriculture in high level education. Hopefully, this study can help other research to gain the perception of the students towards agriculture in the future.
\end{abstract}




\title{
A Review on Effects and Management of Parthenium Weed (Parthenium hysterophorus L.) Specially Focus on Biological Control
}

\author{
${ }^{*}$ M A H Sheikh¹, L Naher ${ }^{1,2}$ and M K Uddin² \\ ${ }^{1}$ Faculty of Agro-Based Industry, Universiti Malaysia Kelantan (UMK), Jeli Campus, \\ 17600 Jeli, Kelantan, Malaysia. \\ 2Institute of food security and sustainable agriculture, \\ ${ }^{2}$ Department of land Management, Faculty of Agriculture, Universiti Putra Malaysia, \\ 43400 UPM Serdang, Selangor, Malaysia. \\ *abdulhalimsheikh@gmail.com
}

\begin{abstract}
This review covering the literature from 1997 to present (2020), delights by the weed of Parthenium hysterophorus $L$. (P. hysterophorus) is an herbaceous flowering weed species that a member of the family Asteraceae. Weeds have been considered as a major threat and act as a hindrance to crop production all over the world, even though the farmers put remarkable efforts to reduce the weeds to grow a better and quality yield. The invasion of $P$. hysterophorus constitutes much economic loss to crops and considered to be a threat to primary production of crops and biodiversity as well which more necessitates on the development of effective control strategy. Our search of the review literature shows that the management of $P$. hysterophorus by following economically, ecofriendly and competitive displacement by using pathogens as biocontrol approach must be established in all the invaded countries. It is typically controlled by conventional management systems like manual, mechanical, and chemical methods, so many challenges have been posed. Physical and mechanical methods are not effective, labor intensive and chemical method may lead to environmental pollution, potential health human risks, creates herbicide resistance to the weed and also adverse effects on non-target beneficial organisms The cost and limitations of control methods now necessitate development of alternative techniques for at least integration into existing weed management practices. These alternative techniques may be based on biological approach using insects, pathogens has been recommended with variable degrees of success. A detailed review of limitations of currently used control methods and the feasibility of development of alternative techniques especially opportunities offered by biological control and summarizes the published papers in developing biocontrol method as sustainable eco-friendly and effective approach against $P$. hysterophorus.
\end{abstract}




\title{
Effective Online Self-Learning During Covid- 19: A Students' Perception with SES Moderation
}

\author{
*S F A Fesol' ${ }^{1}$, N H I Teo ${ }^{1}$, N A Moketar ${ }^{1}$, N H M Zain ${ }^{1}$ \\ and E E Odzaly ${ }^{1}$
}

${ }^{1}$ Faculty of Computer and Mathematical Sciences, Universiti Teknologi MARA Cawangan Melaka, Kampus Jasin, 77300 Merlimau, Melaka, Malaysia

*feirusz@uitm.edu.my

\begin{abstract}
Online learning is a platform that can be used for synchronous and asynchronous modes of communication during lessons has nowadays takes place over the Internet around the world. Distance learning has become an established method used globally in education sector to ensure continuity of teaching and learning ever since the Covid-19 pandemic in the year 2020. In order for online learning to be effective, students have to blends in with the new norms and adjust accordingly including balancing their self-learning skills and behaviour, which is crucial. Thus, this quantitative study demonstrates how the sociodemographic factors and socioeconomic status of a student could influence the students' self-learning necessity and effectiveness as well as their learning habits during Covid-19. The data for this study was collected through online questionnaires distributed via an online platform to a public university community in Malaysia across different faculties, whose learning was disrupted due to the crisis. From the survey, 668 respondents have consented to join the survey. As a result, this study reported that there is a slight increase of $3.2 \%$ of students' self-learning hours before and during the COVID-19 lockdown period. Besides, the study also found that there is a weak association between the five (5) sociodemographic independent variables consist of gender, current year of study, level of study, area of residence, and total family income per month in student's self-learning necessity and student's self-learning effectiveness during COVID-19 pandemic. Online learning promotes new educational process, albeit the results of this study, it still has significantly given an impact on the student's learning habits during Covid-19 pandemic.
\end{abstract}




\title{
Factors That Influenced the Purchase of Gemstone Among Enthusiast In Kelantan
}

\author{
M Z Daud ${ }^{1}$, M Ibrahim² and N S M Anuar ${ }^{1}$ \\ ${ }^{1}$ Faculty of Art \& Design, Universiti Teknologi MARA (UiTM), Cawangan Kelantan, \\ 18500 Machang, Kelantan, Malaysia. \\ ${ }^{2}$ Faculty of Innovative Design and Technology, Sultan Zainal Abidin (UniSZA), 21300 \\ Gong Badak, Terengganu, Malaysia. \\ *zamani266@uitm.edu.my
}

\begin{abstract}
Todays, This research has been conducted to identify three main factors i) the level of knowledge on gemstone, ii) the choices of the types of gemstone among enthusiast, iii) factors that influenced the purchase of gemstone. A quantitative research questions were used to collect information and answered the aforementioned main factors. The total of 302 respondents includes Malay male from all over Kelantan. The focus of the research is on the knowledge of gemstone only in the category of precious gemstone which are diamond, ruby, sapphire and emerald. The outcome of the analysis shows over $86.1 \%$ of respondent can identify the characteristics of natural or synthetic gemstone. However, over $66.6 \%$ of respondents are not confident with the naturalness of the purchased gemstone and are not familiar with the term of the treated gemstone and gemstone certificate. The knowledge about gemstone colour, gemstone-producing countries and the price of gemstone are from the range of $17 \%$ to $84 \%$. Ruby was the most popular choice among the respondents and the price that respondents willing to pay for a gemstone are between RM $500-$ RM 1000. Moreover, most of the respondents agreed that personal factors (age, profession, economy, life style, personality) influenced individual in purchasing the gemstone. Overall, it can be included that the level of knowledge of gemstone among enthusiast in Kelantan is at alarming level based on the findings that $76.8 \%$ of the enthusiast are not familiar with the terms of treated gemstone and gemstone certificate. To make matters worse, it is approximately around $95 \%$ to $99 \%$ treated gemstone available in the market.
\end{abstract}




\title{
Exploring Time Management Skill Among Agriculture Students
}

\section{*Farah Nadzirah Jamrus ${ }^{1}$ and Fadhlina Izzah Saman ${ }^{1}$}

${ }^{1}$ Faculty of Computer Sciences \& Mathematics, University Teknologi MARA (UiTM) Cawangan Melaka, Jasin, 77300, Melaka, Malaysia.

*fnadzirah@uitm.edu.my

\begin{abstract}
The main objective of this study is to analyse the effect of the time management skill among university students on their academic achievement. In this study, Time Management Questionnaire (TMQ) developed by Britton and Tesser was administered to 120 randomly selected Agriculture students in Universiti Teknologi Mara Cawangan Melaka. The respondents were 55 male and 65 female students. To analyse the effect of the time management, regression analysis was used and showed that there is exist positive linear relationship between time management skill and their academic achievement. When the data analysed with respect to gender variable, the female students obtained higher mean time management score than male students. Then, ttest is conducted and revealed that there is a difference in time management skills among gender statistically.
\end{abstract}




\title{
Profiling Crowdsourcing Practices Trend among SME's in Malaysia
}

\section{*Mohd Fitri Mansor ${ }^{1}$, Hasliza Abdul Halim², Noor Hazlina Ahmad $^{2}$, Noor Hidayah $\mathrm{Abu}^{3}$ and Muhammad Asyraf Mohd Kassim ${ }^{1}$}

${ }^{1}$ Faculty of Applied \& Human Sciences, Universiti Malaysia Perlis, 01000 Kangar, Perlis, Malaysia.

${ }^{3}$ School of Management, Universiti Sains Malaysia, 11800 USM, Penang, Malaysia.

${ }^{4}$ School of Technology Management and Logistics Universiti Utara Malaysia, 06010

Sintok, Kedah, Malaysia

*fitrimansor@unimap.edu.my

\begin{abstract}
Small and Medium Enterprises (SMEs) are the important 'engines of growth' for developed and developing countries. They are the main share of total enterprises and contributes significantly to the Gross Domestic Product (GDP), employment and export. Nevertheless, SMEs remain unachieved the expected success due to grapple with the failure risk, survival downturns and uncertainty environment. To overcome these challenges, the SMEs have to explore the best business strategies i.e crowdsourcing practices for their organisation to boost business performance. Therefore, the objective of this study is to investigate and profiling crowdsourcing practices among Malaysian SME's that possibly could be one of the organisational business strategies to complement resources scarcity and improve business performance. This study also exploring the crowdsourcing practices scenario in Malaysia, crowdsourcing business activities, crowdsourcing platforms and its effect towards business performance. The study employs quantitative approach. The findings revealed that, the crowdsourcing trends showed that SMEs not only crowdsource non-core business activities but they also tend to crowdsource some of core business or complex business activities such as new product development, marketing research and innovation activities to increase organisational capability to overcome internal resources constrains. The study also highlights both practical, theoretical implications, limitation and future study.
\end{abstract}




\title{
Probability Influence Factors of Local Youths in Malaysia to Participate towards Career in the Oil Palm Plantation
}

\section{${ }^{\star}$ A Mohammad Amizi ${ }^{1}$, A Norehan², A L Zul Ariff ${ }^{1}$ and M Nursalwani ${ }^{1}$}

${ }^{1}$ Faculty of Agro Based Industry, University Malaysia Kelantan, Jeli Campus, 17600 Jeli, Kelantan, Malaysia.

${ }^{2}$ Finance and Banking College of Business, University Utara Malaysia,06010 Sintok, Kedah, Malaysia.

*amizi@umk.edu.my

\begin{abstract}
The plantation sector, especially the oil palm commodity, is currently the largest agricultural-based contributor to Malaysia economic projection involving both upstream and downstream activities. Due to the rapid expansion in this palm oil industry, there are high labour demands required in this sector. Since the fate of this sector is being put on a stake, recruiting foreign labours is the only way out from this dilemma. As a result, more than $78 \%$ of labour [1] in this sector is mainly came from Indonesia, Bangladesh and the Philippines. Malaysia has become the main attention for the foreign labours to work in this country due to the wages being more competitive and generative working condition, especially in the plantation sector, provides the suitable accommodation compared to their origin country. The pressing issue now plantation and agriculture sectors too much dependence on foreign labour. As a result, all operation in this both sectors cannot be operated especially during covid 19 . One of the best solutions is to hire the local youth to work in oil palm plantation and retain them to work in this sector. This study was done in order to analyse the pull or push factors in constructing a particular pattern of participation among the local's youth which by using Probit model which were working in oil palm plantation. A survey method through questionnaire was used to collect data from 942 of local youths between 16 years to 40 years old as focused respondents which were selected using random sampling method. The results showed the probability the local's youth to work in the plantation sector influence by demographic factors and job satisfaction. From this result can attract the local's youth which was not working in oil palm plantation to substitute foreign labour in plantation.
\end{abstract}




\title{
Implementation Issues on Heritage Shophouses Facade in Kota Bharu, Kelantan
}

\author{
${ }^{*}$ Y Mohd Faudzi ${ }^{1}, \mathrm{~N} \mathrm{Md} \mathrm{Alwi}{ }^{1}, \mathrm{NH}$ Anuar ${ }^{1}, \mathrm{~S}$ A \\ Muhammad $^{1}$,S N A Mohd Nasir ${ }^{1}$, M R Mohd Nasir ${ }^{1}$ and \\ M H K Mhd Zain ${ }^{1}$
}

${ }^{1}$ Faculty of Architecture \& Ekistics, Universiti Malaysia Kelantan, Kampus Bachok Kelantan, Malaysia.

*yasmin.mf@umk.edu.my

\begin{abstract}
This study examines the contributing factors behind the continuing trend of non-compliance with heritage facade guidelines by the owners/occupants of heritage shophouses in Kota Bharu, Kelantan. The exterior facade of a heritage building, the crucial element in retaining and safeguarding the features of local and traditional cityscape, includes their associated signage and advertising. A case study on rows of heritage shophouses in Jalan Temenggung became part of a design task to better understand problems encountered in implementing the legislative heritage guidelines entailed for the signages. This exercise, which included site investigation, observation and data collection such as photographic evidence of the selected cases of the shophouses, was carried out by the second-year architecture students from University Malaysia Kelantan (UMK) in September 2019. Analysis of results compares between the existing row of heritage shophouses and a re-creation of shophouse facades by the students in compliance with the heritage guidelines provided by the local authority, Majlis Perbandaran Kota Bharu (MPKB). Discussion curtails on details of mismatched events between existing legislation and guidance against what was observed and applied by current owners. The outcome of this study shares beneficial information to a range of stakeholders which includes the shophouses owners, the local authority, as well as other the heritage conservation practitioners and scholars interested in Kota Bharu, Kelantan
\end{abstract}




\title{
The Intention of Food Manufacturer toward Application of Online Halal Label in Selangor
}

\section{${ }^{*}$ A L Zul Ariff ${ }^{1}$, R Golnaz², B. Abdullah ${ }^{3}$ and M H Mohd Safuan 4}

${ }^{1}$ Faculty of Agro Based Industry, Universiti Malaysia Kelantan, Locked Bag No. 100, 17600 Jeli, Kelantan, Malaysia.

2John Molson School of Business, Concordia University 1455 De Maisonneuve Blvd. W. Montreal, Quebec, Canada

${ }^{3}$ School of Business and Finance, University of the Western Cape, Robert Sobukwe Road, Bellville, 7535, Republic of South Africa

${ }^{4}$ Ramly Food Marketing, Taman Perindustrian IKS Mukim Batu, 68100 Kuala Lumpur

*zulariff@umk.edu.my

\begin{abstract}
Globally, most Muslim has high attention towards halal food especially here in Malaysia due to the increasing number of Muslim that consumes and promotes the halal food. The purpose of this study is to determine the most influential factors of food manufacturer towards online halal label. A purposive sampling technique was applied in selecting 50 food manufacturers at MAHA event located at MAEPS, Serdang, Selangor. The result of statistical tests, the knowledge, attitude and practices were a statistically significant association with the online halal label application among food manufacturer in Malaysia. From this study, it shows that the application of online halal label as a huge potential in Malaysia as the manufacturer is aware of the online application of the halal label.
\end{abstract}




\title{
The Symmetry Analysis in Sulaiman Esa Paintings Through Islamic Art Concept
}

\section{*W M Z W Soliana ${ }^{1}$, I Marzuki², S Rushana ${ }^{1}$ and G N Hafiza $^{3}$}

\begin{abstract}
${ }^{1}$ Fine Art Department, Faculty of Art and Design, Universiti Teknologi MARA
Cawangan Kelantan, Bukit IImu, 18500 Machang, Kelantan, Malaysia.

${ }^{2}$ Fakulti Reka Bentuk Inovatif dan Teknologi, Universiti Sultan Zainal Abidin Kampus Gong Badak, Terengganu, Malaysia.

${ }^{3}$ Textile Deparment, Faculty of Art and Design, Universiti Teknologi MARA Cawangan Kelantan, Bukit IImu, 18500 Machang, Kelantan, Malaysia.
\end{abstract}

*wliana411@uitm.edu.my

\begin{abstract}
This study aims to identify the mathematical concept evident in the paintings entitled 'Mahsuri II' (1983) by Sulaiman Esa through symmetry analysis. The objective of this study is to do research on the factors connecting art appreciation aspects by describing the concept of symmetry that exist trough the beauty of pattern design in paintings that exhibits Islamic art images. This study involves creative analysis through a qualitative approach with descriptive inter-disciplinary implementation. Symmetric feature research is performed to classify the pattern design of paintings through the process of symmetry involving repetition. The collection of written and visual data was performed by means of documentation, visual recording, and observation methods to obtain information on the subject, design and meaning of the artwork studied. The research uncovered that aesthetical beauty value in Islamic art images that is defined through mathematical expression became the underlying element in paintings design that applies symmetric pattern design concept. It is not an exaggeration to say that symmetry is the basic principle that has long been a hidden structure underpinning the best works of art ever produced in the history of Islamic art. Research has reported that painting can be seen not only from the art's formalistic point of view, but also from the ethnomathematical angle, through the application of symmetrical features in the production of artworks. This study presents some of the ethnomathematical and Malay-Muslims discussions in its vast research. This is an implicit innovation element present in every thought of society. Efforts to enrich the scope of probable new possibilities in the field of painting are very meaningful and beneficial for today's and future generations.
\end{abstract}




\title{
Administrative Related Factors Affecting The Assessment Tax Arrears
}

\section{*S Abdullah¹, M R Abdul Wahab², M H Hanafi² and A Abdul Razak ${ }^{2}$}

${ }^{1}$ Faculty of Architecture and Ekistics, Universiti Malaysia Kelantan, Kelantan, Malaysia

${ }^{2}$ School of Housing, Building \& Planning, Universiti Sains Malaysia, Pulau Pinang, Malaysia

*shardy.a@umk.edu.my

\begin{abstract}
Local government (LG) is an agency that has been empowered through legal provisions to impose the assessment tax. Thus, it directly causes the affairs of tax administration to be parked under the scope and jurisdiction of the LGs. Assessment tax arrear is a long-standing issue that has been faced by the LGs. From time to time, the crisis of assessment tax arrears is considered as getting worse and it requires various proactive actions to be taken including re-evaluating the current administrative process of assessment tax as it is practicising by the LGs. The main purpose of this study is to identify the factors which related to tax administration that has influenced the existence of assessment tax arrears based on the perspective of taxpayers. This study also aims to assess the strength of the relationship between each of the factors involved. The required data were collected through a survey method and a set of related questionnaire form was used as a research instrument. The respondents of this study are consisting of property owners who are subject to pay the assessment tax. In overall, this study has involved 261 respondents. The data collected were analyzed using descriptive and correlation methods. The findings of the study show that there are 8 administrative related factors that have influenced the existence of assessment tax arrears, namely taxation equality and justice, tax beliefs, tax expertise, staff adequacy, payment facility, transparency of services, tax incentives and tax communication. Through this study as well, it was found all the factors have a significant relationship with most of other factors.
\end{abstract}




\title{
The Challenges of Work from Home that Affect Higher Education Productivity during COVID-19 Outbreak
}

\author{
*S N L Ibrahim¹, N Rezali² and Y S M Yunan³
}

${ }^{1}$ Kolej Komuniti Jelebu, Jalan Seperi, 71600 Kuala Klawang, Negeri Sembilan.

${ }^{2}$ Politeknik Tuanku Syed Sirajuddin, Pauh Putra; 02600 Arau; Perlis, Malaysia.

*norzianis@gmail.com

\begin{abstract}
This paper explores the challenging factors of practising work from home (WFH) towards productivity that affected Malaysia's higher education during the COVID 19 outbreak. The practising WFH itself has its conflict, but this effect can be mitigated or even reversed when people have an integration preference. This study analyzed, reviewed, and explained each factor in detail from previous literature's different perspectives. Due to a lack of knowledge, this paper is one to recognize and address the practice of work conceptually from home that leads to higher education productivity in a single environment in a developing country. This research examined the daunting factors of WFH practising that affecting the productivity in Malaysia's higher education learning. The study results will shed some light on our understanding of the challenging factors WFH practices. It also provides researchers with the existing corpus of knowledge and a promise to expand the research stream on WFH practices. The empirical findings will suggest the challenges of working from home and how to face it by the academician in possible ways to obtain considerable potential for improving productivity a higher education institution in Malaysia.
\end{abstract}




\title{
Innovation Dissemination in Online Makerspace Learning
}

\section{${ }^{*}$ A F Kamaruzaman ${ }^{1}$, A R Ismail ${ }^{1,2}, \mathrm{~K} \mathrm{~A} \mathrm{M} \mathrm{Daud}^{1}$ and N Jusoh $^{1}$}

${ }^{1}$ Faculty of Creative Technology \& Heritage, Universiti Malaysia Kelantan, 16300 Bachok, Kelantan, Malaysia

${ }^{2}$ Centre for Management of Environment, Occupational Safety and Health (CMeOSH), Universiti Malaysia Kelantan, 16300 Bachok, Kelantan, Malaysia

*azmul@umk.edu.my

\begin{abstract}
COVID 19 pandemic has shifted the way makerspace operationalize shifted from purely physical space into an online mode for design collaboration and also information dissemination. With the spirit of maker movement which emphasizes sharing, collaboration and making as the vital core of its operation while the online components of makerspace are the platform for design collaboration and innovation dissemination during the global pandemic and the future globalization of innovation. Due to the establishment and the technological advancement of the digital fabrication and open-source hardware and software which is available to the masses, online learning has been the main drive which shapes the way the online makerspace platform operationalize. While there are a lot of articles and research has been done on the sustainability and mechanism of the physical makerspace environment, there are lack of articles discussing the sustainability of the online components of makerspace. The objective of this paper is to review the operation of the online makerspace upon disseminating innovation and ideas. This concept paper will highlight the power of online makerspace upon disseminating ideas and innovation to further stimulating another innovation. The main finding of this review paper is that the dissemination of innovation can stimulate the other user to create another innovation through memory retrieval and idea transformation.
\end{abstract}




\title{
Analysis On Sukor Rahim's Works
}

\section{${ }^{*}$ S. N. Apandi ${ }^{1}$, Hana Hapiz ${ }^{1}$, Farrah Atikah Shaari ${ }^{1}$, S. Sukri', Nordiana A.J ${ }^{1}$, Hanisa Hassan ${ }^{1}$, Nurulahda. $S^{1}$}

${ }^{1}$ Fakulti Teknologi Kreatif dan Warisan, Universiti Malaysia Kelantan 16300 Bachok, Kelantan, Malaysia

*nuranis.m@umk.edu.my

\begin{abstract}
This study aims to scrutinise the aesthetic elements of fruit carvings made by Sukor Rahim during a renowned fruit carving competition, which he was crowned Flying Chef Malaysia title by the organiser. The analysis adopted the aesthetics elements principles of carving motifs approach, which was introduced in Malay Aesthetics by Ali., Z (1989). Three of the six principles are used to analyse the aesthetic elements of the carvings. Qualitative methods are employed to further the study, which was using (1) archival method through analysis of photo documentation of Sukor Rahim's works and next was (2) probing the carvings using Malay Aesthetics approach to measure the aesthetic elements of the selected works. Results showed that Sukor Rahim's works carry overarching aesthetics finesse and layered with intricate aesthetic elements which requires connoisseurship of a carving expert, thus validate Rahim's achievement in the culinary world.
\end{abstract}




\title{
Managing Covid-19 Information In 4.0 Online Digital Media: Issues And Challenges In Malaysia
}

\author{
*Nor Adina Abd Kadir ${ }^{1}$ Mohamad Shafiei Bin Ayub ${ }^{1}, S$ \\ Salahudin Suyurno ${ }^{1}$ and Nursyaidatul Kamar Md Shah ${ }^{2}$
}

\author{
${ }^{1}$ Akademi Pengajian Islam Kontemporari, UiTM Cawangan Melaka, Kampus Alor \\ Gajah, 78000 Alor Gajah, Melaka \\ ${ }^{2}$ Akademi Pengajian Bahasa, UiTM Cawangan Melaka, Kampus Alor Gajah, 78000 \\ Alor Gajah, Melaka
}

*noradina@uitm.edu.my

\begin{abstract}
The advancement of technologies is creating fast and vast information for people around the world. The current communication technologies are also offering individuals the opportunity and platform to be more skilful, creative, and innovative. With such rapid development, the media, printed and electronic, are affected in more ways than imagined. In conjunction with the emergence of Covid-19 also known as the world pandemic, the modern communication technologies play a significant role in filtering the information that gets out to the public. The purpose of this article is to highlight the issues and challenges of using media communication technologies in managing the information related to Covid-19 in Malaysia. The three major issues discussed in this paper are limited accessibility, false or fake news and misinformation. Finally, steps and preventive measures were discussed to ensure the accurate information being circulated to the public.
\end{abstract}




\title{
New Media and Islamic Popular Culture: Challenges in Maintaining Morals in Communication
}

\author{
*S S Salahudin', R Aini Faezah², R Abdul Rauf², A \\ Muhamad Shafie $^{1}$, A K Nor Adina ${ }^{1}$ and Muhammad \\ Taufik M S ${ }^{1}$
}

${ }^{1}$ Academy of Contemporary Islamic Studies (ACIS) UiTM Cawangan Melaka, 78000 Alor Gajah, Melaka.

${ }^{2}$ Faculty Communication and Media Studies UiTM Cawangan Melaka, 78000 Alor Gajah, Melaka.

*ssalahud@uitm.edu.my

\begin{abstract}
The question of morals in communication has become one of the most intensely discussed issues. In relation to this, the presence of various new media platforms has gradually shaped the way people communicate. Despite its numerous positive elements especially in facilitating users' daily activities, new media is also associated with several negative elements including the acts of insulting, mocking, humiliating, as well as the spread of fake news. These misconducts have somehow formed an undesirable culture observed on new media, especially among teenagers, which consequently contributes further to the intense question of moral and ethical degradation associated with teenagers. Therefore, this qualitative study which utilizes a content analysis approach sets out to discover issues pertaining to new media, the Islamic popular culture, as well as the appropriate morals to be applied in new media communication to ensure a cordial relationship among all human beings.
\end{abstract}




\title{
Socioeconomic Impact of Covid-19 on the Lower Middle and Lower Income People in Bangladesh
}

\author{
M R Kabir ${ }^{1,2}{ }^{*}$ M A Islam² and M Z Hossain² \\ ${ }^{1}$ School of Business, Innovation and Technopreneurship, Universiti Malaysia Perlis, \\ Malaysia. \\ ${ }^{2}$ School of Business Administration, East Delta University, Chittagong Bangladesh. \\ *amin@unimap.edu.my
}

\begin{abstract}
The question of morals in communication has become one of the most intensely discussed issues. In relation to this, the presence of various new media platforms has gradually shaped the way people communicate. Despite its numerous positive elements especially in facilitating users' daily activities, new media is also associated with several negative elements including the acts of insulting, mocking, humiliating, as well as the spread of fake news. These misconducts have somehow formed an undesirable culture observed on new media, especially among teenagers, which consequently contributes further to the intense question of moral and ethical degradation associated with teenagers. Therefore, this qualitative study which utilizes a content analysis approach sets out to discover issues pertaining to new media, the Islamic popular culture, as well as the appropriate morals to be applied in new media communication to ensure a cordial relationship among all human beings.
\end{abstract}




\title{
Current Challenges of the Batik Industry in Malaysia and Proposed Solutions
}

\section{*H M Razali' ${ }^{1}$ M Ibrahim², M Omar ${ }^{1}$ and S F M Hashim¹}

${ }^{1}$ Faculty of Art \& Design, Universiti Teknologi MARA, Campus Machang, Bukit IImu, 18500 Machang, Kelantan, Malaysia.

${ }^{2}$ Faculty of Innovative Design and Technology, Universiti Sultan Zainal Abidin, Gong Badak Campus, 21300Kuala Terengganu, Malaysia.

*hartini42@uitm.edu.my

\begin{abstract}
Batik is an art or craft that is produced through a variety of textile designing techniques. In Malaysia, batik is considered as a national heritage art that is the pride of the country. The World-Asia Pacific Craft Council recognizes Malaysian batik as one of the most well-known local crafts globally. This study aims to examine the challenges faced by the batik industry in Malaysia. The literature review method is fully utilized to collect the required data. The results of the study found that the Batik Industry in Malaysia faces the challenge of competition from cheaper and modern external products and even more worrying is the original batik design imitated by irresponsible foreign entrepreneurs by offering lower prices. The lack of skilled workers from young people should also be taken into consideration when many young people voices that they are not interested in working in this industry. A more detailed research study proposal is needed by paying attention to the role of entrepreneurs and designers in the batik industry in Malaysia. They are the leading movers in addressing the challenges and problems that exist in this industry in line with efforts to develop the local batik industry and elevate the art of batik in Malaysia.
\end{abstract}




\title{
Current Challenges of the Batik Industry in Malaysia and Proposed Solutions
}

\section{*H M Razali' ${ }^{1}$ M Ibrahim², M Omar ${ }^{1}$ and S F M Hashim¹}

${ }^{1}$ Faculty of Art \& Design, Universiti Teknologi MARA, Campus Machang, Bukit IImu, 18500 Machang, Kelantan, Malaysia.

${ }^{2}$ Faculty of Innovative Design and Technology, Universiti Sultan Zainal Abidin, Gong Badak Campus, 21300Kuala Terengganu, Malaysia.

* hartini42@uitm.edu.my

\begin{abstract}
Batik is an art or craft that is produced through a variety of textile designing techniques. In Malaysia, batik is considered as a national heritage art that is the pride of the country. The World-Asia Pacific Craft Council recognizes Malaysian batik as one of the most well-known local crafts globally. This study aims to examine the challenges faced by the batik industry in Malaysia. The literature review method is fully utilized to collect the required data. The results of the study found that the Batik Industry in Malaysia faces the challenge of competition from cheaper and modern external products and even more worrying is the original batik design imitated by irresponsible foreign entrepreneurs by offering lower prices. The lack of skilled workers from young people should also be taken into consideration when many young people voices that they are not interested in working in this industry. A more detailed research study proposal is needed by paying attention to the role of entrepreneurs and designers in the batik industry in Malaysia. They are the leading movers in addressing the challenges and problems that exist in this industry in line with efforts to develop the local batik industry and elevate the art of batik in Malaysia.
\end{abstract}




\title{
Generation Z's Purchase Intention of Fast Food: Influential Factors Unveiled in Kluang, Johor
}

\section{*Jeng Young Liew ${ }^{1}$, Nurliyana Atikah Wal Razali', Kooi Huat $\mathrm{Ng}^{2}$ Jia Geng Boon ${ }^{3}$ and Chee Fai Sui ${ }^{4}$}

${ }^{1}$ Faculty of Agro-Based Industry, Universiti Malaysia Kelantan, Jeli Campus, 17600, Jeli, Kelantan, Malaysia.

${ }^{2}$ Department of Mathematical and Actuarial Sciences, Lee Kong Chian Faculty of Engineering and Science, Universiti Tunku Abdul Rahman, Jalan Sungai Long, Bandar Sungai Long, Cheras 43000 Kajang, Selangor.

${ }^{3}$ Faculty of Bioengineering and Technology, Universiti Malaysia Kelantan, Jeli Campus, 17600, Jeli, Kelantan, Malaysia.

${ }^{4}$ Pharmacy Department, Hospital Tapah, Jalan Temoh, 35000 Tapah, Perak.

*ljyoung@umk.edu.my

\begin{abstract}
Fast food industry is mushrooming in Malaysia due to the increasingly demand from consumers. Consumption of fast food has become a climate, where it is particularly popular with Generation Z. Generation Z is defined as a digitally driven demographic cohort, whose possessing a broad diversity of taste, favouritism, and behaviour. Having a clear knowledge on how Generation Z makes purchase decision can help to unveil the key determinants impacting their choices. If the influential factors can be determined, fast food marketers can devise pertinent approaches in taping the market share. This study is conducted to investigate the factors affecting generation Z's purchase intention towards fast food industries in Kluang, Johor using the survey method. Twenty variables that may trigger the Generation Z's purchase intention of fast food were sorted out by literature and interview. Questionnaire, confirmed by Cronbach's Alpha test had been distributed to 400 respondents. Descriptive statistical tests was used to analyse respondent profile. Exploratory factor analysis performed had summarized 7 core factors for the Generation Z's fast food purchase intention: service quality, food value and restaurant environment, food quality, price, promotion attractiveness, humanic clues, and health and marketing. These findings give Kluang's fast food marketers crucial insights pertaining the Generation Z's purchase intention.
\end{abstract}




\title{
Does the Theory of Planned Behavior and Perceived Enjoyment give a big impact on Online Purchase Intention among Gen-Y in East Coast Malaysia?
}

\author{
${ }^{*}$ Fatin Farhana Kamis ${ }^{1}$, Dr. Shah Iskandar Fahmie Ramlee ${ }^{1}$ and \\ Dr. Wan Farha Wan Zulkiffli ${ }^{1}$
}

${ }^{1}$ Faculty of Entrepreneurship and Business, Universiti Malaysia Kelantan, Kampus Kota, 16100 Pengkalan Chepa, Kelantan, Malaysia.

*fatinkamis.fk@gmail.com

\begin{abstract}
The purpose of this research is to examine the factors that can influence online purchase intention among Gen-Y in East Coast, Malaysia. Nowadays, Gen$\mathrm{Y}$ is the most notable consumer of technology. Shopping online has also become a habit for this technologically literate generation. Thus, this research investigated the relationship between online purchase intentions using a basis model of TPB. A quantitative research design had been employed and conducted on 138 respondents which were among Gen-Y in East Coast, Malaysia. Surprisingly, the results of TPB variables did not affect Gen-Y online purchase intention but trust and perceived enjoyment had positive significance effect on their online purchase intention. This research helps to improve the knowledge of researcher in further understanding the online purchase intention among Gen-Y in East Coast, specifically. The recommendation for the future research is to conduct the research by using a different theory and generation such as Gen-Z in different states.
\end{abstract}




\title{
Factors Influencing Participation of Youth Entrepreneurs in Halal Food Product Labelling in Sabah
}

\author{
*M Nursalwani ${ }^{1}, \mathrm{~J}_{\text {Yumiemarnie }}{ }^{1}$, A Palsan Sannasi ${ }^{1,}$, A \\ Mohammad Amizi ${ }^{1}$ and A L Zul Ariff ${ }^{1}$
}

\author{
${ }^{1}$ Faculty of Agro Based Industry, University Malaysia Kelantan, Kampus Jeli, 17600 Jeli, \\ Kelantan, Malaysia. \\ *nursalwa91@gmail.com
}

\begin{abstract}
Malaysia is one of the countries that hold status as a world leader for the Halal economy. Currently, young entrepreneur's involvement in the halal food industry is increasing due to Malaysia government policy which is providing incentives; continue supports and various strategies or programs to develop this group of entrepreneurs. Entrepreneurship is a good idea for the youth to increase their income besides the young generation nowadays is the asset to the economic development of the country. However, participation in halal food labelling for youth entrepreneur is not easy as they are facing many obstacles that prevent them to participate. Thus, this study was conducted to examine the participation of youth entrepreneur in halal food product labelling in Sabah since it is hard for them to obtain halal certification from JAKIM. Besides, there are a few problems that the youth entrepreneur faces to be a Halalpreneur. The problem is they lack knowledge, experiences, and sort of financing to start up their entrepreneurial activity. The sample size is 60 respondents and was conducted in a few districts in Sabah (Keningau, Kota Kinabalu, Sandakan, Tambunan). This study was conducted based on two objectives which are to identify the participation level of the youth entrepreneur in halal food product labelling and to define the most influential factor for the youth entrepreneur's participation on halal food product labelling in Sabah. For the data collection, a survey method that provides questionnaire was used and the other method was by interviewing - asking questions personally, email or by telephonic conversation. The result appears to be the participation level of youth entrepreneur on halal food product labelling in Sabah is high. Then, most influential factor on the youth entrepreneur participation in halal food product labelling in Sabah is the subjective norm. The significance of this study is to be a reference for the policymaker to make the procedure easier for the youth entrepreneur to apply halal certification since the difficult procedure is one of the obstacles for the entrepreneur to get a halal label for their food products.
\end{abstract}




\title{
Education 4.0 and the implications on Professional Development of Academia
}

\author{
*Suja Prem Chandran ${ }^{1}$ and Azri Usman ${ }^{1}$
}
${ }^{1}$ Faculty of Business\& Management, DRB-HICOM University of Automotive Malaysia, Pahang, Malaysia
*suja@dhu.edu.my

\begin{abstract}
Ministry of Higher Education sector in Malaysia has set in motion the Higher Education 4.0 in 2018, focusing on Knowledge, Industry and Humanity. In order to embrace Learning and Teaching 4.0 in Higher Educational Institution, it is vital to focus on Staff Professional Development. This paper is to review the current available methods of Professional Development in the education sector. Identifying the lack of professional development platform explains the deficiency in the staff development and hence their ability to adapt to Education 4.0.The objective of this paper is in alignment to one of the objectives of this conference which is to identify and discuss the problem faced by a sector, this paper is on the higher education institutions. Hence in the future higher education institutions need to develop an efficient and sustainable platform for professional development to bridge the human capital competency gap.
\end{abstract}




\title{
The Effect of Different Electrolytes on The Synthesis of Graphene Sheets by Electrochemical Exfoliation
}

\author{
S S Bhullar ${ }^{1}$ and $* \mathrm{~W}$ W Liu ${ }^{2}$ \\ ${ }^{1}$ Faculty of Chemical Engineering Technology, Kompleks Pusat Pengajian Jejawi 2, Universiti \\ Malaysia Perlis (UniMAP), Taman Muhibbah, 02600 Jejawi, Arau, Perlis, Malaysia. \\ ${ }^{2}$ Institute of Nano Electronic Engineering (INEE), Universiti Malaysia Perlis (UniMAP), \\ 01000 Kangar, Perlis, Malaysia \\ *wwliu@unimap.edu.my
}

\begin{abstract}
The synthesis of high quality and large lateral dimension of graphene flakes has been the main interest of researchers. Synthesis methods including chemical vapor deposition, epitaxial growth and micromechanical cleavage guarantees the desired results, but the cost is high. Electrochemical exfoliation, however, is one of the fast and low-cost alternatives in the synthesis of graphene flakes. In this work, the electrochemical exfoliation of graphite utilized four types of electrolytes. The electrochemical cell was designed using copper foils as the cathode whereas graphite pencil rods as the anode which connected to the DC power supply. Fourier Transform Infrared Spectroscopy (FTIR) showed that the exfoliated graphene samples contained very low quantity of oxygen functional groups. On the other hand, scanning electron microscope (SEM) was employed to examine the morphology in which the surface of exfoliated graphene flakes showed wrinkles structure. In addition, energy dispersive X-ray spectroscopy (EDX) has confirmed that the exfoliated graphene samples primarily contain carbon, oxygen, and platinum. X-ray diffraction (XRD) revealed that exfoliated graphene samples showed a significant peak at about $2 \theta=26^{\circ}$ corresponded to graphite and a low peak at about $10^{\circ}$ corresponded to graphene oxide.
\end{abstract}




\title{
Design and Development of Integrated Portable Pre-Analytical Phlebotomy Unit (IP3U)
}

\section{${ }^{*}$ Azian Azamimi Abdullah"1, Cheng Ee Meng ${ }^{1}$, Lee Kuok Leong $^{2}$, Saroja Rijal ${ }^{2}$, Mohamed Khaled Mohamed Helmy², Nur Ain Natasha Sawadi² and Nur Amy Sharmilia Mohd Saleh²}

${ }^{1}$ Faculty of Electronic Engineering Technology, Universiti Malaysia Perlis, Kampus Alam UniMAP, Pauh Putra, 02600, Arau, Perlis, Malaysia

${ }^{2}$ School of Mechatronic Engineering, Universiti Malaysia Perlis, Pauh Putra Campus, 02600 Arau, Perlis, Malaysia

*azamimi@unimap.edu.my

\begin{abstract}
Pre-analytical phase in phlebotomy process contributes $62 \%$ of errors in the process. This contributes to blood sample rejection that leads to diagnostic and treatment delay and even patient death, a solution is needed to solve the problem related to this issue. Integrated Portable Pre- Analytical Phlebotomy Unit (IP3U) is a device that includes implementation of artificial intelligence (AI) Deep Learning based Optical Character Recognition (OCR) using Tesseract and OpenCV for patient information processing, an image- guided vein diameter visualization for specific needle determination for drawing blood from veins, an automated time response sequence order of blood draw unit, blood specimen volume quantitative analysis using computerized vision, artificial inversion module able immediate mixing of the sample upon blood collection and a specimen storage compartment with temperature monitoring and most important feature with QR code-based patient- sample positive identification system. The device provides an accurate and qualified blood specimen during the pre-analytical at bedsides or in ambulances, emergency rooms, clinics and doctors' offices to diminish the human manual control error that greatly reduce the specimen rejection rate with interconnection via the internet of computing devices for quality monitoring.
\end{abstract}




\title{
Measuring the Banking Performance Based on Corporate Social Responsibility Achievement: Decision Support System Adoption
}

\author{
*O Okfalisa ${ }^{1}, \mathrm{R} \mathrm{Habib}^{1}, \mathrm{R} \mathrm{Hidayati}^{1}, \mathrm{M} \mathrm{Mahyarni}^{2}, \mathrm{~W}$ Alex $^{3}$, \\ N Gusman ${ }^{4}$ and S Saktioto 5
}

\begin{abstract}
${ }^{1}$ Department of Informatics, Universitas Islam Negeri Sultan Syarif Kasim Riau, Indonesia. ${ }^{2}$ Department of Management, Universitas Islam Negeri Sultan Syarif Kasim Riau, Indonesia. ${ }^{3}$ Department of Electrical, Universitas Islam Negeri Sultan Syarif Kasim Riau, Indonesia.

${ }^{4}$ Faculty of Industrial Management, Universiti Malaysia Pahang, 26300 Kuantan, Pahang, Malaysia.

${ }^{5}$ Department of Physic, Universitas Riau, Indonesia.
\end{abstract}

*okfalisa@gmail.com

\begin{abstract}
Corporate Social Responsibility (CSR) discloses the social responsibility of a company in contributing to the quality improvement of the community and society. Currently, the banking industries put into concern on this social responsibility as well as CSR report as environmental issues that leveraging the economic business performance through the application of the Global Reporting Initiatives (GRI) framework. The number of the organization using this framework has increased. Unfortunately, several weaknesses have been reviewed on the adoption of this framework as a sustainability report. Therefore, this study tried to strengthening the GRI model by elaborating on the indicators and subindicators of GRI-4 to measure the priority weighted-based indicators thus it is utilized to rank the banking performance. Herein, the decision support system-based analytical network process (ANP) is applied to assess standard criteria of the GRI sustainability report as a side of economic, social, and environmental aspects. Three banking companies in Indonesia have been selected as alternatives and then analyzed based on its sustainability report as well as performance measurement. Twenty-four experts from academicians and practices have been asked their quantitative perspectives and weighting score of the criteria through the dissemination of the questionnaire. This study reveals the performance of banking companies following the realization of the CSR position. Thus, the financial services authority of Indonesia (OJK) as an Indonesian government agency is advised on the decision-making on the potential banking performance that more pay attention to environmental sustainability. Besides, the employment of the ANP method in this study can strengthen and accomplish the shortcoming of the GRI model in determining the sustainability report.
\end{abstract}




\title{
Perception and Satisfaction of Delivery Services in Malaysia During Movement Control Order
}

\section{*llya Yasnorizar llyas ${ }^{1}$ Abdul Rauf Ridzuan ${ }^{1}$, Rosilawati Sultan Mohideen ${ }^{1}$ and Mohd Hilmi Bakar ${ }^{1}$}

${ }^{1}$ Faculty of Mass Communication and Media Studies, UiTM Melaka, Campus Alor Gajah Melaka Malaysia

*ilyaisyraf@uitm.edu.my

\begin{abstract}
Delivery services in Malaysia has become a new norm. Malaysian are now comfortable with delivery services during the global pandemic of covid-19. This study had been conducted because there are to many issues about delivery services in Malaysia, some people using delivery services and some may not. Some companies have bad management of delivery services. Some delivery services companies have technical issues such as slow delivery, damaged goods, and so on. The aim of this paper is to provide an analysis between the satisfaction level of Malaysian citizen and the perception of Malaysian citizen towards delivery services during the Movement Control Order (MCO). To do so, researchers uses the quantitative method to collect data among Malaysian citizen. The total amount of respondents that answered the questionnaire are 1310. From the findings, Malaysian are satisfied with delivery services $(M=3.17)$. Plus, Malaysian have a positive perception towards delivery services $(\mathrm{M}=3.17)$.
\end{abstract}




\title{
Sustainable Brick Plastic Recycle
}

\author{
*Umar Kassim ${ }^{1}$, N.A.Shuaib ${ }^{1}$, Zakwan.Nasir ${ }^{1}$, Intan.Sulaiman ${ }^{1}$ \\ and S.M.Razak ${ }^{1}$
}

${ }^{1}$ Faculty of Engineering Technology, Universiti Malaysia Perlis , $1^{\text {st }}$ Level Block S2, 02100

Padang Besar, Perlis, Malaysia.

*umar@unimap.edu.my

\begin{abstract}
Brick is a material to set up construction especially the wall parts. There are various types of bricks. However, the focus of this study is on the bricks that is consisted of recycled plastics. Plastic is the most used materials daily by humans and often being disposed in landfills and causes problems to the environment. Waste piles and pollution issues arise if plastic waste is not recycled due to its long time or duration taken to decompose. Plastic is non-biodegradable that remains as a hazardous material for more than centuries. Plastic materials can remain on earth for 4500 years without degradation, which leads to the contamination of soil. The plastic waste is composed of major toxic pollutants and has the potential to cause great harm to the environment in the forms of air, water and land pollution. This study is used plastic waste such as mineral water bottle, containers and products as plastic bricks. Plastic wastes were collected and processed by decomposing them in certain stages of heat to dilute into viscous liquid and incorporated into brick mold with standard specifications. Brick products were produced as soon as the cooling process in the mold completed and removed as interlocking plastic bricks. Compression tests were carried out to characterize mechanical properties and durability of the plastic brick. Recycled plastic materials plus organic waste (brick waste recycles mixed with recycled ceramic waste) is cheaper, durable and lightweight. Production of one-unit brick can reduce and recycle around $5 \mathrm{~kg}$ of plastic waste. The compression test shows that plastic bricks plus organic waste has good strength, durability and specifications as an alternative to replace conventional bricks for the purpose of modern technology construction industry, in particular the Industrialised Building Systems.
\end{abstract}




\title{
Unlimited Human Wants: The Critical View from Islamic Economics Perspective
}

\author{
*M Mohd Zulkifli, ${ }^{1}$, A Hanudin ${ }^{2}$, W Z W Farha ${ }^{1}$, A Azwan ${ }^{1}, \mathrm{H}$ \\ R Razman ${ }^{1}$, M Mahathir ${ }^{1}$ and H R Ratna ${ }^{3}$
}
${ }^{1}$ Faculty of Entrepreneurship and Business, Universiti Malaysia Kelantan, Kampus Kota, Pengkalan Chepa, 16100 Kota Bharu, Kelantan, Malaysia.
${ }^{2}$ Labuan Faculty of International Finance, Universiti Malaysia Sabah 87000 Federal Territory of Labuan, Malaysia
${ }^{3}$ Commerce Department, Politeknik Ungku Omar, Jalan Raja Musa Mahadi, 31400 Ipoh, Perak, Malaysia.
*zulkifli.m@umk.edu.my

\begin{abstract}
This study explores the assumption of unlimited human wants in Islamic economics. From the theoretical approach, this research introduces new ideas of limitless human will. Islamic economists took the assumption of unlimited human wants (AUHW) and then altered and assimilated it with Islamic elements to be regarded as the assumption of Islamic economics. The question is, does AUHW's assumption embrace Islamic economics? If suits, what are the theories of the assumption of unlimited human wants parallel to Islamic? Data used were taken from library studies. For this reason, contents and textual analyses were used. This study found that AUHW 's assertion was parallel to Islamic economics. This study explores a new approach to assessing limitless human desires in Islamic context. Our contributions are confined to this field. Future works may offer unique viewpoints on infinite human needs spanning various geographies. This study offers a new parameter for Muslims to handle Islam-based tools. This study presents a new measure of Muslims discussing of unlimited human wants.
\end{abstract}




\title{
Possibility Outbreak of Covid-19 Malaysia In Cases of Opening National Border: A Systematic Review Approach
}

\author{
*H R Razman ${ }^{1,3}$, M M Zulkiflii ${ }^{1}$, H R Ratna ${ }^{2}$, W Z W Farha ${ }^{1}$, S \\ M H M Zaly ${ }^{3}$, M Y Anuar ${ }^{4}$ and W S W Yusoff ${ }^{5}$
}

${ }^{1}$ Faculty of Entrepreneurship and Business, Universiti Malaysia Kelantan, Kampus Kota, 16000 Kota Bharu, Kelantan, Malaysia.

${ }^{2}$ Department of Commerce, Politeknik Ungku Omar, 31400 Ipoh, Perak, Malaysia.

${ }^{3}$ Faculty of Built Environment and Surveying, Universiti Teknologi Malaysia, 81310 UTM Skudai, Johor, Malaysia.

${ }^{4}$ Faculty of Creative Technology and Heritage, Universiti Malaysia Kelantan, Kampus Bachok, 16300 Bachok, Kelantan, Malaysia.

${ }^{5}$ Centre for Language Studies and Generic Development, Universiti Malaysia Kelantan, Kampus Jeli, 17600 Jeli, Kelantan, Malaysia.

*razmanh@umk.edu.my

\begin{abstract}
Current coronavirus disease 2019 (COVID-19) pandemic pneumonia caused by severe acute respiratory syndrome coronavirus 2 (SARS-CoV-2) is spreading worldwide at an accelerated rate, with estimate reproductive number of 2-2.5, indicating that two or three individuals may be infected with index patient cases. It is totally risky for vulnerable groups and communities where there are insufficient healthcare facilities to treat the infection, causing severe public health emergency. This study further highlights the review of COVID-19 in reopening Malaysia's borders and bringing together the latest options about drafting to reopen the country. Malaysia's border controls have been tightened to deter imported cases, mitigate locally transmitted cases, and increase the capacity of Malaysian health care facilities. There is not a sample size of this study. The purpose of this writing is to examine the possible outbreak of COVID-19 Malaysia in the event of reopening the national border and the safety and security issue related to COVID19. The literature search was conducted via google scholar in order to find out the suitable articles for reference. The aim of the study is to express an opinion that can be viewed by tertiary maternity units capable of treating those affected by the pandemic while ensuring the protection of the people at its core.
\end{abstract}




\title{
Mechanical Properties of Concrete Containing Expanded Polystyrene (Eps) and Palm Oil Fuel Ash (Pofa)
}

\author{
*Osman M H B ${ }^{1}$, Kai O S ${ }^{1}$, Adnan $\mathrm{S} \mathrm{H}^{1}$, Salim $\mathrm{S}^{2}$ Rahman M \\ $\mathrm{A}^{1}$, Jaafar $\mathrm{A}^{1}$, Jeni $M \mathrm{~L} \mathrm{~A}^{1}$ and Yahya $\mathrm{N} \mathrm{F}^{1}$
}

${ }^{1}$ Faculty of Engineering Technology, Universiti Tun Hussein Onn Malaysia, Johor, Malaysia. ${ }^{2}$ Centre for Diploma Studies, Universiti Tun Hussein Onn Malaysia, Batu Pahat, Johor, Malaysia..

*mhairi@uthm.edu.my

\begin{abstract}
This study focuses on the application of expanded polystyrene (EPS) and palm oil fuel ash (POFA) as replacement materials in concrete. In this study, EPS was utilized to replace fine aggregate up to $20 \%$ in the concrete mixture. One the other hand, POFA replaced cement up to $30 \%$ in the concrete mixture. The chemical properties of POFA were determined using XRD analysis and compared with cement. The mechanical properties of concrete cubes containing EPS and POFA were determined based on workability, density, water absorption and compressive strength. The performance of the concrete containing EPS and POFA was then compared with the normal concrete. As a result, the performance of the concrete containing EPS and POFA was determined.
\end{abstract}




\title{
The Effectiveness Of Television In Creating Awareness Towards Movement Control Order (Mco) During Covid-19
}

\author{
*A R Ridzuan ${ }^{1}$, A Luthfia ${ }^{2}$, R S Mohideen ${ }^{1}$, \\ S N S Allam ${ }^{1}$, N A Karim Zamri ${ }^{1}$, A Zulkarnain ${ }^{2}$, \\ S ISMAIL ${ }^{1}$, M H T Abdullah ${ }^{1}$ and RA Aryant W. \\ Puspokusumo ${ }^{2}$
}

${ }^{1}$ Universiti Teknologi MARA, Cawangan Melaka, Kampus Alor Gajah, Melaka, Malaysia

${ }^{2}$ Bina Nusantara University, Jakarta, Indonesia

*abdulrauf@uitm.edu.my

\begin{abstract}
In March 2020, the government had announced for the Movement Control Order due to the outbreak of Covid-19 in Malaysia. COVID-19 is an infectious disease caused by a newly discovered coronavirus. People that infected with COVID-19 will experience mild to moderate respiratory illness and recover without requiring special treatment. As the covid-19 had affected over millions of people across the world, the media have been working overtime in make sure the communities are updated with the news regarding Movement Control Order information to the public. The study aims to identify the effectiveness of media in creating awareness towards the understanding of Movement Control Order (MCO) during Covid-19. The study involves 440 respondents from different backgrounds across Malaysia. The data are collected through Statistical Package of Social Science (SPSS) Version 23. Findings from the SPSS indicated that television has significantly impact on promoting Movement Control Order awareness.
\end{abstract}




\title{
Approach To Qualitative Study Methods: Exploration Of Support Received By Enterprenuer With Disability
}

\section{*Norhasyikin Rozali ${ }^{12}$, Shuhairimi Abdullah ${ }^{1}$, Noor Salwani Hussin $^{1}$, Jamsari Jamaluddin ${ }^{1}$, Ahmad Fahmi Mahmood ${ }^{1}$ and Zuraidi Ahmad Mokhdzar ${ }^{1}$}

${ }^{1}$ Faculty of Applied Science and Humanities, Univeriti Malaysia Perlis, Blok B, Kompleks Pusat Pengajian Jejawi, 02600, Arau, Perlis, Malaysia.

*huwaida_67@yahoo.com

\begin{abstract}
Support is one of the most important elements for a disabled entrepreneur to grow a business. However, this support is not only financial in nature but consists of various other needs. In fact, the support medium is not only the government but also NGO and others. The main purpose of this article is to discuss the objective of the study, which is to explore the support received by entrepreneurs with disability to grow the business. The second objective is to understand the situation experienced by people with disabilities in start business. Therefore, this study was conducted through qualitative methods using a semistructured interview approach involving 8 informants consisting of disabled entrepreneurs to obtain research information.
\end{abstract}




\title{
Magic and Sad Emotion as The Effects of Soul Relief in the Epic of Indera Nata
}

\section{*Afidatul Syazwani Afandi ${ }^{1,2}$, Norazimah Zakaria² ${ }^{2}$ Abdul Halim Ali $^{2}$ and Nasirin Abdillah ${ }^{1}$}

${ }^{1}$ Fakulti Teknologi Kreatif dan Warisan, Universiti Malaysia Kelantan, Kampus Bachok, Beg Berkunci No.01,16300 Bachok, Kelantan, Malaysia

${ }^{2}$ Fakulti Bahasa dan Komunikasi, Universiti Pendidikan Sultan Idris, 35900 Tanjung Malim, Perak, Malaysia

*afidatul@umk.edu.my

\begin{abstract}
Malay epics during the transition era which was the $19^{\text {th }}$ century had the influence of Hindu-Muslim rich with narrative stories in a form of love or romance. The definition of romance originated from a French word romanz with a Latin word Lingua Romana which means all the literary works from the common people. Romance also referred to a fiction word which is imagery or fictional story. Plots in fictional epic were carefully arranged, fully chronological, full of magical and astonishing events (Shahnon Ahmad, 1994). Although they were rich with episodes of fun and sensual love, the Malay epics could not escape from inserting elements of sad emotions functioned as the path of soul relief. This element of sadness was inserted by the author with the purpose to strengthen a relationship when it was tested with obstacles and challenges. Issues and problems highlighted in this study were related to sad emotion as a basis structure in the storyline of epics. This study employed a qualitative study emphasizing on structural descriptive analysis from the text, the epic of Inderanata. Magical events which portrayed sad emotions based on the text were aligned with the soul relief (catharsis). Kettles (1995) in Catharsis: A Literature Review supported catharsis as a process involving emotions. The relationship and alignment were inserted to indicate the effects of soul relief which were the results of sad emotions. The analysis results discovered that there were a number of events in the text indicating sad episodes and describing the sadness which could be connected to the effects of soul relief (catharsis). As a conclusion, the sad emotions and feelings were parts of arts of authorship and effects of soul relief.
\end{abstract}




\title{
Security Risk Assessment of Online Fish Quarantine Information System Using FMEA
}

\author{
*M Megawati ${ }^{1}, \mathrm{O}_{\text {Okfalisa }}{ }^{2}$ and $\mathrm{M}$ Alkarim ${ }^{1}$ \\ ${ }^{1}$ Department of Information Systems, Universitas Islam Negeri Sultan Syarif Kasim Riau, \\ Indonesia. \\ ${ }^{2}$ Department of Informatics Engineering, Universitas Islam Negeri Sultan Syarif Kasim Riau \\ Indonesia. \\ *megawati@uin-suska.ac.id
}

\begin{abstract}
Risk is the main cause of uncertainty in an organization thus it affects the achievement of objectives. Therefore, the identification of risks and employing the procedure to mitigate potential issues is an essential part of effective organizational business. Karoline (Online Fish Quarantine Information System) is an application that monitors the operational activities of the Fish Quarantine Agency, quality control, and safety of fishery products. Lack of updated data management, limited access to the system, and inadequacy of system security put forward this Karoline information system under uncontrolled and at risk. To date, this study tries to measure the risk level of this application using Failure Mode and Effect Analysis (FMEA). This study reveals the place of the significant issue on the values of Risk Priority Number (RPN) assessment viz. cybercrime, firewall, and people. Moreover, the analysis prepared with the recommendation to aid in making the right decision and corrective action for an organization is facing a high risk of the system.
\end{abstract}




\title{
Allocation Of Public Resources To The Public Universities In Bangladesh: Development Initiatives By University Grants Commission
}

\author{
*Jebunnessa ${ }^{1}$ and Md. Aminul Islam ${ }^{2}$ \\ ${ }^{1}$ Department of Public Administration, Jahangirnagar University, Savar, Dhaka-1342 \\ ${ }^{2}$ Faculty of Applied Sciences and Humanities \\ Universiti Malaysia Perlis \\ *jebunjupa@gmail.com
}

\begin{abstract}
The paper explores how much development undertakings including conducting research venture have been taken by the apex authority of regulationof public universities in Bangladesh for instance; University Grants Commission. The study will be capitulated with exploratory research design along with secondary data to come out the fact ofdevelopment perspective of public universities in Bangladesh. The study reveals that no hard and fast rules and regulations available to allocate public resources to the public universities. Allocating public resources determines on the basis of previous distributed public resources data to redistributed public resources for the next year. Generally the commission raises public resources from the four sources that comprises of grants from the government; loans from the government; donation and endowments and receipts of the commission from such other sources as may be approved by the government.Budget towards public universities generally consists of two forms for example; Development budget and Non development budget. Non development budget comprises of paid salary and allowance to the staff and teachers along with administrative cost and other expenses that are prescribed by the assigned authority and development budget composes of physical development of the institutions namely; building infrastructure of those public universities. Availability ofpoor governance, failure of assurance of quality education and adopted fragile accountability mechanismare the leading challenges of the public universities in Bangladesh.
\end{abstract}




\title{
Information on Creating a Healthy Home Environment in Malaysia
}

\author{
*S. N. Nasir ${ }^{1}$, W. O. Ismail ${ }^{2}$ and S. Aziz ${ }^{3}$
}

\begin{abstract}
${ }^{1}$ Faculty of Architecture and Ekistics, Universiti Malaysia Kelantan, Kelantan, Malaysia. ${ }^{2}$ Faculty of Innovative, Design and Technology, Universiti Sultan Zainal Abidin, Terengganu, Malaysia.

${ }^{3}$ Faculty of Architecture and Ekistics, Universiti Malaysia Kelantan, Kelantan, Malaysia.
\end{abstract}

*nuratirah.mn@umk.edu.my

\begin{abstract}
Housing is one of the eight domains of the concept of age-friendly cities or environments of the World Health Organization (WHO). A healthy community ensures the availability of safe, decent, and affordable housing that supports the health of its occupants. Human spends more than 50 percent of his time inside the house, studies have shown that the built environment can affect human health. The unhealthy house can cause many diseases. Unhealthy houses increase the number of asthma, respiratory and skin allergies and lung diseases. Also accidents and domestic injuries are more in these houses. In addition unhealthy houses affect mental and social well-being such as: depression, isolation, stress and behavioral abnormalities. The "Healthy House" is not just designing healthy and hygienic shelter, but also includes complete physical, mental and social well-being in the house and the environment. Thus, the purpose of this paper is about information on creating a healthy home environment in Malaysia.
\end{abstract}




\title{
Internet of Things (loT) and Smart Home Technology in Malaysia: Issues and Challenges for Research in Adoption loT and Latest Technology for Home Building
}

\author{
*Salmiah Aziz ${ }^{1,2}$ and Siti Nuratirah Che Mohd Nasir ${ }^{1,2}$
}

${ }^{1}$ Universiti Teknologi MARA, Kampus Sri Iskandar, Bandar Sri Iskandar, Perak, Malaysia.

${ }^{2}$ Universiti Malaysia Kelantan Kampus Bachok, Bachok, Kelantan, Malaysia.

*myyaarc@gmail.com

\begin{abstract}
The capability of the Internet of Things (IoT) to electronically meter, path and monitor objects in the physical world has encouraged a flow of innovation and interest from many industries. It's probable to driving, chaotic changes across many sector offerings a myriad of potential services and applications. Smart home service, one of the symbolic developing technologies in the IoT era, has changed house equipment into being more intelligent, remote controllable, and interconnected. This paper is division of current the author's research on the adoption of IoT application for home building in Malaysia. The data and information presented in this paper were gathered from the reviews of the available relevant literature related to IoT and smart home in Malaysia. This paper addresses the major concern and challenges in IoT and smart home in Malaysia. Based on the analysis, it was found that three main challenges cited in the literature are perception of usefulness, confidentiality and privacy of consumer data, and absence of enterprise IoT applications in the country. As for Iot and smart home technology improvement in the near future, suggested tackling the current issues on home online education and working from home (WFH) especially because of the problematic pandemic Covid-19 worldwide.
\end{abstract}




\title{
Western and Islamic Wear: How Fashion Bloggers Influence the Malay Fashion Consumers' Purchasing Decision in Reconciling the Collision
}

\author{
*MZM Zain ${ }^{1}$, H Hassan ${ }^{1}$,AT Azizan ${ }^{1}$, SW Hasbullah ${ }^{1}$ RM \\ Zain $^{2}$ and A Ramli ${ }^{2}$
}

${ }^{1}$ Faculty of Creative Technology and Heritage, Universiti Malaysia Kelantan, Bachok Campus, 16300 Bachok, Kelantan, Malaysia.

${ }^{2}$ Faculty of Entrepreneurship and Business, Universiti Malaysia Kelantan, City Campus, 16100 Pengkalan Chepa, Kelantan, Malaysia.

*zaimmudin@umk.edu.my

\begin{abstract}
Malay consumers need to obey the restrictions outlined by religion and culture when it comes to fashion. However, this situation does not stop them from being fashionable. In contrast, they are always looking for alternatives to look stylish or stay in trend while also obeying religious values and cultural context, mainly young consumers. With more choices available in the market, this situation has given them more opportunities to create a distinctive style (mix and match). For instance, they can combine Islamic and Western trends with satisfying the restrictions and desires of modern Malay women as displayed by fashion bloggers, who are able to affect their purchasing decision. This study aims to analyse Malay fashion bloggers' influence on Malay fashion consumers' purchasing decisions, who face the restrictions and challenges of fashion due to religious values and cultural context. In other words, they have to follow the restrictions outlined by religion, for instance, by choosing the apparel that does not resemble their body figures and cover their hair and body, which can avoid them from provoking society. This research underwent a qualitative approach by conducting semistructured interviews with 16 respondents to analyse how Malay female fashion consumers are influenced by Malay fashion bloggers, who guide them on choosing fashion products that satisfy all parties. This study is among the first to study Malay fashion bloggers who have different religions and cultures. Findings also extend studies of fashion bloggers' roles and Muslim fashion consumers.
\end{abstract}




\title{
Consumer Behaviour Towards Foreign Halal Label Product In Selangor
}

\author{
*A L Zul Ariff ${ }^{1}$ \\ ${ }^{1}$ Faculty of Agro Based Industry, University Malaysia Kelantan, Kampus Jeli, 17600 Jeli, \\ Kelantan, Malaysia. \\ *zulariff@umk.edu.my
}

\begin{abstract}
Foreign products with halal label are increasing year by year in Malaysia. Where Selangor which the most popular state with foreign halal label product among consumers either Muslim or Non- Muslim. This resulted a tremendous import of halal food products from various countries. Malaysia obtained the list of certified International Islamic bodies besides Malaysia halal logo. Instead of that, the Muslim consumers can be able to know or identify he logos for international Islamic agencies abroad. This can trigger them in selecting and purchasing foreign products which cause the increasing of foreign halal products in the market. This research objective is to identify the consumer behaviour towards foreign halal label product in Selangor. This study using Theory of Planned Behaviour to structure the questionnaire. A purposive sampling was adapted, and 100 consumers were involved in Selangor during Malaysia International Halal Showcase (MIHAS). The analysis was used descriptive statistics, reliability test, Pearson correlation analysis and factor analysis by using SPSS 21.0. From this study, the attitude is the most influence factors of consumer behaviour toward foreign halal label product in Selangor. This study will be helping the government and researcher to more understand the factors of consumer behaviour toward foreign halal label product.
\end{abstract}




\title{
The Impact Of Muslim Awareness Toward Food Labelling In Malaysia
}

\author{
*A L Zul Ariff ${ }^{1}$ \\ ${ }^{1}$ Faculty of Agro Based Industry, University Malaysia Kelantan, Kampus Jeli, 17600 Jeli, \\ Kelantan, Malaysia. \\ *zulariff@umk.edu.my
}

\begin{abstract}
The purpose of this study is to analyze the impact of Muslim awareness toward food labeling in Malaysian consumers using an extended theory of planned behavior model (TPB). For this reason the study assessed the direct and indirect effect of food labeling on Muslim consumer awareness to consume food product base on the food labeling. A stratified random sampling technique was adopted in selecting 1,219 Muslim consumers in Klang Valley, Malaysia. This study contributes to and extends the understanding of Muslim awareness on food labeling and purchasing behavior tendency, base information exist food labels such as brand, halal label, ingredients, and nutritive value.
\end{abstract}




\title{
An Insight into Qurban Distribution by Mosque During the Period of Movement Control Order (MCO) in Malaysia
}

\author{
*J M Salleh ${ }^{1}$, M A Mahat ${ }^{1}$, S S Suyurno ${ }^{2}$ and A H M Salleh ${ }^{3}$
}

${ }^{1}$ Fakulti Perakaunan, Universiti Teknologi MARA, Cawangan Melaka, 78000 Alor Gajah, Melaka, Malaysia.

${ }^{2}$ Akademi Pengajian Islam Kontemporari, Universiti Teknologi MARA, Cawangan Melaka, 78000 Alor Gajah, Melaka, Malaysia.

${ }^{3}$ Akademi Pengajian Bahasa, Universiti Teknologi MARA, Cawangan Melaka, 78000 Alor

Gajah, Melaka, Malaysia.

*jismi@uitm.edu.my

\begin{abstract}
Qurban or sacrifice is a special Islamic ritual which is performed by slaughtering livestock during specific dates in the Islamic calendar and then distributing the meat to the specific categories of recipients. In Malaysia, it is a common practice that qurban ritual is managed by mosques on behalf of the qurban participants. In addition to the guidelines for the implementation of qurban ritual issued in 2013, the Department of Islamic Development of Malaysia (JAKIM) has issued standard operating procedures (SOPs) for the implementation of qurban, including its distribution during the movement control order (MCO) period in 2020. In the absence of the appropriate internal control system, there is a risk that the qurban distribution managed by mosque might not reach the targeted recipients, particularly the poor and needy as outlined under the Islamic laws i.e., Shariah. The study discussed the relevant issues pertinent to qurban distribution such as the risk of maldistribution and explained how the inherent risks in qurban distribution could be mitigated by applying five components of internal control issued by the Committee of Sponsoring Organisation (COSO). A proposed model of internal control for qurban distribution was also outlined. The findings of the study can provide an avenue for other researchers to undertake studies on different issues involving the management of qurban distribution.
\end{abstract}




\title{
Impact of Participation on Agro-food Entrepreneurship (Frozen Food) and Marketing Strategy Training Module among Housewife and Single Mother in Kelantan
}

\section{*T A B Tengku Halimatun Sa'adiah ${ }^{1,2}$, M N Maryana ${ }^{1,2}$, M Nursalwani ${ }^{1}$, Z Suhana ${ }^{1,2}$, R K Raja Ili Airina ${ }^{1}$ and M Seri Intan $^{1}$}

\author{
${ }^{1}$ Faculty of Agro Based Industry, Universiti Malaysia Kelantan, Jeli, Kelantan, Malaysia \\ ${ }^{2}$ Institute of Food Security and Sustainable Agriculture Research (IFSSA), Universiti Malaysia \\ Kelantan, Jeli, Kelantan, Malaysia \\ *halimatun@umk.edu.my
}

\begin{abstract}
Agro-food entrepreneurship is one of the sectors that is popular in Malaysia. However, the failure rate in Malaysia is higher because people involved in agro-food entrepreneur are not aware of the business challenges and lacking knowledge about financial, marketing and management skills. The purpose of this research is to study the impact of participation of housewife and single mother in Agro-food Entrepreneurship (Frozen Food) and Marketing Strategy Training Module in Kelantan. A survey using a self-administered questionnaire has been conducted among 70 respondents who are involved in the Agro-food Entrepreneurship (Frozen Food) and Marketing Strategy Training Module in Kelantan through pre and post-assessments. The findings indicate that all respondents are interested in joining Agro-food Entrepreneurship (Frozen Food) and Marketing Strategy Training Module in Kelantan, and they have agreed that this training can improve the knowledge, skill and their quality of life. This study may provide useful information in identifying the best mechanisms to encourage women, especially housewife and single mothers' participation in the Agro-food entrepreneurship training or program.
\end{abstract}




\title{
Factors Influencing Postharvest Technology Acceptance among Fruit Vegetable Farmers in the East Coast Economic Region (ECER), Malaysia
}

\section{*T A B Tengku Halimatun Sa'adiah ${ }^{1,2}$, M Maizatul Vanisha ${ }^{3}$, M N Maryana ${ }^{1,2}$, L. Naher ${ }^{1}$ and R Fazidah ${ }^{4}$.}

\footnotetext{
${ }^{1}$ Faculty of Agro Based Industry, Universiti Malaysia Kelantan, Jeli, Kelantan, Malaysia

${ }^{2}$ Institute of Food Security and Sustainable Agriculture Research (IFSSA), Universiti Malaysia

Kelantan, Jeli, Kelantan, Malaysia

${ }^{3}$ Agrobank, Kuala Lumpur, Malaysia

${ }^{4}$ Faculty of Plantation and Agro Technology, Universiti Teknologi MARA, Jengka, Pahang, Malaysia.
}

*halimatun@umk.edu.my

\begin{abstract}
Nowadays, despite having many post-harvest technologies being introduced to the farmers in helping to maintain crop shelf life, the percentage of post-harvest losses is still high. Although the phenomenon of new post-harvest technology acceptance has been well appreciated, the increasing characteristics phenomenon of technology rejection is yet to be understood and studied. The objective of this study is to determine the factors influencing post-harvest technology acceptance among fruit vegetables farmers in the East Coast Economic Region (ECER). A structured questionnaire was designed based on combinations of the Technology Acceptance Model (TAM) and Theory of Planned Behaviour. This study has employed a simple random sampling technique in selecting 105 fruit vegetables in ECER to answer the questionnaire. The findings indicate that fruit vegetable farmers in ECER have accepted the post-harvest technology, but they do not use and apply the technology. The factors derived which are perceived usefulness $(\mathrm{M}=4.11, \mathrm{SD}=0.622)$, perceived ease of use $(\mathrm{M}=3.84, \mathrm{SD}=0.588)$ and attitude $(\mathrm{M}=3.89, \mathrm{SD}=0.680)$ have all shown a high mean score. The findings of this study emphasise on the factor that influencing technology acceptance in improving and maintaining the quality of fruits vegetables to reduce the postharvest losses.
\end{abstract}




\title{
The Identity of Kelantan Peranakan Chinese through Clothing: An Aesthetic Morphology Approach
}

\author{
*Hanisa Hassan ${ }^{1}$, Nasirin Abdillah ${ }^{1}$, Mohd Zaimmudin Mohd \\ Zain $^{1}$, Siti Nur Anis Apandi ${ }^{1}$ and Nik Maheran Nik \\ Muhammad $^{2}$
}

\begin{abstract}
${ }^{1}$ Faculty of Creative Technology and Heritage, Universiti Malaysia Kelantan.
${ }^{2}$ UMK Institute of Entrepreneurship Management, Universiti Malaysia Kelantan.
\end{abstract}

*hanisa@umk.edu.my

\begin{abstract}
The term, 'peranakan' refers to a community that traces its lineage to the first waves of Hoklo (Han Chinese) settlers who interacted, especially through marriage, with the local people of the Malay Peninsula and Indonesian Archipelago. There are various types of the Peranakans in Malaysia such as the Baba-Nyonya, Chitty, Kristang (mostly in Melaka) and other Peranakan Muslims of Indian, Malay and Arab descent known as Jawi Peranakan. The Kelantan Peranakan Chinese (also known as Cina Peranakan Kelantan in Malay) is another unique ethnic group of Peranakans characterised by its mixture of three cultures: the local Malay of Kelantan, Chinese and Thai. However, this acculturated ethnicity seems to be less appreciated by the younger generation of the Kelantan Peranakan Chinese. One of the reasons is perhaps due to a general perception of the Kelantanese people that label them as cina kampung or cina bukit. To the older generation of the Kelantan Peranakan Chinese, they are proud to be called cina kampung whereas the younger generation may view this term as derogatory, implying that they are not advanced or modern people. The dwindling sense of pride among the younger generation may have resulted in the dying culture of the Kelantan Peranakan Chinese. A diluting image in their cultural artefacts is a case in point. Clothing, which is one of the important cultural artefacts, is gradually forgotten by the younger generation. Modern clothing is more appealing to them compared to the simplicity of clothing worn by their elder folks in the kampung (village). This study is aimed at examining the clothing of the Kelantan Peranakan Chinese, particularly, by studying its components of design elements using the aesthetic morphology approach. The formalistic aspect of the clothing, for instance, the ubiquitous paired blouse and sarong are a reflection of three cultural amalgamation of Malay, Chinese and Thai. The aesthetic aspect is also shown through their humble way of clothing hence symbolising a simple way of life of the community of Kelantan Peranakan Chinese. The finding thus concludes that the form and style of clothing worn by the Kelantan Peranakan Chinese is distinctive from other Peranakans in different states of Malaysia.
\end{abstract}




\title{
The Effects of COVID-19 in the Garment Industries of Bangladesh and Ways to Overcome its Challenges
}

\author{
*Saleh Uddin Mansur Ahmed ${ }^{1}$, Dr. Adi Anuar Bin Azmin ${ }^{1}$ and \\ Dr. Yoshifumi Harada ${ }^{1}$ \\ ${ }^{1}$ School of Business Innovation and Technopreneurship \\ University Malaysia Perlis \\ *mansur786@gmail.com
}

\begin{abstract}
The COVID-19 pandemic is impacting the global economy, which can be considered as a catastrophic situation for the job market and a crisis to the entire world economy. Bangladesh is one of the high-risk countries due to the COVID19 pandemic and the related social and economic losses. There is a considerable risk that economic stagnation would drive a significant population back into poverty. The aim of this paper is to analyze the effect of COVID19 on the garment industries in Bangladesh, its employees, and the impact on the overall economy of Bangladesh. Publication of scholarly literature, the study of different books, journals, webpages, and the different analyses were taken into consideration to find out the impact of this pandemic.
\end{abstract}




\title{
The Influence Of Integrated Management System (Ims) On Innovation Performance In Malaysia Construction Industry
}

\author{
${ }^{*} \mathrm{~N}$ Z Zainol ${ }^{1}$, F A Ibrahim ${ }^{1}$, M M Ahmad ${ }^{1}$, M Z A Mohd \\ Zahid $^{1}$ and M B H Ab Manaf ${ }^{1}$
}

${ }^{1}$ Faculty of Civil Engineering Technology, Universiti Malaysia Perlis, Malaysia

*norrazman@unimap.edu.my

\begin{abstract}
Globally, the construction industry has become a complicated, critical, and exponentially developed leads to increase difficulties and required more innovative and better management system. This leads the organization to find a better solution to their management approach. The international standards in quality, environment, safety, security, supply chain, etc. have been combined to form a comprehensive system called integrated management system (IMS). By implementing a management system standard, organizations can benefit from global management experience and good practice, but the issues arise on the success factors and how they affect the performance of the company. There had been plenty of researches son IMS elsewhere, but this research was focusing on the construction industry in Malaysia in term of innovation performance. The approach is quantitative by disseminating questionnaire to the construction players in the northern region of Peninsular of Malaysia. The IMS's attributes, i.e. integration of IMS and integrated audits, are found to have positive relationship toward the innovation performance of an organization. The model moderately explained $52.8 \%$ proven that the attributes should be the focal point of the organization to increase their success factors in boosting their performance, especially in its innovation.
\end{abstract}




\title{
Raised Flooring; a Traditional Designed Architectural Element as "Passive Design" system in Future Building. Case Study: Masjid Kampung Laut, Kelantan.
}

\section{*N I M Amin ${ }^{1,3}$ M R M Nasir ${ }^{1,3}$, I L H Ibrahim $^{1,3}$ and M R Khairuddin $^{2,3}$}

${ }^{1}$ Department of Interior Architecture

${ }^{2}$ Department of Architecture

${ }^{3}$ Faculty of Architecture and Ekistics, Bachok, Kelantan, Malaysia

*izzati_amin86@yahoo.com

\begin{abstract}
Building Industries contributes to a great number of carbon footprint through all these years. Through a proper planning, this industry can reduce the impacts to the earth generally and towards the environment specifically. This study was dedicated to propose an old traditional design found in 400 years building to be reapplied in modern construction as a "passive design" system. Raised timber flooring was commonly applied in South East Asia's traditional buildings due to the availability of the material and suitability for the climate. Masjid Kampung Laut was chosen as the case study due to its excellent reputation compared to the age period of the building. Till this moment, Masjid Kampung Laut is still function very well and benefit excellently to the community where it was located; Nilam Puri, Kelantan. This study was conducted in qualitative method, involving several types of data collection. The intention of this research whereby proposing towards the architects, designers, developers, engineers, and all the main players in the construction industry to reuse the design element of "raised floor" in modern buildings such as residentials, resorts and hospitality, mosques, retails, transit shelters and terminals, restaurants, schools, office buildings and etc. This revolution in design will at the end push the authorities to consider the design to be used in government buildings, as it also represent our architectural identity, energy sustainable, as well benefits the environment. In conclusion, the traditional architecture element of raised timber flooring could be redesigned and recommercialised to suit the future buildings. This design should be given a chance as it surely can benefit the building itself, the users, and the environment globally.
\end{abstract}




\title{
Online Distance Learning (ODL) as learning mechanism in post Covid-19: A Modified Unified Theory of Acceptance and Use of Technology (UTAUT) Model
}

\author{
*Dziauddin Sharif ${ }^{1}$ and Nik Rozilaini Wan Mohamed ${ }^{2}$ \\ ${ }^{1}$ Academy Contemporary Islamic Studies, Universiti Teknologi Mara, Kampus Bandaraya \\ Melaka, 75300 Melaka, Malaysia. \\ ${ }^{2}$ Faculty of Hotel and Tourism Management, Universiti Teknologi Mara, Kampus Bandaraya \\ 75300 Melaka, Malaysia. \\ *dziau646@uitm.edu.my
}

\begin{abstract}
This study established a newly integrative model to explain the determinants of Universiti Teknologi MARA (UiTM) students' Behavior Intention BIs toward using online distance learning (ODL) at an IPTA level. A conceptual model was built based on the UTAUT model in to extend this adequately validated framework by incorporating two additional predictor variables (technology readiness and perceived credibility) both were supportive in the result. Data were collected from 181 participants with experience in using online distance learning (ODL). The results shown a high consistency and reliability, thereby demonstrating that the proposed model holds substantial a new explanatory. This study revealed that technology readiness is a key factor that significantly influences Universiti Teknologi MARA (UiTM) student's BIs toward using online distance learning $(\mathrm{ODL})$.
\end{abstract}




\title{
Effect of Solvent to Matrix Weight Ratio and Stearic Acid Treatment on the Mechanical Properties of Poly(Methyl Methacrylate)/Palm Kernel Shell Composites
}

\author{
*B. Y. $\operatorname{Lim}^{1}$, C. H. Voon ${ }^{2}$, S. F. Lye ${ }^{1}$ and P. L. Teh ${ }^{1}$ \\ ${ }^{1}$ Faculty of Chemical Engineering Technology, Universiti Malaysia Perlis, Taman Muhibah, \\ 02600 Jejawi, Perlis, Malaysia. \\ ${ }^{2}$ Institute of Nanoelectronic Engineering, Universiti Malaysia Perlis, Seriab, 01000 Kangar, \\ Perlis, Malaysia.
}

*bylim@unimap.edu.my

\begin{abstract}
In this study, poly(methyl methacrylate)/palm kernel shell (PMMA/PKS) composites were prepared by solution casting. The effect of solvent to matrix $(\mathrm{S} / \mathrm{M})$ weight ratio and stearic acid (SA) treatment on PMMA/PKS composites were studied. PMMA pellets were dissolved and PKS powders were dispersed into acetone, separately. PMMA solution and PKS suspension were then mixed in ultrasonic bath. The mixture was then poured into a glass petri dish to evaporate acetone at room temperature and finally PMMA/PKS composite thin film was obtained. PMMA/PKS composites were characterized by using SEM and were subjected to tensile test. It was found that tensile strength, modulus of elasticity of composite increased but elongation at break decreased with the increasing S/M ratio and with SA treatment. The improvement of the mechanical properties was due to the improved interfacial bonding following the SA treatment and the formation of crystallized PMMA domain in the composite with the increasing $\mathrm{S} / \mathrm{M}$ ratio. SEM images revealed even fracture surfaces as $\mathrm{S} / \mathrm{M}$ increased and with the application of SA treatment that indicate better matrix-filler adhesion. It can be concluded that S/M increment and SA treatment improved mechanical properties of PMMA/PKS composite.
\end{abstract}




\title{
Effect of Portions and Particle Sizes on Ultimate Properties of Oil Palm Fronds
}

\author{
S Mohamed Sharizal ${ }^{1}$, M A Salam ${ }^{2}$, S O Sharifah Aisyah ${ }^{1}$, I \\ Mohamad Zamzani ${ }^{3}$, A L Zul Ariff ${ }^{4}$ and $*$ E. R. Aweng ${ }^{1}$
}

${ }^{1}$ Faculty of Earth Science, Universiti Malaysia Kelantan, Locked Bag No. 100, 17600 Jeli, Kelantan, Malaysia.

${ }^{2}$ Department of Environmental Science and Disaster Management, Faculty of Science,

Noakhali Science and Technology University, Noakhali-3814, Bangladesh.

${ }^{3}$ Kelantan State Department of Environment, Lot 322-324, Seksyen 27, Jalan Sri Cemerlang, 15300, Kota Bharu, Kelantan, Malaysia.

${ }^{4}$ Faculty of Agro Based Industry, Universiti Malaysia Kelantan, Locked Bag No. 100, 17600 Jeli, Kelantan, Malaysia.

*aweng@umk.edu.my

\begin{abstract}
The ultimate properties are important in order to determine the percentage of constituent elements of material which contributes to combustion. Combustion is one of the important elements to determine whether a material is suitable to be used as a solid fuel or not. Thus, the objective of this study is to evaluate the effect of portions and particle sizes on the ultimate properties of oil palm fronds. The ultimate analysis parameters are carbon, hydrogen, nitrogen, sulphur and oxygen. The carbon $(\mathrm{C})$, hydrogen $(\mathrm{H})$, nitrogen $(\mathrm{N})$ and sulphur $(\mathrm{S})$ elements were determined using a CHNS/O Analyzer, Perkin Elmer 2400 Series II base on ASTM D3176 standard, while oxygen $(\mathrm{O})$ was determined by the difference of other percentages from $100 \%$. The average percentage of carbon of bottom, middle and top portion of oil palm fronds for smaller particle size $(0.5 \mathrm{~mm})$ were $43.46 \pm 0.10 \%$, $43.37 \pm 0.04 \%$ and $43.32 \pm 0.04 \%$ respectively. On the other hand, the average percentage of carbon of the same portion of oil palm fronds for bigger particle size $(1.5 \mathrm{~mm})$ were $44.30 \pm 0.04 \%, 43.82 \pm 0.02 \%$ and $43.69 \pm 0.04 \%$ respectively. Meanwhile, the average percentage of hydrogen of the same portion of oil palm fronds for smaller particle size $(0.5 \mathrm{~mm})$ were $5.41 \pm 0.02 \%, 5.38 \pm 0.02 \%$ and $5.34 \pm 0.01 \%$ respectively. The average percentage of hydrogen of the same portion of oil palm fronds for bigger particle size $(1.5 \mathrm{~mm})$ were $5.50 \pm 0.04 \%, 5.43 \pm 0.02 \%$ and $5.33 \pm 0.01 \%$ respectively. The average percentage of nitrogen of the same portion of oil palm fronds for smaller particle size $(0.5 \mathrm{~mm})$ were $0.44 \pm 0.02 \%, 0.45 \pm 0.02 \%$ and $0.48 \pm 0.02 \%$ respectively and for bigger particle size were $0.40 \pm 0.01 \%, 0.46 \pm 0.01 \%$ and $0.47 \pm 0.02 \%$ respectively. The average percentage of sulphur of the same portion of oil palm fronds for smaller particle size $(0.5 \mathrm{~mm})$ were $0.31 \pm 0.02 \%, 0.34 \pm 0.01 \%$ and $0.35 \pm 0.01 \%$ respectively and for bigger particle size were $0.32 \pm 0.02 \%, 0.33 \pm 0.01 \%$ and $0.34 \pm 0.01 \%$ respectively. Last but not least the average percentage of oxygen of the same portion of oil palm fronds for smaller particle size were $50.38 \pm 0.01 \%, 50.51 \pm 0.02 \%$ and $50.51 \pm 0.02 \%$ respectively and for bigger particle size were $49.58 \pm 0.02 \%$, $49.96 \pm 0.02 \%$ and $50.17 \pm 0.03 \%$ respectively. Based on the results of the ultimate analysis above, it can be concluded that oil palm fronds have the potential to be utilised as solid fuel.
\end{abstract}




\title{
Route Selection (RouteSel) Process in GreedLea Routing Protocol for Internet of Vehicle (loV) Network Environment
}

\section{${ }^{*}$ O Normaliza ${ }^{1}$, Y Naimah ${ }^{1}$, E E S Mohamed ${ }^{1}$ and $\mathrm{H}$ Zulkifli $^{1}$}

${ }^{1}$ Faculty of Electronic Engineering Technology, Universiti Malaysia Perlis (UniMAP), Perlis, Malaysia.

*normaliza@unimap.edu.my

\begin{abstract}
The low road efficiency problem triggered by the congestion and traffic accident is the reason of enhancing conventional transportation system in the world. It showed an awful picture of increasing traffic accidents with the growing number of vehicles. Road efficiency is constantly the main issue in the transportation system, hence supporting road efficiency must be in line among the traffic safety idea [1]. Particularly, loV is a main factor in Vehicle Cyber Physical Systems (VCPS) [2]. Road side unit (RSU) is an important factor for Vehicle to everything (V2X) communication, where it is an access point for linking the loV network to the other networks [3]. In the loV, the information exchange is generally produced of V2X which is vehicle-toinfrastructure (V2I) and vehicle-to-vehicle (V2V). It is important that safety message such as road condition, traffic information and traffic accidents consistently delivered to other vehicle in a timely manner for safety applications. Therefore, a number of studies have been done to design and develop a dependable routing protocols in Vehicular Ad-hoc Network (VANET) [4]-[10]. Though, in VANET, a transmission using single hop is generally incapable to serve all the proposed receivers because of partial radio range across a long distance. Consequently, the integrated routing protocol is needed to improve a communication system between vehicles in loV network. Moreover, achieving a stable level performance in term of high throughput, less packet loss and less link failure in loV is a challenging problem. In this paper, those key performance is analyzed and has been discussed in result section.From the results, it shows that the GreedLea routing protocol delivered $10 \%$ improved performance compared to existing Greedy perimeter stateless routing (GPSR) routing protocol in term of packet delivery ratio, average delay and path loss.
\end{abstract}




\title{
The Beauty in the Malay Manuscript. Appreciation of Art
}

\section{${ }^{*}$ M Omar ${ }^{1}$, M Ibrahim², H M Razali ${ }^{3}$ and S F M Hashim}

${ }^{1}$ Faculty of Art \& Design, Universiti Teknologi MARA, Machang Campus, 18500 Machang Kelantan, Malaysia.

${ }^{2}$ Faculty of Innovative Design and Technology, Universiti Sultan Zainal Abidin, Gong Badak Campus, 21300 Kuala Terengganu, Malaysia.

${ }^{3}$ Faculty of Art \& Design, Universiti Teknologi MARA, Machang Campus, 18500 Machang Kelantan, Malaysia.

${ }^{4}$ Faculty of Art \& Design, Universiti Teknologi MARA, Machang Campus, 18500 Machang Kelantan, Malaysia.

*mazni867@uitm.edu.my

\begin{abstract}
This paper aims to discuss the beautiful ornament on manuscript illumination in the Malay world. The beauty of the decorative variety in the illumination of the manuscript will be seen through the appreciation of art using the formalistic aspects of art. This study involves the study of literature through a qualitative approach to collect data from previous studies. As a result of analyzing past studies, researchers found similarities and differences in findings. In terms of similarities decorative features in the Malay manuscript illuminations highlighting the use of the gold which refers to the symbol of luxury, class, identity and style. While the similarity in terms of motifs, most use flora motifs (plants) that refer to nature as inspiration. Therefore, in terms of differences, the researchers found various findings of the study, namely the use of motifs other than flora motifs. Among other motives found in the Malay, manuscript illumination is characterized by geometric motifs, structure, symmetry, cosmology, and vegetal. Researchers also argue that the decorative style of the manuscript illumination reflects the expertise and subtlety of the manuscript decorator in revealing the natural beauty of Allah S.W.T. creation. This concept of beauty means inner beauty and external beauty (form and content).
\end{abstract}




\title{
Comparison between Perceived and Expectation Citizen-Centric Public Service Satisfaction During Pandemic Outbreak in Malaysia
}

\section{*S H M Amin ${ }^{1}$, S D M Wahid², A J M Ali ${ }^{1}$, A Abdullah¹, S M Ali² And S N A Azis²}

${ }^{1}$ Faculty of Administrative Science and Policy Studies, Universiti Teknologi MARA, Cawangan Negeri Sembilan, Kampus Seremban,70300, Negeri Sembilan, Malaysia.

${ }^{2}$ Faculty of Business Managament, Universiti Teknologi MARA, Cawangan Melaka, Kampus Alor Gajah,78000, Melaka, Malaysia.

*hajjar@ uitm.edu.my

\begin{abstract}
Citizen-centric is a concept that defines as shifting of service delivery from government's interest to citizen's interest. The citizens of different socioeconomic classes may experience a similar quality of public services, but they may reach different conclusions about a service because their evaluations are shaped by different sets of perceived and expectation performance. Past scholars confirmed that the comparisons between citizen's perceived-expectation relationship were not intensively explored and required further investigation. Therefore, this paper aim to compare the impact of citizen-centric public service satisfaction among citizen on what they perceived as compared to their expectation. Utilizing, the expectancydisconfirmation model of satisfaction, this paper offers a quantitative approach by providing intensive comparison for citizen's perceived-expectation relationship. We employ paired sample t-test to answer the mean differences between tested relationship. This paper successfully identifies six mean differences namely performance, responsiveness, reliability, information quality, service quality and participation on the relationship between perceived and expectation. We believe this paper can benefit the supply side in conducting requirement in gathering and designing of citizen-centric public service satisfaction model in the future.
\end{abstract}




\title{
Islamic Psychospiritual Interventions Against Teenage Delinquency Problems According to Imam al-Ghazali
}

\author{
*I Farhana ${ }^{1,2}$, S Nabilah1, S.Snuar ${ }^{1}$, S.Ahmad, S \\ Marpuah $^{1}$ \\ ${ }^{1}$ Centre of General Studies and Co-Curricular, Universiti Tun Hussein Onn Malaysia, \\ Batu Pahat, Johor. \\ ${ }^{2}$ Faculty of Applied Science and Technology, Universiti Tun Hussein Onn Malaysia, \\ Batu Pahat, Johor. \\ *intan@uthm.edu.my
}

\begin{abstract}
The problem of delinquen youths in society today is alarming despite numerous prevention and rehabilitation being done to curb the issue. Statistics from the Jabatan Kebajikan Masyarakat (JKM) showed an increase in the number of delinquency teenagers indicating the need for improvements to existing prevention. Teenagers are national assets that need to be morally formed to become an outstanding human being of the world and the hereafter that can form a personal and thus develop the country. There is a need for the formation of a psychospiricual model to prevent the addition of delinquen teens in Malaysia. Islamic psychospiritual therapy is an effort to treatment and rehabilitation for problems related to feelings, thoughts and behaviors that use islamic practices and best practices. This therapy treatment focuses on knowing yourself, filling of the self with good behaviors and self-esteem towards happiness in the world and the hereafter. This therapy is seen as suitable for delinquency teenagers to form admirable and personal morals. Thus, in order to treat the problem of delinquen youth, this therapy uses the Imam al-Ghazali approach which is seen as suitable for treating souls, spirits, intellect and desire.
\end{abstract}




\title{
Impact of Buried Oxide Thickness in Substrate-gate Integrated Silicon Nanowire Field-Effect Transistor Biosensor Performance for Charge Sensing
}

\author{
Y M Tan ${ }^{1},{ }^{*} M$ F M Fathil', M N M Nuzaihan², N Sabani ${ }^{1}$, \\ X Y Teoh', M K Md Arshad ${ }^{1,2}$, S C B Gopinath", ${ }^{2,3}$ S F A \\ Rahman $^{2}$ and U Hashim²
}

${ }^{1}$ Faculty of Electronic Engineering Technology, Universiti Malaysia Perlis, 02600 Arau, Perlis, Malaysia.

${ }^{2}$ Institute of Nano Electronic Engineering, Universiti Malaysia Perlis, 01000 Kangar, Perlis, Malaysia.

${ }^{3}$ Faculty of Chemical Engineering Technology, Universiti Malaysia Perlis, 02600 Arau, Perlis, Malaysia.

*mohamadfaris@unimap.edu.my

\begin{abstract}
The paper investigated on performance in charge sensing for substrate-gate integrated silicon nanowire field-effect transistor biosensor at different thickness of the buried oxide layer, sandwiched in between the topsilicon and substrate layers. The device structures with different buried oxide thickness ranging from 100 to $200 \mathrm{~nm}$ were designed and simulated using the Silvaco ATLAS device simulation software. The increase of buried oxide thickness reduced the strength of induced electric field that contributes to the formation of inversion layer for current flow through the silicon nanowire channel, hence contributed to the increase in threshold voltage. For simulation of charge sensing, the device demonstrated the ability to identify different Interface charge values ranging from $-5 \times 1010$ to $-9 \times 1010 \mathrm{e} \cdot \mathrm{cm}-2$ applied on the surface of the silicon nanowire channel to represent target charge biomolecules that bound to the biosensor in actual detection. Significant change in threshold voltage can be observed due to the applied interface charge density values and was evaluated to determine the sensitivity for charge sensing performance. The device shows better performance when designed with buried oxide thickness of $200 \mathrm{~nm}$ at sensitivity mof 1.151 $\mathrm{V} / \mathrm{e} \cdot \mathrm{cm}-2$.
\end{abstract}




\title{
Art Appreciation of the Malaysia Independence Day Logo 2020
}

\section{*S F M Hashim¹, M Ibrahim³, A Abd Jamil², S A C Cob², M Omar ${ }^{1}$ and H M Razali ${ }^{1}$}

${ }^{1}$ Faculty of Art \& Design, Universiti Teknologi MARA, Campus Machang, Bukit Ilmu, 18500 Machang, Kelantan, Malaysia.

${ }^{2}$ Faculty of Art \& Design, Universiti Teknologi MARA, Seksyen 1, 40450 Shah Alam, Selangor, Malaysia

${ }^{3}$ Pusat Pengaian Reka Bentuk. Fakulti Reka Bentuk Inovatif Dan Teknologi, Universiti Sultan Zainal Abidin Kampus Gong Badak, 21300 Kuala Nerus, Terengganu, Malaysia

*sitifairuz@uitm.edu.my

\begin{abstract}
From the perception of Art Appreciation, requires two main aspects, namely formalistic and content. These two aspects come together to form a work of art. The logo is one of the results of art in the form of digital art that are always used in graphic design. This paper is conducted to identify the visual characteristic of the Malaysian Independence Day logo. Researchers only chose Independence Day for the year 2020 to be analyzed because it is the logo for the current year and is the latest logo design created compared to the previous two years using the same logo. To achieve the purpose, this method of this study is qualitative, which is to use the study of art appreciation evaluation analysis in the context of form and content. It clearly shows the formalistic aspects used in translating the literal and implicit meanings in the Independence Day 2020 logo. This logo features various artistic elements of art and principles of design, as described in this study. It also gives sense to the events that took place during the year. This study has combined the theoretical aspects of Formalistic art with graphic design that is the study of the Independence Day logo. A logo can be considered successful if all sections of society understand it. This logo is created every year, according to the theme and identity of the country. The logo design refers to the symbolism of a multiracial society that is pluralistic and dignified the culture in this country. Through the analysis that has been made, the creation of the Independence Day 2020 logo can be accepted because the logo is simple and easy to understand by the community. The use of the right logo can change people's perception of something.
\end{abstract}




\title{
Designing Effective Online Assessment Implementation Strategies for Tertiary Language Courses-Narratives on Preliminary Overview of Challenges
}

\section{${ }^{*}$ Norkhairi Ahmad ${ }^{1}$, Ina Suryani Ab Rahim² and Salawati Ahmad ${ }^{3}$}

${ }^{1}$ Industrial Linkages Section, Universiti Kuala Lumpur Malaysia France Institute, 43650 Bandar Baru Bangi, Selangor Malaysia.

${ }^{2}$ Center for International Languages, Universiti Malaysia Perlis, 02600 Arau, Perlis, Malaysia.

${ }^{3}$ Center for Language Studies, Universiti Tun Hussien Onn Malaysia, 86400 Parit Raja, Batu Pahat, Johor, Malaysia.

*norkhairi@unikl.edu.my

\begin{abstract}
The emergence of 21st century education and digital education era has transformed traditional transactional learning which is primarily teachercentered to a more facilitated independent learning with heavy incorporation of the online mode. Tertiary courses including languages therefore require a set of sound online assessment strategies to cater to the blended/flipped learning synchronously delivered for undergraduates. Within this context, this study aims to investigate present challenges in implementing online language assessment for tertiary language courses and the need to design effective implementation strategies. Before such strategies could be developed, challenges and issues must be identified and mitigated. Via a DELPHI based qualitative approach and stratified purposive sampling, data was elicited from eighteen expert respondents from nine public universities who gave their views and reactions to a set of structured interview questions. Thirteen challenges that fall into four categories of issues were identified. They must be addressed in planning for smooth online language assessment system. The findings also indicate that specific online language assessment guidelines and framework for is deemed necessary to ensure best educational practices are applied to ensure attainment of course and programme outcomes.
\end{abstract}




\title{
Simulation of Runoff using HEC-HMS for Ungauged Catchment
}

\section{A Nazirah ${ }^{1},{ }^{*}$ W O Wan Mohd Sabki ${ }^{1}, \mathrm{H}$ Zulkarnian ${ }^{1}$ and A Afizah ${ }^{1}$}

${ }^{1}$ School of Environmental Engineering, Universiti Malaysia Perlis, Kompleks Pusat Pengajian Jejawi 3, 02600 Arau, Perlis, Malaysia.

*wansabki@unimap.edu.my

\begin{abstract}
Hydrological modelling is a conceptual representation of a complex characteristic of real hydrologic features which developed to understand, analyse, predict and manage water resources in a watershed. The simulation of surface runoff was developed in the catchment of centre in Perlis State by using Hydrologic Modelling System (HEC-HMS). Estimation and prediction the flow in ungauged catchment were carried out by transporting parameters from the gauged catchment. In this study, parameters for ungauged catchment were derived from information close to ungauged catchment. The percent difference of peak flow and runoff for calibration at donor catchment showed reduced from $8.9 \%$ to $5.9 \%$ (peak discharge) and from $29.19 \%$ to $6 \%$ (volume runoff). The model calibration was indicated the value of Curve Number is 60 and the recession constant is 0.8 , respectively. The result showed that the model successfully predicted of gauged catchment runoff and peak flow for calibration (94\% and $94.1 \%)$, and validation $(85.12 \%$ and $79.95 \%$ ). This study have a significant contribution for future development of water resource in Perlis State and in ungauged catchment of Perlis.
\end{abstract}




\title{
Applying Islamic Marketing Ethics Among Muslimpreneurs of Small-scale Business During Covid19 MCO: A Comparison Between Types of Social Network System (SNS)
}

\section{*M S Muhammad Taufik¹, P R Mohd Faizal ${ }^{2}$, A R Abdul Qayyum², M A Noorfazreen2 and N Nor Afifa ${ }^{3}$}

\author{
${ }^{1}$ Academy of Contemporary Islamic Studies (ACIS) UiTM Cawangan Melaka, 78000 \\ Alor Gajah, Melaka \\ ${ }^{2}$ Academy of Contemporary Islamic Studies (ACIS) UiTM Cawangan Melaka Kampus \\ Jasin, 77300 Merlimau, Melaka \\ ${ }^{3}$ Academy Of Language Studies, UiTM Cawangan Melaka Kampus Jasin, 73000
} Merlimau, Melaka

*taufiksharipp@uitm.edu.my

\begin{abstract}
The outbreak of COVID-19 forced the Malaysian government to implement the Movement Control Order (MCO) in phases starting March 18, 2020. The implementation of the MCO has affected business continuity, especially among Muslimpreneurs involved in small-scale business. Restricting business hours and business movements to limited time periods and movements, entrepreneurs have turned to online and digital business methods specifically for marketing, supplying, and delivering goods. As a Muslim, Muslimpreneurs should not compromise with any unethical element in their entrepreneurial activities. Thus, business marketing and promotional activities conducted digitally and online should be in line with the Islamic law as well as the basic principles of ethics in Islamic business. This study used a content analysis approach to examine the implementation of Islamic marketing ethics in the sharing of business advertisements through Social Network System which is popular among Muslimpreneurs in Malaysia. For that purpose, a total of 45 samples of advertisements have been randomly studied from WhatsApp, Instagram and Facebook applications. This study found that over $90 \%$ of Muslimpreneurs have adhered to the basic principles of Islamic marketing ethics in their advertising material. At the same time, Muslimpreneurs are also found to prefer sharing quality ads and more on Facebook compared to WhatsApp and Telegram.
\end{abstract}




\section{Film Adaptation as A New Medium in Understanding Literature}

\section{*Sudirman Kiffli ${ }^{1}$, Nasirin Abdillah ${ }^{1}$ and Farrah Atikah Saari ${ }^{1}$}

${ }^{1}$ Fakulti Teknologi Kreatif dan Warisan, Universiti Malaysia Kelantan, Kampus Bachok, 16300 Bachok, Kelantan, Malaysia.

*sudirman.k@umk.edu.my

Abstract: A literary work, conventionally, can exist in an oral or writing form that requires its readers to listen and read in order to comprehend. This conventional concept of enjoying literary works has resulted in the waning interest to be involved in literature among the younger generation. It is deemed pivotal that adaptations of literature into films may attract the attention of this generation in order to understand a literary work. Based on this notion, this study aims at bringing to the fore the importance of film adaptation so as to comprehend the adaptation concept, analyse film adaptation in Malaysia and evaluate its significance to whom it may concern. It is discovered preliminarily, in this study that the adaptation process is essential in the efforts to enhance understanding of literary works among readers. It is hoped that this study may open up more discussions on the film adaptation and further embrace its impacts on society as film is one of the powerful technological tools that notably characterises the 4.0 Industrial Revolution (4IR). 


\title{
Economic Determinants Tourism Performance: Perspective of Thailand's Tourism Sector
}

\section{*Syahiru Shafiai ${ }^{1}$, Intan Maizura Abd Rashid', Najuwa Mohd Nasir ${ }^{1}$, Suzana Ab Rahman², Hamidah Norman ${ }^{3}$ and Suhailah Ibrahim ${ }^{3}$}

\author{
${ }^{1}$ Universiti Teknologi MARA (UiTM) Melaka, Kampus Alor Gajah, Km 26 Jalan Lendu, \\ 78000 Alor Gajah, Melaka, MALAYSIA. \\ ${ }^{2}$ Universiti Malaysia Perlis, Kampus Alam UniMAP Pauh Putra \\ 02600 Arau, Perlis, Malaysia. \\ ${ }^{3}$ Kolej Universiti Islam Melaka, Batu 28, Kuala Sungai Baru, \\ 78200 Melaka, Malaysia \\ *s.shafiai@uitm.edu.my
}

\begin{abstract}
Like other products, tourists purposely go through the process of arranging and decision-making in selecting the vacation goal. They massively spend their time and exertion in effectively gathering information and thoroughly assessing the elective goals some time recently the ultimate decision is being settled. Basically, the destination choice is influentially decided by attractiveness, and quality in which the sightseers see. With its intangible nature and social suggestions, in spite of the fact that the buy recurrence is low, the buy esteem is significantly high. As Thailand takes over the ASEAN chair for 2019, various prospects are opened up for hospitality linked businesses to attract visitors from ASEAN countries. The number of international tourist arrivals to Thailand in 2018 reached 38.12 million people. Tourism is one of the greatest vital sectors pouring the Thai economy, which can constantly generate great income for Thailand. Based on an allencompassing approach, this research has exposed that integrating various strategies for tourism expansion with sound government policies and proactive management practices have led to significant positive outcomes towards mutual success of tourism sectors of Thailand. Additionally, the paper delivers considered policy to drive long-lasting enhancements in tourism sector, exchange rate and service sectors through efficient management and intelligent utilization of resources in tourism sector.
\end{abstract}




\title{
Review on The Influences of Atmospheric Effects of Commercial Settings Towards Consumers' Emotions, Perceptions and Behaviors
}

\section{*N Ramlee' ${ }^{1}$ I Said², W S N W Mohamad', K Hassan ${ }^{1}$ and $\mathrm{R}$ Hasan $^{1}$}

${ }^{1}$ Faculty of Architecture and Ekistics, Universiti Malaysia Kelantan, Kampus Bachok, 16300 Bachok, Kelantan, Malaysia.

${ }^{2}$ Faculty of Built Environment and Surveying, Universiti Teknologi Malaysia, 81310

UTM Skudai, Johor, Malaysia

*liyana.r@umk.edu.my

\begin{abstract}
In many environments, atmospheric effects have been extensively studied to assess human activities in enclosed buildings in response to environmental stimuli. The goal of this paper is to examine a review of 25 studies on atmospheric influences on consumers' emotions in the business environment over the past 20 years. The synthesis involves elements used as environmental stimuli that have been commonly used and the results of previous studies. In short, in atmospheric studies with stimuli such as spatial layout, color, scents, lighting and music are the most discussed variables influencing human emotions through emotion.
\end{abstract}




\title{
Determinants Of Job Rotation Among Employees In Malaysia Education Sector
}

\author{
*W N W M Radzi ${ }^{1}$, S N Ramlan'1, I M A Rashid², I H A \\ Samah $^{2}$, A S Amir ${ }^{1}$, W A F W Husain ${ }^{3}$ and N M Nasir ${ }^{1}$ \\ ${ }^{1}$ Universiti Malaysia Perlis, Kampus Alam UniMAP Pauh Putra \\ 02600 Arau, Perlis, Malaysia. \\ ${ }^{2}$ Universiti Teknologi MARA (UiTM) Melaka, Kampus Alor Gajah, Km 26 Jalan \\ Lendu, 78000 Alor Gajah, Melaka. \\ ${ }^{3}$ Universiti Malaysia Pahang, 26600 Pekan, Pahang, Malaysia.
}

*radzi@unimap.edu.my

\begin{abstract}
This research explores determinants of job rotation among employees in education sector. Job rotation has become one of technique used by employers to rotate their employees' assigned jobs throughout their employment. Most employers use job rotation as a strategy for employees to take new tasks on different jobs for a period of time before rotating back to their original position. According to Azzam (2013), job rotation is an effective administrative tool, and it is used in many organizations to achieve different goals. This research can be used for organization or employers to understand the determinants of job rotation among employees. So, a questionnaire were distributed among employees in education sector. This study are using descriptive survey to investigate the relationship between motivation, training, skill and knowledge and performance toward job rotation. Total of 342 set of questionnaire were collected out of 400 respondent. The dependent and independent variables were analysed by mean, and standard deviation and mean of frequency distribution. Statistical Package for the Social Science (SPSS) software are use in this project. Factors such as motivation, training, skill and knowledge and performance is influence the determinants of job rotation among employees in education sector were analysed. In this study, revealed that motivation, training, skill and knowledge and performance belief have significant relationship with determinants of job rotation among employees in education sector. This research could help to boosting employee's morale. This research also recommended that future researchers should target larger sample size.
\end{abstract}




\title{
Troductory Analysis Of Factors Affecting Intercultural Couples In The Context Of Malaysia
}

\section{*Wan Ahmad Fauzi Wan Husain"1, Suraiya Ibrahim¹, Wan Sallha Yusoff ${ }^{1}$, Intan Maizura Abd Rashid ${ }^{2}$ and Irza Hanie Abu Samah ${ }^{3}$}

${ }^{1}$ Universiti Malaysia Perlis, Kampus Alam UniMAP Pauh Putra 02600 Arau, Perlis, Malaysia.

${ }^{2}$ Faculty of Business Management, Universiti Teknologi MARA (UiTM) 78000 Alor

Gajah, Melaka. Malaysia

${ }^{3}$ Universiti Teknologi Malaysia, 81310 Skudai, Johor Bahru, Johor, Malaysia.

*fauzi@unimap.edu.my

\begin{abstract}
A study of communication processes forms inside intercultural marriages will profit numerous people, especially couples who are occupied with such connections. At the point when people find out about other people who experience comparative impediments or conditions, they can re-examine their own circumstance with a progressively exact focal point. Commonly, this changed perspective produces development in the person who is looking for answers and frequently impacts this present individual's life partner. An investigation of this sort additionally adds to the field of advising. The psychological wellness field is persistently extending and looking for extra understanding and learning about human behaviour. Humans are perplexing animals, in this manner, visit perceptions and academic examinations are important for improved cognizance. Pre-marriage, conjugal, and family mentors benefit from an investigation of intercultural relational unions as all social orders depend on relational unions and familial relationships. These relationships determine the health of a society.
\end{abstract}




\title{
Applying Islamic Marketing Ethics in Marketing Digitalization During The COVID-19 MCO Period in Malaysia: A Guide to Small- Scale Muslimpreneurs
}

\section{${ }^{*}$ P R Mohd Faizal ${ }^{1}$, M A Suhaida ${ }^{2}$, D Norizah ${ }^{1}$ and N Nor Afifa $^{3}$}

\author{
${ }^{1}$ Academy of Contemporary Islamic Studies, Universiti Teknologi MARA (UiTM), \\ 78000 Alor Gajah, Melaka. \\ ${ }^{2}$ Faculty of Business Management, Universiti Teknologi MARA (UiTM) 78000 Alor \\ Gajah, Melaka. \\ ${ }^{3}$ Akademi Pengajian Bahasa, Universiti Teknologi MARA (UiTM) Melaka, 78000 Alor
} Gajah, Melaka.

*faizal061@uitm.edu.my

\begin{abstract}
The implementation of the Movement Control Order (MCO) due to the spread of COVID-19 outbreak has affected business continuity, especially Muslimpreneurs involved in small-scale business. The restrictions have forced business activities to adapt and change, entrepreneurs have turned to online and digital business methods specifically for marketing, supplying, and delivering goods sold. As a Muslim, Muslimpreneurs should not compromise with any unethical element in their entrepreneurial activities. Thus, the marketing and promotion activities of their business conducted digitally should be in line with Islamic law and the basic principles of ethics in Islamic business. This qualitative study seeks to elaborate on the impact of Covid-19 and MCO towards small-scale Muslimpreneurs and how the digitalization of business activities will help businesses of Muslimpreneurs survive and thrive. The data in this study were collected from previous studies suited with the aim of this study. This study will help in developing a standard of Islamic Marketing Ethics in advertising as Islamic advertising concept stands contrary to the contemporary practices. With a growing concern for business ethics, this study is an attempt to bring Islamic ethics into advertising practice. This will not only eradicate the ill-effects of contemporary advertising but also provide sound evidence for revising advertising policies. This study also adds to the developing field of Islamic marketing, by being the first attempt of its kind in paving the way for Islamic advertising. This study concludes that Islamic Marketing Ethics which derived from Islam teaching framework (Iman, Islam \& Ihsan) taken for granted of people to live in conducive, peace and joy.
\end{abstract}




\title{
The Impact Of Tourism Performance On Sports Industry In Thailand and Indonesia
}

\author{
*M H Amlus' ${ }^{1}$, I M A Rashid², I H A Samah³, N \\ Muhammad $^{1}$, A F Salleh ${ }^{1}$ and A Z Abdullah ${ }^{1}$ \\ ${ }^{1}$ Sport Engineering Research Centre (SERC), Universiti Malaysia Perlis,02600 Arau, \\ Perlis, Malaysia \\ ²Universiti Teknologi MARA (UiTM) 78000 Alor Gajah, Melaka. Malaysia \\ ${ }^{3}$ Universiti Teknologi Malaysia, 81310 Skudai, Johor Bahru, \\ Johor, Malaysia. \\ *harith.amlus@unimap.edu.my
}

\begin{abstract}
The COVID-19 epidemic has thrown Indonesia's sports calendar into confusion, with many high-profile sporting events rescheduled or postponed for the foreseeable future. Tourism is one of the greatest vital sectors pouring the Thai economy, which can constantly generate great income for Thailand and Indonesia. The number of international tourist arrivals to Thailand in 2018 reached 38.12 million people and Indonesia sport tourism received 250,000 foreign tourists in 2018. Based on an allencompassing approach, this research has exposed that integrating various strategies for tourism expansion with sound government policies and proactive management practices have led to significant positive outcomes towards mutual success of tourism sectors of Thailand. Additionally, the paper delivers considered policy to drive longlasting enhancements in tourism sector, exchange rate and service sectors through efficient management and intelligent utilization of resources in tourism sector. The recent shocks in provide and demand within the world aren't because of sudden economic reasons. Indeed, associated with Covid-19 that causes speedily spreading world health issues and life threats round the world coping with the social issues created by Covid-19 pandemic, they ought to not neglect the economic changes created by this pandemic. The government-ordered lockdowns have discontinuous life for billions and within the same time creates economic collapse situation. The foremost vital of those economic changes in developing countries with high fragility is exchange rates caused by sports and tourism industry, as a result of exchange rates will directly have an effect on several economics variables, from inflation to foreign trade, from the balance of payments to interests. Therefore, this analysis calculates the result of COVID-19 to sports and tourism business for affected countries within the worldwide. Thus, this study evaluated the impact tourism performance to detect the economic changes in sports industry.
\end{abstract}




\title{
The Economic Determinants Of Sports Industry In Malaysia
}

\author{
${ }^{*}$ M H Amlus ${ }^{1}$, I M A Rashid², I H A Samah ${ }^{3}$, N \\ Muhammad $^{1}$, A F Salleh ${ }^{1}$ and A Z Abdullah ${ }^{1}$
}

\author{
1Sport Engineering Research Centre (SERC), Universiti Malaysia Perlis,02600 Arau, \\ Perlis, Malaysia \\ 2Universiti Teknologi MARA (UiTM) 78000 Alor Gajah, Melaka. Malaysia \\ 3Universiti Teknologi Malaysia, 81310 Skudai, Johor Bahru, \\ Johor, Malaysia. \\ *harith.amlus@unimap.edu.my
}

\begin{abstract}
Sports thought-about united of the foremost vital components in national development. Since independence in 1957, Malaysian government has place such a lot efforts and measures on sports development. Asian nation sporadically goes through periods of distress associated with sport performance. Asian nation spends plenty of cash and experience on its high performance athletes. Programs facilitate high athletes perform higher in coaching, endure injury, train the mental facet of performance, and aid athletes and coaches in alternative areas similarly. this can be cash that's well spent. Indeed, if the govt. goes to pay cash supporting sport this can be wherever these funds belong. The Malaysian tourism sector has widened its scope by venturing into extreme sports tourism. With this new development, tourism opportunities square measure created and boosting the Malaysian tourism business growth. the aim of this paper is to see the predictors of sports tourism involvement in Asian nation from the economics perspective. The recent shocks in provide and demand within the world aren't because of sudden economic reasons. Indeed, associated with Covid-19 that causes speedily spreading world health issues and life threats round the world coping with the social issues created by Covid-19 pandemic, they ought to not neglect the economic changes created by this pandemic. The government-ordered lockdowns have discontinuous life for billions and within the same time creates economic collapse situation. The foremost vital of those economic changes in developing countries with high fragility is exchange rates caused by sports and tourism industry, as a result of exchange rates will directly have an effect on several economics variables, from inflation to foreign trade, from the balance of payments to interests. Therefore, this analysis calculates the result of COVID-19 to sports and tourism business for affected countries within the worldwide. This study evaluated the impact using supply and demand curve to detect the economic changes in tourism industry. Lastly, tourism and sports sector became an intermingled strategy for several nations to get important value. Malaysia, for instance, in its National Key Economic space (NKEA) under the tourism sector indicates international sports events as a serious economic activity to push.
\end{abstract}




\title{
An Application of TAM Model Towards Influencing Online Purchase Intention during Covid-19 Pandemic for Fresh Agricultural Products: A Preliminary Findings
}

\section{${ }^{*}$ R A Karim ${ }^{1}$, A Rahayu ${ }^{2}$, N Mahmud ${ }^{1}, \mathrm{H}$ Monoarfa $^{2}, \mathrm{~A}$ Z Bahtar $^{1}$, Z A Nazari ${ }^{1}$ and F Adirestuty ${ }^{2}$}

\author{
${ }^{1}$ Universiti Teknologi MARA (UTTM) 78000 Alor Gajah, Melaka. Malaysia \\ ${ }^{2}$ Universitas Pendidikan IndonesiaJl. Dr. Setiabudhi No. 229 Bandung 40154 Jawa \\ Barat, Indonesia.
}

*rizuwan305@uitm.edu.my

\begin{abstract}
Online shopping was one of the essential services allowed to continue their operation by the federal government during the 2020 Malaysia Movement Control Order (Perintah Kawalan Pergerakan), commonly referred to as the MCO. In response to the MCO order, numbers of consumers who purchased their daily necessity through online increased tremendously. However, Malaysian consumer prefer to buy fresh agricultural product at physical stores and it will affect the initiative of the federal government to slow down the spread of Covid-19 in Malaysia. In the online purchasing intention for fresh agricultural products among Malaysia consumers' literature, Technology Acceptance Model (TAM) such as perceived usefulness, perceived ease of use attitude are under researched. Therefore, this study investigated TAM model as a framework to analyse factors influencing online purchase intention during the Covid-19 pandemic for fresh agricultural products. This study employs a quantitative research design and questionnaire was distributed by using electronic survey or e-survey via Google Form among Malaysian internet users in Peninsula Malaysia. Sample were consumers who had some experienced in purchasing fresh agricultural products through online during the Covid-19. Respondents were selected using convenience sampling. SmartPLS software version 3.0 were used to analyzed the data. The findings revealed perceived usefulness, perceived ease of use and attitude are three factors that influenced online purchased intention for fresh agricultural products during Covid-19 Pandemic. Therefore, the overall findings can help the online grocers to understand factors that forming consumer attitudes and soon developing intention to purchase fresh agricultural products via online.
\end{abstract}




\title{
The Challenges of Service-Learning in Malaysia University from Educators Perspective
}

\section{${ }^{*}$ A H Nurul Ashikin ${ }^{1}, \mathrm{H}$ Hanum ${ }^{1}$, M S Amir Farhan ${ }^{1}, \mathrm{M} \mathrm{N}$ Mohd Faiz², S S Sharifah Dara Naqiyah², A H Rosniza² and $\mathrm{H} \mathrm{Hasnah}^{2}$}

${ }^{1}$ Faculty of Applied Science and Humanity, Universiti Malaysia Perlis, Pusat Pengajian UniMAP-Kampus Jejawi, 02600 Arau, Perlis, Malaysia.

${ }^{2}$ Royal Institution Research and Community Division), Universiti Malaysia Perlis,

Tingkat 9, Bangunan KWSP, 01000 Kangar, Perlis, Malaysia

*nashikin@unimap.edu.my

\begin{abstract}
In Malaysia, the current educational blueprint has included initiatives toward enhancing service learning, as this pedagogical approach is seen as the means to achieve the national educational goals of producing graduates with the necessary skills for employability (Malaysian Education Blueprint, 2015-2025). The implementation of service-learning is at the stage where it needs to be incorporated in a more structured and systematic manner into the academic program (Ministry of Education Malaysia, 2015). The main objective of this paper is to analyse the educator's knowledge and understanding in implementing SULAM in public university and to identify the common challenges surrounding service learning among the educators in the public university. The research was designed to be an exploratory qualitative with the respondents consisting of the lecturers of the Malaysia University. Based on the analysis of the perspectives from educators, most of the educators agreed that SULAM is as a form of experiential education in which students engage in activities that address community needs together with structured opportunities intentionally designed to promote student learning and most of the educators voiced their anxiety over the SULAM implementation in reality. The five issues rated as the most critical challenges to the implementation of SULAM in preservice educators included financial constraints, poor time management, virtual implementation barrier, lack of administrative issue and relationship with the community.
\end{abstract}




\title{
Effectiveness of the Implementation of Geography Field Study Among Form Six Students
}

\section{${ }^{*} \mathrm{H}_{\text {Mahat }}{ }^{1}$, N A A Wan Pauzan ${ }^{1}$, M Hashim¹, Y Saleh ${ }^{1}, \mathrm{~N}$ Nayan ${ }^{1}$, S B Norkhaidi ${ }^{1}$ and Suhendro ${ }^{2}$}

${ }^{1}$ Department of Geography and Environment, Faculty of Human Science, Universiti Pendidikan Sultan Idris, Malaysia.

${ }^{2}$ Postgraduate Geography Education Candidate, Universitas Pendidikan Indonesia, Indonesia.

*hanifah.mahat@fsk.upsi.edu.my

\begin{abstract}
This study aims to look at the effectiveness of Geography fieldwork study among form six students in Machang, Kelantan. A quantitative approach was applied in this study by using a questionnaire as an instrument. A simple random sampling method was used for the selection of respondents and the total number of respondents was 80 form six students who were taking Geography in some selected schools in the Machang district in Kelantan. Four study variables were used, namely interest, understanding, skills and effectiveness, in the implementation of the Geography fieldwork study. Descriptive analysis was used to examine the level of each variable I, II, III and IV, and inferential analysis (Pearson's correlation and regression) was used to examine the relationships and influential contributions of each study variable. The findings showed that all of the variables, namely interest $(\mathrm{M}=2.89, \mathrm{SP}=0.32)$, understanding $(\mathrm{M}=2.87$, $\mathrm{SP}=0.32)$, manipulative skills $(\mathrm{M}=2.33$, $\mathrm{SP}=0.50)$, soft skills $(\mathrm{M}=2.75$, $\mathrm{SP}=0.44)$ and the effectiveness of the implementation $(\mathrm{M}=2.90, \mathrm{SP}=0.30)$ were at a moderate level. The results of the Pearson's correlation analysis also found that there was a significant positive relationship between the interest and understanding variables $(r=$ $0.538, p<0.005)$, understanding and manipulative skills $(r=0.556, p<0.005)$, manipulative skills and soft skills $(r=0.595, p<0.005)$ and soft skills with effectiveness $(r=0.677, p<0.005)$. In addition, regression analysis showed that soft skills had the highest impact on the effectiveness of the Geography field study by $45.8 \%$ with $R^{2}=$ $0.581, \mathrm{~F}(26.030)=0.324, \mathrm{P}<0.05$. In conclusion, this study finds that students show an interest, understanding, and skills in the effectiveness of the Geography field study. This shows that the implementation of Geography field study in schools can bring about change among students, and indicates that an effective Geography field study can enhance students' interest, understanding and skills in the subject of Geography and is able to give students the opportunity to be more innovative and to think creatively.
\end{abstract}




\title{
Self-Efficacy of Catering Students of Faculty Technical And Vocational Education, University Tun Hussein Onn Malaysia In The Field of Career That Will Be Pursued
}

\author{
${ }^{*}$ N S Ahmad Idris ${ }^{1}, \mathrm{~N} \mathrm{H} \mathrm{L} \mathrm{Abdullah}{ }^{1}$, M Mohamed $^{1}$ and A \\ N Paimin ${ }^{1}$
}

${ }^{1}$ Faculty of Technical and Vocational Education, Universiti Tun Hussein Onn Malaysia, 86400 Parit Raja, Johor, Malaysia

*hidayahl@uthm.edu.my

\begin{abstract}
The increasing rate of unemployed graduates in Malaysia has received alarming attention in recents years. One of the factors that contribute to the unemployment problem is the lack of self-efficacy among graduates in making career choices. Therefore, this study was conducted to identify the self-efficacy of catering students to make decision on career field options to be pursued either as a teacher, hospitality employee or entrepreneur. The design of this study is a quantitative descriptive study through survey and questionnaire is used as research instruments. A total of 66 catering students of year 3 and 4 from Faculty of Technical and Vocational Education (FPTV) were selected as the study sample. The data obtained were analyzed using Statistical Package for Social Science (SPSS) version 22.00 software involving mean, standard deviation, and ANOVA. The results showed that the mean scores of self-efficacy of catering students were high to become teachers $(M=4.11, S D=0.617)$ and followed by hospitality employee $(M=3.87$, $\mathrm{SD}=0.574)$ and entrepreneurs $(\mathrm{M}=3.93, \mathrm{SD}=0.514)$. However, there was no significant difference between the three career fields with a value of $p=0.052$. In conclusion, catering students have high self-efficacy in venturing into the field of career when graduating from university. Graduates need to see the importance of enhancing self-efficacy because it opens paths for career opportunities and advancement.
\end{abstract}




\title{
A Survey on Preferred Learning Styles among Undergraduates during the ODL Mode
}

\author{
*S M M Zain ${ }^{1}$, A A Sharip ${ }^{1}$, R M Saidi ${ }^{1}$, N N A Rahid ${ }^{1}$ and \\ N A M Rashid ${ }^{1}$
}

${ }^{1}$ Faculty of Computer and Mathematical Sciences, Universiti Teknologi MARA Cawangan Melaka Kampus Jasin, 77300 Merlimau, Melaka. Malaysia.

*maisarah1582@uitm.edu.my

\begin{abstract}
An investigation of learning styles is important in ensuring effective learning to take place. In relation to this, effective instructional learning methods can be identified by exploring students' preferred learning styles. The objective of this study is to investigate the preferred learning styles among undergraduates in Malaysia during the Open and Distance Learning (ODL) mode. This study investigates the differences in learning styles among undergraduates from various faculties. A number of 452 undergraduates participated in this study. Whereby the data were collected using the Barbe VAK model. The data were analysed using the mean scores based on three VAK learning categories; visual learning, auditory learning, and kinaesthetic learning. The analysis results showed that the most preferred learning style among the Science and Technology undergraduates was the visual learning style. The results of this study will benefits educators, especially for content preparation that fits best with the preferred learning styles.
\end{abstract}




\title{
Hikayat Merong Mahawangsa (2011) From A Film History Perspective
}

\author{
${ }^{*}$ F Hamadun ${ }^{1}, \mathrm{~N}$ Abdillah ${ }^{1}$ and N Yusoff ${ }^{2}$ \\ ${ }^{1}$ Faculty of Creative Technology and Heritage, Universiti Malaysia Kelantan, Bachok \\ Campus, 16300, Bachok, Kelantan, Malaysia. \\ ${ }^{2}$ Faculty of Film, Theatre \& Animation, Universiti Teknologi MARA, Puncak Perdana \\ Campus, 40150, Shah Alam Selangor, Malaysia. \\ *fairul.h@umk.edu.my
}

\begin{abstract}
Hikayat Merong Mahawangsa (2011) is an adapted film, based on one of the well-known traditional Malay texts that seeks to elevate traditional Malay literature. The film is said to be quite special in Malaysian film history because it achieved a decent success internationally. It is produced by the local talent, Yusry Abd Halim. The film may have been popular among Malaysians, but there is still a lack of research on it, especially from the perspective of history. This paper thus seeks to address the historical aspects of the film using David Bordwell's theory, in particular, the 'historical poetics of cinema' (1989). By applying this particular theory, this study will examine the historical aspects of Hikayat Merong Mahawangsa, from the original traditional text to the modern filmic product of the hikayat. Specifically, the thematical, narrative and stylistical elements will form bases of arguments in this research, following the framework of Bordwell's historical poetics of cinema. It is found that the film, Hikayat Merong Mahawangsa (2011) has strong western influences or affiliations, perhaps due to demands on meeting up to international standards. This has resulted in massive changes of the original traditional text so as to 'suit' the demands of the international market.
\end{abstract}




\title{
Aesthetic Study on Historic Building of Toko Merah Using Phenomenology and Artefact Theory Approach
}

\author{
${ }^{*} \mathrm{R}$ C Permatasari ${ }^{1}$ and S Sukri ${ }^{2}$
}
${ }^{1}$ Department of Interior Design, Faculty of Design and Creative Art, Universitas MercuBuana, South Meruya No.1, Kembangan, West Jakarta, Indonesia ${ }^{2}$ Faculty of Creative Technology and heritage, University Malaysia, Kelantan, Malaysia.

*chandrarezky@mercubuana.ac.id

\begin{abstract}
Toko Merah is one of the cultural heritage buildings in the old city of Jakarta that has a change of form and function based on the history of different holdings which appeared maintained and preserved. Currently, the building is not fully utilised; only some of the building is rented as a meeting house. The Toko Merah building has different functions based on its history of ownership. The existence of this building which sets in the early history of the establishment of the twin luxury house makes it the icon of the cultural heritage building. It is now called Toko Merah. The method used in this research is qualitative descriptive based on the history of the Toko Merah with a phenomenological approach specifically chosen to observe the aesthetic form of space in search of the essential meaning of the Toko Merah building.The results show the phenomenon of the Toko Merah building as a cultural heritage building has an essential aesthetic meaning as a cultural heritage building which needs to be studied and explored more in the narrative of adaptive reuse and should be maintained and preserved so that it can be utilised wherebymeaningful interpretation and usage can be materialised. It will eventually be celebrated as a heritage building which preserves that memory of the past.
\end{abstract}




\title{
A Comparison of Technologies for Smart Queueing System to Cater Social Distancing Issue
}

\section{*A A Sharip", N N A Rahid"1, S M M Zain¹, S A Halim¹, A G Buja ${ }^{1}$ and $\mathrm{F} \mathrm{H} \mathrm{Halim}{ }^{1}$}

${ }^{1}$ Faculty of Computer and Mathematical Sciences, Universiti Teknologi MARA Cawangan Melaka Kampus Jasin, 77300 Merlimau, Melaka

*anis588@uitm.edu.my

\begin{abstract}
Due to Coronavirus disease, many new norms are being introduced and one of them is a social distancing. This article focuses on the comparison of technologies that can be adopted in developing a smart queueing system that cater the social distancing issue. Several technologies are discussed in this paper are including ultra-wide band, RFID, NFC, Geo-fence, Wi-Fi and Bluetooth. The discussion is based on the technology specification and how those technologies can assist in enforcing social distancing in queueing process or activity.
\end{abstract}




\title{
From Classes into Practices: The Impacts of Implementing SULAM in Public University on The Students
}

\author{
*H Hanum¹, M S Amir Farhan¹, A H Nurul Ashikin¹, M N \\ Mohd Faiz², S S Sharifah Dara Naqiyah², A H Rosniza², \\ and $\mathrm{H}$ Hasnah²
}

\author{
${ }^{1}$ Faculty of Applied Science and Humanity, Universiti Malaysia Perlis, \\ 02600 Arau, Perlis, Malaysia. \\ ${ }^{2}$ Royal Institution Research and Community Division, Universiti Malaysia Perlis, \\ Tingkat 9 Bangunan KWSP, 01000 Kangar, Perlis, Malaysia.
}

*hanum@unimap.edu.my

\begin{abstract}
Service-learning has been implemented in teaching and learning pedagogical approaches as the modern way to integrate theoretical obtained in the classroom into practices in real-world situations. Hence, the Ministry of Higher Education has introduced Service Learning Malaysia University for Society (SULAM) in 2019 was to demonstrate a multidimensional concept that embraces curriculum and co-curriculum of pedagogical approaches to service and educational opportunities through Malaysia Education Blue Print 2015-2025 (for Higher Education) to produce holistic graduates who are entrepreneurial and balanced. Therefore, this study focuses on the impacts of implementing SULAM programme in public university toward the students in term of i) knowledge and understanding, ii) functional work skills, and iii) ethics and professionalism after they conducted and carried out the service-learning project with the community. This study was designed based on a quantitative approach administrated to the 352 respondents from different faculties at Universiti Malaysia Perlis (UniMAP). Data were collected through questionnaires and analysed using SPSS to identify the impacts of implementing SULAM programme towards the student. The findings of this study uncovered that there were positive impacts of implementing SULAM programme integrate with student's academic curriculum such as the students were able to utilize the knowledge and have deeper understanding conducting servicelearning projects under SULAM programme with the community, the students managed to improve and empowered their functional work skills after successfully carried out the projects involved the community, and lastly the students proudly can facilitate themselves to perform outstanding ethics and professionalism while they conducting service-learning projects under SULAM programme in the public university. The implementation of SULAM programme was made successful in UniMAP through the involvement of the service-learning ecosystem consisted the students, lecturers, faculties, communities, agencies and industries.
\end{abstract}




\section{Influence of Rehal Design on User Comfort}

\section{${ }^{*} \mathrm{~N}$ Ahmad ${ }^{1}$, E F M Ghoni ${ }^{1}$, D Mohamad ${ }^{1}, \mathrm{M} \mathrm{H}$ Harun $^{1}, \mathrm{M}$ Y M Naser ${ }^{1}$, J Jaafar ${ }^{1}$, M E Z Abdullah ${ }^{1}$, S N D Sukri ${ }^{1}$ and A M Yusoff ${ }^{1}$}

${ }^{1}$ Faculty of Creative Technology and Heritage, Universiti Malaysia Kelantan 16300

Bachok, Kelantan, Malaysia.

*nooraziah@umk.edu.my

Abstract. This study is to examine the use of Rehal in Maahad Tahfiz Daril Ulum (MAFIZ). It focuses on the user's reflection about the rehal. The questionnaires are used as the instrument from 26 respondents comprising students studying in MAFIZ. Data analysis is performed by frequency and percentage. The results of the study found that the design of the book rest was uncomfortable and required improvements. 


\title{
Men's Denim Jeans Of Doodle Arts: Innovations and Advances Thru Fashion Design
}

\author{
*Azwady Mustapha ${ }^{1}$ and Nur Izzaty Mohd Roslan ${ }^{1}$
}

${ }^{1}$ Faculty of Creative Technology and Heritage, University Malaysia Kelantan, UMK 16300, 16300 Bachok, Kelantan. Malaysia.

*azwady.m@umk.edu.my

\begin{abstract}
Expression of feelings through doodles paintings can picturizes the character of an individual over a technology. The designated doodles carry variety meanings to be delivered to the audiences. Doodles reference came from Zuusaha@ and it empowers humans to nurture the mother earth. Denim being nostalgic, constant and something doesn't change from one season to the next are one of the reasons they love denim. There are a lot of innovations in jeans denim all over the world. In this study, expression of feelings through Doodles paintings can picturize the character of an individual. The objectives were to understand what the cutting styles look good, able to differentiate suitable styles and develop men's personality towards jeans styles. The quantitative data will be analyzed. This study will able to understand the personality of self-identity reflection towards men in Kuala Lumpur using Statistical Package for the Social Science (SPSS). The study emphasized on different types of styles, either men's personality was reflected by denim jeans.
\end{abstract}




\title{
Literature Review on Technology Acceptance Model: The Enhanced Variables of Venkatesh's UTAUT Model on Students' Acceptance of Use on Online Distance Learning
}

${ }^{*} \mathrm{~N}$ R W Mohamed ${ }^{1}$, D Sharif ${ }^{2}$ and M N Muhayiddin ${ }^{3}$

${ }^{1}$ Faculty of Hotel and Touriasm Management, Universiti Teknologi Mara, Kampus Bandaraya Melaka, 75300 Melaka Malaysia

${ }^{2}$ Academy Contemporary Islamic Studies, Universiti Teknologi Mara, Kampus

Bandaraya Melaka, 75300 Melaka Malaysia.

${ }^{3}$ Faculty of Entrepreneurship and Business University of Malaysia, Kelantan Malaysia, UMK 16300, 16300 Bachok, Kelantan. Malaysia.

*rozilaini@uitm.edu.my

\begin{abstract}
This paper detailed the unified theory of acceptance and use of technology (UTAUT) that has been used widespread in IT system and other areas, and the initiative of this paper is to introduce the UTAUT theory evidences and relation in online distance learning at universities. This paper reviewed the literature on UTAUT from multiple perspectives on theoretical analysis of UTAUT and its expansion and continuing for research going forward. Based on Venkatesh (2003), framework of theory evaluation, this paper continuing UTAUT and its extensions developed from few sets of constructs as the parts of a theory and as the whole theory. This review identifies many distinctions of UTAUT, progress related to this theory that has further development, and it relation to online distance learning at IPTA in Malaysia. This paper will allow a significant future work, the theoretical contributions of UTAUT using expanding and cross-context concept. Our conclusion reveals several limitations that lead other researchers to continue a UTAUT study framework that can serve as the theoretical foundation for future research.
\end{abstract}




\title{
FILM COATING FROM SWEET POTATO STARCH (Ipomea batatas L) WITH LACTIC ACID BACTERIA (Lactobacillus acidophilus)
}

\section{*Miksusanti ${ }^{1}$, Indah Solihah², Dina Permata Wijaya², Ferlinahayati ${ }^{1}$, and Maria Ulfa ${ }^{1}$}

\begin{abstract}
${ }^{1}$ Department of Chemistry, Faculty of Mathematics and Natural Sciences, Universitas Sriwijaya, JI. Palembang-Prabumulih, Km. 32, Ogan Ilir, South Sumatra, Indonesia ${ }^{2}$ Department of Pharmacy, Faculty of Mathematics and Natural Sciences, Universitas Sriwijaya, JI. Palembang-Prabumulih, Km. 32, Ogan Ilir, South Sumatra, Indonesia
\end{abstract}

*miksusanti@unsri.ac.id

\begin{abstract}
This study aims to analyze the effect of variations concentration of (Lactobacillus acidophilus) in edible coatings and their antibacterial activity against E. coli using the well diffution method. This study used an edible coating of Prebiotic from purple sweet potato starch and (Lactobacillus acidophilus) with dilution variations (10-6 , 10-7, 10-8, 10-9) as probiotics. In this study physical properties were tested for edible coatings such as color tests with visual observations, water content by the gravimetric method and viscosity using Viscometer Ostwald. The content of organic acids in edible coating solutions was measured using the HPLC method. Organoleptic test was conducted with taste and color parameters on the A-E scale of 30 respondents. Research results showed edible coating discoloration before and after incorporation from deep purple to brown. The value of water content and viscosity also changed from $62,8 \%$ to $71,4 \%$ and $569,97 \mathrm{cp}$ to $486,64 \mathrm{cp}$ respectively. The best antibacterial activity of edible coating incorporation with (Lactobacillus acidophilus) was $263,76 \mathrm{~mm} 2$. Organoleptic test on grapes that have been coated with edible coating showed that covered with edible coating contains probiotics (Lactobacillus acidophilus) has no effect on respondents' perception. Lactic acid and acetic acid were exist in edible coating wich were incorporated with (Lactobacillus acidophilus).
\end{abstract}

Keywords: Film edible coating, Probiotic, Lactobacillus acidophilus, E. coli, organic acids, sweet potato starch 


\title{
Designing 2D Motion Graphic as Learning Multimedia in Vocational High Schools in the Computer Network Engineering Department
}

\author{
${ }^{*}$ Agung Adi Firdaus ${ }^{1}$, Rizqia Salsabila ${ }^{1}$, Gilang \\ Ramadhan ${ }^{1}$, Mohammad Nashrullah ${ }^{1}$ \\ ${ }^{1}$ Universitas Negeri Semarang \\ *agungfirdaus119@gmail.com
}

\begin{abstract}
Choosing the right learning media can help students understand the material and make learning more efficient and effective. The media that exist today are very diverse because they are supported by advances in information technology. One form of information technology that helps to learn is animation. The animation is a medium that is considered to be able to help students understand and absorb messages from learning. The computer network is a very broad science that includes network topology. There are still many schools providing network topology material using monotonous learning methods so it is difficult to understand, even though network topologies have many types and characteristics that require delineation and imagination. The data collection method used is the method of interviews conducted with the staff of the development section of the Information and Communication Technology Development Center of the Education and Culture Office, field observation methods, and literature study methods. The test consisted of a trial playing animation (single-user test), a validation test by a media expert, and a validation test by a material expert. Single user testing in the form of animation playback using VLC Media Player on the ASUS X454Y laptop media shows that the development of motion graphics is successful. The results of the media expert's validation test got a score of $83.6 \%$, indicating that the media made is very valid and can be used without requiring revision, but the audio aspect of the narrator is considered to be less than optimal. While the material expert test obtained a score of $94.2 \%$, it shows that the material made is very valid and can be used without revision.
\end{abstract}

Keywords: Motion Graphic, Learning Multimedia, School 


\title{
Fouling of Heat Transfer Surface in Industry: A review
}

\author{
${ }^{*}$ Intan Suhada Azmi ${ }^{1}$ and Muhamad Nazri Murat ${ }^{1}$ \\ ${ }^{1}$ School of Chemical Engineering, Universiti Sains Malaysia, Nibong Tebal, Pulau \\ Pinang, Malaysia \\ *intan89@ymail.com
}

\begin{abstract}
A large amount of polymer can be accumulated on heat transfer surfaces during the synthesis and processing of polymers. This deposit is undesirable and is generally referred to as fouling. It has been identified as a big unsolved problem in heat transfer. Current literature on fouling has been reviewed. Based on this, numerous experiments and methods have centred on the reduction, removal and prevention of fouling, where a variety of attempts have been made to explain and mitigate fouling. Fouling can be caused by several reactions, including polymerisation, auto-oxidation or thermal decomposition. The wide variety of process streams and operating conditions present in the industry continues to make the most distressing circumstances unique, making a general overview of the issue difficult. A greater knowledge of the issue and the processes that contribute to the deposition of deposits on the surface would create opportunities for the industry to minimise or even eliminates the problem. By obtaining historical industrial data, further understanding of fouling can be studied with possibility of proposing prediction model through empirical studies to minimize and ultimately eliminate fouling
\end{abstract}




\title{
ANALYSIS OF STRESS DISTRIBUTION ON THE RECTANGULAR AND STAR BLADE FOR PLASTIC CRUSHER MACHING USING FINITE ELEMENT ANALYSIS
}

\section{Nalendro Mataram ${ }^{1}$, Noer Aden Bahry ${ }^{1}$, Nuruddin Wahyu Eko Saputro ${ }^{1}$, Sabaruddin Syach ${ }^{1}$, and *Sigiet Haryo Pranoto $^{1}$}

${ }^{1}$ Mechanical Engineering Departement, Faculty of Science and Technology, Universitas Muhammadiyah Kalimantan Timur, Indonesia

*shp904@umkt.ac.id

\begin{abstract}
Plastic waste is one of the biggest environmental problems in big cities and even the world. Plastic waste is a type of waste that is difficult to decompose by soil. Recycling is one solution to reduce plastic waste in the world. A plastic crusher machine is one solution, this machine can convert plastic packaging into plastic pellets, especially those made from polyester which is often used in bottle packaging. The crusher blade is an important component of the crusher machine. Before making process machinery, necessarily need their design process design and analysis of the machine. The finite element analysis method is widely used to assist in the analysis process. The results of this analysis can help and be considered before machine manufacturing. There are 2 different blades to consider, rectangular and star-shaped. The analysis results obtained on the blade of the chopping machine for the rectangular shape of the von mises stress at the $200 \mathrm{~N}, 400 \mathrm{~N}$, and $600 \mathrm{~N}$ loaders are $1.285 \times 103 \mathrm{~N} / \mathrm{m} 2,2.570 \times 103 \mathrm{~N} / \mathrm{m} 2$, and $3.855 \times 103 \mathrm{~N} / \mathrm{m} 2$. The displacement obtained is $1.080 \times 10-6 \mathrm{~mm}, 2.160 \times 10-6 \mathrm{~mm}$, and 3.241 x 10-6 mm. The maximum von mises stress yield on consecutive star-shaped blades is $8.890 \times 102 \mathrm{~N} / \mathrm{m} 2,1.778 \times 103 \mathrm{~N} / \mathrm{m} 2$, and $2.667 \times 103 \mathrm{~N} / \mathrm{m} 2$. The displacement obtained is $1.211 \times 10-6 \mathrm{~mm}, 2.422 \times 10-6 \mathrm{~mm}$, and $3.633 \times 10-6 \mathrm{~mm}$. The results of the analysis show that the shape of the star blade is better because at the same time the stress and displacement experienced by the star-shaped blade are smaller than the rectangular shape. The safety factor generated from this simulation is 15 , where the number is more than 1 which means it is safe.
\end{abstract}

Keywords: Von mises stress, Displacement, Blade shape, Finite element analysis, Safety factor 


\title{
DESIGN AND BUILD A CHOPPING MACHINE FOR PROCESSING PLASTIC WASTE MATERIALS
}

\section{Dede Zulrahman ${ }^{1}$, Muhammad Khairul ${ }^{1}$, Syam Ramadhani Saputra ${ }^{1}$, Muhammad Rizki Ananda ${ }^{1}$, and *Sigiet Haryo Pranoto ${ }^{1}$}

${ }^{1}$ Mechanical Engineering Departement, Faculty of Science and Technology, Universitas Muhammadiyah Kalimantan Timur, Indonesia

*shp904@umkt.ac.id

\begin{abstract}
Plastic packaging is the main material that is widely used in the food and beverage industry, all plastic products cannot be recycled in a short time. Waste processing must apply the $3 R$ process, namely by limiting waste generation (reduce), reusing waste (recycle) and recycling waste (recycle) using recycling tools. It is recorded that the use of plastic among Indonesians in 2019 is 67 million tonnes per year. Indonesia is in the 2nd rank for domestic waste producer. In designing this crusher type plastic chopping machine, the design is carried out in the form of a design drawing, calculation and material selection of the chopping machine components, including: power, blades, shafts, bearings, pegs, v-belt transmission and pully. This plastic crusher machine with a capacity of $30 \mathrm{~kg} /$ hour has dimensions of $80 \mathrm{~cm} \times 60 \mathrm{~cm} \times$ $140 \mathrm{~cm}$ with a simple construction, easy to operate. The shaft used is $35 \mathrm{~mm}$ in diameter, the $v$-belt uses type A with a length of $2050 \mathrm{~mm}$, the drive unit uses an electric motor with an installed power of $2 \mathrm{HP}$ with a rotation of 1400 rpm coupled with an automatic emergency system. The results of testing the performance of the plastic chopper machine with a filter hole diameter of 8 $\mathrm{mm}$, obtained the percentage of the chopping length of the plastic and the bottles that were smaller or equal to $3-5 \mathrm{~mm}$. From the results obtained from these measurements the machine is functioning properly in accordance with the design and performance of the plastic chopping machine.
\end{abstract}




\title{
Development of Lightweight waste-based geopolymer aggregates - A Review
}

\section{Dickson Ling Chuan Hao ${ }^{1 *}$, Rafiza Abd Razak ${ }^{1,2}$, Zarina Yahya $^{1,2}$, Mohd Mustafa Al Bakri Abdullah², Alida Abdullah²}

${ }^{1}$ Faculty of Civil Engineering Technology, Universiti Malaysia Perlis (UniMAP), Perlis, Malaysia.

${ }^{2}$ Geopolymer \& Green Technology, Centre of Excellence (CEGeoGTech), Universiti Malaysia Perlis (UniMAP), Perlis, Malaysia.

*dlch6179@gmail.com

\begin{abstract}
The uses of lightweight aggregate can bring advantages to the construction field. Lightweight aggregate had been used due to its lower density and can reduce the dead load applied to the structural elements. Due to the amount of natural resources such as natural aggregate had decreased, producing lightweight aggregate from industrial waste materials can overcome the problem. There is different type of method used to produce lightweight aggregate such as sintering, cold bonding and autoclaving. The properties of lightweight aggregate such as specific gravity, water absorption, crushing strength and impact value are reviewed. Besides that, the review regarding the mechanical and thermal properties are also important for the usage of lightweight aggregate in concrete. The review also indicates that aggregate produced by using cold bonding method and autoclaving method potential can be used in the concrete.
\end{abstract}




\title{
The Optimum Mix of Indonesian Very High- Performance Concrete (VHPC)
}

\author{
M. Shahib Al Bari ${ }^{1}$, Andini Dwi Agustin ${ }^{1}$, and Januarti \\ Jaya Ekaputri ${ }^{1,2^{*}}$,
}

${ }^{1}$ Department of Civil Engineering, Faculty of Civil, Planning and Geo Engineering, Institut Teknologi Sepuluh Nopember, Surabaya, 60111, Indonesia

${ }^{2}$ Geopolymer \& Green Technology, Centre of Excellence (CEGeoGTech), Universiti Malaysia Perlis (UniMAP), Perlis, Malaysia.

* januarti@ce.its.ac.id

\begin{abstract}
In general, a Very High-Performance Concrete (VHPC) has compressive strength of 120-150 MPa, high workability, low permeability, and less shrinkage. However, unavailability of VHPC mix in Indonesia makes it difficult to achieve that strength. This paper studied the mix design of VHPC using Indonesian local materials to achieve strength up to $120 \mathrm{MPa}$. Sequence Experimental method was selected according to the variable order: fine aggregate, superplasticizer, and admixture. The fine aggregate consists of river sand, silica sand and glass powder. A High Range Water Reducer type is used as an additive to ensure the workability. The admixture used were of silica fume and fly ash. The suitable materials were quantitatively determined by compression strength test on $3^{\text {rd }}$ and $7^{\text {th }}$ day. The optimum mix design was tested by compression strength and tensile strength. In addition, the effect of hook-end steel fiber in the VHPC was observed. In this study, it is found that the VHPC with cement, silica fume, silica sand, glass powder, superplasticizer, accelerator, and water to binder ratio $(\mathrm{w} / \mathrm{c})$ of $28 \%, 9 \%, 41 \%$, $8 \%, 1 \%, 1 \%$, and 0.14 respectively achieved a $28 \mathrm{~d}$ compressive strength of $128 \mathrm{MPa}$. The application of silica sand and glass powder with the maximum size of $0.53 \mathrm{~mm}$ and $75 \mu \mathrm{m}$ respectively, increased the compactness of VHPC. The silica fume as a binder has particle size $<100 \mu \mathrm{m}$ filled the concrete pores and increase the cohesion. The hook-end steel fiber is not recommended because of its large size which decreased the compressive strength. However, it increased the tensile strength.
\end{abstract}




\title{
Mechanical Effect on Different Geopolymer Filler in Glass Reinforced Epoxy Composite
}

\section{Mohammad Firdaus Abu Hashim ${ }^{1,2, \star}$, Che Mohd Ruzaidi Ghazali $^{1,3}$, Yusrina Mat Daud ${ }^{1,2}$, Meor Ahmad Faris Meor Ahmad Tajudin ${ }^{1,2}$, Mohd Mustafa Al Bakri Abdullahn, Farah Farhana Zainal ${ }^{1,2}$, Saloma Hasyim ${ }^{4}$, Hasri $^{5}$, Hartati $^{5}$, i, Intan Syafikah Sulaiman ${ }^{2}$}

${ }^{1}$ Center of Excellence Geopolymer \& Green Technology (CEGeoGTech), School of Materials Engineering, Universiti Malaysia Perlis, (UniMAP), 02600 Jalan Kangar-

Arau, Perlis, Malaysia

${ }^{2}$ Faculty of Chemical Engineering Technology, Universiti Malaysia Perlis, (UniMAP), Perlis, Malaysia

${ }^{3}$ Faculty of Ocean Engineering Technology and Informatic, Universiti Malaysia Terengganu (UMT), 21030 Kuala Nerus, Terengganu Darul Iman

${ }^{4}$ Civil Engineering Department, Faculty of Engineering, Sriwijaya University

${ }^{5}$ Fakultas Matematika \& IImu Pengetahuan Alam, Universitas Negeri Makassar, Kampus FMIPA UNM, Parangtambung, JL. Mallengkari, Makassar, 90224, Indonesia

* afirdaushashim@unimap.edu.my

\begin{abstract}
Glass reinforced epoxy are widely known in oil and gas industry as glass reinforced epoxy pipe. However, glass reinforced epoxy has limitation such as demanding careful handling due fabrication, installation and transportation because of brittle nature itself and low compressive strength. The aim of this research is to characterize and study the effect of different geopolymer filler in the glass reinforced epoxy pipe composites. Filament winding method will be used in producing glass reinforced epoxy composite. Samples will be prepared with different weight percentage of geopolymer filler loading and different types of geopolymer filler which is fly ashbased geopolymer and kaolin-based geopolymer with $10 \mathrm{wt} \%$ - 40wt\% of geopolymer filler loading. Microstructure showed spherical shaped of fly ash raw material and platelike structure for kaolin raw material. After undergoes the mechanical testing involved compressive test, pipe sample of glass reinforced epoxy filled with $20 \mathrm{wt} \%$ of fly ashbased geopolymer filler showed the best performances above them all. The compressive strength value was $43.05 \mathrm{MPa}$. Glass reinforced epoxy composite pipe filled with different geopolymer are not widely used in this research area. Therefore, by using geopolymer as a filler can improve the properties of glass reinforced epoxy composite pipe. Hence, a waste material like geopolymer can reduce the cost of material and improve the environment.
\end{abstract}




\title{
Review on Mechanical Properties of Metakaolin Geopolymer Concrete by Inclusion of Steel Fibers
}

\author{
Meor Ahmad Faris ${ }^{1,2, a^{*}}$, Mohd Mustafa Al Bakri \\ Abdullah, ${ }^{1,3}$, Shamala Ramasamy ${ }^{1,2}$, Mohammad Firdaus \\ Abu Hashim ${ }^{1,2}$, Abdullah Abdul Samad ${ }^{2}$, Mohd Al-Hafiz \\ Mohd Nawi \\ ${ }^{1}$ Center of Excellent Geopolymer and Green Technology, School of Materials \\ Engineering, University Malaysia Perlis, Perlis, Malaysia. \\ ${ }^{2}$ Faculty of Mechanical Engineering Technology, University Malaysia Perlis (UniMAP), \\ Perlis, Malaysia \\ ${ }^{3}$ Faculty of Chemical Engineering Technology, University Malaysia Perlis (UniMAP), \\ Perlis, Malaysia \\ * meorfaris@unimap.edu.my
}

\begin{abstract}
This study summarized the recent achievement in developing fiber reinforced geopolymer concrete. The factor of replacing Ordinary Portland Cement (OPC) which is due to the emission of carbon dioxide where pollutes the environment globally is well discussed. The introduction towards metakaolin is presented. Besides, the current research trend involved in geopolymer also has been reviewed for the current 17 years to study the interest of researchers over the world by year. Factors that contribute to the frequency of geopolymer research are carried out which are cost, design, and the practicality of the application for geopolymer concrete. Besides, the importance of steel fibers addition to the geopolymer concrete is well discussed. The fundamental towards metakaolin has been introduced including produce by calcined kaolin, calcined temperature, chemical composition, geopolymerization process, and other properties. Alkali activators which are mixing solution between sodium hydroxide $(\mathrm{NaOH})$ and sodium silicate $\left(\mathrm{Na}_{2} \mathrm{SiO}_{3}\right)$ have been reviewed. The mechanical properties of fibers reinforced metakaolin-based geopolymer concrete which is compressive and flexural are thoroughly reviewed. The compressive and flexural strength of fiber-reinforced metakaolin geopolymer concrete shows some improvement to the addition of steel fibers.
\end{abstract}




\title{
Response Surface Methodology Approach for Optimization of Acid Orange II Degradation using $\mathrm{Fe}_{3-\mathrm{x}} \mathrm{Mn}_{\mathrm{x}} \mathrm{O}_{4}-\mathrm{MKSF}$ Catalyst
}

\section{Amirah Annasuha Azmi ${ }^{1}$, Rasyidah Alrozi ${ }^{1,2^{*}}$, Nor Aida Zubir ${ }^{1,2}$, Nadhratul Nur Ain Abdul Rahman ${ }^{1}$ and Mohamad Anuar Kamaruddin ${ }^{3}$}

${ }^{1}$ Faculty of Chemical Engineering, Universiti Teknologi MARA, Cawangan Pulau

Pinang, 13500, Pulau Pinang, Malaysia

${ }^{2}$ Hybrid Nanomaterials, Interfaces \& Simulation (HYMFAST), Faculty of Chemical

Engineering, Universiti Teknologi MARA, Cawangan Pulau Pinang, 13500, Pulau

Pinang, Malaysia

${ }^{3}$ Environmental Technology Division, School of Industrial Technology, Universiti Sains

Malaysia, Pulau Pinang, Malaysia

* arasyidah.alrozi@uitm.edu.my

\begin{abstract}
This study presents a response surface methodology (RSM) approach for optimization of acid orange II (AOII) degradation using montmorillonite-KSF clay supported $\mathrm{Fe}_{3-\mathrm{x}} \mathrm{Mn}_{\mathrm{x}} \mathrm{O}_{4}\left(\mathrm{Fe}_{3-\mathrm{x}} \mathrm{Mn}_{\mathrm{x}} \mathrm{O}_{4}-\mathrm{MKSF}\right)$ catalyst. Central composite design (CCD) in RSM was applied in order to determine the influence on percentage of AOll removal of four operational variables $(\mathrm{pH}$ solution, catalyst dosage, concentration of $\mathrm{H}_{2} \mathrm{O}_{2}$ and initial concentration of AOII). The higher percentage of AOII removal achieved was $88.88 \%$ for the following operating conditions: $2.5 \mathrm{pH}$ solution, $0.4 \mathrm{~g} / \mathrm{L}$ catalyst dosage, $15 \mathrm{mM}$ $\mathrm{H}_{2} \mathrm{O}_{2}$ concentration and $45 \mathrm{mg} / \mathrm{L}$ AOII initial concentration. Analysis of variance (ANOVA) has identified the significant factor on the experimental design response. Interestingly, correlation coefficient $\left(R^{2}\right)$ of 0.967 indicates a good estimation between the predicted and actual/experimental values. Such findings revealed the detailed correlation of the four operational variables towards AOll removal in the heterogeneous Fenton-like reaction using $\mathrm{Fe}_{3}$ ${ }_{x} \mathrm{Mn}_{\times} \mathrm{O}_{4}-\mathrm{MKSF}$ catalyst.
\end{abstract}




\title{
Flexural Test on Pratt Type Truss Structure Using Single CFS Material
}

\section{Nindyawati ${ }^{*}$, Karyadi ${ }^{1}$, and Roro Sulaksitaningrum ${ }^{1}$}

\author{
${ }^{1}$ Jurusan Teknik Sipil Universitas Negeri Malang, Indonesia. \\ * nindyawati.ft@um.ac.id
}

\begin{abstract}
Cold Formed Steel (CFS) was used because the structure's dead weight was $35-50 \%$ lighter than wood. Lightweight steel sped up the assembling process and reduced the total project cost. Cost and duration are essential in a project; thus, CFS became a popular material choice. CFS bar was assembled into a truss to improve the ability to withstand the flexure. The CFS truss increased the area moment of inertia. The Pratt truss had the effective ability to hold the tensile strength. Besides, stated that the Pratt truss was the strongest model and had more ability to hold the load than the Howe and Warren models.
\end{abstract}




\title{
The Study on Warren Truss used a Single Cold Formed Steel for the Beam
}

\section{Nindyawati ${ }^{*}$, Karyadi ${ }^{1}$, and Roro Sulaksitaningrum ${ }^{1}$}

\author{
${ }^{1}$ Jurusan Teknik Sipil Universitas Negeri Malang, Indonesia. \\ * nindyawati.ft@um.ac.id
}

\begin{abstract}
Generally, building materials have limited availability. The use of building materials must be optimized as well as possible. Construction can work optimally has many indicators. One of the important things is to minimize the use of construction materials while maintaining structural stability. Popular truss structures used include Warren, Pratt, and Howe. Warren truss type structures are considered to be economical truss structures. The Warren truss also exhibits a high-value weight-to-stiffness ratio, indicating good stability. In this study, a beam truss was used using Cold-Formed Steel (CFS) material.
\end{abstract}




\title{
Performance of Energy Encryption for Medium Field Wireless Power Transfer System by Optimization Switching Frequency
}

\section{Nur Hazwani Hussin ${ }^{1^{*}}$, Muhammad Mokhzaini Azizan ${ }^{1}$ and Azuwa Ali ${ }^{1}$}

${ }^{1}$ Faculty of Technology Electric Engineering, Universiti Malaysia Perlis.

*nurhazwanihussin@yahoo.com

\begin{abstract}
Encryption is a very important technique used to protect energy transmission channels from unauthorized receiver. It can be utilized to transmit data securely over the wireless medium. Encryption techniques of wireless power transfer (WPT) are important in the research on the effects of security key for security of energy transfer to the authorized receiver. The energy encryption scheme of WPT is proposed to chaos theory. Chaos theory is applicable to the logistic map to propose as a security key to chaotically regulate the switching frequency. Furthermore, for chaos theory characteristic effect power and distance performance. Therefore, this paper investigates mainly effective power based on mobile charging application. This research is focusing on performance of energy encryption in medium field for wireless power transfer system by optimization switching frequency. This research is dedicated to the performance of energy encryption for medium field wireless power transfer system based on mobile charging application. The optimization to transport the power in this research based on power is $10 \mathrm{~W}$. The research utilized MATLAB simulation to compare the performance.
\end{abstract}




\title{
Setting Time and after Setting Properties of High Calcium Fly ash Geopolymers with different Concentration of Sodium Hydroxide
}

\section{Rosnita Mohamed ${ }^{1,2 *}$, Rafiza Abd Razak ${ }^{1,2}$, Mohd Mustafa Al Bakri Abdullah ${ }^{1}$,Liyana Ahmad Sofri ${ }^{1,2}$, Ikmal Hakem Aziz', Noor Fifinatasha Shahedan ${ }^{1}$}

${ }^{1}$ Geopolymer \& Green Technology, Centre of Excellence (CEGeoGTech), Universiti Malaysia Perlis (UniMAP), Perlis, Malaysia.

${ }^{2}$ Faculty of Civil Engineering Technology, Universiti Malaysia Perlis (UniMAP), Perlis, Malaysia.

* rosnitamohamed21@gmail.com

\begin{abstract}
Setting time in geopolymers is known as the time taken for transition phase of liquid to solid of the geopolymer system in which is represented in initial setting and final setting. Setting time is significant in construction field specifically for application in construction field. This study intends to determine the setting time of high calcium fly ash geopolymers and the properties of the geopolymers after setting (1-day age). This includes determination of heat evolved throughout geopolymerization using Differential Scanning Calorimeter. After setting properties determination includes compressive strength and morphology analysis at 1-day age. High calcium fly ash was used as raw materials. Meanwhile for mixing designation, alkali activator was a mixture of sodium silicate and sodium hydroxide (molarity varied from $6 \mathrm{M}-14 \mathrm{M}$ ) with ratio of 2.5 and solid-to-liquid ratio of 2.5 . From this study, it was found that high calcium fly ash geopolymers with $12 \mathrm{M}$ has reasonable setting time which is suitable for on-site application as well as an optimal heat evolved $(-212 \mathrm{~J} / \mathrm{g})$ which leads to highest compressive strength at 1-day age and no formation of micro cracks observed on the morphology. Beyond $12 \mathrm{M}$, too much heat evolved in the geopolymer system can cause micro cracks formation thus lowering the compressive strength at 1-day age.
\end{abstract}




\title{
The Effect of Sodium Silicate to Accelerate The Geopolymerization Process of Low Calcium Fly Ash
}

\section{Ririn Eva Hidayati ${ }^{1}$, Fitria Sandi Faradilla ${ }^{1}$, Dadang, ${ }^{1}$, Nurlina ${ }^{2}$, Djoko Hartanto ${ }^{1}$, Didik Prasetyoko ${ }^{1}$ and Hamzah Fansuri ${ }^{*}$}

${ }^{1}$ Department of Chemistry, Faculty of Science, Institut Teknologi Sepuluh Nopember, Kampus ITS Sukolilo, Surabaya 60111, Indonesia.

${ }^{2}$ Department of Chemistry, Faculty of Math and Science, Universitas Tanjungpura, Pontianak 78111, Indonesia.

*h.fansuri@chem.its.ac.id

\begin{abstract}
In this research, the effect of sodium silicate $\left(\mathrm{Na}_{2} \mathrm{SiO}_{3}\right)$ on the geopolymerization of fly ash type $\mathrm{F}$ (low calcium) has been studied. The variations of $\mathrm{Na}_{2} \mathrm{SiO}_{3}$ used in the synthesized of geopolymers were 19, 32, and $41 \%$. The fly ash from three different power plant sources has been characterized using XRF, XRD, PSA, and SEM. Fly ash-based geopolymers were tested for mechanical strength and setting time with a Vicat needle. The additions of $19 \% \mathrm{Na}_{2} \mathrm{SiO}_{3}$ caused the geopolymer to not form a paste and could not be molded. Then the addition of $41 \% \mathrm{Na}_{2} \mathrm{SiO}_{3}$ decreased the mechanical strength of the geopolymer. The best geopolymer was obtained by adding $32 \% \mathrm{Na}_{2} \mathrm{SiO}_{3}$, produced a compressive strength of $21.62 \mathrm{MPa}$ with a setting time of 30 hours.
\end{abstract}




\title{
Removal of Selected Heavy Metal Species by Using Pressmud and Earthenware Clay as Binary Sorbent
}

\author{
A G N Izzati ${ }^{1}$, A Harlina $^{1 *}$, A A Hamidi ${ }^{2}$ \\ ${ }^{1}$ School of Industrial Technology, Persiaran Sains, Universiti Sains Malaysia, 11800, \\ Pulau Pinang, Malaysia \\ ${ }^{2}$ School of Civil Engineering, Engineering Campus, Universiti Sains Malaysia, 14300, \\ Nibong Tebal, Pulau Pinang, Malaysia \\ * harlinaa@usm.my
}

\begin{abstract}
This study focuses on the suitability of earthenware clay (EC) and pressmud (PM) mixtures as a landfill liner to retain heavy metals in the sanitary landfill leachate. The Fourier-Transform Infrared Spectroscopy (FTIR) and Cation Exchange Capacity (CEC) were employed to characterise these binary sorbents. The earthen clay (EC) was mixed with pressmud, the waste from the sugar refinery process, in the ratio of $0,10,30,50,80$, and $100 \%$ by weight. The cation exchange capacity (CEC) values of the mixture improved significantly when the weight ratios of pressmud were increased. The batch study proved that the combinations of EC-PM could retain $\mathrm{Cd}, \mathrm{Co}, \mathrm{Cr}, \mathrm{Cu}, \mathrm{Mn}$, $\mathrm{Pb}$, and $\mathrm{Zn}$ from leachate in $69-100 \%$. This study also proved that pure pressmud could act as an excellent sorbent to retain more than $85 \%$ of heavy metals in the leachate. In this study, S6 (which is pure pressmud or PM100) can perform as an excellent sorbent to remove these heavy metals species from leachate.
\end{abstract}




\section{Organic Waste Removal Using Pervaporation Method Based Ceramic Hydrophobic Geopolymer Membrane: A Review}

\section{Agustina Limbong Allo ${ }^{1}$, Nur Fadilla ${ }^{1}$, Andi Ida Nurfaida Nur ${ }^{1}$, Subaer ${ }^{1 *}$, Rafiza Abd Razak ${ }^{2}$}

${ }^{1}$ Geopolymer \& Green Materials Group, FMIPA, Universitas Negeri Makassar, Jl. Dg. Tata Raya Kampus Parangtambung, Makassar, Indonesia

${ }^{2}$ Geopolymer \& Green Technology, Center of Excellence (CEGeoGTech), Universiti Malaysia Perlis, Perlis, Malaysia

* subaer@unm.ac.id

Abstract. Household and industrial activities are the main sources of hazardous organic liquid waste. Harmful organic compounds contained in discarded wastewater cause various health and environmental problems. One of the methods to separate hazardous substances from liquid waste is pervaporation. Pervaporation is a method of separating a mixture using a membrane. This method has been proven to be effective in the separation of organic compounds from water bodies. $\mathrm{ZnO} / \mathrm{rGO}$ geopolymer ceramic membranes can be used as pervaporation membranes to separate volatile organic compounds from water bodies. This membrane passes only volatile organic compounds and repels water molecules due to its hydrophobic nature. This article is a review of pervaporation technology for water purification that is effective and easy to develop. 


\title{
Development of High Strength Alluvial Brick by Incorporative of Coconut Fibre
}

\section{Rafiza Binti Abd Razak ${ }^{1,2^{*}}$ Rubneswaran Sagaran ${ }^{1}$, Mohd Mustafa Al Bakri Abdullah², Zarina Yahya ${ }^{1,2}$, Subaer Junaidi ${ }^{3}$}

${ }^{1}$ Department of Civil Engineering Technology, Faculty of Engineering Technology, Universiti Malaysia Perlis (UniMAP), 02100 Padang Besar, Perlis, Malaysia.

${ }^{2}$ Geopolymer \& Green Technology, Center of Excellence (CEGeoGTech), Universiti Malaysia Perlis, Perlis, Malaysia

${ }^{3}$ Geopolymers \& Green Material Group, Physics Department, FMIPA, Universitas Negeri Makassar, Indonesia

* rafizarazak@unimap.edu.my

\begin{abstract}
The new properties of alluvial brick can be created by addition to the coconut fibre. An analysis on compressive strength and water absorption percentage of alluvial brick and coconut fibre alluvial brick are presented in this research.There are four main different operations are involved in the process of manufacturing of alluvial bricks such as preparation of alluvial clay and coconut fibre, moulding of bricks, pre-drying of bricks and burning of bricks at $500^{\circ} \mathrm{C}, 600^{\circ} \mathrm{C}$ and $700^{\circ} \mathrm{C}$. The results showed that the alluvial soil brick (without coconut fibre) burnt at $600^{\circ} \mathrm{C}$ exhibits the highest compressive strength of $17.33 \mathrm{MPa}$ and water absorption rate is $5.56 \%$ after soaked 24 hours in water. By using $600^{\circ} \mathrm{C}$ as the optimum temperature, alluvial bricks incorporating of coconut fibre are burnt. The highest value of compressive strength of coconut fibre alluvial brick is $16.57 \mathrm{MPa}$ and the water absorption is $11.11 \%$. The outcomes of this research proved that the pure alluvial soil brick which not mixed with any add mixtures can be used in the construction project and it can be considered as a new type of brick in construction material.The coconut fibre alluvial brick also has fulfil the requirements to contribute to sustainable development as coconut fibre alluvial brick is made use of waste coconut fibre that environmental friendly and at the same time, it could decreases the waste material disposal.
\end{abstract}




\title{
Synthesis and Characterization of Geopolymer Grout from Fly Ash Class C
}

\section{* Shamala Ramasamy ${ }^{1,2, a)}$, Ragunathan Santiagoo ${ }^{2,3}$, Razi Ahmad ${ }^{3}$, Norhafezah Kasmuri4, Meor Ahmad Faris $^{1,2}$ and Hiba Mohanad ${ }^{1}$}

${ }^{1}$ Faculty of Engineering Technology, Universiti Malaysia Perlis (UniMAP), P.O. Box 77, D/A Pejabat Pos Besar, Kangar, Perlis 01000, Malaysia.

${ }^{2}$ Center of Excellence Geopolymer and Green Technology, School of Material Enginering, Universiti Malaysia Perlis, Komplek Pengajian Jejawi 2, 02600 Arau, Perlis, Malaysia.

${ }^{3}$ School of Environmental Engineering, Universiti Malaysia Perlis, Komplek Pusat Pengajian Jejawi 3, 02600, Jejawi, Pelis, Malaysia

${ }^{4}$ Faculty of Civil Engineering, Universiti Teknologi MARA, 40450 Shah Alam, Selangor, Malaysia.

*shamala@unimap.edu.my

\begin{abstract}
Typical grout material is made from ordinary Portland cement. This work focuses on feasibility of producing fly ash based geopolymer grouting material. Geopolymer based materials actually have several advantages but the improvement of their rheological performances remains a challenging task, as the raw materials, especially sodium silicate and metakaolin, do not have favorable properties and the main chemical admixtures used to optimize cement-based materials have not been found compatible. Considering the performances in both fresh and hardened states, a comprehensive study is necessary to develop a promising geopolymer based grout material. Fly ash allowed reducing the viscosity and increasing the setting time and the stabilizer provided the fresh mixes with better homogeneity and stability. Detailed morphological study of raw fly ash was performed in this work. Scanning electron microscopy shared the macrospehre and inner microsphere structure within fly ash micrographs. Curing condition and solids to liquid ratio is kept constant in this study. The different concentration of $\mathrm{NaOH}$ solution (10 M and $12 \mathrm{M}$ ) and sodium silicate-to-sodium hydroxide $\left(\mathrm{Na}_{2} \mathrm{SiO}_{3} / \mathrm{NaOH}\right)$ ratios $(1.5,2.0,2.5$ and 3.0) were used in the production of geopolymer.
\end{abstract}




\title{
The Effect of Seawater Chemical Behaviour on Geopolymer Paste based on Strength for Underwater Construction Application
}

\section{* Liyana Jamaludin ${ }^{1,2, a)}$, Norsuhaila Nawi ${ }^{1, b)}$, Rafiza Abd Razak $^{1,2, \mathrm{c})}$, Mohd Mustafa Al Bakri Abdullah ${ }^{2, \mathrm{~d})}$ and Muhammad Jabir Suleiman@Ahmad ${ }^{3, e}$}

${ }^{1}$ Faculty of Engineering Technology, Universiti Malaysia Perlis (UniMAP), P.O. Box 77, D/A Pejabat Pos Besar, 01000 Kangar, Perlis, Malaysia.

${ }^{2}$ Center of Excellence Geopolymer and Green Technology (CEGeoGTech), School of Material Engineering, Universiti Malaysia Perlis, P.O. Box 77, D/A Pejabat Pos Besar, 01000 Kangar, Perlis, Malaysia.

${ }^{3}$ Advanced Material Research Centre (AMREC), SIRIM Berhad, Lot 34, Jalan Kulim Hi 2/3, Kulim Tech Park, 09000 Kulim, Kedah, Malaysia.

*liyanajamaludin@unimap.edu.my

\begin{abstract}
Concrete structure that located underwater should be withstand physical, chemical and mechanical action of sea water under varying environmental conditions. The surface degradation due to the presence of salts and a temperature difference in continuous immersion will effects the lifetime of underwater concrete. Geopolymer is a renovation for an alternative to Portland cement concrete and eco-friendly construction material that can withstand aggressive chemical attack. Geopolymer paste were formed by combining class $\mathrm{F}$ fly ash with sodium silicate and sodium hydroxide followed by curing at temperature $70^{\circ} \mathrm{C}$ for 24 hours. The geopolymer paste specimen immersed in the seawater for $1,3,7,28$ and 60 days to study the effect of chemical behaviour towards strength of geopolymer paste.
\end{abstract}




\title{
Effect of Sodium Aluminate on the Fresh and Hardened Properties of Fly Ash-Based One- Part Geopolymer
}

\author{
${ }^{*}$ Ooi Wan-En"1, Liew Yun-Ming ${ }^{1}$, Ho Li-Ngee², Mohd \\ Mustafa Al Bakri Abdullah' ${ }^{1}$ \& Ong Shee-Ween ${ }^{1}$ \\ ${ }^{1}$ Center of Excellence Geopolymer and Green Technology (CeGeoGTech), School of \\ Materials Engineering, Universiti Malaysia Perlis (UniMAP), Kangar, 01000 Perlis, \\ Malaysia. \\ ${ }^{2}$ Centre of Frontier Materials Research, School of Materials Engineering, Universiti \\ Malaysia Perlis (UniMAP), 02600, Arau, Perlis, Malaysia.. \\ *ymliew@unimap.edu.my
}

\begin{abstract}
The properties of geopolymers varies according to the type of material used. The behavior of one-part geopolymers with manipulative solid activators has to be examined. This paper presents the synthesis of fly ashbased one-part geopolymer with varying sodium metasilicate-to-sodium aluminate $\left(\mathrm{NaAlO}_{2} / \mathrm{Na}_{2} \mathrm{SiO}_{3}\right)$ ratio. The geopolymer binder employed "just add water" technique to produce one-part geopolymer. The $\mathrm{NaAlO} / \mathrm{Na}_{2} \mathrm{SiO}_{3}$ ratios were set at 1.0 to 3.0. Setting time of fresh one-part geopolymer was examined through Vicat needle apparatus. Mechanical and microstructural properties of developed specimens were also analysed after 28 days of curing in ambient condition. Study found out that increasing $\mathrm{NaAlO}_{2}$ content delayed the setting time of one-part geopolymer paste. The highest strength was achieved at $\mathrm{NaAlO}_{2} / \mathrm{Na}_{2} \mathrm{SiO}_{3}$ ratio of 2.5 , which is $33.65 \mathrm{MPa}$. Microstructural analysis revealed a homogeneous structure at the optimum ratio.
\end{abstract}




\title{
Effect of Composition on Melt Flow and Density of Polypropylene Copolymer/Kaolin Geo-Filler Composites
}

*Zulaikha Zulkifli 1,b), Yusrina Mat Daud 1,2,a), Farah Farhana Zainal 1,2,c), Mohammad Firdaus Abu Hashim 2,3,d) and Yurdakul Aygörmez ${ }^{4, e)}$

${ }^{1}$ School of Materials Engineering, Universiti Malaysia Perlis, 02600 Arau, Perlis, Malaysia.

${ }^{2}$ Green Technology (CEGeoGTech), School of Materials Engineering, University Malaysia Perlis (UniMAP), P.O Box 77, d/a Pejabat Pos Besar, 01000 Kangar, Perlis, Malaysia

${ }^{3}$ Faculty of Engineering Technology, Universiti Malaysia Perlis, Level 1, Block S2,UniCITI Alam Campus, Sungai Chuchuh, 02100 Padang Besar, Perlis, Malaysia.

${ }^{4}$ Yildiz Technical University, Faculty of Civil Engineering, Civil Engineering Department, Davutpasa Campus, Istanbul, Turkey.

*yusrina@unimap.edu.my

\begin{abstract}
This study examined the effects rheological properties of different composition kaolin and kaolin geo-filler in polypropylene composites. Polypropylene copolymer with varying composition of kaolin geo-filler $0 \%, 2 \%$, $4 \%, 6 \%, 8 \%$, and $10 \%$ was prepared. Kaolin is an aluminosilicate based mineral filler was used to prepare geopolymer paste by combining with alkaline activator solution. The polypropylene composite was compounded by using a twin-screw extruder and the melt flow index was determined by constant weight pressure of $2.16 \mathrm{~kg}$ at $230^{\circ} \mathrm{C}$ in 10 minutes. Knowing the melt flow index is necessary to predict and control the process as the study has demonstrated that composition of kaolin filler and kaolin geo-filler affects the melt flow at varies composition. Composites with kaolin geo-filler has demonstrated high melt flow index process and having better distribution and flow.
\end{abstract}




\title{
Flexural Properties of Thin Fly Ash Geopolymers at Elevated Temperature
}

\section{${ }^{*}$ NG Yong-Sing ${ }^{1, a)}$, LIEW Yun-Ming ${ }^{1, b)}$, MOHD MUSTAFA AL BAKRI Abdullah ${ }^{1, c)}$, NG Hui-Teng ${ }^{1, d)}$ and LYNETTE WEI LING Chan ${ }^{2, \mathrm{e})}$}

${ }^{1}$ Center of Excellence Geopolymer and Green Technology (CEGeoGTech), School of Materials Engineering, Universiti Malaysia Perlis (UniMAP), 01000 Kangar, Perlis, Malaysia

${ }^{2}$ Ceramic Research Company Sdn Bhd (Guocera-Hong Leong Group), Lot 7110, 5 1/2 Miles, Jalan Kapar, 42100 Klang, Selangor, Malaysia

*nicholas.zai.1130@gmail.com

\begin{abstract}
This paper reports on the flexural properties of thin fly ash geopolymers exposed to elevated temperature. The thin fly ash geopolymers were synthesised using $12 \mathrm{M} \mathrm{NaOH}$ solution mixed with designed solids-toliquids ratio of $1: 2.5$ and $\mathrm{Na}_{2} \mathrm{SiO}_{3} / \mathrm{NaOH}$ ratio of $1: 4$. Thin fly ash geopolymers with the dimension of $160 \mathrm{~mm} \times 40 \mathrm{~mm} \times 10 \mathrm{~mm}$ underwent heat treatment at different elevated temperature $\left(300^{\circ} \mathrm{C}, 600^{\circ} \mathrm{C}, 900^{\circ} \mathrm{C}\right.$ and $\left.1150^{\circ} \mathrm{C}\right)$ after 28 days of curing. Flexural strength test was accessed to compare the flexural properties of untreated and heat-treated thin geopolymers. X-Ray Diffraction (XRD) analysis was performed to determine the phase transformation of geopolymers at elevated temperature. Results showed that application of heat treatment boosted the flexural properties of thin fly ash geopolymers as the flexural strength increased from 6.5 $\mathrm{MPa}$ (room temperature) to $16.2 \mathrm{MPa}$ $\left(1150^{\circ} \mathrm{C}\right) . \mathrm{XRD}$ results showed that the presence of crystalline phases of albite and nepheline contributed to the increment in flexural strength.
\end{abstract}




\title{
The Potential EBSD Analysis in the Investigation of Ground Granulated Blast Furnace Slag Geopolymer at High Temperature
}

\author{
${ }^{*}$ Ikmal Hakem Azizi,a), Mohd Mustafa Al Bakri \\ Abdullah ${ }^{1, b)}$, Mohd Arif Anuar Mohd Salleh ${ }^{1, c)}$, Sorachon \\ Yoriya $^{2, d)}$, Rafiza Abd Razak ${ }^{1,3, e)}$ and Rosnita \\ Mohamed ${ }^{1,3 f)}$
}

${ }^{1}$ Center of Excellence Geopolymer and Green Technology (CEGeoGTech), School of Materials Engineering, Universiti Malaysia Perlis (UniMAP), P.O Box 77, D/A Pejabat Pos Besar, 01000 Kangar, Perlis, Malaysia.

${ }^{2}$ National Metal and Material Technology Center (MTEC), National Science and Technology Development Agency (NSTDA), 114, Thailand Science Park, Pahonyothin Rd., Khlong 1, Khlong Luang, Pathum Thani 12120, Thailand.

${ }^{3}$ Department of Civil Engineering Technology, Faculty of Engineering Technology, Universiti Malaysia Perlis (UniMAP), 02100 Padang Besar, Perlis, Malaysia.

\section{* ikmalhakem@unimap.edu.my}

\begin{abstract}
This paper elucidated the potential of electron backscatter diffraction analysis for ground granulated blast furnace slag geopolymers at $1000^{\circ} \mathrm{C}$ heating temperature. The specimen was prepared through the mechanical ground with sandpaper and diamond pad before polished with diamond suspension. By using advanced technique electron backscatter diffraction, the microstructure analysis and elemental distribution were mapped. The details on the crystalline minerals, including gehlenite, mayenite, tobermorite and calcite were easily traced. Moreover, the experimental Kikuchi diffraction patterns were utilized to generate a self-consistent reference for the electron backscatter diffraction pattern matching. From the electron backscatter diffraction, the locally varying crystal orientation in slag geopolymers sample of monoclinic crystal observed in hedenbergite, orthorhombic crystal in tobermorite and hexagona crystal in calcite at $1000^{\circ} \mathrm{C}$ heating temperature.
\end{abstract}




\title{
Additive Manufacturing in Biodegradable Coronary Artery Stents Fabrication: A Review
}

* Noorhafiza Muhammad ${ }^{1,2}$, Amirul Asyraf Azli², Mohd Mustafa Albakri Abdullah ${ }^{1,3}$, Siti Noor Fazliah Mohd Noor $^{4}$, Mohd Shuhidan Saleh ${ }^{2}$ and Norshah Afizi Shuaib ${ }^{1,2}$

${ }^{1}$ Geopolymer and Green Technology, Centre of Excellence (CEGeoGTech, Universiti Malaysia Perlis, UniMAP, Malaysia

${ }^{2}$ Faculty of Mechanical Engineering Technology, Universiti Malaysia Perlis (UniMAP), Perlis, Malaysia.

${ }^{3}$ Faculty of Chemical Engineering Technology, Universiti Malaysia Perlis (UniMAP), Perlis, Malaysia.

${ }^{4}$ Craniofacial \& Biomaterial Sciences Cluster, Advanced Medical and Dental Institute, Universiti Sains Malaysia, Bertam, 13200 Kepala Batas, Pulau Pinang, Malaysia.

*noorhafiza@unimap.edu.my

\begin{abstract}
Additive manufacturing in the polymeric stent fabrications has shown enormous potential especially in producing biodegradable coronary stents productions. This technology has shown a promising results with the positive findings from the reported works by the researcher. This work reviews the key features and capabilities of additive manufacturing, which include the types of 3D printers, 3D printing parameters, the principle and deposition mechanism for additive manufacturing and information on 3D printing approaches in stent fabrication. It has been foreseen that this technology would able to produce future generation of stent.
\end{abstract}




\title{
Experimental study of laser welding dissimilar materials
}

\section{*Noorhafiza Muhammad ${ }^{1,2}$, Yap How Hean², Mohd Shuhidan Saleh², Mohd Fathullah Ghazli ${ }^{1,2}$ and Norshah Afizi Shuaib ${ }^{1,2}$}

${ }^{1}$ Geopolymer and Green Technology, Centre of Excellence (CEGeoGTech, Universiti Malaysia Perlis, UniMAP, Malaysia

${ }^{2}$ Faculty of Mechanical Engineering Technology, Universiti Malaysia Perlis (UniMAP), Perlis, Malaysia.

*noorhafiza@unimap.edu.my

\begin{abstract}
Laser welding on dissimilar materials is widely used and has significance application in industry. Laser welding is the best method which can offer high strength of joint especially for joining of dissimilar metals contrast to conventional method. Conventional welding more often had an insufficient penetration depth and a wider heat affected zone which prompts to reduce joint quality. This work exhibits a weld possibility on low carbon steel and high carbon steel surface utilizing low power fiber laser in pulse wave modes. The objective of this research work is to investigate the influence of laser welding parameters of welding speed and pulse width on weld geometry and mechanical properties (microhardness) of welded metal. The parameters used is the welding speed $(1.67 \mathrm{~mm} / \mathrm{s}$ to $8.33 \mathrm{~mm} / \mathrm{s})$ and pulse width $(3 \mathrm{~ms}$ to $5 \mathrm{~ms})$. The optimum weld geometry was with the largest aspect ratio (1.42) with parameter of welding speed $(1.67 \mathrm{~mm} / \mathrm{s})$ and pulse width $(3.0 \mathrm{~ms})$. In addition, it was found that microhardness profiles showed a rise in hardness value at fusion zone and heat-affected zones as the solidification process proceeds rapidly. As conclusion, appropriate utilization of parameters can improve the quality of weld joints and durability of products.
\end{abstract}




\title{
Design and Development of Fire Escape Window Grille Keyless Locking Sytem
}

\author{
${ }^{*}$ Mohd Shuhidan Saleh ${ }^{1}, \mathrm{Ng}$ Kuan Yee ${ }^{1}$, Noorhafiza \\ Muhammad ${ }^{1,2}$, Mohd Fathullah Ghazli ${ }^{1,2}$ and Norshah \\ Afizi Shuaib ${ }^{1,2}$
}

${ }^{1}$ Faculty of Mechanical Engineering Technology, Universiti Malaysia Perlis (UniMAP), Perlis, Malaysia.

${ }^{2}$ Geopolymer and Green Technology, Centre of Excellence (CEGeoGTech, Universiti Malaysia Perlis, UniMAP, Malaysia

*noorhafiza@unimap.edu.my

\begin{abstract}
The most fire-related fatalities are due to the smoke inhalation of the toxic gases. It is related to the victims being trapped in the building when the building was on fire. It was also reported that major deaths from fire related are from the toxic gases inhalation produced by the fire while the deaths due to fire flames and burning was about one third of the total deaths. The access to the exit door was blocked and they could not exit through the window due to the permanent grille installation. It was well aware that most Malaysian homeowners installed grilles on their house windows or doors for security reason since there are lots of break-ins incidences. To overcome the issue, this work introduces a window grille with keyless locking system. The design incorporated keyless system that can be operated or opened without a key. Several designs for implementing this solution have been described. These designs are divided into three sections, which is a grille design, expansion designs which use to accommodate a wide range of window-sized and keyless locking systems. The size and type of grille suitable for Malaysian residents as well as the more efficient keyless locking system has been studied in detail using the method of case study and survey method. Step of patent research, market analysis and benchmarking are used as methods for collecting reference data. The most effective fire escape window grille keyless locking system has been studied and designed from this project. An important factor in designing a fire window grille is the design that can be opened and does not require a key operation. Durability testing and analysis has been carried out to show the availability and feasibility of this design and the possibility of improvement that will change the design. The results of the design and analysis tested are presented such that they can be used as an aid to the design of fire escape features.
\end{abstract}




\title{
Catalytic Materials Properties and Requirement for Dehumidification of Air in Nitrogen Pressure Swing Adsorption Process (PSA)
}

\author{
${ }^{*}$ M.A. Idris ${ }^{1,2}$, A.H. Norzilah1, N.F.M. Yunos ${ }^{1}$, D. \\ Murizam $^{3,4}$, C.P. Faizul ${ }^{1}$, S.N. Sabki ${ }^{5}$ and S. Illias ${ }^{3}$ \\ ${ }^{1}$ Faculty Chemical Engineering Technology, Universiti Malaysia Perlis, 02600 Jejawi, \\ Arau, Perlis, Malaysia \\ ${ }^{2}$ Frontier Materials Research, Centre of Excellence (FrontMate), Universiti Malaysia \\ Perlis (UniMAP), Perlis, Malaysia \\ ${ }^{3}$ Faculty Mechanical Engineering Technology, Universiti Malaysia Perlis, Pauh Putra \\ Campus, 02600, Arau, Perlis, Malaysia \\ ${ }^{4}$ Geopolymer \& Green Technology, Centre of Excellence (CEGeoGTech), Universiti \\ Malaysia Perlis (UniMAP), Perlis, Malaysia \\ ${ }^{5}$ Faculty Electronic Engineering Technology, Universiti Malaysia Perlis, Pauh Putra \\ Campus, 02600 Arau, Perlis, Malaysia \\ *asri@unimap.edu.my
}

\begin{abstract}
Nitrogen production by two-layer cyclic pressure swing adsorption (PSA) system was used for effective water vapor and oxygen removal from air. The system consists of two fixed bed adsorption columns, each containing two layers of catalytic adsorbents consisting of silica gel and carbon molecular sieves. To gain in-depth insights about the process, a descriptive relation considering thermodynamic properties with kinetic and equilibrium equations has been reviewed. The catalytic materials properties including it reaction was count into this equation. Then, the equation was used in predicting the optimized pressure for water removal and oxygen adsorption. and $6.0-6.2$ bar at humidifier trap could be the optimum for this system at room temperature. It is also found that the optimum swing pressure is 4.5 bar at carbon molecular sieve. In this optimization the properties of commercially available particulate carbon molecular sieves were taken for materials reaction parameter.
\end{abstract}




\title{
Effect of Acetic Acid Leaching Process on Rice Husk
}

\author{
${ }^{*}$ C P Faizul ${ }^{1,3}$, D Murizam ${ }^{2,3}$ and W.A. Rahman ${ }^{1,3}$
}

${ }^{1}$ Faculty Chemical Engineering Technology, Universiti Malaysia Perlis, 02600 Jejawi, Arau, Perlis, Malaysia

${ }^{2}$ Faculty Mechanical Engineering Technology, Universiti Malaysia Perlis, Pauh Putra Campus, 02600, Arau, Perlis, Malaysia

${ }^{3}$ Geopolymer \& Green Technology, Centre of Excellence (CEGeoGTech), Universiti Malaysia Perlis (UniMAP), Perlis, Malaysia

*faizul@unimap.edu.my

\begin{abstract}
Rice husk is one of the most agricultural wastes in the milling process. It contains the highest amount composition of silica (SiO2) compared with other agricultural waste. Rice husk can be utilized to produce various types of useful renewable resources, which contain silica (SiO2). husk. Rice husk was collected from Kuala Kedah, Kedah. Acetic acid $(\mathrm{CH} 3 \mathrm{COOH})$ has been used as leaching solution. The aim of this study is to determine the effect of acetic acid on rice husk. Raw rice husk and leached rice husk were subjected to thermal treatment at $800{ }^{\circ} \mathrm{C}$ for 3 hours in the furnace. Raw rice husk and leached rice husk has been analysed using X-Ray fluorescence (XRF), scanning electron microscope (SEM) and Fourier transform infrared spectroscopy (FTIR). The highest mass percent element silicon (Si) content which is $97.4 \%$ under the optimum condition with $5 \%$ of acetic acid, $90{ }^{\circ} \mathrm{C}$ solution temperature, and 30 minutes stirring time.
\end{abstract}




\title{
The Roles and Activities of Carbon Species in Cathode Materials of IT-SOFC : A Review
}

\author{
${ }^{*}$ D. Murizam ${ }^{1,2}$, M.A. Idris ${ }^{3,4}$ N.M.N Azira ${ }^{3}$, N. F. M. \\ Yunos $^{3}$, AA Samat ${ }^{1}$ and W.A. Rahman ${ }^{1,2}$
}

\author{
${ }^{1}$ Faculty Mechanical Engineering Technology, Universiti Malaysia Perlis, Pauh Putra \\ Campus, 02600, Arau, Perlis, Malaysia \\ ${ }^{2}$ Geopolymer \& Green Technology, Centre of Excellence (CEGeoGTech), Universiti \\ Malaysia Perlis (UniMAP), Perlis, Malaysia \\ ${ }^{3}$ Faculty Chemical Engineering Technology, Universiti Malaysia Perlis, 02600 Jejawi, \\ Arau, Perlis, Malaysia \\ ${ }^{4}$ Frontier Materials Research, Centre of Excellence (FrontMate), Universiti Malaysia \\ Perlis (UniMAP), Perlis, Malaysia \\ *murizam@unimap.edu.my
}

\begin{abstract}
Perovskite oxide ceramics are extensively researched as a good potential electrode for intermediate temperature SOFC (IT-SOFC). While it was showing a good electrical potential when pairing to doped-ceria electrolyte, the reliability of the electrodes diminished over time due to the carbon poisoning effect which found to increase the polarization resistance due to the occurrence of carbon species in the electrode cell. These carbon elements whether originated from the air or within the cathode itself reacted with oxygen gases to form carbonated phases which are responsible for polarization resistance increment. Thus, the formation of carbonated phases in the present of carbon species within the cathode materials are ultimately important to investigate in details. The carbon poisoning in cathode involved a complex mechanism of reaction between carbon and oxygen species at the reaction sites on cathode surfaces. While maximizing the cathode surface to increase the active sites for oxygen exchange will promote the ionic conductivity, this work would also be enhancing catalytic activity of carbon species. Therefore, further investigation on carbon poisoning in BSCF due to carbonate formation are seem required in developing a reliable cathode. This paper reviewed the current research trends in reducing the $\mathrm{CO} 2$ poisoning effects in IT-SOFC development
\end{abstract}

